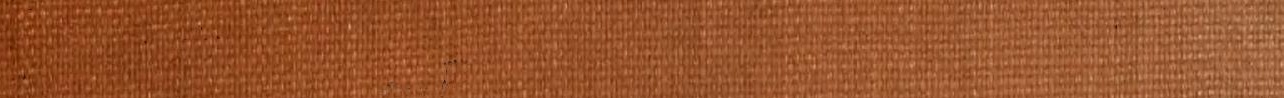



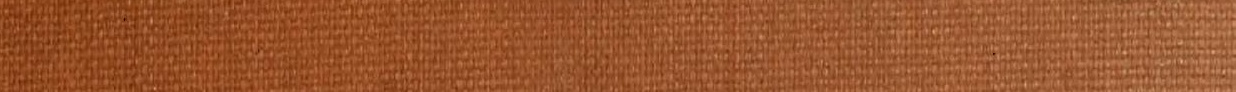
S.

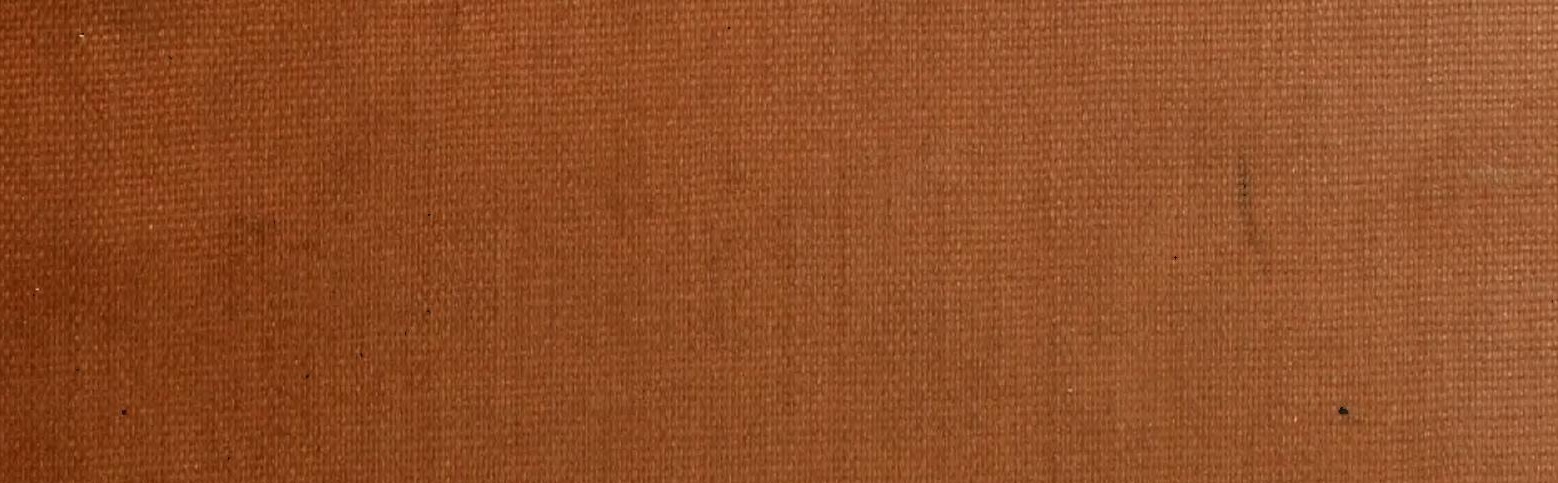
3.

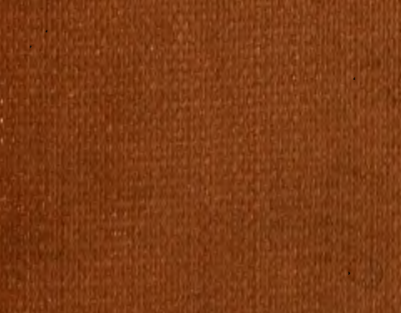

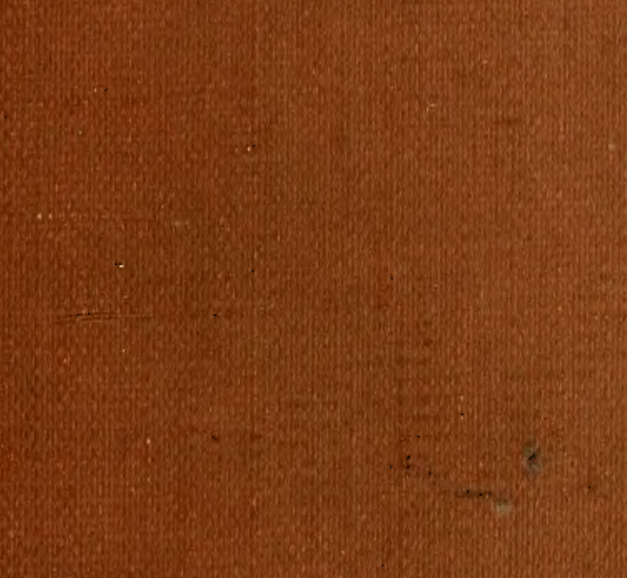




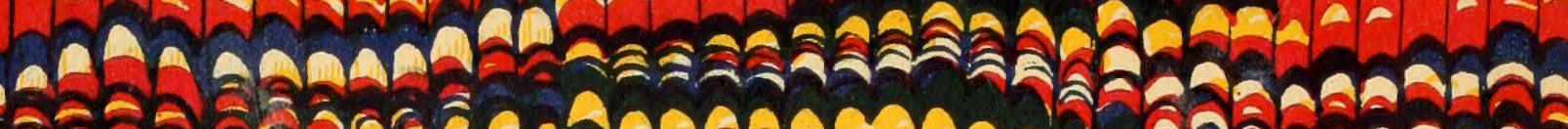

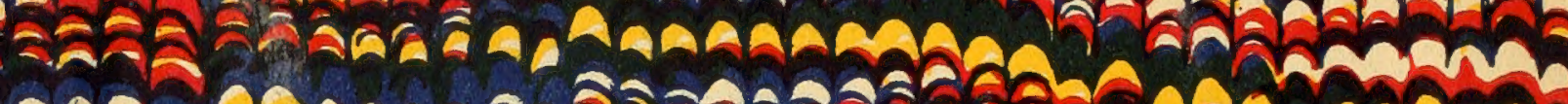

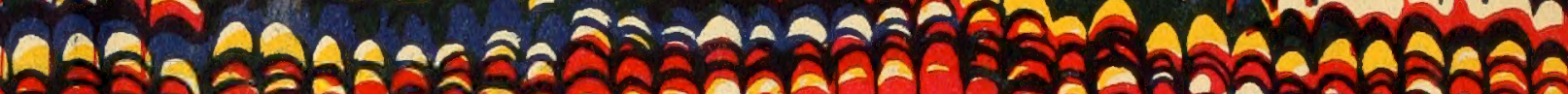



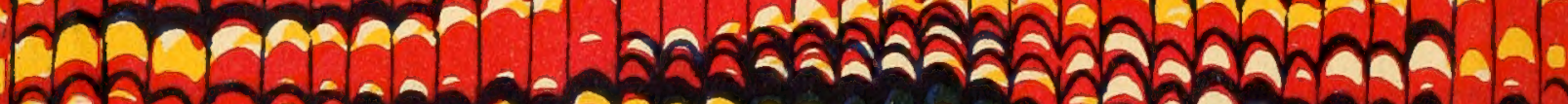

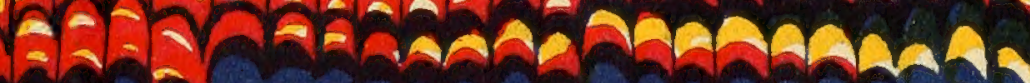
ล

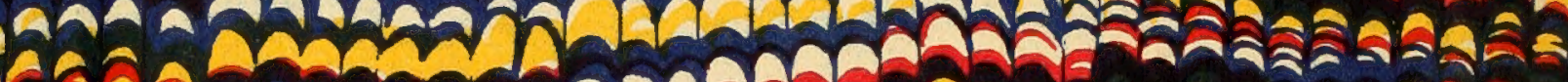
2ล口

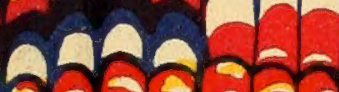

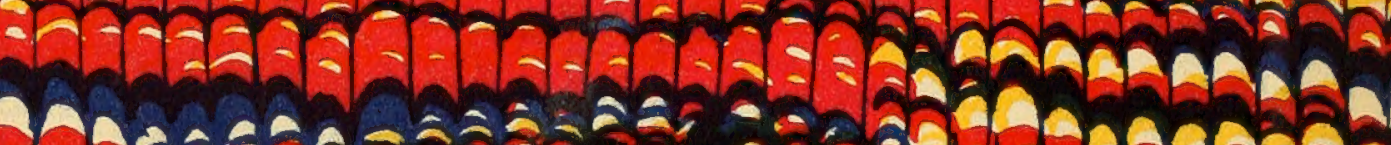

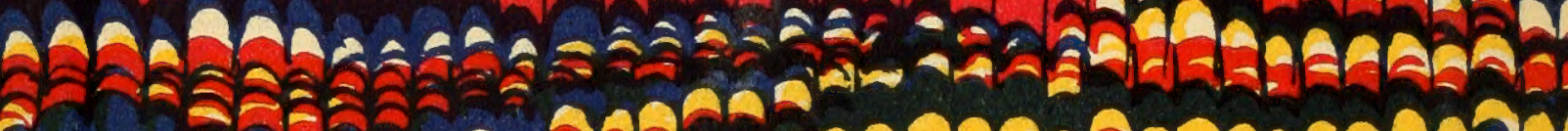

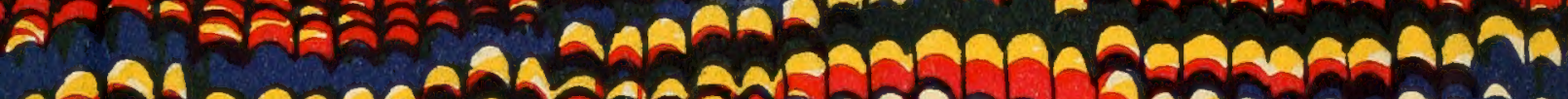
Q

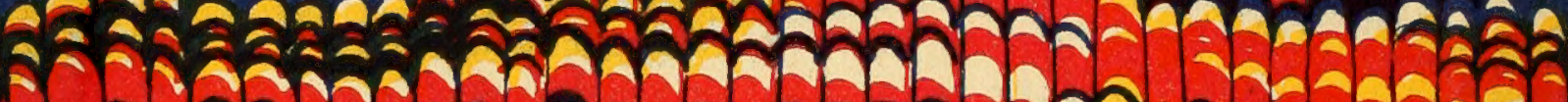

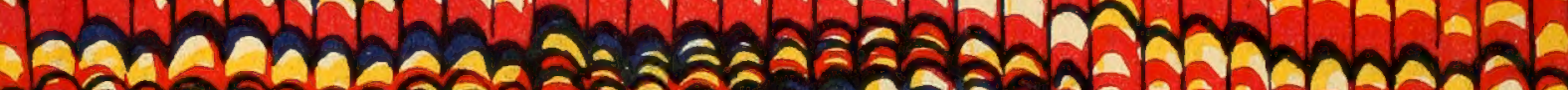

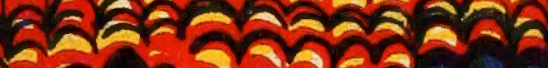

in ânân ล

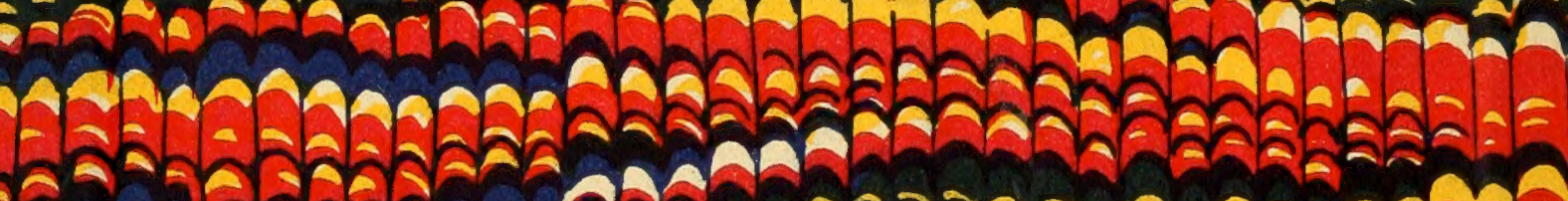
Q D.

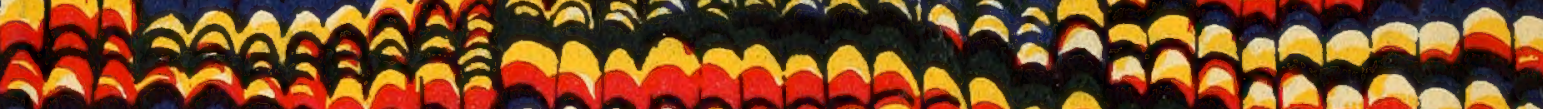

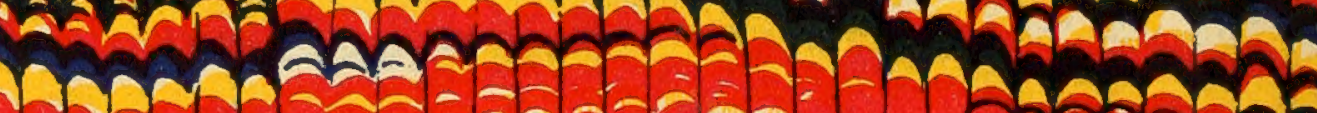

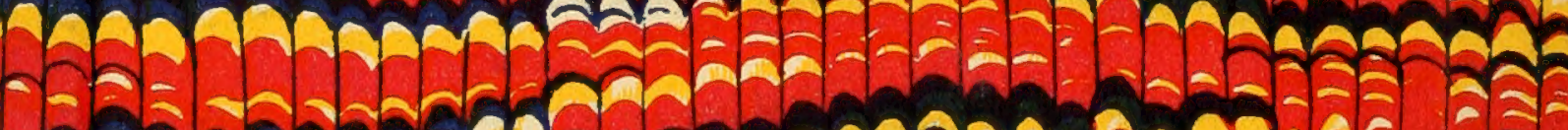

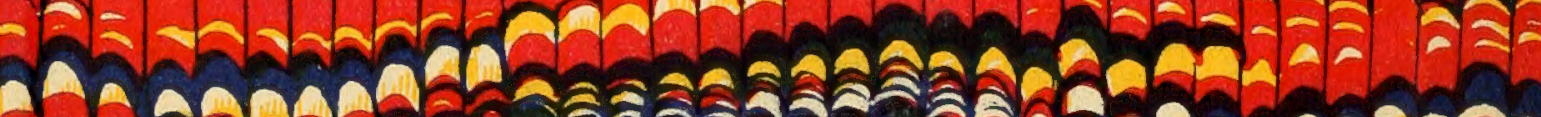

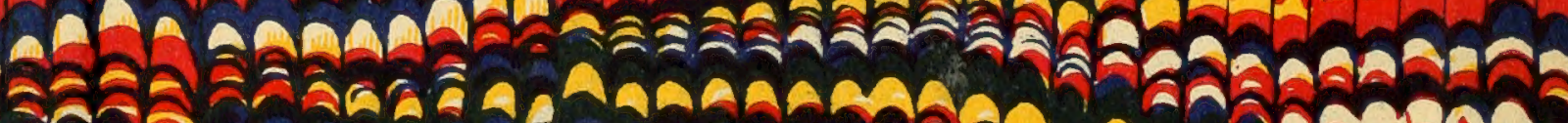

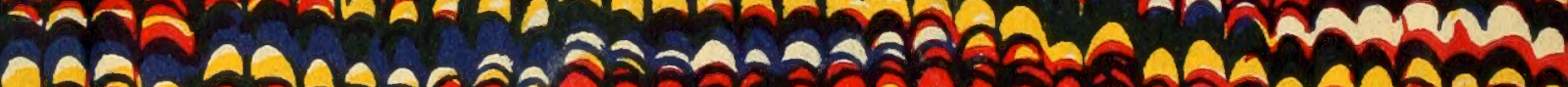

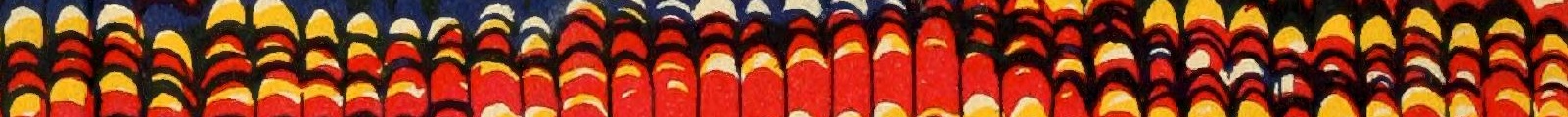

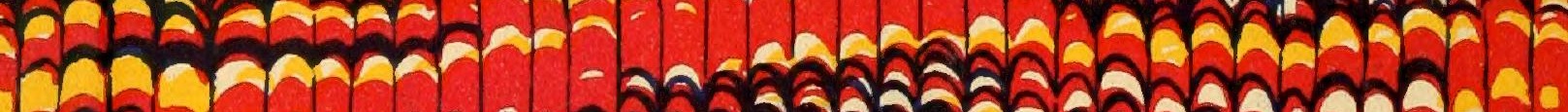

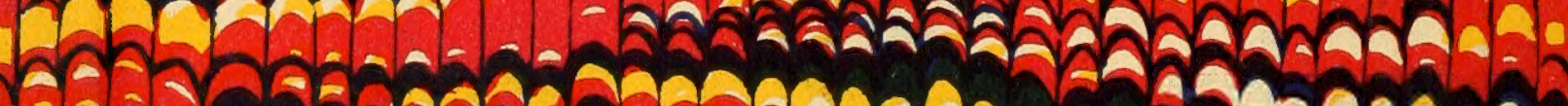

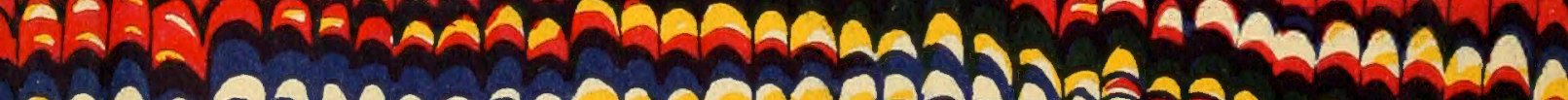

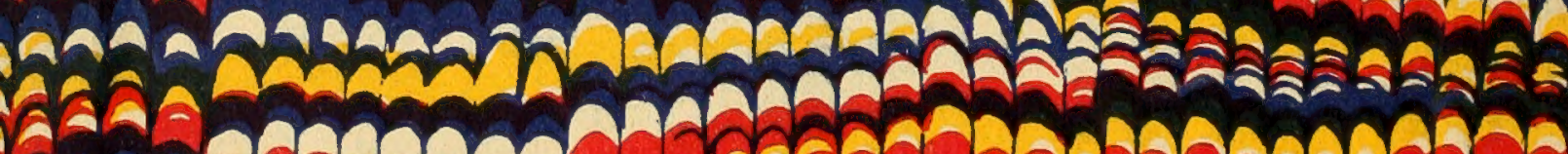



Case 19 She 1F 





\section{THE FUR SEALS AND OTHER LIFE OF THE PRIBILOF ISLANDS, ALASKA, IN 1914}

By Wilfred H. Osgood, Edward A. Preble, and George H. Parker

From BULLETIN OF THE BUREAU OF FISHERIES, Volume XXXIV, 1914

Document No. $820: \because: \quad: \quad: \quad: \quad: \quad: \quad: \quad$ : Issued June r9, r915



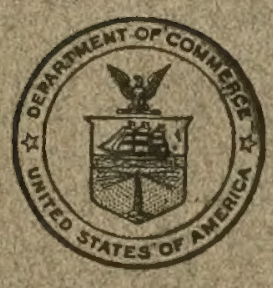

285745

WASHINGTON : : : : : : GOVERNMENT PRINTING OFFICE : : : : : : : : : 1915 



\title{
THE FUR SEALS AND OTHER LIFE OF THE PRIBILOF ISLANDS, ALASKA, IN 1914
}

\author{
By Wilfred H. Osgood, Edward A. Preble, and George H. Parker
}

From BULLETIN OF THE BUREAU OF FISHERIES, Volume XXXIV, I9I4

Document No. $820:: \quad: \quad: \quad: \quad: \quad: \quad: \quad: \quad:$ Issued June I9, I915

\section{terite solicler}


ADDITIONAL COPIES

OF TIIS PUBLCATION MAY BE PROCURED FROM THE SUPERINTENDENT OF DOCUMENTS GOVERNMENT PRINTING OFFICE WASHINGTON, D, C.

AT

50 CENTS PER COPY 
THE FUR SEALS AND OTHER LIFE OF THE PRIBILOF ISLANDS, ALASKA, IN 1914

By Wilfred H. Osgood, Edward A. Preble, and George H. Parker 



\section{CONTENTS.}

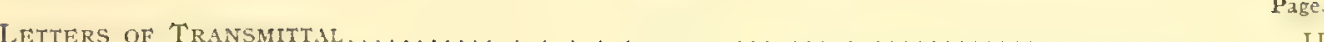

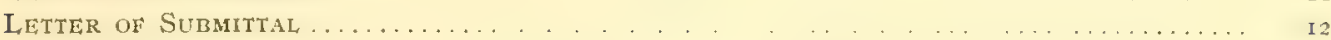

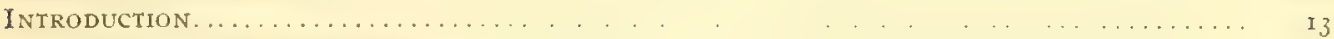

Personnel and instructions....... . . . . . . . . . . . . . . . . . I3 $_{3}$

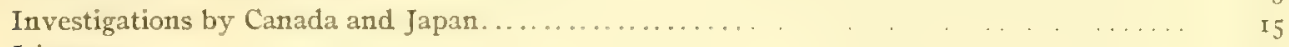

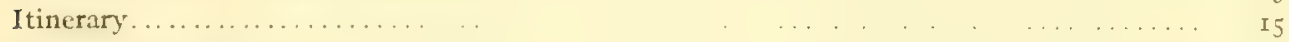

Impartial nature of the investigation. ....................... . . . .

Acknowledgments............... . . . . . . . . . . . . . . .

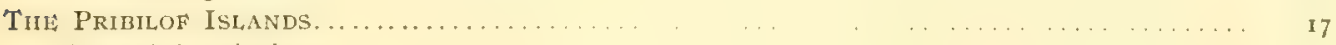

General description................. . . . . . . . . . . . I7

Vegetation.......................... . . .

Climate.................. . . . . . . . .

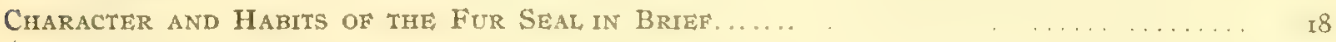

General characteristics......... . . . . . . . . . . . . Is

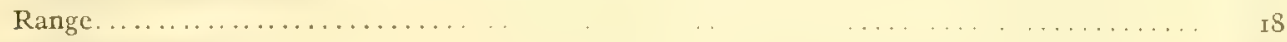

Breeding habits......................... I9

Habits of bachelors................ . . . . . 20

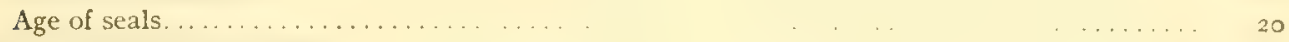

SEALING Histori IN BRIEF............. . . 2r

Russian management........ . . . . . . . . . . 21

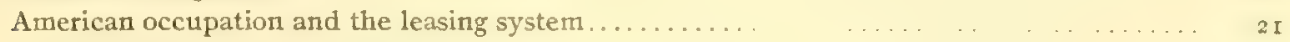

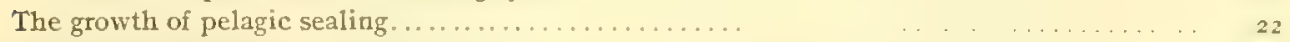

The Paris Tribunal and the modus vivendi.......... . . . . . . . . . . 22

Special investigations. ....... $\quad \ldots \ldots \ldots \ldots \ldots \ldots \ldots \ldots \ldots$

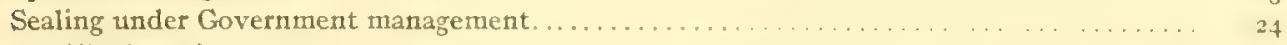

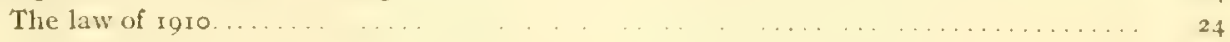

The treaty suspending pelagic sealing . . . . . . . . . . . . . . . . . . 24

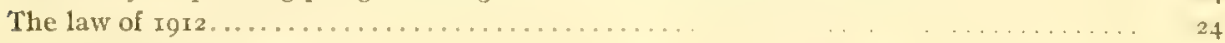

Revenue from fur seals. ...... . . . . . . . . . . . . . . . . . 25

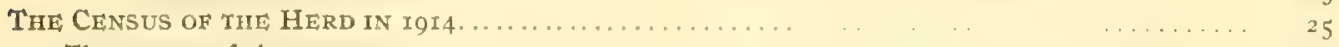

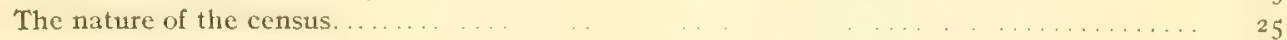

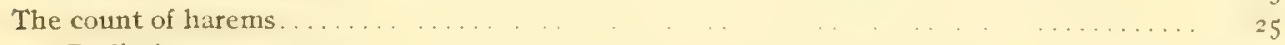

Preliminary counts....................... . . 26

Height of season counts. ........... . . . . . . . . . . 26

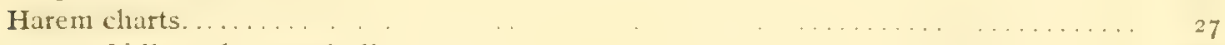

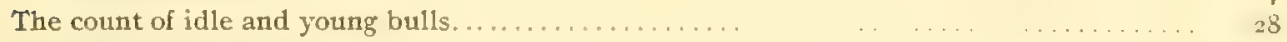

The count of half bulls......... . . . . . . . . . . . . . . . . . . . 28

The count of bachelors....... $\ldots \ldots \ldots \ldots \ldots \ldots \ldots \ldots$

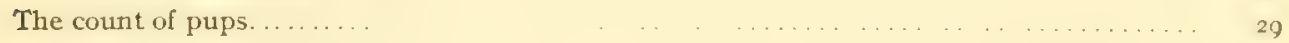

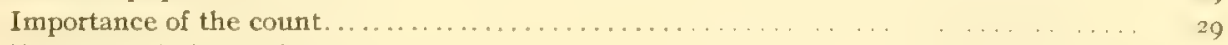

The method of counting pups. ............................ 30

The count of dead pups. . . . . . . . . . . . . . . . 3 I

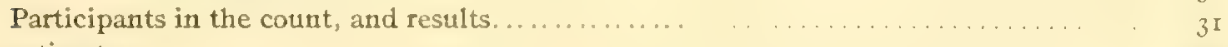

The estimates ............ $\quad \ldots \ldots \ldots \ldots \ldots \ldots \ldots 3^{2}$

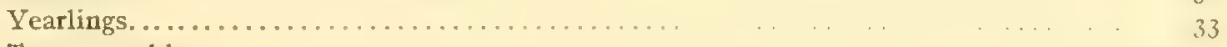

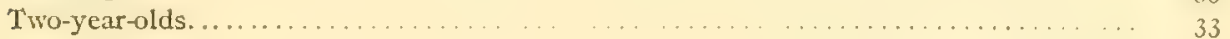


THE CENSUS OF THE HERD IN IgI4-Continued.

The estimates-Continued.

Page.

Three-year-old males. . . . . . . . . . . . . . . . . . . . . . . . . . . . . 34

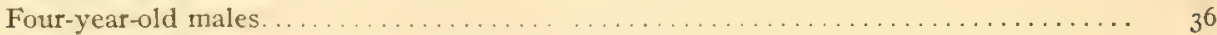

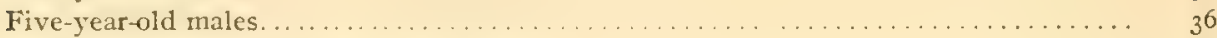

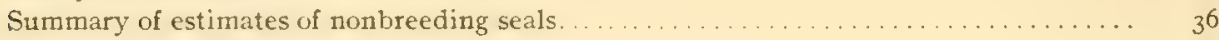

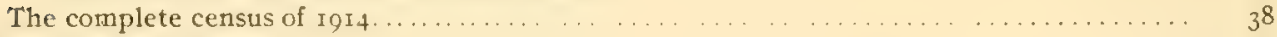

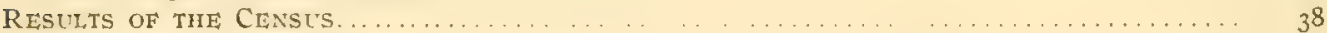

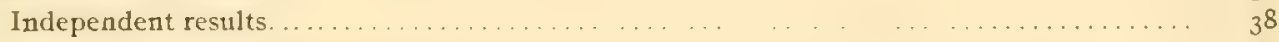

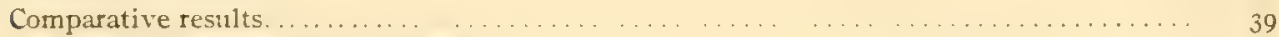

Comparison of harems and idle bulls . . . . . . . . . . . . . . . . . . . . 39

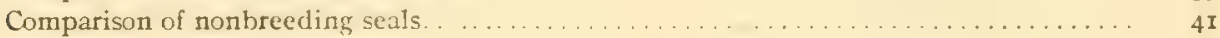

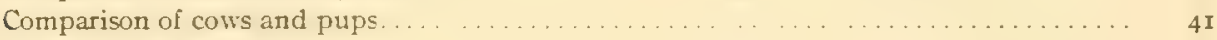

The census in the future . . . . . . . . . . . . . . . . . . . . . . . 45

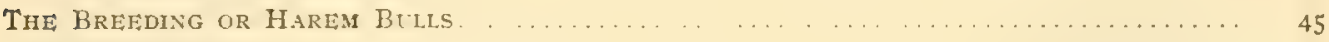

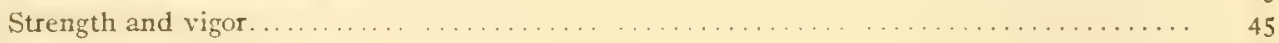

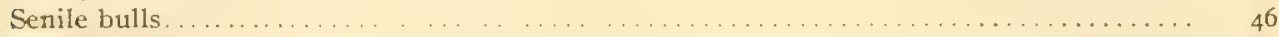

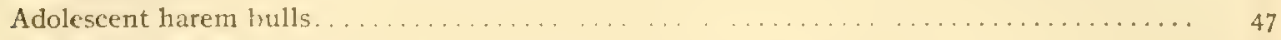

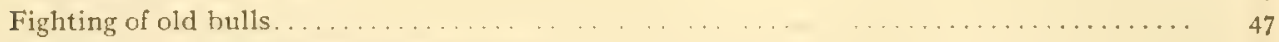

Significance of the increase of harem bulls... $\ldots \ldots \ldots \ldots \ldots \ldots \ldots \ldots . \ldots \ldots$

The ideal proportion of harem bulls......... . . . . . . . . . . . . . . . 49

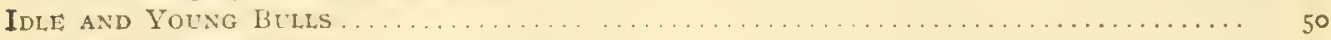



Irregular distribution . . . . . . . . . . . . . . . . . . . . . . . . . . . .

Idle bulls as a desirable breeding element. . . . . . . . . . . . . . . . . . 52

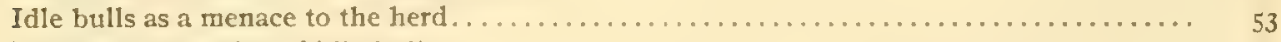

The ideal proportion of idle bulls. . . . . . . . . . . . . . . . . . . . . . . . 54

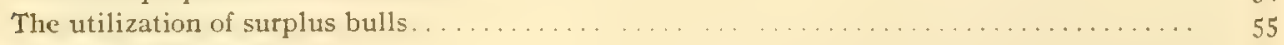

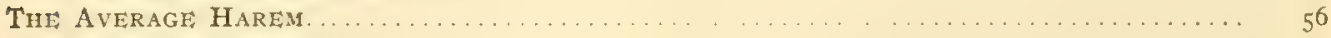

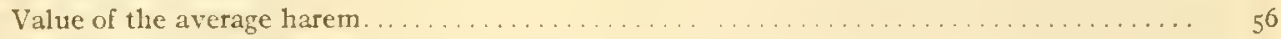

Variation of average harems. . . . . . . . . . . . . . . . . . $56 \ldots \ldots \ldots \ldots \ldots \ldots$

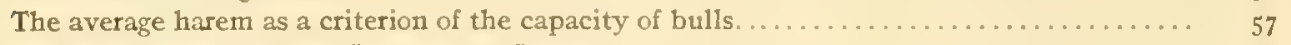

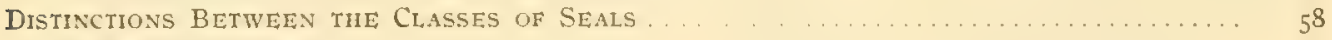

General distinctions. . . . . . . . . . . . . . . . . . . . . . . . . . . . . 59

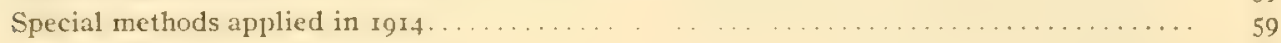

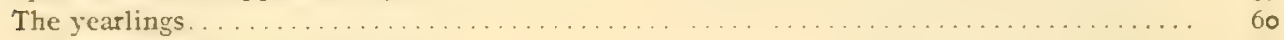

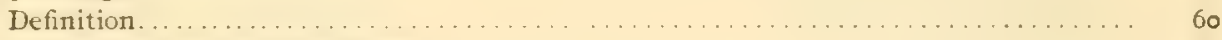

Limited knowledge of yearlings . . . . . . . . . . . . . . . . . 60

Records of yearlings . . . . . . . . . . . . . . . . . . . . . .

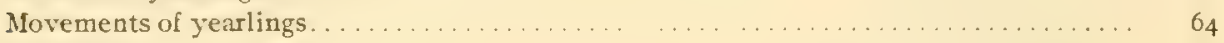

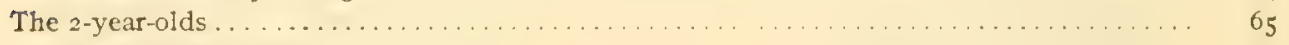

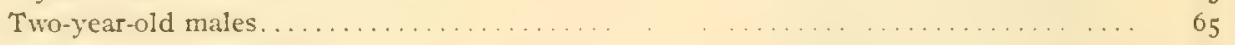

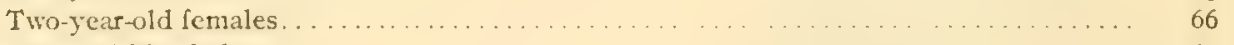

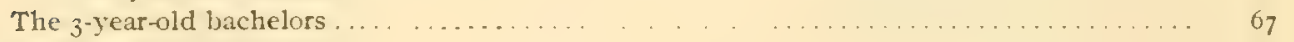

The ${ }_{4}$-year-old bachelors. . . . . . . . . . . . . . . . . . . . . . . . . . . 69

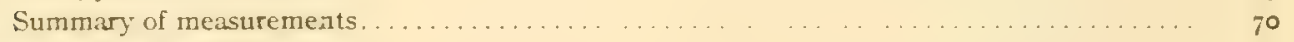

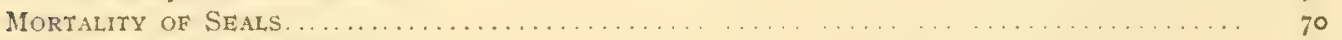

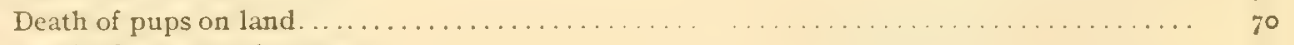

Death of young seals at sea. ............ . . . . . . . . . . . . . . . $7^{2}$

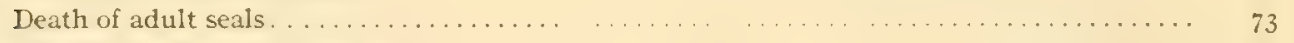

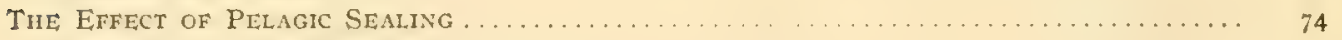

Losses due to pelagic sealing . . . . . . . . . . . . . . . . . . . . . . . . . . . 74

Information to be gained from the cessation of pelagic sealing . . . . . . . . . . . . . 74

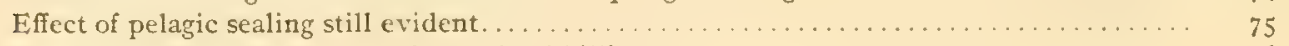

Pelagic sealing indirect cause of close land killing ........................... 76 


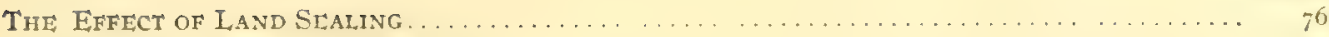

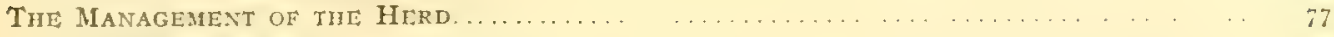

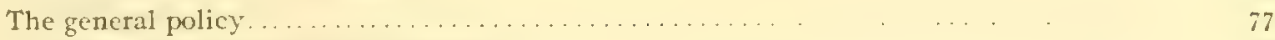

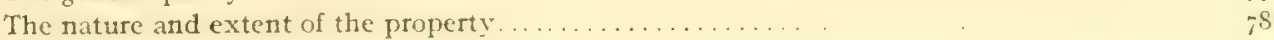

Management based on principles employed with domestic arimals............... i $^{S}$

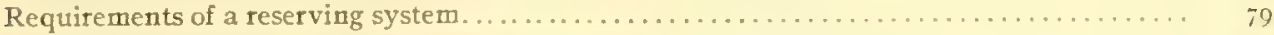

Confinement of killing and reserving to one class............... 79

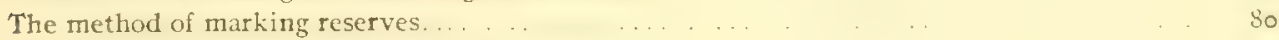

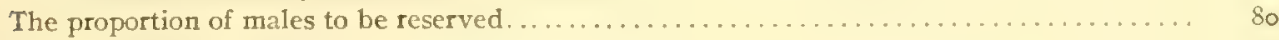

Methods of Driving, Killing, and Curing Skins . . . . . . . . . . . . . . . . . . $8_{5}$

Need for shorter drives. ...... . . . . . . . . . . . . . . . . . . 35

Killing....................... . . . . . . 86

Females and old seals in drives..... . . . . . . . . . . . . . . . . 86

The sealing season.............. . . . . . . . . . . . . . . 88

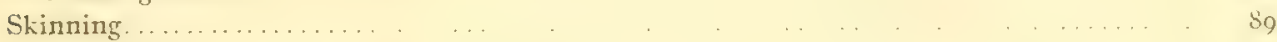

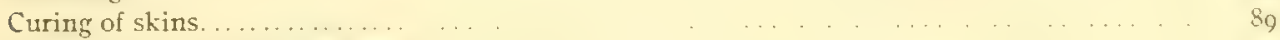

Need of competent supervision . $\quad \ldots \quad \ldots . . .60$

Measurements versus weights ... . . . . . . . . . . . . . . . . no

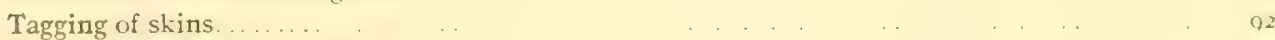

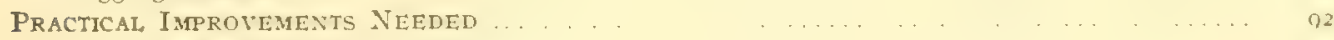

Present unimproved condition of plant. . . . . . . . . . . .

Reforms contemplated ly lessees $\ldots \ldots \ldots 3$

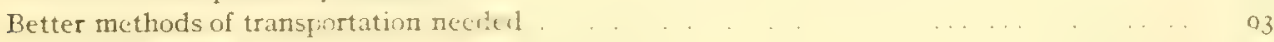

Roads and trails........ . . . . . . . . . . . 03

Supply ship........ . . . . . . . . . . . . . 0.1

Cold-stozage plants......... . . . . . . . . . . . . . . . 95

Rookery improvements. .... . . . . . . . . . . . . . . . . . . 95

Marked rocks............ . . . . . . . . . . . . . . . . . . 95

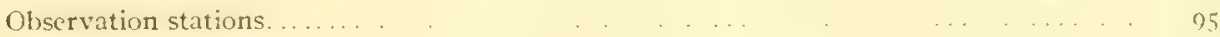

Improvement of ground ... . . . . . . . . . . . . . . . . . . . . . . . . 96

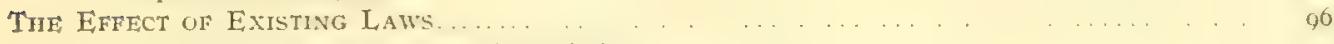

The law effective for longer than intended . . . . . . . . . . . . . . . $\quad . \quad 97$



Evils of leasing system not possible under Government management............... ${ }^{S}$

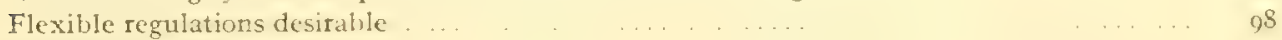

Reserves unduly large. .......... . . . . . . . . . . . . . . . . . 99

Matters for special discretionary power ................................ 100

Emergency action............. . . . . . . . . . 100

Annual sale of skins. ............ . . . . . IOI

Specimens for scientific purposes............................... Ior

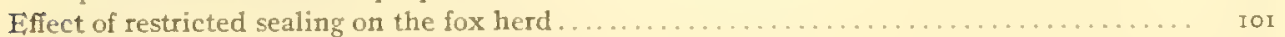

The treaty............. . . . 102

Early solution of practical problems important......................... ro3

Gradual development of efficiency necessary ................. I0 3

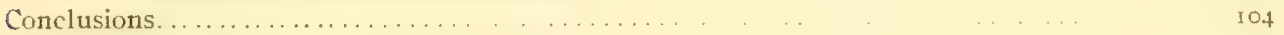

THE Foxes : . . . . . . . . . . . . . . . . . . . . . . 105

General considerations ...... . . . . . . . . . . . . . . . . 105

Former abundance....... . . . . . . . . . . . . . . 106

Decline from lack of food... . . . . . . . . . . . Io6

Diseases............. ... . . . . I08

Food ..................... . . . .

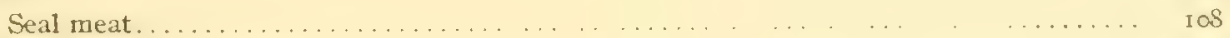

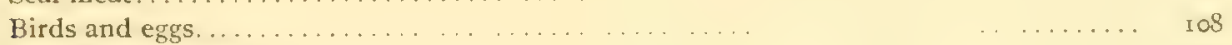

Miscellaneous food. . . . . . . . . . . . . . . . . . . . . . . . 
TrE Foxes-Continued.

Food-Continued.

Page.

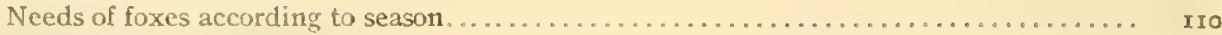

Ilistory of spectal feeding . . . . . . . . . . . . . . . . . . . . . . . .

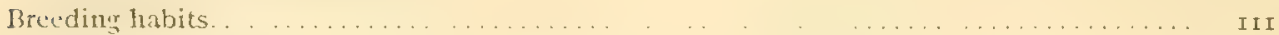



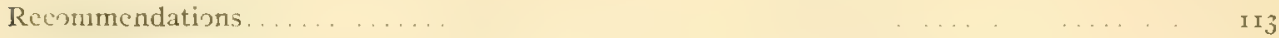

Feeding and method of capturing. ............................

Reserves for breeding . . . . . . . . . . . . . . . . . . . . . . . .

Elimination of white foxes. . . . . . . . . . . . . . . . . . . . . . .

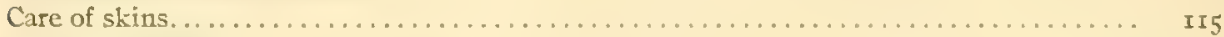

Sale for lirecding. .... . . . . . . . . . . . . . . . . . . . . .

Experiments in domesticatino foxes. ...... . . . . . . . . . . . . . . .

TIRE REINDEER. . . . . . . . . . . . . . . . . . . . . . . . . . .

Introduction and growth of licrd . . . . . . . . . . . . . . . . . . . .

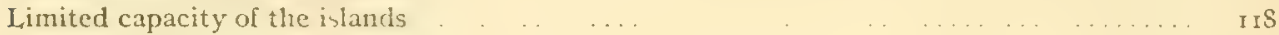

Indiference of natives regarding reindeer. .............................. 8

Use and value of the herd . . . . . . . . . . . . . . . . . . . .

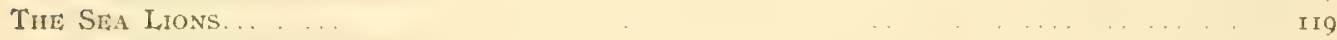

Early abundance and uses. . . . . . . . . . . . . . . . . . . . . . . . .

Breeding labits. ... . . . . . . . . . . . . . . . . . . . . . . . . . . .

Numbers killed in former years. . . . . . . . . . . . . . . . . . . . . . . . . . . .

Measures for preservation. . $\ldots \ldots \ldots$ I2r

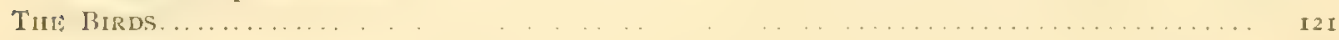

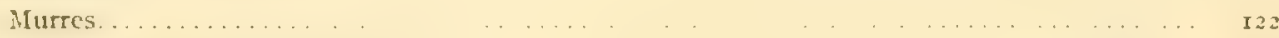

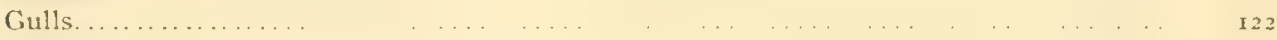

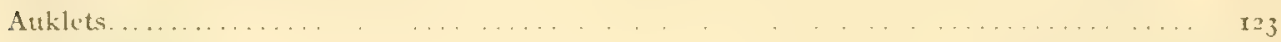

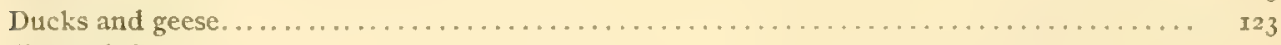

Shore birds . . . . . . . . . . . . . . . . . . . . . . . . . . . .

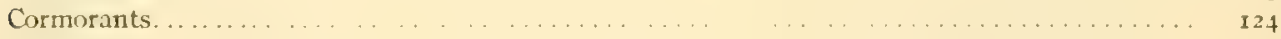

Measures for protection. . . . . . . . . . . . . . . . . . . . . . . . . . .

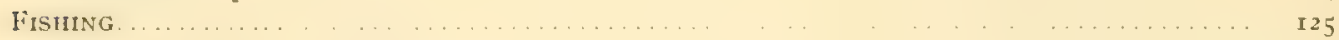

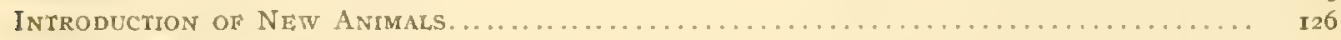

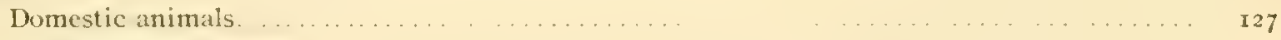

Horses and mules. . . . . . . . . . . . . . . . . . . . . . . . . . . . . . . .

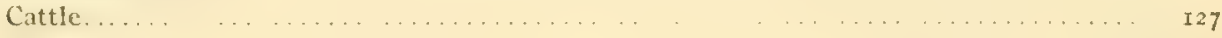

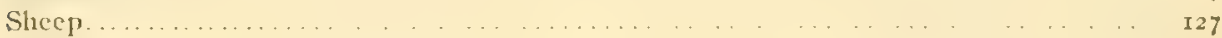

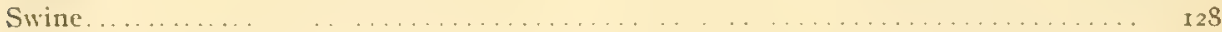

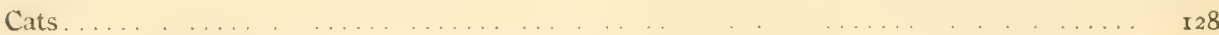

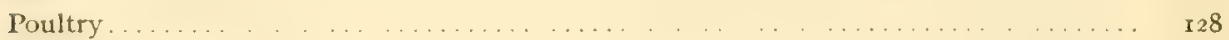

Wild animals. . . . . . . . . . . . . . . . . . . . . . . . . . . . .

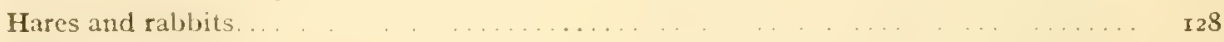

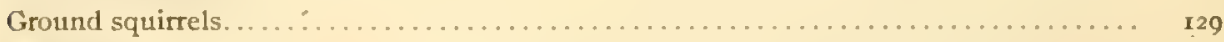

Muskrats. . . . . . . . . . . . . . . . . . . . . . . . . . . . . . . . . .

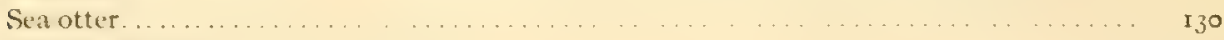

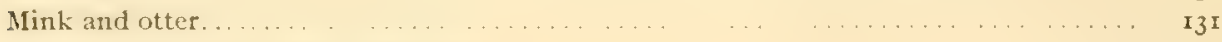

Lemmings and other small mammals . . . . . . . . . . . . . . . . . . . . . .

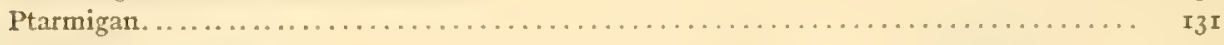

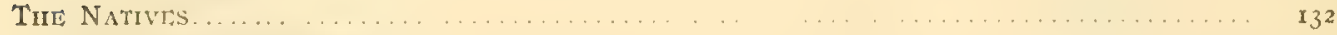

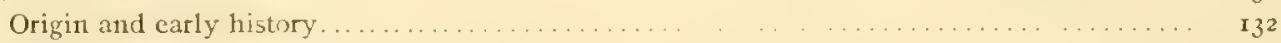

Relation to lessees. . . . . . . . . . . . . . . . . . . . . . . . . . . . .

Conditions under Government managenent. . . . . . . . . . . . . . . . . .

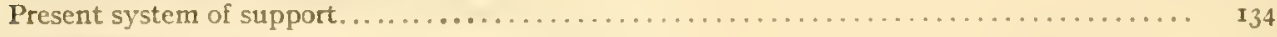

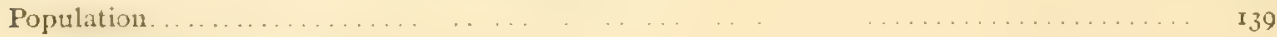

Practical ability of natives . . . . . . . . . . . . . . . . . . . . . 
THE NATIVES-Continued.

I'age.

Knowledge of sedils ovcrestimated ..... . . . . . . . . . . . . I .

Proposed removal of natives impractical . . . . . . . I .

Present appropriation inadequate . . . .

Food requirements. . . . . . . . . It:



Hygiene and sunitation... . . I +3

Morals............. . . . . . . . . . . . . .

Religion........... . . . . I . . . . .

Education............ . . . . . . . . . . . . . . . .

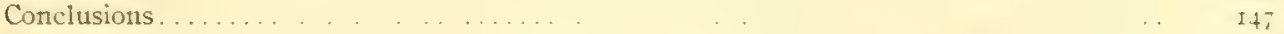

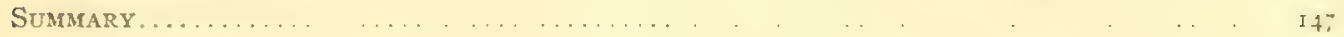

Existing conditions. . . . . . . . . . . . . . . . .

Conclusions. . . . . . . . . . . . . . . . . . . . .

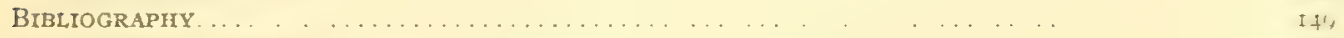

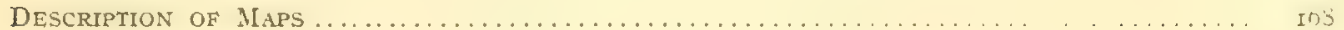




\section{TABLES AND NUMERICAL RECORDS.}

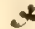

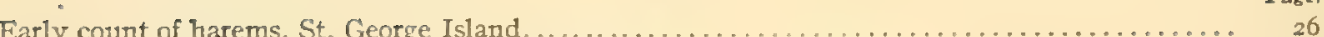

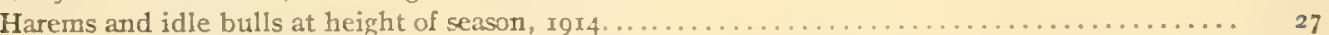

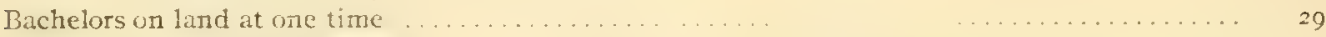

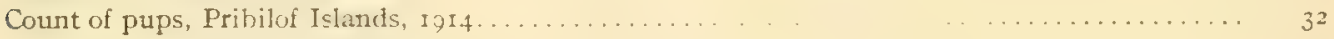

Comparison of actual counts of pups with estimates based on an average harem............ 34

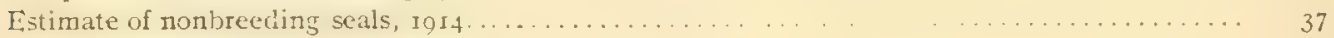

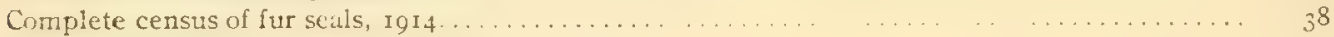

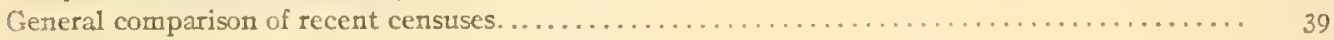

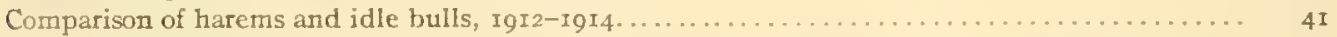

Demonstration of probable abnormal mortality of old cows, $1913-1914 \ldots \ldots \ldots \ldots \ldots \ldots \ldots . . .43$

Number of pups and percentages of decrease or increase in IgI3 and in IgI4 compared with the year before.

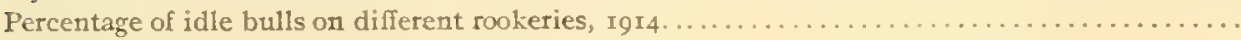

Mortality in relation to idic bulls

Prices received for skins of large seals.

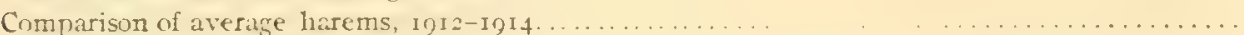

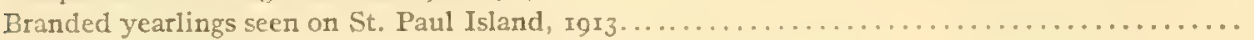

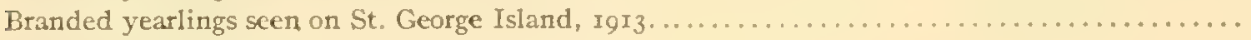

Measurements and weights of male yearlings, St. George Island . . . . . . . . . . . . . . . . .

Measurements and weights of two-year-old males. . . . . . . . . . . . . . . . . . . . .

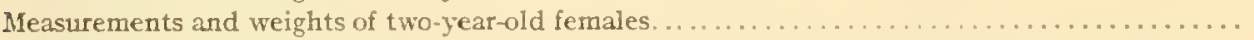

Measurements of three-year-old males, with weights of skins, St. Paul Island, July I, Igr4.....

Measurements of four-year-old males, with weights of skins, $1914 \ldots \ldots \ldots \ldots \ldots \ldots \ldots \ldots$

Condensed measurements of young males.

Moriality of pups, summer of rert .

Estimated minimum number of females, Igr4-1926.

Estimated inaximum number of females, I0r4-I926 . . . .

Estimated mean number of bearing and virgin cows, $1914-1926 \ldots \ldots \ldots \ldots \ldots \ldots \ldots$

Estimated minimum number of males, I914-I926, under operation of law of $1912 \ldots \ldots \ldots \ldots$.

Harem and idle bulls and annual increments required under various estimates at ratio of one bull to thirty-five cows.

Comparison of results of present, law, and of a reserving system based on an estimated mean rate of increase of cows.

Bulls provided by law in excess of requirements of maximum, minimum, and mean estimates of cows. .

Extracts from St. Paul $\log$ regarding cows in drives . . . . . . . . . . . . . . . . .

Number of foxes taken on Pribilof Islands, $1890-1913 \ldots \ldots \ldots \ldots \ldots \ldots \ldots \ldots \ldots \ldots \ldots \ldots \ldots$

Sea lions killed on St. Paul Island, I8

Number and size of households on Pribilof Islands, rgr4 ....................... I43 


\title{
PLATES.
}

\section{$*$}

Facing page.

PIATE I. Old bull in prime condition awaiting arrival of cows, Kitovi Rookery, June 22, I914.. IS

II. I. Cow and pup sleeping, Kitovi Rookery, August 23, I9I4 .............. 2.2

2. Cow nursing pup, Tolstoi Rookery, August 25, Igr $4 \ldots \ldots \ldots \ldots . \ldots 2$

III. Bachelors sieeping on Tolstoi sands, August 25 , I9I $4 \ldots \ldots \ldots \ldots \ldots \ldots \ldots \ldots$

IV. I. Fur-seal pups on Tolstoi Rookery, August 25 , IgI $\ldots \ldots \ldots \ldots \ldots \ldots \ldots . \ldots \ldots$

2. Fur-seal pup on Gorbatch Rookery, August rg, rgr4 . . . . . . . . . 30

$\mathrm{V}$. Old bull showing usual emaciation at close of breeding season. ............... 34

VI. Roving bachelors on front of Kitovi Rookery, August $23,1914 \ldots \ldots \ldots \ldots \ldots \ldots \ldots . \ldots$

VII. Tolstoi flat after disorganization of the harems, August $23,1914 \ldots \ldots \ldots \ldots . . . . .50$

VIII. Old cows in front of Gorbatch Rookery, August $I_{3}$, I9I4 . . . . . . . . . 5.4

IX. Skulls of male seals showing changes due to growth and age: I. Two-year-old. 2.

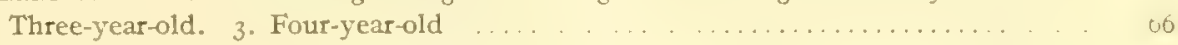

$\mathrm{X}$. Skulls of male seals showing changes due to growth and age: T. Five-year-old. 2.

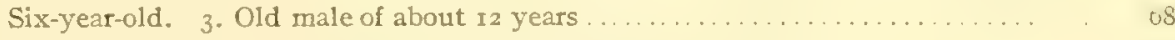

XI. Cows and pups swimming, Vostochni Rookery, August $17,1914 \ldots \ldots \ldots \ldots . . . .$. it

XII. Branded cow, probably I2 years of age, Kitovi Rookery, August 23, I914......... ;3

XIII. Young seals hauled on Tolstoi Beach, St. Paul Island, August 25, 19 4 ............. So

XIV. Driving and podding seals for a food killing, St. Paul Island, August 8, I9I4........ 80

XV. Sea Lion Rookery at Northeast Point, St. Paul Island, June 28 , I9I4............ I 20

XVI. Murres or arries on Walrus Island, July 16 , I9I4 . . . . . . . . . . . . . I 22

XVI1. Natives' dwelling houses with seal meat drying, St. Paul Island, July ,9, IgI4. . . ... I I 2

XVIII. Native laborers moving hospital building, St. Paul Island, August 24, I914........ I.44

\section{$* *$}

\section{DESCRIPTION OF MAPS.}

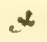

ROOKERIES, SHOWING NUMBER AND LOCATION OF HAREMS AT HEIGHT OF SEASON, IOI4.
\end{abstract}

St. Paul Island.

I. Kitovi......

2. Lukinin

3. Gorbatch...

4. Ardiguen

5. Reef.

6. Sivutch

7. Lagoon.

8. Tolstoi.

9. Zapadni.

I0. Iittle Zapadni.

II. Zapadni Reef

12. Polovina.
St. Paul Island-Continued.

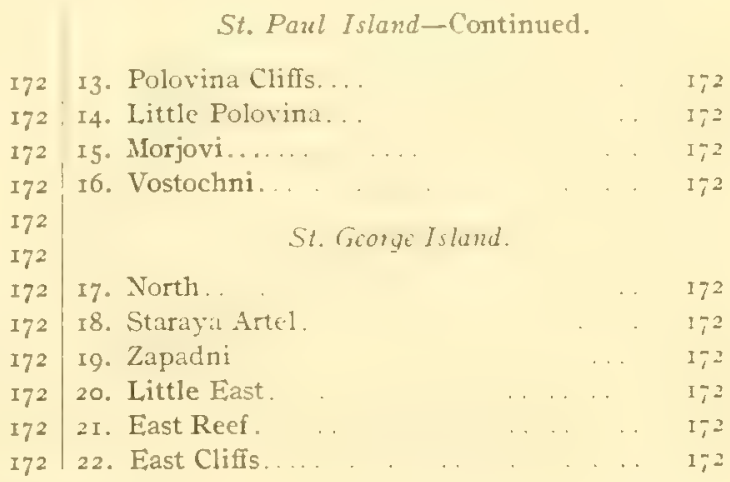

GENERAL MAPS,

23. St. Paul Island, with Otter Island and Sea Lion Rock 



\section{LETTERS OF TRANSMITTAL. ${ }^{a}$}

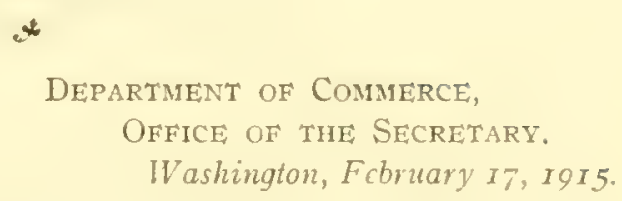

Miy DeAR Senator Fietcher: I transmit herewith a report of Wilfred H. Osgood, Edward A. Preble, and George H. Parker, scientific assistants of the Bureau of Fisheries, on the fur seals and other life on the Pribilof Islands in I9I4, and request that you obtain the consent of the Senate to have the report printed as a congressional document.

When the present Administration took charge it found in full force and vigor the existing law providing for a closed season for the seal herd belonging to the United States on the Pribilof Islands. This law was approved August 24, 1912, effective immediately, and will expire by its own limitation August 24, 1917.

The Department has felt that it had two duties in this important matter. The first was to enforce the law in letter and in spirit, and this has been done. The second was to ascertain from unprejudiced and dispassionate sources the effects of the law and to inform Congress about them as fully as possible. This is now done.

In view of the sharp controversy that has existed on the subject of the fur-seal herd it was deemed necessary that the persons selected by the Bureau of Fisheries as scientific assistants to study this problem should be persons who were free from all previous connection with the subject, but who were qualified by training and experience to determine and present the facts. It was required also that they should be severally qualified to carry on as separate individuals the particular lines of scientific study necessary to a full understanding of the problem.

Under these circumstances the president of the National Academy of Sciences, the Secretary of the Smithsonian Institution, and the Secretary of Agriculture were requested to make nominations of persons who might be temporarily employed for the purpose. The National Academy of Sciences nominated Prof. George H. Parker, of Harvard University, Cambridge, Mass.; the Secretary of the Smithsonian Institution nominated Mr. Wilfred H. Osgood, of the Field Muscum of Natural History, Chicago, Ill.; and the Secretary of Agriculture nominated Mr. Edward A. Preble, of the Bureau of Biological Survey, Department of Agriculture. The three persons named were selected by the Department of Commerce and employed by the Bureau of Fisheries as temporary scientific assistants, and were instructed to proceed to the Pribilof Islands, there to ascertain the facts and to submit them to the Department for transmission to Congress. Full details are found in the attached report.

As Great Britain, through the Dominion of Canada, and Japan are financially interested in the American seal herd under the terms of the treaty abolishing pelagic sealing, these countries also of their own motion arranged to send representatives to the Pribilof Islands in I9I4, and two experts from Canada and one from Japan visited the islands while our own inquiry was progressing. The facts concerning this matter appear in full in the report. 
The report is accompanied by three large traced maps of the Pribilof Islands, of which blue prints have been taken for the records of the Department, and by 2 I smaller maps illustrating the report in detail.

The purpose of the Department has been to provide Congress with an unbiased statement of the actual facts to assist it in the preparation of such further legislation, if any, as it may deem wise to enact. It is my earnest hope that this has been accomplished.

Yours, very truly,

Hon. Duncan U. Finetcher,

Wil,LIAM C. REDFIELD, Secretary.

Chairman Committee on Printing,

U. S. Senate, Washington, D. C.

DEPARTMENT OF COMMERCE,

BUREAU OF Fisheries,

Washington, Jamuary 25, 1915.

SIR: There is transmitted herewith, for the information of the department, a report entitled "The Fur Seals and Other Life of the Pribilof Islands in rgr 4," by Wilfred H. Osgood, Edward A. Preble, and George H. Parker, special assistants whom the department engaged to visit the Pribilof Islands and investigate the conditions thereon during the sealing season of 1914 . The report is accompanied by a limited number of photographs illustrating important phases of the subject and a series of maps showing the location and extent of the seal rookeries.

In view of the comprehensive scope of the report, the purpose of the investigation on which it is based, and the large economic interests involved I beg leave to recommend that the report be submitted to Congress with a view to its publication and distribution. Respectfully,

The SECreTARY OF COMMERCE.

H. M. Surth, Commissioner.

\section{$* *$ \\ LETTER OF SUBMITTAL.

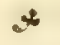 \\ DEPARTMENT OF COMERCE, BUREAU OF FISHERIES, Washington, Jamuary 23, I9I5.}

SiR: We have the honor to submit a report entitled "The Fur Seals and Other Life of the Pribilof Islands in I9If," being the result of investigations carried out in response to instructions received from the Secretary of Commerce under date of May 26, 1914 .

Very respectfully,

WILFRED H. OSGOOD.

EdWard A. Preble.

George H. Parker.

Dr. Hugh M. SMITH,

Commissioner of Fisheries. 


\section{THE FUR SEALS AND OTHER LIFE OF THE PRIBILOF ISLANDS, ALASKA, IN 1914.

\author{
*
}

BY WILFRED H, OSGOOD, EDWARD A. PREBLE, and GEORGE H. PARKER.

\section{INTRODUCTION.}

PERSONNEL AND INSTRUCTIONS.

In the spring of 1914 , at the instance of the Secretary of Commerce, steps were taken to send three investigators to the Pribilof Islands to examine and report on the condition of the fur-seal herd. To this end the president of the National Academy of Sciences, the Secretary of the Smithsonian Institution, and the Secretary of the Department of Agriculture were requested to make nominations. The only restriction imposed was that the nominees should have had no previous connection with the fur-seal question, in order that they might approach the subject uninfluenced by the controversies which have for some time beset the subject. The nominations were as follows: George H. Parker, of Harvard University, Cambridge, Mass, by the National Academy of Sciences; Wilfred H. Osgood, of the Field Museum of Natural History, Chicago, Ill., by the Secretary of the Smithsonian Institution; and Edward A. Preble, of the Bureau of Biological Survey, Department of Agriculture, by the Secretary of Agriculture. All having accepted, a conference was held in Washington on April 20, and tentative plans were formulated. In due time the nominees were appointed as temporary special assistants of the Bureau of Fisheries, and detailed individual letters of instructions were issued to them. The nature of these instructions is indicated by the following letter which was addressed to G. H. Parker, and which is essentially like those sent to the others:

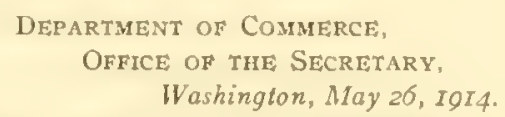

DEAR SIR: You have been engaged as a temporary special assistant of the Department of Commerce, Bureau of Fisheries, beginning June $\mathrm{x}, \mathrm{IgI4}$, and you are assigned to an investigation of the Alaskan fur seals and various questions connected therewith, in cooperation with Mr. Wilfred H. Osgood and Mr. Edward A. Preble, in accordance with the instructions which are contained herein or which may hereafter be issued.

You will arrange to sail for the Pribilof Islands from Seattle on or about June 8 , on the revenue cutter $\mathrm{McC}$ ulloch, which is under orders from the Treasury Department to carry your party to the seal islands. Your return trip from the seal islands to a point where a regular passenger steamer is available will likewise be made on a revenue cutter which will be detailed for the purpose.

The time of your sojourn on the islands is left to your discretion. It is hoped, however, that you will remain as long as it is possible to obtain information of value bearing on the special object of your visit. 
You have been selected for this service because, not having previously been identified with or in any way concerned with fur seals or the fur-seal controversy, it is expected that your observations and conclusions will be uninfluenced by past contentions but will depend wholly on the existing conditions. It is desired that you confine yourself to the facts that may be established by your inquiries, and not become involved with profitless discussion or controversy over previous conditions.

The main purpose of your investigation is to ascertain the actual state of the Alaskan seal herd in I9I4, and to make that condition known to the department, with recommendations touching all important administrative matters growing out of the intemational, economic, and biological relations of the seal herd. Incidentally, it will be necessary for you to consider ( $I$ ) the welfare of the native inhabitants of the islands and the duty of the Government thereto as related to the conservation and utilization of the seal life; and (2) the foxes, reindeer, birds, and other animals of the islands, and their proper treatment with reference to the best interests of the Government and the natives.

Without assuming to restrict your investigations in any way whatever, I will indicate the following subjects as among those requiring special attention:

I. A census of each rookery and hauling ground, so that the numerical strength of each component of the herd may be known. Especially valuable will be the actual enumeration of the pups before they have taken to the water, because this affords the only accurate knowledge of the number of breeding females present. The census requires much time and care, and should be participated in jointly and be certified to by the members of your party and the available members of the staff on the islands.

2. The adequacy of the various components of the herd with regard to the reestablishment of the herd, and especially the sufficiency of male life in view of the recent apparent marked increase in the number of mature females as a result of the suspension of pelagic sealing.

3. The strength of the surplus male life in relation to the close-time provisions of existing law and to treaty obligations.

4. The quota of seals of specified ages that should be taken for the food and other purposes of the natives, in view of the provisions of law and of the condition of the herd. As soon as practicable after your arrival on the islands and after full consideration of the needs of the natives, the department desires a telegraphic recommendation to cover the food killings during the height of the season and a supplementary recommendation prior to your departure from the islands.

5. The general and special effects of the suspension of pelagic sealing on the size and condition of the herd.

6. The propriety of the methods of driving, killing, and skinning now practiced; the presence of female seals in the drives; the probability of the killing of immature females regularly or accidentally through inability to distinguish them from the bachelors.

7. Natural mortality among young and old seals on the islands, especially that due to disease.

8. Evidences of injury to the herd from fighting and trampling among surplus bulls, resulting from the operation of existing law.

It is desired that there be obtained a full photographic record of the rookeries, hauling grounds, etc., and that the historical series of rookery views be continued as far as possible. Furthermore, as a part of the general publicity plans of the department, there should be taken a typical set of motion-picture photographs illustrating the various phases of seal and native life on the islands.

So far as your other duties will permit, I am particularly desirous that you should give attention to the native inhabitants and determine what changes, if any, should be made in the relations of the Government to their social, educational, sanitary, business, and other interests.

The regular employees of the bureau on the seal islands will be instructed to accord you every facility and assistance in your work, and you will have access to and full use of all the official records on the islands and in Washington.

As soon as practicable after your retum, and preferably before December I, I desire to have a full report embodying the results of your investigations, and recommendations based thercon.

Very truly, yours,

(Signed) WILLIAM C. REDFiEL, Secretary.

Prof. GEORgE H. PARKER,

Harvard University, Cambridge, Mass. 
INVESTIGATIONS BY CANADA AND JAPAN.

Canada and Japan, being interested financially in the American seal herd by the terms of the treaty abolishing pelagic sealing, also arranged to send representatives to the Pribilof Islands in r9r4. A few days before the date assigned the American investigators for leaving for the Pribilof Islands, the State Department received from the British and Japanese ambassadors the following communication, which was referred to the Department of Commerce:

$$
\text { NOTE VERBALE. }
$$

During the past 25 years naturalists of unquestioned ability and integrity have been at great pains to acquire a fuller knowledge of the life of the fur seals frequenting the North Pacific Ocean. 'They have devoted much attention to the subject and have made a close personal study thereof on the seal islands. Whilst these studies have resulted in a consensus of opinion on many aspects of seal life, it appears that there is still some divergence of view, for instance as to the best course to rehabilitate the herd.

In view of the importance of the matter to Canada and Japan, as well as to the United States, a suggestion has been made that the present time calls for the appointment of a committee of experts for these three countries to visit the Pribilof Islands during the summer, and after a thorough investigation into the conditions there prevailing, to submit a joint report and recommendations, if they can agree on such, for the consideration of the United States Government.

It is desired to know what view the United States Government take of this proposal, and as the experts should be on the islands by the month of July, it is hoped that the United States Government will be able to give the matter their early consideration.

MAY 29, I9r4.

To this request the Department of Commerce replied through the Department of State, expressing the belief that, on account of the late date, it would be impracticable to secure the necessary authority to enter into the formal joint investigation proposed, but that arrangements to send three expert assistants to the islands had already been made; that the department would welcome the representatives of Canada and Japan to the seal islands, and would afford them every possible facility for making their investigations, and through its assistants would cooperate with them so far as possible. To this end, the agents on the islands and the special assistants were instructed to extend to the foreign visitors all possible courtesy and assistance.

With this understanding, two experts from Canada and one from Japan visited the islands during the investigation. The representatives of Canada were Mr. James M. Macoun, naturalist of the Geological Survey of Canada, and Mr. B. IV. Harmon, of the Dominion Department of Marine and Fisheries. The representative of Japan was Dr. T. Kitahara, biologist of the Imperial Japanese Fisheries Bureau. The American and foreign representatives worked cooperatively during the season, and though nothing of a deliberative nature was done jointly, the observation of fact and particularly the enumerations of seals, were matters of joint labor by both Americans and foreigners.

\section{ITINERARY.}

Pursuant to instructions the three assistants assembled at Seattle, Wash., on the evening of June 8. Upon the arrival of the Canadian representatives, the combined party went on board the revenue cutter $M c C$ ulloch, Capt. P. H. Uberroth commanding, and left for the Pribilof Islands on June II. St. Paul Island was reached in the late afternoon of June $2 \mathrm{I}$, and the party was hospitably received by the officials in charge. S4512 -S. Doc. $980,63-3-2$ 
The investigators remained on St. Paul Island until July ro when they went to St. George Island on the Bureau of Fisheries steamship Albatross, Lieut. L. B. Porterfield commanding. Here they remained until July 15 , when they were taken back to St. Paul on the revenue cutter Tahoma, Capt. R. O. Crisp commanding. The next day, July i6, a trip to Walrus Island was made on the same vessel, and an opportunity for observing its extensive bird rookeries was afforded.

On July 24, Dr. T. Kitahara, the Japanese representative, arrived on St. Paul Island on the United States revenue cutter Manning.

A visit to Otter Island, formerly the site of an extensive hauling ground, was made on July 27 on the Tahoma. On August 3 the entire party-Americans, Canadians, and Japanese-having finished the count of the seal pups on St. Paul, went to St. George on the Tahoma to make a similar count there. This work was finished on the morning of August 5, and in the afternoon of that day all returned to St. Paul.

On August 6, Mr. Parker, Mr. Kitahara, and Mr. Harmon left St. Paul for Seattle and their respective homes. Messrs. Nacoun, Osgood, and Preble continued to make further observations until August 3 , when, through the courtesy of Capt. W. E. Reynolds, in command of the Bering Sea fleet, they left on the reventue cutter Manming, Capt. F. G. Dodge commanding. The party arrived at Seward, Alaska, via Unalaska, on September 6, and left Seward on the steamship Alameda on September 9, arriving in Seattle un September 17 .

\section{IMPARTIAL NATURE OF THE INVESTIGATION.}

In accordance with the desire of the Secretary of Commerce, the observations and inquiries of 1914 were conducted, so far as possible, without reference to previous opinions. The entire subject was approached without prejudice and with the desire only to ascertain the actual conditions. Nothing was taken for granted, and whenever it was found necessary to refer to previous conditions all points concerned were subjected to scrutiny and verification by actual observation. The same policy has been pursued in the preparation of the report, and though conclusions of others have been consulted freely they have not been accepted unless confirmed by observations in 1914. In the treatment of special subjects, it has sometimes been necessary, for the sake of clearness, to repeat in part under one subject matter which may be found in full under another.

The preparation of the report has been carried out mainly by Mr. Osgood and Mr. Preble. Owing to the press of other duties, Mr. Parker has been unable to give continuous active assistance, but he has prepared certain sections, revised others, and critically examined the entire manuscript. Therefore the complete report, both as to detailed statement and general conclusions, is subscribed to by each of the co-authors.

\section{A.CKNOWLEDGMENTS.}

In the course of the investigations material aid was received from many persons, to all of whom grateful acknowledgment is made. Special thanks are due the officers of the Revenue-Cutter Service, who were ready to aid at all times-the necessity of moving back and forth between the two main islands in order to make particular observations at certain times rendered this ready cooperation invaluable. The agents and other employees of the Bureau of Fisheries on the islands and elsewhere, and the operators of the naval radio stations freely rendered service whenever required. 'Thanks 
for various courtesies are due also to the representatives of Canada and Japan, with whom the most cordial relations were maintained during daily association.

Finally, it should be stated that certain of the suggestions made in the present report have been previously urged, some of them repeatedly. To former observers in the field and to many others who in the past have been more or less directly concerned with the activities on the islands, acknowledgment is made for such ideas and facts found in their printed reports as were confirmed by observations in I9I4. To give credit in each case is impracticable, but passing acknowledgment is made in various instances in the body of the report.

\section{THE PRIBILOF ISLANDS.}

GENERAL DESCRIPTION.

The Pribilof Islands are situated in Bering Sea in latitude $57^{\circ}$ north and longitude I $70^{\circ}$ west, and are of volcanic origin. The nearest land is Unalaska Island, 214 miles to the southward; the next nearest is St. Matthew Island, 220 miles to the north. The distance from the mainland of Alaska is a little over 300 miles. The group comprises five islands, St. Paul and St. George, lying about 40 miles apart, being the principal ones. The others are Otter Island, Walrus Island, and Sea Lion Rock, which lie close to the shores of St. Paul.

St. Paul is about $13 / 2$ miles long and $72 / 3$ miles wide and has a shore line of about 45 miles, composed of alternate stretches of sand and broken rock, in some cases backed by cliffs, the highest of which attain an elevation of nearly 400 feet. Several cinder cones are distributed over the island, the highest being Rush Hill, which is 665 feet above mean high tide. Much of the surface is very rough in character but extensive stretches of comparatively smooth ground, clothed with lichens and herbaceous plants, occupy many of the valleys and low plateaus. There are many fresh water ponds, the largest about 2 miles in length, but all are very shallow.

St. George Island is about 12 miles long and $4 \frac{1}{2}$ miles wide and has a coast line of about 30 miles. It is bordered mainly by abrupt cliffs, the highest of which rise nearly a thousand feet sharply from the water. There are several hills in the interior of the island, the highest of which is 946 feet above sea level. Various shallow ponds and many marshes, from which a few small streams descend to the sea, distinguish St. George from its larger companion, which is devoid of running water.

Otter Island, 6 miles south of St. Paul, is only three-fourths of a mile in length; its shore is mostly precipitous, rising in one place to a height of 300 feet. The other islets, Walrus Island and Sea Lion Rock, also near St. Paul, are merely ledges of rock scarcely elevated above the wash of the sea.

On the shores of the two larger islands the fur seals have most of their breeding rookeries and hauling grounds. The seals when breeding choose rocky beaches or bowlder-strewn ledges. The rookeries are usually separated from each other by stretches of sand or by abrupt clifs, or in some cases by sections which have been abandoned. The breeding masses usually extend back from the water's edge but a short distance.

Sea Lion Rock has a breeding rookery, and Otter Island formerly had a hauling ground, and once, in 1896 , a single harem, but so far as known was not resorted to by 
seals during igr4. All the islands are the breeding resorts of myriads of sea birds. Their great numbers and the protection which they enjoy during the breeding season make them fearless and confiding, and they afford an exhibition of bird life which can scarcely be surpassed anywhere in the world.

\section{VEGETATION.}

The three larger islands are remarkable for the abundance and beauty of their floral display. The flowering plants include a great variety of subarctic species, which from early June until late August beautify the grassy slopes and plains. There are also many ferns and mosses and lichens, and a variety of grasses. No trees whatever grow on the islands, and the shrubs are represented only by a few creeping willows and dwarfed heath-like plants. The two smaller islands are devoid of vegetation with the exception of a few grasses and one or two insignificant herbs.

\section{CLIMATE.}

The range in temperature is very slight, the thermometer seldom rising above $50^{\circ}$ $F$. in summer, and in winter ranging usually between $20^{\circ}$ and $25^{\circ}$ and rarely falling lower than $12^{\circ}$. There is much precipitation, usually falling in the form of drizzly rains or light snows. Chilly fogs are of almost constant occurrence during summer and the winds are at other seasons sometimes very violent. In winter the pack ice from the Arctic frequently closes in about the shores.

\section{CHARACTER AND HABITS OF THE FUR SEAL IN BRIEF.}

\section{GENERAL CHARACTERISTICS.}

The Alaska fur seal (Callorhinus alascanus), although similar in general appearance, has certain characters by which it is recognized by naturalists as distinct from the seals inhabiting the Russian and Japanese islands lying near the coast of Asia. It has a range peculiar to itself and is not associated at any season of the year with the other species of fur seals. With a few allied species, it is remarkable among large animals for its highly gregarious and polygamous nature and its habit of performing a long annual migration. It comes to land only in summer for the purpose of breeding and rearing its young; the remainder of the year is spent entirely at sea. It is an animal of exceedingly strong instincts and relatively small intelligence. The disparity in size between the sexes is very great, the adult male being nearly or quite five times as heavy as the female. Moreover, the male matures more slowly than the female, and thus it results that seals of different ages and sexes are different in appearance and to some extent in habit. The names by which the different ages and classes of seals have come to be known, therefore, are somewhat peculiar. The breeding males are bulls, the females are cows, while the young are pups. The males just approaching full maturity are called half-bulls, while the younger males are termed bachelors. The breeding ground is a rookery, and the place resorted to by the bachelors is a hauling ground.

\section{RANGE.}

Practically all the individuals of the herd during some part of the season from May until December make the Pribilof Islands their home. The winter and early 


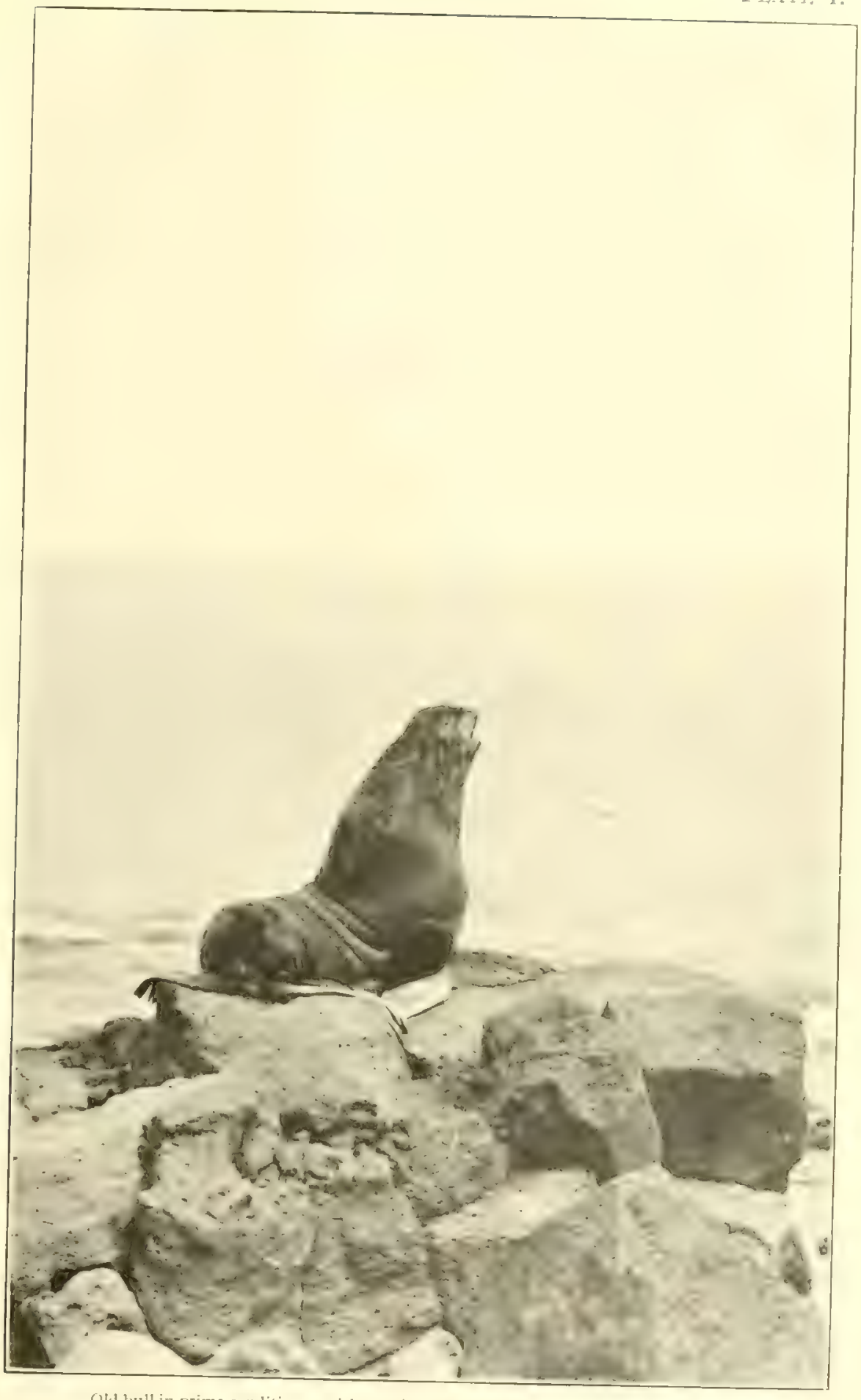

Old bull in prime condition awaiting arrival of cows, Kitovi Rookery, June 22, Igr4. 

spring months are spent entirely at sea. The nuigration route in general is southward to the passes of the Aleutian Islands, then eastward and southeastward along the coast of Alaska, British Columbia, and the United States to the latitude of southern Califormia. The adult males remain farthest north, wintering south of the Aleutian Chain and in the Gulf of Alaska. The younger males go somewhat farther and the females the farthest of all. Returning from their winter resort, the seals reach the islands in general according to their age, the older animals first and the youngest last. The adult males begin to reach the Pribilof Islands about the rst of May; the adult females and the older bachelors arrive there mainly in June; the 2-year-olds mainly in July; and the yearlings in the latter part of August and early September.

\section{BREEDING HABITS.}

On reaching the islands the old bulls at once take their places on the rookery ground, in many cases, perhaps in most, choosing the same spot occupied in former years. They remain on the place selected throughout the entire breeding season without eating. Once the place is chosen they can scarcely he forced by any means to forsake it, and display the most extraordinary courage and persistence in maintaining their position against the assaults of their rivals or the efforts of man. During May and June the numbers on the rookery increase, each bull on arriving taking such place as he can obtain, sometimes by dispossessing another, but as a rule by selecting an unoccupied spot. Thus the late comers settle about the ends or the rear of the breeding ground. Shortly after the Ist of June the females of 3 years and over begin to arrive. Each is pregnant, and is impelled by her condition to seek a place to give birth to her pup. The females on arrival at once land and join a bull, and within a few days, sometimes a few hours, they give birth. Each day other cows arrive, and the harems grow rapidly. The arriving cows show a tendency to join the larger groups, and consequently there is an uneven growth, some bulls securing large harems early in the season, while others near by, apparently equally strong and vigorous, may still have no cows. Farly in the season, before the arrival of the cows, there is some display of rivalry among the bulls, and late arrivals attempting to gain a place near the center of the rookery are frequently subject to the joint attack of several bulls already in place. In general, however, the stationed bulls spend much of this time in sleeping, and incoming ones gradually fill in the unoccupied territory. As the height of the season approaches and cows come in heat in large numbers, the bulls become continuously alert and active. Those at the rear that have not obtained cows attempt to abduct some from the large harems, and some fighting ensues. When bulls are in abundance, a certain number are unable to secure harems and are known as idle bulls, though the observer finds them far from idle. In I9I 4 there were comparatively few of this class of bulls. The number of cows to a harem varies greatly, frequently being more than 50 and occasionally exceeding 100, while in many cases it is very small - from 2 or 3 to a dozen. The large harems are clearly due more to advantage of position than to fighting prowess of the bulls in charge of them.

A few pups are born as early as June Io, but the majority between June 20 and July 20. After the latter date the births decrease, but many occur during the last io days of July and a few during the first week in August. An occasional birth occurs as late as August ro or I5, and one on August 27 is recorded. Each female bears one 
pup and one only, and of the total number born approximately half are males and half females. The weight of the pup at birth is about 12 pounds. Within a few days after giving birth the female is impregnated; it therefore follows that the period of gestation is a few days short of one year. In the interval she nurses her pup, but otherwise shows comparatively little parental solicitude. After impregnation the mother seal, being free to go and come, takes the first of a series of journeys to sea for the purpose of feeding, going from 50 to roo miles or more, and, after gorging on fish, remains in the water until digestion has taken place. While their mothers are at sea the pups form small "pods" by themselves outside the harems. On returning, the cow finds her pup among the thousands which now throng the rookeries, and stays with it a short time, the pup partaking freely of the abundant store of milk. These journeys to and from the feeding grounds are kept up until November, when old and young leare the islands.

The decline in the number of pups born marks the end of the breeding season. The old bulls, grown thin and relatively weak from their long fast and protracted harem service, leave the rookeries and after a short rest go to sea to feed and recuperate. Even before the bulls leave, during the last week in July, they relax the strict discipline which they have maintained earlier in the season and the cows come and go at will, and idle bulls and eager young bachelors throng the grounds they dared not enter previously. At this time also the 2-year-old virgin females cone ashore for their first impregnation. After this "break-up" there is more or less mingling of all classes of seals. The great majority of the cows continue to frequent the breeding grounds and the bachelors mostly resort to the hauling grounds, but cows often wander among the bachelors and bachelors play among the cows. During the first week in August a few pups begin to play in the water and to make short excursions from shore. By the latter part of August pups may be seen swimming and frolicking along the shores at considerable distances from the rookeries. They continue to come ashore to nurse, however, and leave with the majority of the cows and bachelors in November. During August and later months yearlings are frequently seen playing among the pups.

\section{HABITS OF BACHELORS.}

The bachelors or younger males remain during the summer mainly by themselves, hauling out in large bands in the vicinity of the breeding ronkeries on separate areas known as hauling grounds. Unlike the breeding males, they make frequent excursions to sea to feed and remain fat the entire summer. While on land they pass much of the time sleeping and playing with each other, and until late in the season are kept from the breeding grounds by the old bulls. It is from these hauling grounds that the drives for killing are made. Some of the bachelors remain until December, and an occasional few are observed during the winter.

\section{AGE OF SEALS.}

The male seal is capable of breeding at the age of 5 years or even 4 , but does not normally breed until 6 or 7 . The female is normally impregnated as a 2 -year-old and gives birth to her first pup at the age of 3 years. Nales and females, however, have approximately the same length of life, from I2 to I4 years. Fortunately the data regarding this important matter are fairly conclusive. Numerous females branded as pups not later than 1902 were seen in 1914 , showing that many cows live at least 12 
years. One cow observed in 19 I4 bore a large $T$ brand consisting of a transverse bar across the shoulder and a longitudinal mark leading from it down the back. This brand is believed to have been made in 1899 , and if this be true the cow still bearing it must have been 15 years old in 1914. She was in good condition and bore a healthy pup. The age attained by the bulls is attested by scattered records of animals which have been recognized from year to year by various peculiarities or special marks. It is also evidenced by the disappearance within a linited time of the large surplus of bulls produced by the lack of regular killing during the modus vivendi.

\section{SEALING HISTORY IN BRIEF.}

\section{RUSSIAN MANAGEMENT.}

When the Pribilof Islands were discovered by the Russians, in 1786 , they were uninhabited, but a number of small colonies of natives from the Aleutians were at once established. In 1799 the islands passed into the control of the Russian-American Co., which remained in charge until the purchase of Alaska by the United States in I867. The records of their early operations are imperfect, but so far as arailable they indicate that some $\mathrm{r}, 82 \mathrm{I}, 639$ seals were taken between $\mathrm{I}_{7} 86$ and $\mathrm{I} 834$. The catch consisted largely of young ones of the year, and both males and females were taken, and by 1835 the herd had become so reduced that restrictive measures were recognized as necessary. From 1835 to 1867 , when the killing was more restricted and females were spared, the herd gradually increased. During this period at least 608,000 seals were taken. At the time of the purchase of Alaska in 1867 , the herd contained, according to various estimates, from two to five million animals.

\section{AMERICAN OCCUPATION AND THE LEASING SYSTEM.}

In 1868 and I 869 about 242,000 and 87,000 seals, respectively, were taken on the Pribilof Islands by various independent parties. On July I, I 870 , a law was enacted providing for the leasing of the sealing privilege for a term of 20 years, at an annual rental of not less than $\$ 50,000$ and a tax of $\$ 2$ on each skin taken. Under the terms of this act, a lease was entered into with the Alaska Commercial Co., a corporation including some of the American sealers who had operated on the islands in 1868 and 1869 . This company agreed to pay an annual rental of $\$ 55,000$ and a tax of $\$ 2.621 / 2$ on each skin taken. Certain concessions were made to the natives and the right to make further rules and regulations governing the industry was vested in the Secretary of the Treastry. Under the lease the company took a quota of about ioo,ooo seals annually until i 889 . The total number of skins taken on the islands during the 20-year period was $1,977,377$ and the revenue to the Government was $\$ 6,020,152$. Upon the expiration of the first lease the Secretary of the Treasury advertised for bids for the lease of the sealing privilege for a further period of 20 years. Although the Alaska Commercial Co. made an effort to secure a renewal of the lease, a more favorable bid was received from another corporation, the North American Commercial Co., to whom the contract was awarded on March I2, I890. The new lease provided for a rental of $\$ 60,000$ per annum, and a tax of $\$ 9.62 \frac{1}{2}$ on each skin taken. More liberal provisions were made for the care of the natives, and the number of seals to be killed annually was placed at the discretion of the Secretary of the Treasury. For the first year the number was 60,000. During the 
20 years of its incumbency the North American Commercial Co. took on the Pribilof Islands a total of 342,651 skins. The revenue to the Government was $\$ 3,453,844$. The leasing systern was discontinued in 19 I 0.

\section{THE GROWTH OF PELAGIC SEALING.}

Until I 889 the Alaska Commercial Co. had little difficulty in getting its annual quota of 100,000 skins. For some years previously an additional catch was obtained by independent operators who killed seals at sea during their migrations and feeding excursions to and from the islands. These pelagic sealers originally comprised chiefly Canadians and Americans, but in later years many Japanese engaged in the business. Beginning to operate extensively about IS79 they rapidly increased in number and in 1889 their recorded catch was 29,858 seals. In addition, as became evident from later investigations, they killed many seals which could not be retrieved, and still more important, from 60 to 80 per cent of their catch were females whose death involved the loss of their unborn pups, or the starvation of newborn ones left on land, or both. During the period from 1868 to 1878 , inclusive, the recorded pelagic catch totaled 72,134 . From 1879 to I 91 I, inclusive, the total catch was 904,506 . The largest recorded catch, 59,568 skins, occurred in 1891 .

\section{THE PARIS TRIBUNAL AND THE MODUS VIVENDI.}

Recognizing that the brutal and wasteful killing at sea was greatly against the interests of the herd, the United States sought to establish jurisdiction in Bering Sea as a closed sea and seized a number of Canadian sealing vessels found operating there. This led to a controversy with Great Britain, which resulted in a treaty concluded February 29, I 892 , consigning the whole matter to the deliberation of a tribunal of arbitration which met at Paris in the summer of 1893 . Pending this treaty and the result of the deliberations of the tribunal, an agreement between the United States and Great Britain was entered into in June, I89I, by which the latter country prohibited British subjects from sealing in the eastern part of Bering Sea, and the United States prohibited all killing whatever by its citizens excepting that of 7,500 seals annually for the food of the natives of the Pribilofs. Though originally effective for only one year, this agreement, now known as the "Mlodus vivendi," was renewed in I 892 and i 893 .

Among the results of the work of the Paris tribunal was a set of regulations closing to pelagic sealing a zone of 60 miles in radius about the Pribilof Islands, and prohibiting it entirely between May I and July I. These regulations went into effect in the summer of 1894 , and of course affected only the citizens of the United States and Great Britain. They were subject to reexamination at intervals of five years. The experience of a single season showed that the result was ineffective, since the catch from pelagic sealing increased, and the seal herd continued to decline. The United States, therefore, requested Great Britain to consicier the revision of the regulations. This request was declined, and in I 896 this country accepted the proposal of Great Britain that the two countries institute independent scientific investigations of the entire matter at the close of the five-year trial period. These investigations were made in I 896 and 1897 and a voluminous report on the work of the American investigators was published in 1898 . In the meantime, on December 29, I 897 , Congress had enacted a law forbidding American citizens from engaging in pelagic sealing at any time or place. 


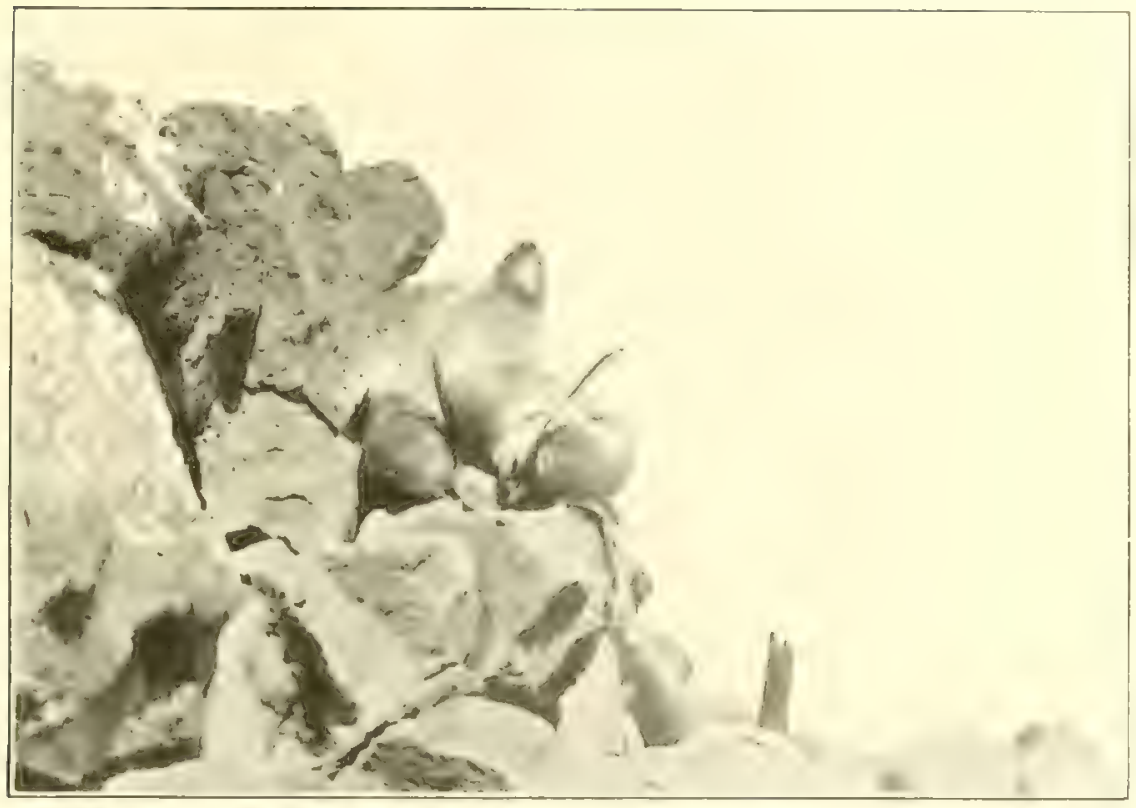

1. Cow and pup sleping, Kitovi Roukery, Auzust 23, InI4.

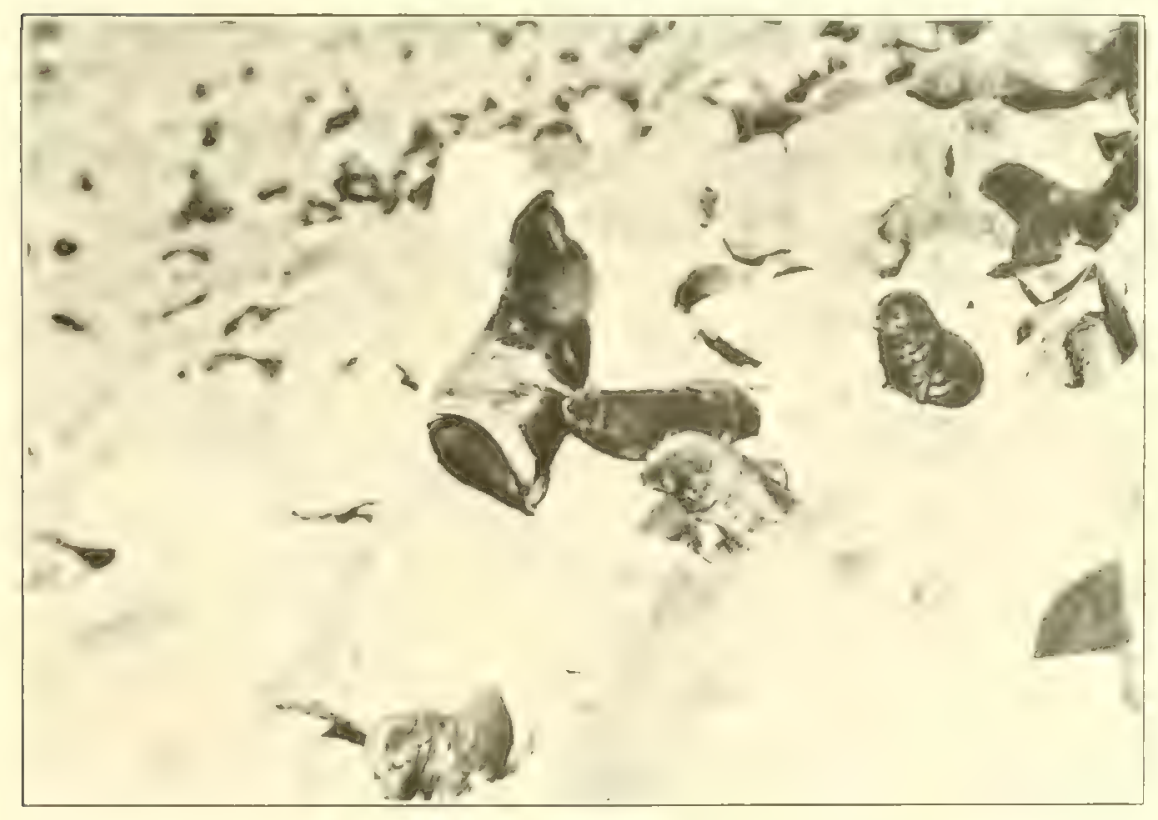

2. Cuw nursing Iup, Tolvtri Rookers", Ausust 25, Ior4. 

SPECIAL INVESTIGATIONS.

On the acquisition of Alaska by the United States it became evident that the fur seals of the Pribilofs represented a source of revenue concerning which very little was known. In the spring of 1872 Henry W. Elliott was sent to the islands by the Secretaries of the Smithsonian Institution and the Treasury. He remained until the spring of 1873 and later published a report which has appeared in several forms and which still remains the principal source of information regarding the early history of the islands and their activities. Mr. Elliott was on the islands also in the summers of 1874 and 1876 . In the summer of 1890 , as a special agent of the Treasury Department, he again visited the Pribilofs. With him at this time was associated William Palmer, a naturalist in the employment of the United States National Museum.

In the summer of $\mathrm{I} 89 \mathrm{r}$ a joint commission representing Great Britain and the United States visited the Pribilof Islands. The members for the United States were C. Hart Merriam and Thomas C. Mendenhall, and for Great Britain George S. BadenPowell and George M. Dawson. A brief joint report was submitted by the commission in March, 1892 , and detailed reports to their respective countries by the representatives of the United States and Great Britain were published later.

The appointment of a second joint commission representing Great Britain and the United States to reconsider the result of the work of the Paris tribunal has already been referred to. This commission consisted of David Starr Jordan, Jefferson F. Moser, Leonhard Stejneger, Frederic A. Lucas, Charles H. Townsend, George A. Clark, and Joseph Murray, representing the United States. Those representing Great Britain were D'Arcy W. Thompson, Gerald E. H. Barrett-Hamilton, James M. MIacoun, and Andrew Halkett. Investigations were made by this commission in the summer and autumn of I 896 and again during the same season in 1897 . Several assistants accompanied the American commission to do special work under its direction.

In the spring and summer of 1892 Barton W. Evermann, as a special commissioner under the State Department, made extensive studies regarding pelagic sealing in the North Pacific. In the course of his investigations he visited the Pribilof Islands.

Frederick W. True, of the United States National Museum, visited the Pribilofs for the purpose of studying the fur seals in the summer of I 895 .

Charles $\mathrm{H}$. Townsend made important studies of the fur seals on the Pribilof Islands during some nine seasons, in 1885,1892 to 1896 , inclusive, and in 1898 and 1900.

In the summer of $1906 \mathrm{Edwin}$ W. Sims, of the Department of Commerce and Labor, investigated the fur seals of the Pribilofs.

As a special investigator to perform the naturalist's duties, Harold Heath spent the season of 1910 on the islands and made a census of the herd and certain special studies.

In the summer of $1913 \mathrm{H}$. W. Elliott and A. F. Gallagher went to the Pribilof Islands as special agents of the House Committee on Expenditures in the Department of Commerce.

George A. Clark, secretary to the American commission of 1896 and I 897, visited the Pribilofs in 1909, I912, and 1913 as a special agent of the Bureau of Fisheries and made detailed studies of the seal herd. 
In addition to the results obtained by special investigators, valuable additions to the knowledge of fur seals have been made by certain of the regular employees on the islands, among whom Naturalists W. L. Hahn and M. C. Marsh and Agent W. I. Lembkey may be specially mentioned.

\section{SEALING UNDER GOVERNMENT MANAGEMENT.}

During the period of leasing the sealing privilege the work of the Government on the Pribilofs was confined mainly to keeping a check on the operations of the lessees and in the management of the affairs of the natives. But under a law which provided for the abandoning of the leasing system the Govenument assumed direct charge of all the activities on the islands in I 9 ro.

The law of I9I0.- Toward the close of the term of incumbency of the North American Commercial Co., it was decided to abandon the system of leasing. The act authorizing this was passed on April 2 I, I9ro. It provided that all sealing should be done under the authority of the Secretary of Commerce and Labor through agents and officers whose employment it authorized; the natives were to be employed and their wants provided for; the sealskins were to be sold to the best advantage of the Government; the purchase of the plant of the former lessees was authorized; and authority was given the department to furnish and maintain on the islands stores of necessary supplies. The lease haring expired on May I, I910, the supplies were purchased and shipped to the islands, the plant of the retiring company was purchased for $\$ 60,54 \mathrm{r} .48$, and sealskins to the number of 12,920 were taken during the first season. These skins yielded a net revenue to the Government of $\$ 403,964.94$.

During the year I9I I the operations on the islands were conducted in much the same way as in 1910. The sealskins taken were 12,002 in number; the net receipts therefrom were $\$ 385,862.28$.

The treaty suspending pelagic sealing.-On December 15 , I9II, a treaty became effective between the United States, Great Britain, Russia, and Japan, abolishing sealing on the high seas for a period of 15 years. By its provisions the United States and Russia, as owners or guardians of the seal herds, agreed to pay to Great Britain and Japan, for the relinquishment of their interest in pelagic sealing, a percentage, 15 per cent to each, of the product of the land sealing to be conducted by each of the two nations. In like manner Japan agreed to pay to the United States, Great Britain, and Russia, respectively, ro per cent of the land catch from the small but growing herd under her jurisdiction.

The law of 1912.- On August 24, 1912, the Congress of the United States passed a law prohibiting all killing of fur seals on the Pribilof Islands for a period of five years except the number needed as food for the natives, and providing for a breeding reserve of not less than 5,000 3-year-old males annually during the life of the treaty suspending pelagic sealing.

Under the operation of this law, only the skins of seals taken for food have been handled. These, including 9 skins carried over from the previous season, numbered 3,773 in 1912 . The net proceeds were $\$ 130,640.57$.

In $1913,2,296$ sealskins were taken. With the exception of 400 , which were withdrawn from immediate sale, these were sold and the net proceeds were about $\$ 50,000$. The sealskins taken in 1914 , reported as 2,896 in number, have not been sold. 
Revenue from fur seals.-During the three years of Government management the net revenue from the sale of sealskins has amounted to a total of approximately $\$ 970,468$. As elsewhere stated, $\$ 6,020, \mathbf{I} 52$ was derived during the period of the first lease of the sealing privilege and $\$ 3,453,844$ during the second lease. Since the acquisition of Alaska by the United States in 1867 , therefore, the direct revenue to the Government from the fur seal has amounted to approximately $\$ 10,444,464$. Considerable additional revenue has accrued to the Government from the importation of dressed skins from foreign countries.

Fox skins taken since the leasing system was discontinued have yielded net revenues as follows: In I9I I, \$15,096.58; in I9I2, $\$ 20,505.17$; and in I9I3, about $\$ 17,000$. The fox skins taken in the winter of $1913-14$, and numbering 280 , are still on hand.

THE CENSUS OF THE HERD IN 1914.

THE NATURE OF THE CENSUS.

The natural desire for complete figures has led most investigators in the past to attempt a full census of all classes of seals, although it has never been possible to make such a census absolutely accurate. The total number of seals living is, of course, a general measure of the state of the herd, but certain classes are more important than others. It is still impossible to make a full census without some proportion of estimate, but the cessation of pelagic sealing has provided opportunity for actual counts of the breeding elements of the herd, the old males and females and the young of the year. With these elements positively known and killing records complete for several years, the nonbreeding seals can be estimated by making use of the number supposed to die from natural causes. At present the rate of mortality must be inferred, and herein lies the only element of uncertainty in the census. The census of I9I4 has the advantage of known birth rates for the two preceding years in addition to the absence of killing at sea, and to this extent it is open to less objection than the figures obtained for previous years.

The classes of seals actually counted for the census are the breeding or harem bulls in active service, the idle bulls found on the breeding ground, and the roung pups of the season. Actual counts were made also of half bulls and bachelors, but gave only partial results of value chiefly as a check upon the estimates.

The classes estimated are the yearlings and 2-year-olds of both sexes, and the bachelors from 3 to 5 years of age. The number of breeding cows was directly inferred from the number of pups.

\section{THE COUNT OF HAREMS.}

Since 1896 counts have been made annually of the actual number of harems or breeding families in the herd. The number of bulls having harems gradually increases from the time the cows begin to arrive in June until the middle of July, when, at the so-called "height of the season," the number reaches a maximum and thereafter rapidly declines. The harem count, therefore, is always made at the height of the season, from July io to July 20 , and the results obtained from year to year are thus fairly comparable. Bulls having but one cow at the time the count is made are, of course, included as harem bulls, and since the number of such bulls must vary even from hour to hour, this con- 
stitutes a slight element of unavoidable uncertainty. It is plain also that the more idle bulls there are the more single cow harems may be expected. The maximum development of the different rookeries is not strictly contemporaneous, and this also adds a variable feature to the harem counts. Such irregularities are probably compensated in the results from year to year, and in any event the total number of harems and idle bulls is not affected.

The method of counting is simple and reliable. The rookeries are mostly extended along the shore in linear formation frequently beneath low cliffs from which the observer can look over them with ease. In the present condition of the herd the number of bulls in tier formation between the shore and the back of the rookery does not often exceed five, and marked rocks and natural prominences are sufficient for all necessary subdivision of rookery space into areas for successive counting. A few of the massed sections, as the flat under Hutchinson Hill and certain parts of Reef Rookery, offer difficulties which will increase as the herd grows and which could be overcome by simple devices. In such places repeated counts were made by four individuals until complete agreement was reached. The large relative size of the bull makes him conspicuous even at a considerable distance, and except when fully recumbent in a heavily massed area, he can not possibly be overlooked.

Preliminary counts.-In order to overcome the lack of previous experience and to make general preliminary observations, numerous counts of harems and various classes of seals were made before the height of the season. In this way counts were made at least once for every rookery on St. Paul Island and some rookeries were counted from three to six times. In addition, weekly counts were made of all the rookeries on St. George Island in late June and early July by Mr. G. Dallas Hanna. Therefore, when the height of the season arrived those engaging in the count were familiar with the peculiarities of each rookery and all were agreed as to the method to be employed. As early as June 29, the total number of bulls in position on St. Paul Island was $1,060$.

Owing to exigencies of transportation, it was necessary to make the count of harems on St. George Island on July I3-14, 1914, a few days earlier than desirable. On these dates, 219 harems and 12 idle and young bulls were found as follows:

Early count of harems, St. George Island.

\begin{tabular}{|c|c|c|}
\hline Rookery. & Harems. & Idle bulls. \\
\hline 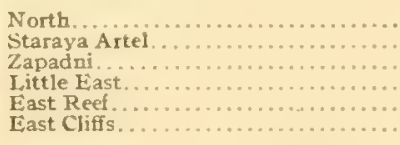 & $\begin{array}{r}85 \\
46 \\
15 \\
1 \\
14 \\
58\end{array}$ & $\begin{array}{l}3 \\
7 \\
1 \\
0 \\
1 \\
0\end{array}$ \\
\hline Total .... & 219 & 12 \\
\hline
\end{tabular}

Height of season counts.- The height of season counts on St. Paul Island were made July 17 , I8, and 19. Sea Lion Rock, or Sivutch, was counted July 20. The counts were made jointly by Messrs. Osgood, Parker, Preble, and Harmon except that of Sea Lion Rock which was counted by Parker and Harmon only. The early count made on St. George Island being obviously unsatisfactory, arrangements were made for a 


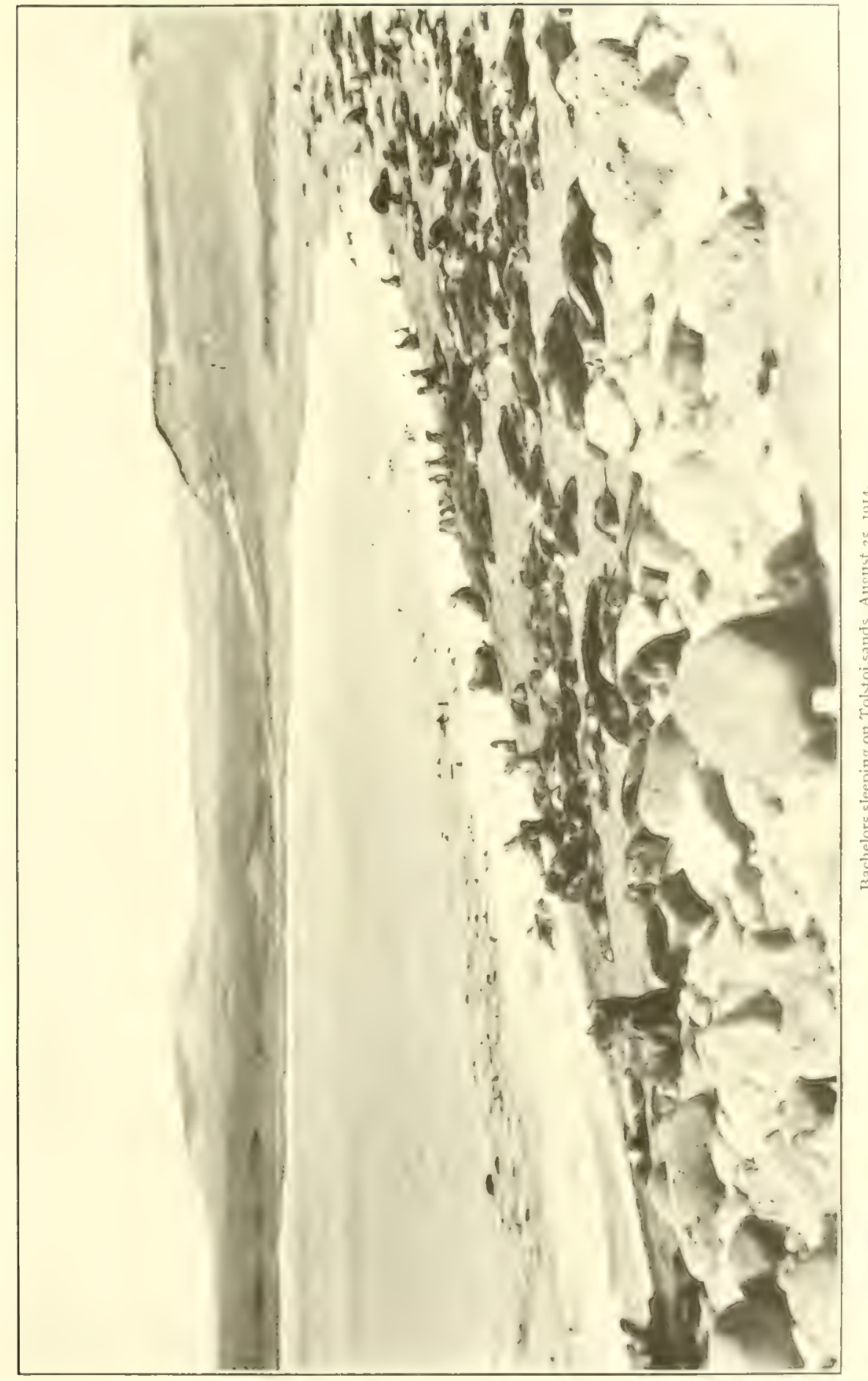



recount July I9-20 by G. Dallas Hanna, school-teacher on St. George Island. Mr. Hanna's figures, therefore, are used in making up the totals, which are as follows:

Harems and idle bulls at height of season, I9I4.

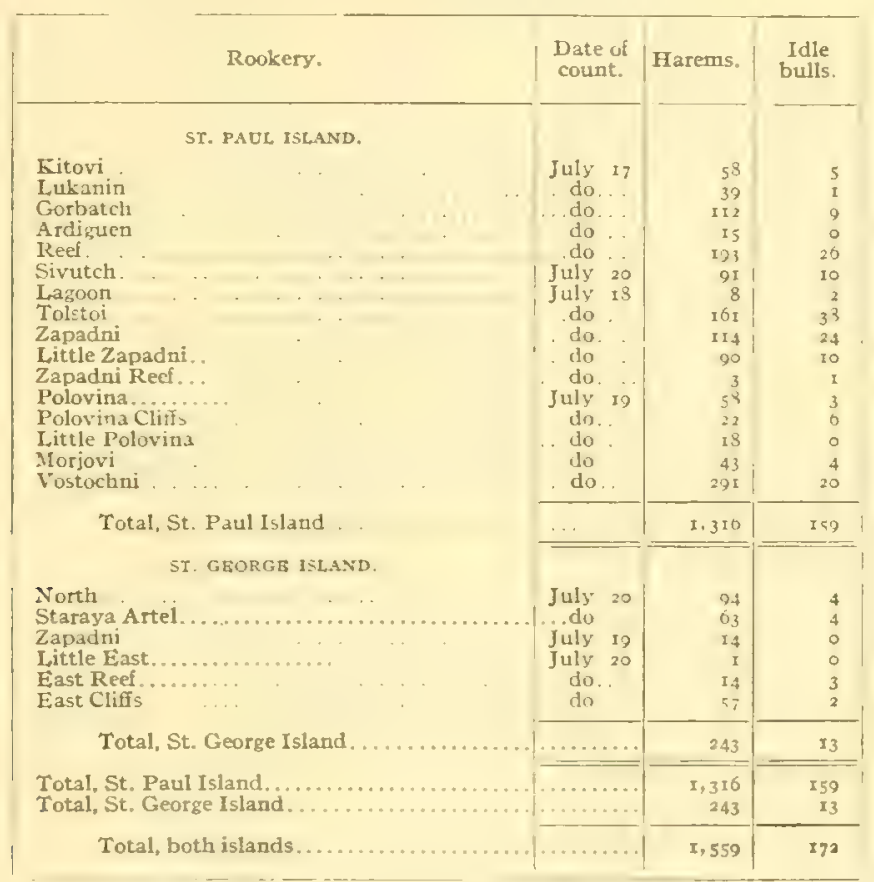

Harem charts. - Graphic representation of the size and extent of the fur-seal herd has usually consisted in the coloring or shading of the areas occupied and in distinguishing, so far as possible, the breeding areas from the hauling grounds. For various reasons, this has proved unsatisfactory as an accurate measure of the herd, although for general comparisons it has been valuable. All such devices, to be of permanent value, should be based upon data which can be stated in exact terms and which utilizes fixed marks or natural features that can be identified by future observers.

Before the investigation of I9I4 was begun it was found that unpublished charts showing the number and approximate position of the harems on each rookery had been made in 1912 and again in 1913 by Special Investigat or G. A. Clark. These charts showed the contours of the topography as surveyed by the United States Coast and Geodetic Survey and also indicated the position of the rocks on which conspicuous numbers were painted at the time of the survey. These charts were so obviously based upon sound method and their comparative value was so evident that their use was continued in I9I 4 . Blank copies were carried to the rookeries while the harem counts were being made and the position of the harems with reference to the marked rocks was roughly indicated by pencil notes. Immediately thereafter duplicate copies were made transcribing the notes in uniform style for all the rookeries. The field charts thus made have been the basis of the charts published with the present report. The scale is necessarily too small to show the exact position of each harem, but the number and approximately the arrangement of harems between any two numbered rocks is according to the facts. 


\section{THE COUNT OF IDLE AND YOUNG BULLS.}

The idle and young bulls were counted at the same time as the harem bulls. They include only bulls that were on the breeding ground at that time obviously waiting for opportunity to obtain harems. During preliminary counting an attempt was made to distinguish between those that stood their ground and those commonly called "quitters" because they retreat from man. But as the season advanced some of the quitters were observed to pass into the category of harem bulls, so when the height of the season counts were made all hulls about the back and sides of the rookeries were regarded as idle bulls unless plainly less than 6 years of age. Certain others stationed at the water's edge in front of the rookeries were by mutual agreement regarded as idle bulls. Young bulls on the hauling grounds were not considered at this time. The result of the count of idle bulls is included in the statement of the harem count on a preceding page.

THE COUNT OF HALF BULLS.

The half bulls of 5 and 6 years of age are roving much of the time, sometimes being about the breeding areas, at other times on the hauling grounds, while at all times a considerable proportion are undoubtedly at sea. 'Their well-developed "wig" or mane readily distinguishes them from bachelors of 4 years and under, while their smaller size prevents confusion with the old bulls. The number on land at any one time can be counted with a great degree of accuracy. They were counted on St. Paul Island on July 28 , the count being made practically simultaneously by different observers stationed for the purpose on different rookeries. A few days later a similar count was made on St. George Island by G. D. Hanna. The total result showed 748 half bulls for the whole herd, and although it may have included a few previously engaged in harem service, and of course takes no account of those at sea, it furnishes some measure of the strength of this class of seals, which is obriously greater than it has been for a number of years.

\section{THE COUNT OF BACHELORS.}

Counting bachelors may be compared to counting a swarm of bees, part of which is in the hive and the remainder out gathering honey. The full number can not be determined with accuracy although various devices are available as the basis of estimates. Those on land at a given time may be closely approximated by a process of combined counting and estimating. After some experience, results may be obtained in this way which, as minimum figures, are wholly reliable. It is often possible to find a herd of bachelors practically all of which are lying asleep, so an observer in an elevated position with a good field glass can count them with considerable accuracy. Conditions for counting in this manner are particularly farorable on St. George Island. A large herd of bachelors in which all or many individuals are in motion can only be estimated by connting those on a certain space and correlating the number obtained with the total space occupied. At times the bachelors on a given hatling ground may be driven back a short distance and divided into small pods which are successively counted as they form in an irregular line to return to the sea. Taking all data of this sort into consideration, the observer spending an entire season on the islands is in no doubt as to the approximate number of bachelors usually found on each hauling ground. Since the bachelors move about to a certain extent from one hauling ground to another and even pass 
back and forth with some frequency between St. Paul and St. Ceorge Islands, the whole number hauled at a given time can only be determined by simultaneous observations on all the hauling grounds. The party on the islands in I9I4 was large enough for such observations and accordingly they were made on St. Paul on July 28. A count on St. George Island was made a few days later by G. D. Hanna. The half bulls of 5 and 6 years were distinguished from the remainder, which consisted of 2,3 , and 4 year olds. No yearlings were seen, although it is possible a very small number may have been present. The results of the so-called "one-day" count are as follows:

Bachelors on land at one time.

\begin{tabular}{|c|c|c|}
\hline Rookery and island. & $\begin{array}{l}2,3, \text { and } 4 \\
\text { year olds. }\end{array}$ & Half bulls. \\
\hline 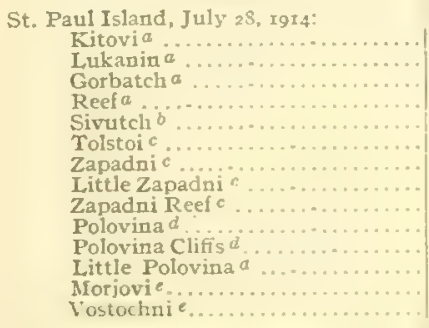 & $\begin{array}{r}220 \\
175 \\
500 \\
\mathbf{x}, 500 \\
500 \\
534 \\
\mathbf{x}, 290 \\
251 \\
3 \\
500 \\
45 \\
45 \\
300 \\
3,150\end{array}$ & $\begin{array}{r}26 \\
11 \\
39 \\
69 \\
30 \\
38 \\
30 \\
30 \\
1 \\
50 \\
2 \\
2 \\
41 \\
161\end{array}$ \\
\hline Total, St I'uul I land. & 9,013 & 530 \\
\hline 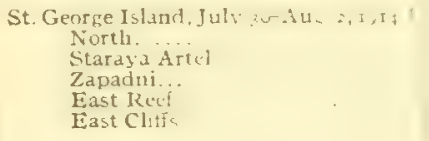 & $\begin{array}{l}41 \mathrm{II} \\
6 \mathrm{II} \\
252 \\
13 \mathrm{II} \\
75 \mathrm{I}\end{array}$ & $\begin{array}{l}64 \\
43 \\
24 \\
44 \\
43\end{array}$ \\
\hline $\begin{array}{l}\text { Total, St. George Island........ } \\
\text { Total, St. Paul Island......... }\end{array}$ & $\begin{array}{l}2,186 \\
9,013\end{array}$ & $\begin{array}{l}218 \\
530\end{array}$ \\
\hline Total, both islands......... & 11,199 & 748 \\
\hline
\end{tabular}

Counted by B. WV. Harmon and A. G. Whitrey.

b Estimated from distant view but supported by better observations at other times. e Counted by G. H. Parker and T. Kitahara.

a Counted by W. H. Osgood, E. A. Preble, and J. M. Macoun.

$e$ Counted by W. H. Osrood and F. A. Preble.

$f$ Counted by G. D. Hanna.

THE COUNT OF PUPS.

Importance of the count.-Since 1897 , when it was discovered that the number of pups greatly exceeds the number of cows on land at any one time, the importance of an enumeration of the pups has been apparent. Unlike the other classes of seals, all the pups for a time are on land at once, and the only obstacle in the way of exact knowledge of their number is that of actual enumeration. Until the abolition of pelagic sealing, however, a complete count of pups was not attempted, since it involved driving the cows into the sea and exposing them to the sealing fleet. In I9I2 and I9I3, with this danger past, complete counts of pups were made. The results of these counts were of the utmost importance, for they not only gave a measure of the new generation in the herd, but also furnished an accurate index of the number of breeding cows, since each cow gives birth annually to one pup. In I9I4, therefore, another complete count of pups was made. 
The method of counting pups. - At first glance it would seem impossible to count a mass of closely packed, squirming fur-seal pups as they are found on the rookeries. A little study and experiment, however, soon convinces that it can be done very satisfactorily by the method employed in 1912 and 1913 . This consists in gradually driving the pups off in small groups, or pods, and successively counting these pods until all have passed in review. About August I practically all the pups have been born, and the majority are several weeks old, strong, active little fellows, able to tumble about the rocks and to progress on favorable ground in a somewhat jerky lope, which takes them along at a rate almost equal to that of a man walking. Although able to swim and although they do so voluntarily about a week later, they will not take to the water at this time unless very hard pressed.

At the same time the adults are present on the rookenes in reduced numbers. Many of the old bulls have gone, and those that remain, with some notable exceptions, have lost their former stubbornness and pugnacity. The cows, no longer held by the bulls, flee in a body to the sea, leaving only the pups and a few surly bulls on land. The counting squad then advances and by prodding with long poles urges the bulls into the water or isolates them from the pups in case they prove too recalcitrant. The pups huddle together in large pods or scurry into holes and crevices in the rocks. Beginning at one end of the rookery, or at a runway near the middle if two squads are working, the counters start a small pod of pups back toward the tnoccupied space. The first pod moved is generally a small one sometimes started with a little difficulty and counted as a whole, if necessary. After this it becomes easy to induce successive pods to cross the open space and join those already counted. As soon as one pup, stronger or more venturesome than his fellows, starts across others follow in rapid succession, and so they go like sheep, one at a time, two abreast, and three abreast, galloping past the counters, who stand at one side, notebook in hand. In case the file widens beyond the possibility of accurate counting, assistants stationed on either side and somewhat behind the advancing line close in and either cut off the pod completely or bring it to proper attenuation by causing the pups in advance to move faster and those behind to reduce their speed. Now and then pups start back toward their original positions or some of those uncounted move in an undesired direction, but confusion from such moves is prevented by native assistants whose duty is to hold the line between the counted and the uncounted. As each section of rookery space is cleared, the counters search all the crevices and small caverns in the rocks in which pups may be concealed. On some rookeries such places are very numerous, and to make sure that none are overlooked it is necessary to pull out the pups one by one and drive them back to space previously surveyed. This is usually quite laborious and requires much time and patience. No less than $S_{4}$ pups were extracted in this way from a single cavern under Polovina Cliffs. That some were overlooked in such places is, of course, not impossiole, but the work was so thoroughly done in all cases that the number must be exceedingly small. The fur-seal pup at this time is an animal of 15 to 20 pounds in weight and about 2 feet in length, including the hind flippers. Therefore, one is not likely to be missed, except by accident.

It is undeniable that counting pups creates a great disturbance of the rookeries. It literally moves each rookery a short distance along the shore, causing every seal to change position and bringing about a general commotion which to one unacquainted with 


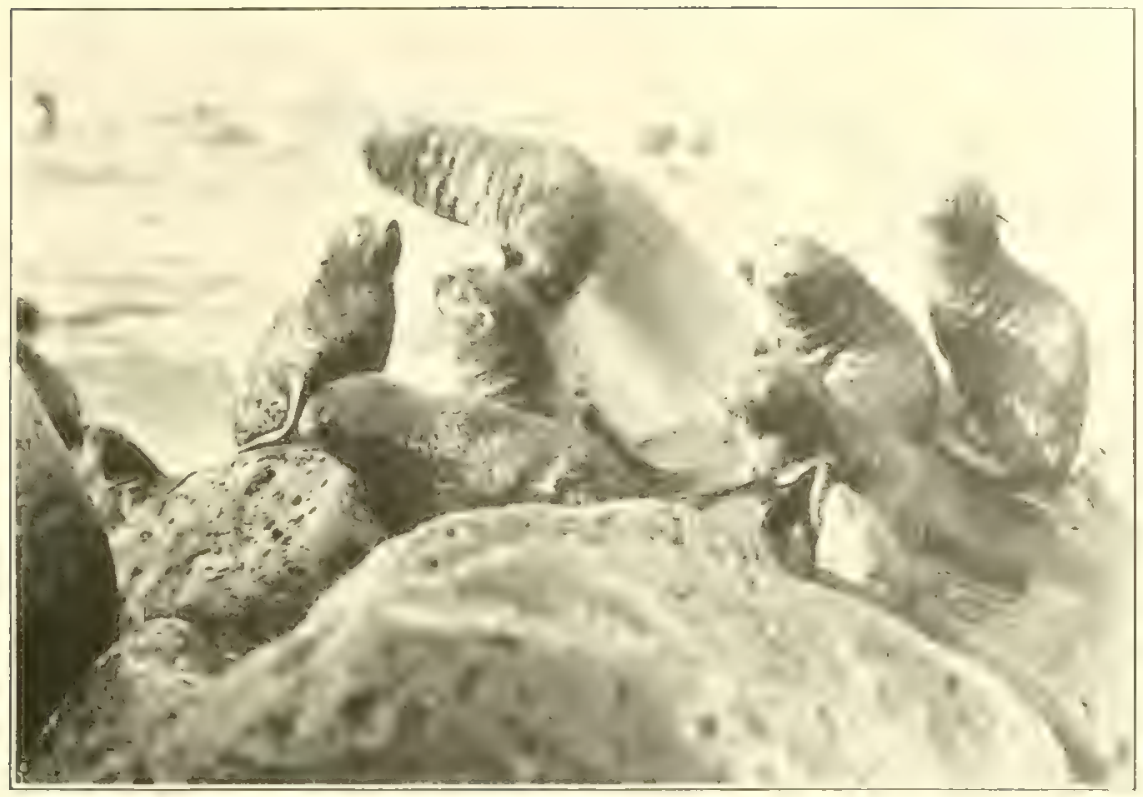

x. Fur-seal pups on Tolstui Rookery, Ausust 25, IgIs.

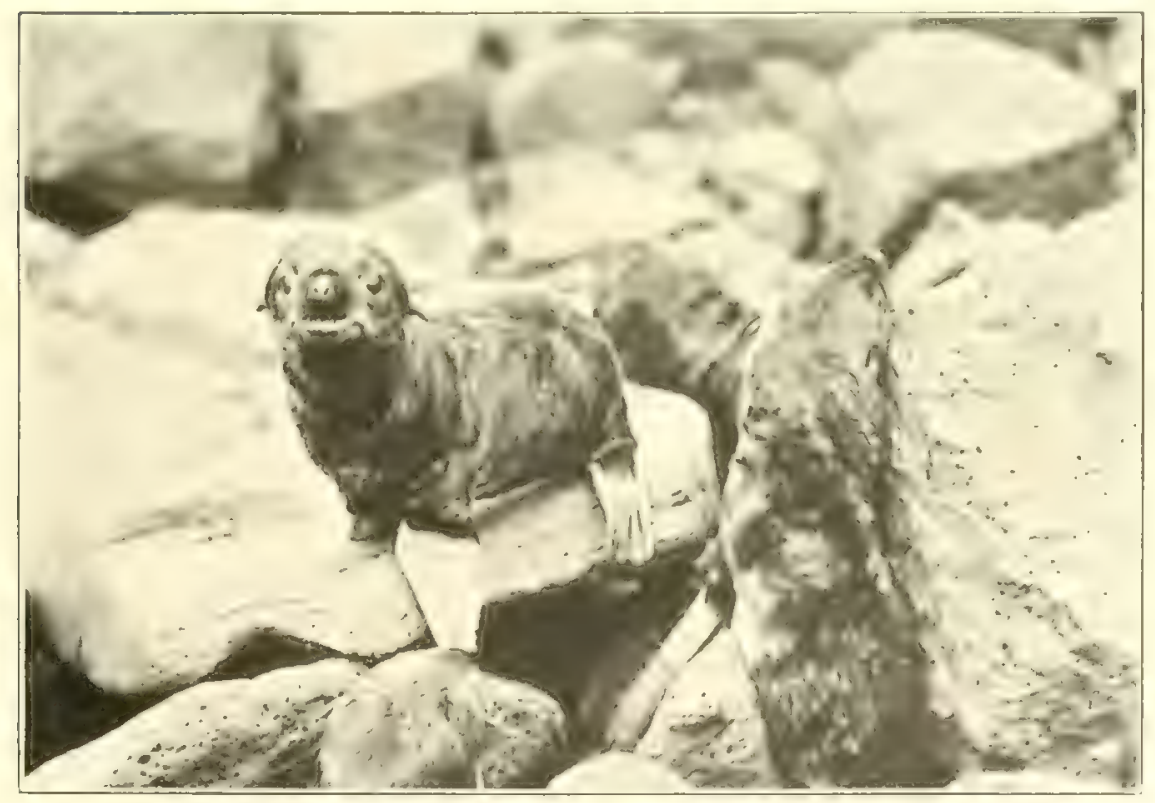

2. Fur-seal pup on Gorbatch limkery, Aurust rg, Igr4. 

the nature of fur seals might seem calculated to cause harm. That it really has no serious result is evident by the ease and rapidity with which normal conditions are resumed. The seals, particularly the bulls, have a powerful instinct for location, and their ability to recover their relative positions after great disturbance seems little short of miraculous. While counting is still going on at one end of a rookery the space just passed over is rapidly being repopulated, and within a half hour after the count is finished one finds the whole rookery as if nothing had happened, the cows peacefully sleeping or nursing their pups and the pups whose mothers are at sea gathered in pods playing or slecping.

In the course of the count considerable adroitness is required to avoid crowding the pups into large pods, in which the weaker ones are exposed to the possibility of being smothered by others which heap themselves over them. Out of the 93,000 pups counted in I 914 only 22 came to death in this way. This loss was due partly to overzealous assistants and partly to the difficulty of directing assistants in the continual clamor; but when it is considered that perhaps not more than one-third of the pups so killed would have reached maturity, the actual loss to the herd is seen to be so small that it is scarcely worth a second thought.

As the count must be made before any of the pups have learned to swim, the few that are born after this time can not be enumerated. This number is very small, however, and only serves to make it more evident that the totals accepted are minimum figures. The only further factor of uncertainty is the impossibility of securing an exact total for the dead pups, some having been carried away by the foxes and others having disintegrated or been trampled out of sight before the count is made. These are the only reasonable objections to stating that the pup count gives exact results, and they only serve to strengthen the conviction that the totals accepted can not by any possibility be too large. For, considering the welfare of the herd, the results are minimum figures and therefore absolutely safe.

The count of dead pups. - The dead pups are recorded as they are found during the process of counting the live ones. They are scattered over the rookeries with considerable regularity, and the percentage found on the different rookeries varies but little. They lie in various stages of decomposition, sometimes stretched out on the sand and sometimes nearly hidden from view in crevices between the rocks. As successive sections of rookery space are cleared in the counting of the live pups one member of the counting squad makes it his special duty to pace the ground and record all the dead pups, while as the work progresses other members of the party from time to time call his attention to dead pups noted in obscure places. After a given breeding area is finished the adjacent hauling grounds also are searched for dead pups, and so far as possible identifiable remains are noted when strewn about fox dens encountered in going to and from the rookeries. It is evident therefore that practically all dead pups are enumerated.

Participants in the count, and results. -The count of pups was made from July 29 to August 5. The Canadian and Japanese experts were invited to join with the Americans and the services were enlisted also of Mr. A. G. Whitney, school-teacher, on St. Paul Island, and of Mr. A. H. Proctor, agent, and Mr. G. Dallas Hanna, school-teacher, on St. George Island. The count, therefore, was conducted and subscribed to by the following persons: IV. H. Osgood, G. H. Parker, E. A. Preble, G. D. Hanna, A. H Proctor, S1512 -S. Doc. $980,63-3-3$ 
and A. G. Whitney, Americans; J. M. Macoun and B. W. Harmon, Canadians, and T. Kitahara, Japanese. The help of Mr. Whitney, who had assisted in the count in I913, was most valuable. The party was divided into two squads, making it possible to do the work expeditiously and finish before the pups were ready to take to the water. On St. Paul Island, Kitovi, Ardiguen, and the Zapadnis were counted by Parker, Kitahara, and Harmon; Lukanin, Tolstoi, Lagoon, and IIorjori by Osgood, Preble, and Whitney, assisted by Macoun, except on Lagoon; Gorbatch, Reef, the Polovinas, and Vostochni were counted jointly, Parker, Kitahara, and Harmon forming one squad and Osgood, Preble, Macoun, and Whitney another. On St. George Island, Zapadni was counted by Osgood, Preble, and Hanna; Staraya Artel and North by Parker, Kitahara, Harmon, and Proctor, and East rookeries by Parker, Preble, Kitahara, Harmon, and Proctor. It is thus seen that no less than three individuals of three different nationalities participated in practically every count. All members of the party expressed themselves as convinced of the thoroughness of the method and the reliability of the results. The error in counting is only that limiting any human act, and in this case is almost negligible, and certainly on the side of conservatism.

Following is the result of the count:

Count of pups, Pribilof Islands, Ior4.

\begin{tabular}{|c|c|c|c|c|}
\hline Rookery. & $\begin{array}{l}\text { Date of } \\
\text { count. }\end{array}$ & $\begin{array}{l}\text { Living } \\
\text { pups. }\end{array}$ & $\begin{array}{l}\text { Dead } \\
\text { pups. }\end{array}$ & Total. \\
\hline ST. PAUL ISLAND. & & & & \\
\hline Kitovi & July $3 \mathbf{I}$ & 2,072 & 47 & 2,119 \\
\hline Lukanin & do.... & $I, 76 x$ & 73 & I, 834 \\
\hline Gotbatch & July 30 & 6,067 & 85 & 6,152 \\
\hline Ardiguen & July 3 I & 645 & II & 656 \\
\hline Reef & do..... & 13,353 & 206 & 13,559 \\
\hline Sivutch. & July 30 & 3,984 & 68 & 4,052 \\
\hline Lagoon & Aug. I & 373 & 2 & 375 \\
\hline Tolstoi & do.... & 9,760 & 174 & 9,934 \\
\hline Zapadni..... & $\mid \ldots$ do..... & 7,499 & 126 & 7,625 \\
\hline Little Zapadni. & ...do..... & 4,840 & 79 & 4,919 \\
\hline Zapadni Reel.. & $\ldots$ do..... & 203 & 3 & 206 \\
\hline Polovina & July 29 & $3 \cdot 4 \hat{S}_{4}$ & 71 & 3.555 \\
\hline Polovina Cliffs.. & 1...do..... & $\mathrm{I}, 43 \mathrm{I}$ & 18 & $\mathbf{1}, 449$ \\
\hline Little Polovina. . & ...do..... & 910 & 37 & 927 \\
\hline Morjovi.......... & Aug. 3 & 2,268 & 44 & 2,312 \\
\hline Vostochni............... & ...do..... & 19.210 & 499 & 19,709 \\
\hline Total... & 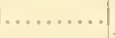 & 77,960 & 2,523 & 79.383 \\
\hline ST. GECRGE ISLAND. & & & & \\
\hline North........ & Aug. 4 & 5,189 & II2 & 5,301 \\
\hline Staraya Artel. . & ... do..... & 4,215 & 63 & 4,278 \\
\hline Zapadni... & do.... & T.015 & 8 & $I, 023$ \\
\hline Little East. . & Aug. 5 & 25 & I & 26 \\
\hline East Reef.... & ...do..... & 576 & 5 & 581 \\
\hline East Cliffs. & ... do.... & 2,627 & $3 \mathbf{I}$ & 2,658 \\
\hline Total. & & $13,6.47$ & 220 & $x_{3}, 867$ \\
\hline Total, St. Paul Island... & & 77,860 & I, 523 & 79,383 \\
\hline Total, St. George Island. & & 13,647 & 220 & 13,867 \\
\hline Grand total, both islands... & & 91,507 & $\mathbf{I}, 743$ & 93,250 \\
\hline
\end{tabular}

THE ESTIMATES.

If all the bachelor seals came to land at any one time, it would be possible to count them with a fair degree of accuracy by driving and jodding as in the case of the pups. But, although approximately the same number is found on each hauling ground for considerable periods, there is always a large and indeterminate number in the sea, moving 
from place to place, going far out to feed, passing from one hauling ground to another, and crossing between St. Paul and St. George Islands. Moreover, it is highly probable that a considerable proportion of the yearlings do not come to land at all. Therefore no complete enumeration of nonbreeding seals is possible.

Since it is from this class of seals that the output of salable skins is derived, a knowledge of their numbers is of the highest importance and it is a lack of such knowledge that has caused much loss to the Government in the past. The fortunate condition which under proper authorization will make it possible to obtain a large part of this knowledge in the future has been discussed in another place (p. I03). For the census of I9I4, however, only estimates are possible, and they can not be regarded as more than carefully considered approximations. It is with some reluctance that they are put forth, although all conclusions drawn from them are supported by convictions derived from actual observation. Every effort has been made to make them conservative and in no case are they less so than those of previous investigators.

The basis of the estimates in most cases has been the birth rate. Fixed percentages for assumed natural mortality in successive years plus the number of seals killed have been subtracted from the number born, the remainder being the supposed number surviving. The assumed percentages of natural loss are 50 per cent for the first year, I 5 per cent for the second, Io per cent for the third, and 5 per cent for the fourth. So far as the percentages have a definite numerical basis, it is that of the quotas which the lessees found it possible to secure during commercial killing. They are the percentages which seemed to prevail during pelagie sealing and therefore are ult raconservative when applied to present conditions.

Producing but one young annually and subjected to constant killing for more than Ioo years, the fur seal still maintains itself in numbers which, although reduced, are by no means small. It has made ready recuperative response to every partial suspension of killing and its present condition as shown by observations in the past season is unmistakably one of rapid increase. Therefore, it is evident that these percentages give results much more likely to be underestimates than otherwise. An underestimate tends to the conservation of the herd by fostering limited killing. All that can be said against it is that it may involve some money loss to the Government. An overestimate, on the other hand, would endanger the herd, and while it might lead to action productive of immediate revenue, it would in the end also cause money loss.

Ycarlings. -These are estimated as one-half the pups known to have been born in I9I3, as determined by the full count made by special investigator $\mathrm{G}$. A. Clark. The theory that 50 per cent of each year's pups are lost during the first season is not as yet definitely proved but may be accepted as closely approximating the truth and as furnishing a basis for fair comparison with former estimates. Whatever may be the truth, it is believed that the first year's mortality is less than 50 per cent rather than more, so the estimate may be regarded as a moderate one. This loss, of course, includes the pups that die on the islands as well as those lost at sea. The deaths before the migration amount, under present conditions, to from 2 to 3 per cent of the pups borm.

The total of pups counted in $19 \mathrm{I} 3$ was 92,269 ; therefore the yearlings alive in 1914 are estimated as $46, \mathrm{I} 35$.

Two-year-olds.-These were born in 1912 and were included in the full count of that year which totaled 81,984 . On the basis of 50 per cent first year's mortality there 
should have been 40,992 of them as yearlings in 1913. As none of them were killed, they should have returned the next year in numbers undiminished except from natural causes. As a matter of fact they appeared in $19 r_{4}$ in large numbers, constituting in the latter part of the season at least two-fifths of the bachelors found on the hauling grounds. Exact enumeration of them is impossible since all are not present at any one time. In I912, 5,529 of these seals were branded as pups and a considerable number of these were found throughout the season of I9It, but this furnishes no criterion of the total number of surviving 2 -year-olds. The only feasible method of estimating them is by subtracting a fixed percentage from the number estimated as yearlings the preceding year. This percentage has been rather arbitrarily determined as 15 per cent, but from experience during commercial killing in past years it is evident that the result obtained in this way is a conservative one. That is, in former years with the herd approximately the same size as now and in spite of the drain of both land and pelagic killing, the lessees found it possible to obtain a quota of 2-year-olds as large or larger than the number estimated in this way. Deducting I 5 per cent from 40,992 , the number of yearlings estimated for 1913, gives 34,844 as the number of 2 -year-olds in 1914, half of these being males and half females.

Three-year-old males. - These were born in I9II, a year for which only very incomplete data are available. No count of pups was made in that year, nor any determination of the average harem even for a single rookery. The count of harems was made, however, and this combined with knowledge of the conditions in I 9 Io and 19 I 2 fumish practically the only data for estimating the number born in rgr I. There are two methods of making such an estimate, one by deductions drawn from the average harem on a single rookery known for 1910 and 1912 , the other from the count of pups in I9I 2 and the relative effect of pelagic sealing.

The average harem method may be considered first. During pelagic sealing or in all years previous to 1912 , the birth rate for a given year was estimated by counting the pups on one or several rookeries only and determining the average number of pups to a harem for these rookeries, after which this average harem was multiplied by the total number of harems, the result being the supposed total number of pups, and by inference, the number of cows. Applying this method to the years 1912, 1913, and 1914, for which we have actual counts, it is apparent that the estimates for former years must be greatly below the facts. This is shown by the following tabulation:

Comparison of actual counts of pups with estimates based on an average harem.

\begin{tabular}{|c|c|c|c|c|c|c|}
\hline 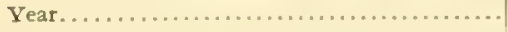 & 1909 & I9ro & IgII & 1912 & $19 r_{3}$ & I9I4 \\
\hline Total number of harems... & 1,387 & $I_{1} 38 \mathrm{r}$ & $I, 369$ & $\mathrm{x}, 358$ & $I, 403$ & J, 559 \\
\hline Pups counted on Kitovi. & $\mathbf{x}, 979$ & $I, 966$ & & $x, 975$ & $\mathbf{x}, 855$ & 2, II \\
\hline  & 36.0 & 31. 7 & a 345 & $37 \cdot 3$ & 42.2 & 36.5 \\
\hline Estimate of pups, entire herd, under average & & & 47,23 & 50,653 & 59,206 & 56,003 \\
\hline 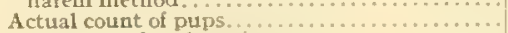 & 49.952 & 43,777 & 47,230 & $\begin{array}{l}5 \\
81,984\end{array}$ & $\begin{array}{l}59,200 \\
92,269\end{array}$ & 93,250 \\
\hline Percentage of underestimate. ........... & - enconat & & ........... & 38.2 & 35.8 & 38.9 \\
\hline
\end{tabular}

a Mean between figures for $19 \mathrm{ro}$ and $\mathrm{Igra}$.

The inference is thus very strong that the estimates for 1909 and 19 Io are less than two-thirds of the actual number and that a similar estimate for rgI I would be proportionately small. Since the total number of harems (actually counted) for I9I I falls 


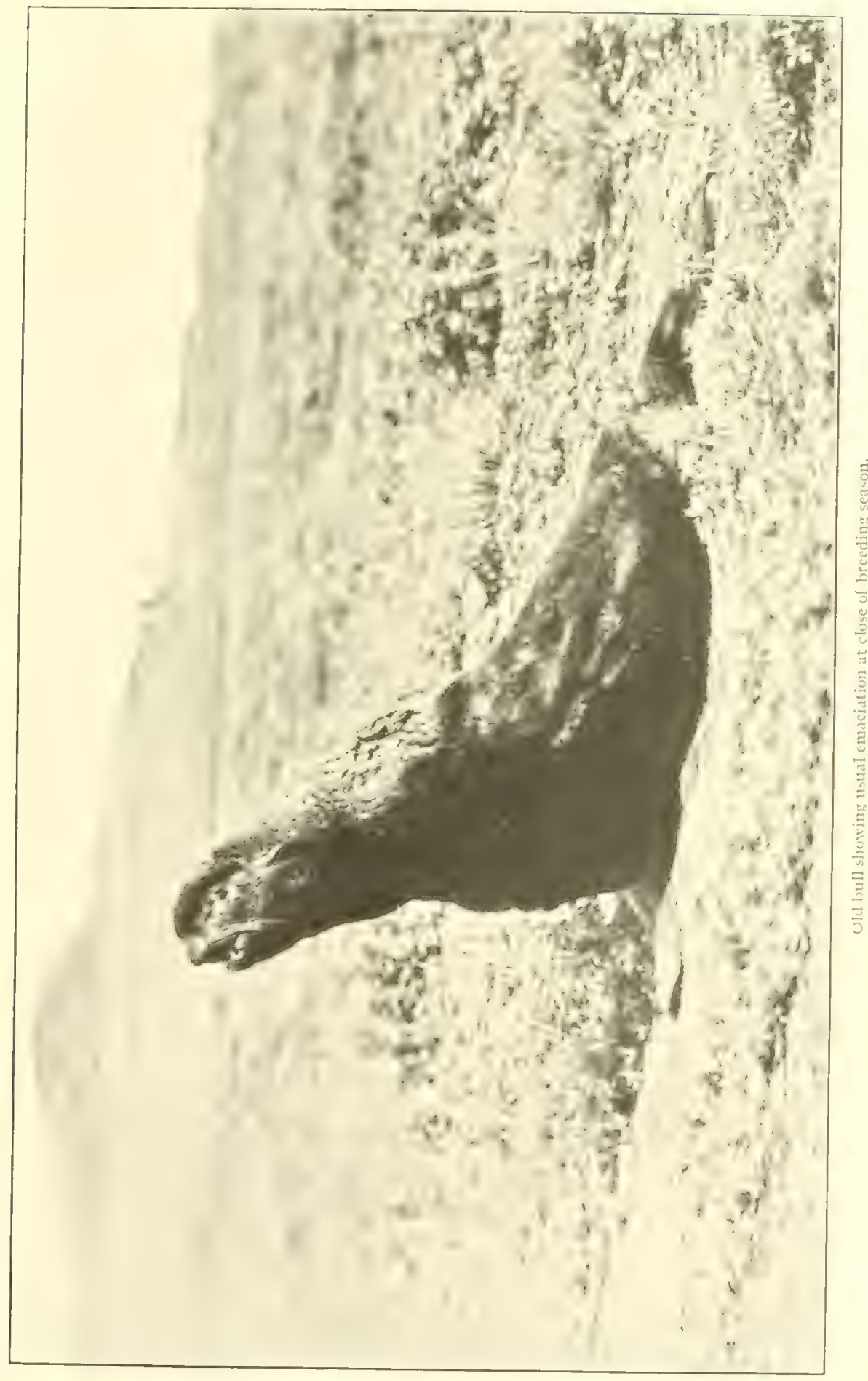



between the numbers for 1910 and 1912 , we may assume that the average harem does the same. This gives 34.5 as the estimated average harem on Kitovi in IgII, and multiplying this by 1,369 , the total number of harems, gives 47,230 as the estimated total of pups. Assuming that this is two-thirds of the actual number gives 70,845 , total pups in IgI $\mathrm{I}$, the best result that can be obtained with the data available.

Considering now the other method, we find that a very reasonable argument may be advanced that, since the herd was in a declining condition, the number of pups born in Igr w would not be smaller than the number born in I9r2. The treaty abolishing pelagic sealing went into effect December I5, igrr. Therefore pelagic sealing was going on in I9I I only slightly less than in rgro. There is little doubt that from ro,00o to I 5,000 cows were lost to the herd in I9I I through this means. Since we know that in spite of this drain the cows of I9II produced 81,984 pups in 1912, it is reasonable to suppose that the cows of I9Io, having been subjected with the whole herd to one season less of pelagic sealing, would produce at least as many pups as those of rgII. From this reasoning, therefore, the assumed births in IgI I might be stated in round numbers as 82,000 . It is evident, however, that pelagic sealing created many abnormal conditions in the herd, and in view of the pup count of I9I4 showing practically no increase over that of I9I3, as well as various figures obtained by the Japanese on Robben Island, it is unsafe to assume fixed rates of annual increase or decrease. There are too many factors involved to make it possible to say with certainty that such an estimate is a conservative one.

Taking both estimates into consideration, the one of 70,845 and the other of 82,000 , it may be concluded that the number born in I 91 I was between 70,000 and 80,000 . For our purposes, and keeping on the side of conservatism, 75,000 may be taken as a number open to no serious objections. Taking off 50 per cent for first year's mortality and I 5 per cent for the second year, leaves 31,875 2-year-olds in 1913 , of which half, or I 5,937 , were males.

It is necessary next to deduct the number of 2-year-old males killed in 19r3. The only basis for determining this is the weight of the skins, and, although this is known to be unreliable, it fumishes the best approximation of the truth that can be obtained. The food killings in I 913 were mostly intended to include only 3 -year-olds, but a number of skins weighing less than $5 \frac{3}{4}$ pounds were taken. For purposes of an estimate made before a thorough study of the subject of weights and ages, it may be assumed that skins weighing under $5 \frac{3}{4}$ pounds were those of 2 -year-olds. Of 2,399 seals killed in the calendar year I 9 I 3 there are records of weights of the skins of 2,357 , of which 5 I 5 were, on this basis, 2-year-olds. Subtracting this from 15,937 leaves 15,422 as the estimated number of 2-year-old males at the close of the year $19 \mathbf{I}^{3}$. Although it is probably too high, ro per cent liss may be assumed for the next year in order to keep the estimate on the safe side. This gives us 13,880 as the number of 3-year-old males in $19{ }^{4} 4$. This is purely an estimate, but in the light of past experience in the killing of large quotas it can not be regarded as excessive. Three-year-olds were seen in large numbers on all the hauling grounds and in all the food drives. On August 81,572 bachelors were driven from Reef hauling ground and 447 were killed. At least 4 II of these, or 26 per cent of those driven, on the basis of the weight of the skins, were 3 -year-olds. This result might be applied in various more or less unsatisfactory ways to estimate the total number of 3 -year-olds, but it is of value principally as proof that seals of this class 
were present in large numbers. The estimate of 3 -year-old males at the beginning of I9I 4 , therefore, is 13,880 .

Four-year-old males. -The 4-year-olds living in I9I4 were born in the summer of I9Io. There was no count of pups in that year but an estimate was made by the average harem method discussed under the estimate of 3-year-olds (p. 34). Using this method, the average harem on Kitori, which was 31.7 , was multiplied by the total number of harems, giving as a result 43,777 . The estimated error in the method requires an addition of $2 \mathrm{I}, 888$ which gives 65,665 as the probable increase for 1910 . Reducing this by 50 per cent for the first year's mortality and I 5 per cent for the second leaves 27,907 of both sexes or 13,954 2-year-old males in 1912 . Although the killings in I9r2 were supposed to include a considerable number of 2 -year-olds, the records show only $54 \mathrm{I}$ vielding skins that weighed less than $53 / 4$ pounds and these, therefore, are all that can safely be assumed as 2 -year-olds. Deducting these and in addition Io per cent for natural deaths in the third year, reduces the total to 12,072 3-year-olds at the opening of the season of 1913 . Of these, I,6 ro were killed having skins weighing from $5 \frac{3}{4}$ to 8 pounds, inclusive, and therefore 10,462 were left. The natural mortality in the fourth year is believed to be very small, perhaps negligible, but it may be granted for the sake of conservatism that it is as much as 5 per cent. Therefore the estimated number of 4 -year-olds in 1914 is 10,462 less 523, or 9,939. Although no exact count was possible, the number of 4 -yearolds observed on the hauling grounds in the season of $19 \mathrm{I}+$ was sufficient to make it reasonably certain that this estimate is not beyond the facts. They were seen on all the hauling grounds and in some cases constituted fully 25 per cent of the bachelors present at a given time.

Five-year-old males. - The 5-year-olds of I9I4 are of the generation of 1909 and were subjected to both land and pelagic sealing as 2-year-olds. The best method of estimating their present numbers is based on the breeding reserve of I9I2. In that year, before killing began, 2,005 bachelors supposed to be 3 -year-olds were given a temporary brand and reserved as breeders, exempt from killing for at least one season. In 1913, they became 4-year-olds and if we allow 5 per cent for possible deaths during the winter, they then numbered $\mathrm{I}, 905$. Since killing in 1913 was restricted largely to 3 -year-olds, the reserve of the previous year was subjected to no more than a slight decrease. According to the records, 247 skins weighing over 8 pounds and under 12 pounds were taken in 1913 , and at least the majority of these were probably 4 -year-olds. This leaves 1,658 , and since the loss in the fifth year is doubtless too small to be taken into account, it is safe to say there were $1,65^{8}$ 5-year-old males living in r9r4. About one-third of them were to be seen on land at any time during the season of I914. A count of half bulls made practically simultaneously on all the hauling grounds in 1914 showed $74^{8}$ present, and of these it can be said that 5 -year-olds constituted 80 per cent or more. It is probable also that more than 2,000 escaped in 1912 and 1913 , since the killings in those years were confined to a few hauling grounds and since the records of weights show that no very large number of 2 -year-olds was killed on land in I9I. It is evident, therefore, that the estimate of 5 -year-olds is well within the facts. Next year, there should be from I,500 to 2,000 lusty 6 -year-olds ready if necessary for harem duty.

Summary of estimates of nonbreeding seals.-The following table shows the number of nonbreeding seals estimated to be present in I9I4, and the method of making the estimate: 
Yearlings:

Estimate of nonbreeding seals, IgI4.

Pups born in $r 9 \mathrm{r} 3$ and actually counted......................... 92,269

Deduction for natural mortality in first year, 50 per cent.............. 46 , 134

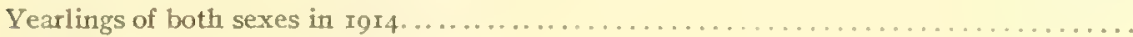
Two-year-olds:

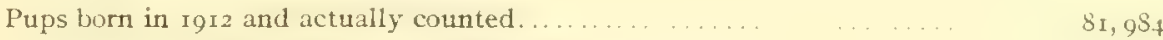

Deduction for natural mortality in first year, 50 per cent. . . . . . . . . . . 40, 992

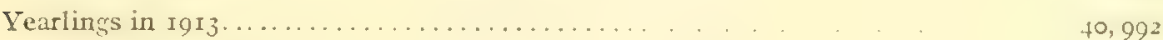

Deduction for natural mortality in second year, 15 per cent . . . . . . . . . 6 , I48

Two-year-olds of both sexes in $1914 \ldots \ldots \ldots \ldots \ldots \ldots \ldots \ldots \ldots \ldots \ldots \ldots \ldots \ldots \ldots . \ldots \ldots, 8 \ldots \ldots$ Three-year-old males:

Pups born in IgI $\mathrm{I}$, on the basis of the estimated average harem on one rookery,

Kitovi.................................. 47,230

Addition for probable error in method.......................... $23,6 r_{5}$

Estimated number of pups born in $\mathrm{rgr}$, by average harem method ......... 70,845

Estimated number of pups born in 1911 , by inference from number counted in $1912,82, \infty$

Conservative mean between the results of the two methods . . . . . . . . . .

Deduction for first year's mortality, 50 per cent...................... 37,500

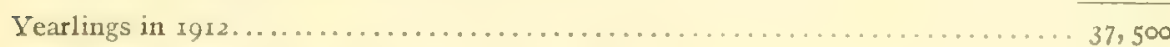

Deduction for second year's mortality, 15 per cent. . . . . . . . . . . . . 5,625

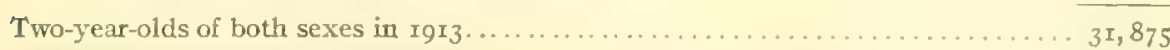

Deduction for females, so per cent... . . $\quad 15,93^{8}$

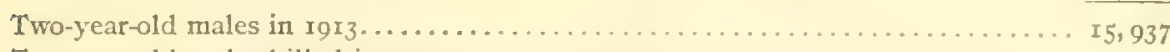

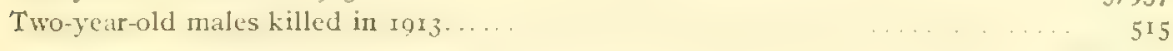

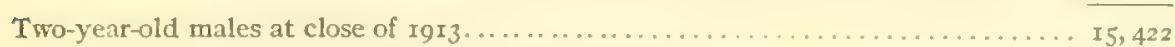

Deduction for mortality in third year, ro per cent.................

Three-year-old males at beginning of $1914 \ldots \ldots \ldots \ldots \ldots \ldots \ldots \ldots \ldots \ldots \ldots \ldots, 880$ Four-year-old males:

Estimate of number born in I9ro, based on average harem of Kitovi ....... 43,777

Addition for estimated error in method .......................

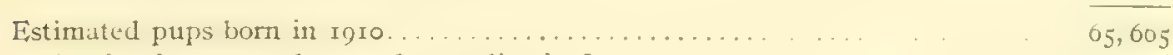

Deduction for assumed natural mortality in first year, 50 per cent . . . . . . . 32,833

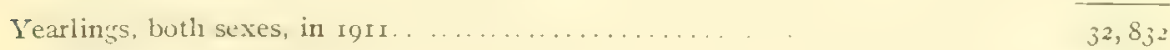

Deduction for natural mortality in second year; is per cent............ 4,925

Two-year-oids, both sexes, in 1912..

Deduction for females, 50 per cent . . . . . . . . . . . . . . . . . . . 953

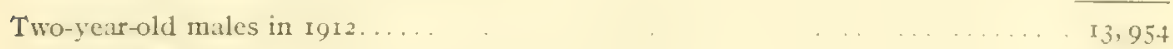

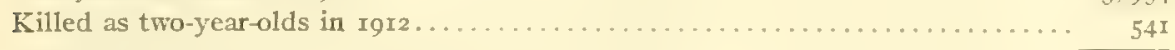

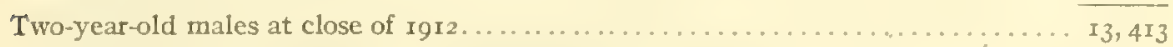

Deduction for natural mortality in third year, to per cent $\ldots \ldots \ldots \ldots \ldots \ldots \ldots$ I, 34 I

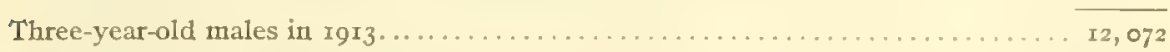

Killed as three-year-olds in $1913 \ldots \ldots \ldots \ldots \ldots \ldots \ldots \ldots \ldots \ldots \ldots \ldots \ldots \ldots \ldots \ldots$

Three-year-olds at close of $\operatorname{Ig}_{3} 3 \ldots \ldots \ldots \ldots \ldots . \overline{10,462}$

Deduction for mortality in fourth year, s per cent.$\quad 523$

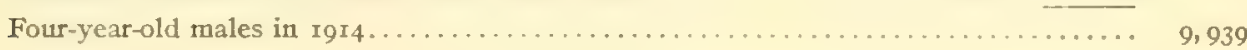


Five-year-old males:

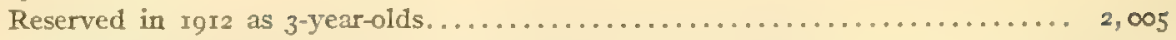

Deduction for possible mortality in fourth year, 5 per cent.............. Ioo

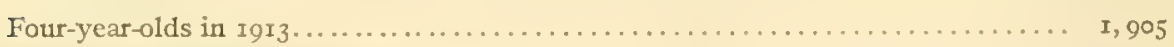

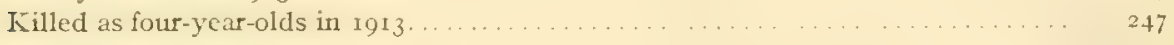

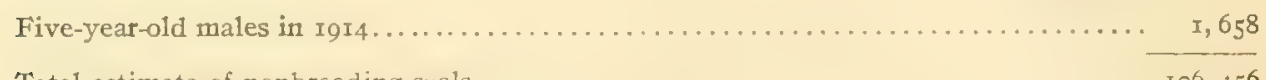

Total estimate of nonbreeding suals

THE COMPLETE CENSUS OF 1914.

Following is a summary of the results of the counts and estimates. Discussion of the methods used in obtaining the figures may be found elsewhere.

Complete census of fur scals, 1914 .

Pups (actual count) . . . . . . . . . . . . . . . . . . . . . . . . . . . a 93,250

Bearing cows (inferred from number of pups, including dead) . . . . . . . . . . . . . . 93,250

Yearlings of both sexes (based on known birth rate in 1913) . . . . . . . . . . . . . . 46, I35

2-year-olds of both sexes (based on known birth rate in 1912 ) . . . . . . . . . . . . . . 34,844

3 -year-old males (based on assumed birth rate in $\mathbf{r g} \mathbf{I}$ ) . . . . . . . . . . . . . . . . 3,880

4-year-old males (based on estimated birth rate in I910) ....................... 9,939

5 -year-old males (based on known reserve of $19 \mathrm{r} 2) \ldots \ldots \ldots \ldots \ldots \ldots \ldots \ldots \ldots \ldots \ldots \ldots \ldots \ldots$

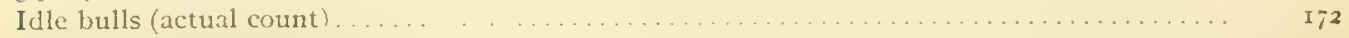

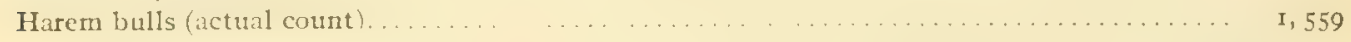

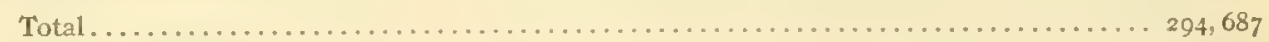

Total, exclusive of pups....................................... 201,439

\section{RESULTS OF THE CENSUS.}

\section{INDEPENDENT RESULTS.}

Whatever past conditions may have been, the census of I9I4 shows the fur-seal herd to contain upward of 294,000 animals, by no means a small number. The relative proportions of the different classes of seals, while not yet wholly ideal, are such as to indicate clearly that they can be made so in another year. Furthermore, they are such as to forecast a rapid expansion of the herd in the near future. There are not less than 93,250 mature breeding cows and by conservative estimate about 17,000 virgin cows, or a total stock of approximately 110,000 breeding females. There are I,559 harem bulls and $i_{7} 2$ idle bulls, and although this may not be as many as desirable it is gratifying to note that there are at least 1,600 half bulls of five years of age which may have effected some service in the season of I9I 4 and which will undoubtedly participate in the harem life of 1915. With allowance for probable natural deaths, there will be on the islands in 1915 not less than 3,000 bulls of 6 years of age and over. A reasonable calculation of the cows to be served next year would be 99,000 adults and i 8,500 virgin 2 -year-olds, a total of 118,500 . The 3,000 bulls, therefore, if evenly distributed, would have 39 to 40 cows each, a number which is certainly not greater than their capacity. Thus all apprehension as to insufficiency of male life will cease in I9I5.

a This includes 1.743 pups already dead at the time of the count, but for comparative purposes this is desirable, the same method having been followed in 1912 and $19{ }^{3}$. Since a large percentage of the pups will not survive the first winter, they form at best a variable element so far as the total seals of all classes is concerned. The strength of the berd at the opening of the season of $\times 914$ is shown by the total, exclusive of pups. 


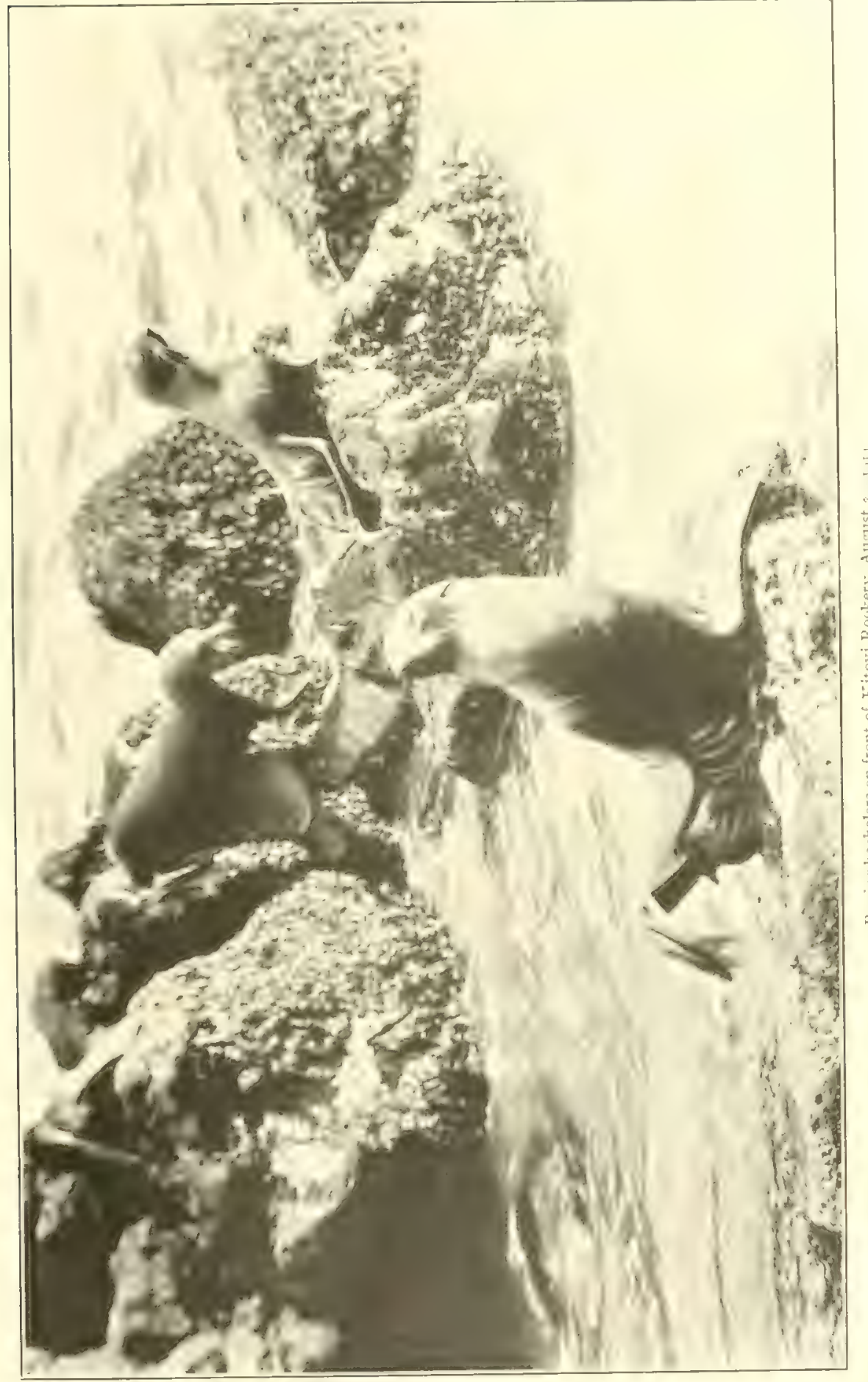



The hauling grounds in 1914 are teeming with bachelor seals of 4 years of age and under. There are nearly 10,000 4-year-old bachelors and upward of 13,000 3-yearolds, so male life for the future is more than assured. The 9,000 to 10,000 4-year-olds living in I9I 4 will, if wholly spared, undoubtedly create an overstock of males, and this constitutes the principal undesirable feature of the herd as found in 1914 . The welfare of the herd demands that some of them should be killed in I9I5. By so doing and by killing a sufficient number of 4 -year-olds and 3 -year-olds at the same time the relative proportions of the different classes of seals would be adjusted to a basis as nearly ideal as our knowledge permits. No matter what course is pursued, the important question will always be what proportion of young males may be killed with safety. The proportion is the same now that it always will be, and nothing is gained by delay. Whether the proportion be small or large, it is obviously safe to take it now as well as in future years.

\section{COMPARATIVE RESULTS.}

Comparing the results of the census of I9I4 with those of 1912 and I9I3, made in much the same manner and at the same stage of the season, ${ }^{a}$ we find various informing features. Although there is a general increase; it is not evenly distributed and it is evident that various imperfectly understood effects of land and pelagic sealing in previous years are involved. The general comparative results of the three censuses are shown in the following table:

Gencral comparison of recent censuses.

\begin{tabular}{|c|c|c|c|}
\hline Class of seals. & $1952 a$ & $\operatorname{Ig} \mathrm{I}^{a}$ & I9I4 \\
\hline Breeding bulls.... & 1,358 & I, 403 & I, 559 \\
\hline Breeding cows.. & 85,984 & 92,269 & 93,250 \\
\hline Idle bulls . . . . . . . . . . . . . . . & 113 & 105 & 172 \\
\hline Young bulls (chiefly 5-year-olds). & 199 & 259 & 1,658 \\
\hline 4-year-old bachelors. . . . . . . . . . . & 100 & 2,000 & 9,939 \\
\hline 3-year-old bachelors. . . . . . . . & 2,000 & $10, \infty$ & 13,880 \\
\hline 2-year-old bachelors. . . . . . . . & $21, \infty$ & $I_{5}, \infty 00$ & 17,422 \\
\hline Yearling bachelors. . . . . . . . . . . . & $I_{3}, 000$ & 20,000 & 23,068 \\
\hline 2-year-old cows. . . . . . . . . . . . . . . . . . . . . . . & $\$ 1, \infty 00$ & 55,000 & 17,422 \\
\hline Yearling cows.................. & $x_{3,000}$ & 20,000 & 23,067 \\
\hline 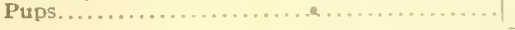 & $8 \mathbf{r}, 984$ & 92,260 & 93.250 \\
\hline Total .... & $255,733 \quad \mid$ & $=68,305 \quad \mid$ & 294,687 \\
\hline
\end{tabular}

a See Clark, Science, N. S., XXXVIII, p. 919, Dec. 26, 1913; also Bur. Fisheries Doc. 7So, D. 97. I913; and Hearings Comm. Exp. Dept. Commr., H. R., No. 2, 63rd Cong., 2ad sess., pp. 494-499, 1914.

Comparison of harems and idle bulls.-In 19I2 there were only 1,358 harems, the smallest number during American ownership, and the number had been less than 1,400 in every year since 1906 . In 1913 there was a slight increase to 1,403 , and in 1914 there were as many as 1,559 , showing the most marked increase and in fact the only important one since that following the modus vivendi some 20 years ago.

With few exceptions, the harem bulls of igr 4 were at least 6 years old, and therefore were killable seals of 2 and 3 years, respectively, in 19 IO and I9I I, when land killing was practically undiminished. Moreover, 200 skins (8-12 pounds) were taken in I9I2, which were mostly of 4 -year-olds. Therefore the increase in harem bulls in rer 4 can not have been due to the limitation of land killing unless it is assumed that with former

a Fair comparison is not possible with the census made by $\mathbf{M r}$. H. W. Elllott in rgr3, since it was made some two weeks earlier in the season when a large number of pups were still unborn. 
conditions prevailing a larger number would have been killed as 4 -year-olds in 1912 , the first year of the suspension of commercial killing. This is scarcely probable, so it is plainly evident that the increase was accomplished in spite of land killing and was wholly due to the cessation of pelagic sealing, the toll of which was reduced in rig I and entirely cut off in 1912 and I9I3. Considering both harem bulls and idle bulls, the total stock of breeding males has grown from $1,47 \mathrm{I}$ in 1912 to 1,505 in 1913 and to $\mathrm{I}, 74 \mathrm{I}$ in I9I 4 , irrespective of land killing.

The increased number of harems in I9I 4 also shows that the number of young bulls counted in 1912 and 1913 did not include all that were living. The total of harem bulls, idle bulls, and young bulls in the census of 191,3 was 1,767 . These classes furnished the harem bulls and idle bulls for I9I t to the number of $1,7.3 \mathrm{I}$, which makes it necessary to assume a mortality between seasons of only 36 , a number much too small, since the evidence is clear that approximately one-sixth of the harem bulls die annually. The difference between $I 9 I_{2}$ and $I_{9} I_{3}$ is $I_{62}$, which indicates a smaller discrepancy but still a discrepancy. Both cases illustrate what is evident throughout the study of fur seals, namely, that the numbers of nonbreeding seals are almost invariably underestimated.

Although the increase in harem bulls is not evenly distributed, the great majority of the rookeries show at least a little increase. The only ones on St. Paul Island failing to do so are Zapadni Reef, Little Polovina, and Vostochni, and of these Zapadni Reef remains unchanged, while the decrease on Little Polovina and Vostochni is insignificant, amounting to only five harems in all. Notwithstanding the great increase on St. Paul Island, there is shown a general decrease on St. George Island, the only rookery having an increase being Staraya Artel, which shows four harems more than in 1913. The total number of harems on St. George in $19 \mathrm{I}_{4}$ is 243 , as against $26 \mathrm{r}$ in 1913 and $28 \mathrm{I}$ in I912. The most obvious explanation of this condition is that it is due to the gregarious instinct and the tendency for the larger herd to recruit itself from the smaller one. Whether or not this be a wholly sufficient explanation, it is of interest to note that the same principle does not seem to be effective in all cases when applied to the different rookeries on St. Paul Island. Thus some of the smaller rookeries show large percentages of gain, while Vostochni, the largest of all, is one of the very few showing an actual loss. Moreover, St. George, while having a decrease of bulls, has an increase of cows, so the cause, if there be any definite one, is evidently peculiar.

The total number of idle bulls in $191_{4}$ is 172 , and although this is not a large number it should be noted that the rate of increase over $\operatorname{IgI}^{1} 3$ is over 60 per cent. The distribution of idle bulls is somewhat irregular, and although they seem most numerous about large rookeries and massed sections, this is not always the case. For example, East Cliffs, a rookery of 57 harems, had only two idle bulls, while Lagoon, with 8 harems, had the same number, and Zapadni Reef, with 3 harems, had I idle bull. In general, the increase in idle bulls seems to be largest on rookeries having a large increase of harems, as Zapadni and Tolstoi. 
Comparison of harems and idle bulls, I9I2-19I4.

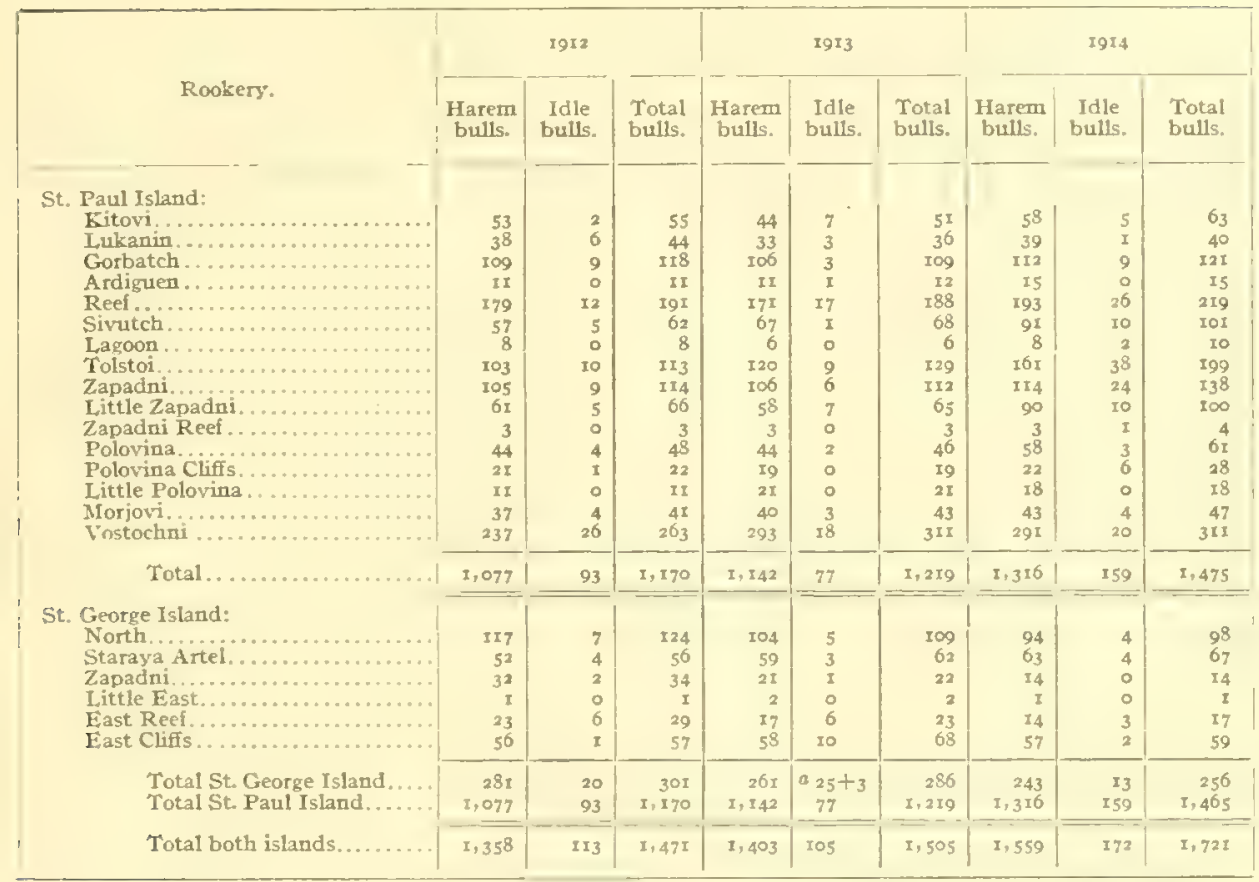

a Addition for later count, the first count having been made slightly before the height of the season.

Comparison of nonbreeding seals.-A general increase in all classes of nonbreeding seals is perhaps the most obvious comparative result of the census. The total increase of all classes from 1913 to 1914 is 25,959 , and of this only 1,204 are breeding seals, leaving 24,755 as the increment of nonbreeding animals. The classes showing the greatest gains are the 4 and 5 year old males, which have more than quadrupled. In the case of the 5-year-olds, the number is still not far from ideal, but the number of 4 -yearolds is unquestionably excessive and disproportionate. It is obviously the result of the limited killings of I II 3 and I9I4. That it provides conditions for an overstock of males in 1915 and 1916 is so clear that there is no room for argument. Two and 3 year old males also show a steady increase since 1912 and are now living in numbers beyond all possible future need for breeding purposes. The subsequent effect of these large numbers of surplus males is more fully discussed elsewhere. A tabular comparison of the estimates of nonbreeding seals is found on another page (p. 37).

Comparison of cows and pups.-A somewhat unexpected result of the census is the very small increase shown in the number of breeding cows and pups. In 1913 there were 92,269 pups and in 1914 there were 93,250 , an increase of only 981 . It is inconceivable that such a small increment could have been possible unless the herd was in abnormal condition. Any idea that the figures are wrong may be dismissed immediately, for the testimony of nine men who counted in I9I4, as well as that of several others who counted in 1912 and 1913 , is that the method of counting is sound and the results reliable. Abnormal conditions, therefore, must furnish the explanation. These 
conditions might be due to one or more of three causes: (1) disease, (2) effects of land killing, and (3) effects of pelagic sealing. If disease is in any way responsible, the nature of it is wholly unknown and no direct eridence of its existence in the past or at present is available. Disease, then, can not be considered.

Taking up the possible effects of land killing, we find room for considerable argument. That land killing may have reduced male life to numbers insufficient for breeding purposes is certainly not impossible, for there must be some stage of depletion of males at which cows will begin to escape service. Whether or not a shortage of males existed, land killing can be blaned only in so far as it supplemented pelagic killing. To the effect of land killing was added that of pelagic killing, and the two combined to reduce the stock of breeding males. That land killing alone was not responsible is shown by the increase of harem bulls in I9I3 and I9I4, which were exposed to the full measure of land killing but had a partial respite from pelagic killing.

If all the cows were not served in 1913 , this would be evident in 1914 only by a reduced number of births, or by a small increase, since cows without pups might easily come and go undetected. There was only a very small increase of births in I9I4, so, regardless of land killing, it is necessary to determine so far as possible whether or not the supply of males in 1913 was inadequate from any cause whatever. In 1913 there were I,403 harem bulls, IO5 idle bulls, and $259^{a}$ young or half bulls, a total of 1,767 possible breeders. These bulls had the responsibility of 92,269 adult cows and 1 5,000 virgins or nubiles, a total of 107,269 cows, making an average of 60.6 cows to each bull. If the half bulls are not included, the average is increased to $7 \mathbf{I}$. These undoubtedly are high averages, much higher than desirable, but that they are so high as to allow cows to go unserved is difficult to prove. Such conditions may be detrimental in the long rum, but that the bulls, at least for a time, are equal to such emergencies can not be questioned. Even when bulls are in superabundance, harems of more than 60 cows are voluntarily cared for with great frequency, and there is unlimited evidence that every healthy bull is capable of serving 60 to 70 cows whenever opportunity permits or necessity requires. Granting the capacity of the bulls, it remains to inquire what their opportunities were and whether the average is faitly applied. In I9r3, as in 19r4 and other seasons, there were doubtless many harems of small size, some in fact consisting of only one cow. Therefore, if all cows are served, some of the bulls must care for a number considerably above the average, and when the elements of time and varying rookery conditions are considered the possibility that at least a few cows may have gone unserved is greatly increased. This possibility could scarcely be admitted if numerous idle bulls were present. At best, however, it can only be regarded as a bare possibility, for the reduced number of males in 1913 can not be wholly responsible for the small increase of cows and pups in 1914 , because the same relative number of males was present in 1912 and a large increase of cows and pups followed in igr 3 . The results of insuficient male life should have been as apparent in 1913 as in 1914. This makes it clear that other causes than a shortage of bulls must be sought for the small increment of I9I4.

This brings us to further consideration of pelagic sealing which affected not only males but females. It was stopped in $191 \mathbf{I}$, so no direct loss of females since that time

a As shown on a preceeding page, this number is too small, but since it is not certain that all of this class normally breed, this need not be considered here. 
can be laid at its door. But its indirect ramifying effects can not cease until an entire regeneration of the herd has taken place. In a normal herd the cows would consist of evenly graded proportions of roung and old, and approximately one-tenth would drop out each year through natural termination of life. The indiscriminate slaughter of pelagic sealing probably destroyed these proportions, causing the death rate at present to be abnormal. Although it is known that pelagic sealers secured large numbers of old cows, it is also to be remembered that the young cows spend more time at sea than the old ones and therefore must have been more exposed to the sealer. It naturally follows that the cessation of pelagic sealing may have left the herd in 19 I I with a preponderance of aged cows. If this be the case, the number of deaths from old age in the succeeding years would be abnormal and disproportionate, perhaps very few in $19 \mathrm{r} 2$ and very many in I913. An increase in young male life is plainly evident in I9I4, making it reasonable to infer a similar increase of young females, and thus the supposition is favored that the small total of females is due to losses among those advanced in years. Therefore it is not improbable that the number of old cows dying in I9I-I4 was almost equal to the number of young ones bearing pups for the first time, and if so the total number of cows and pups in 1914 is explained. The result would have been accomplished by a death rate among old cows only $3 \frac{1}{2}$ per cent above the normal. This is shown by the following statement:

Demonstration of probable abnormal mortality of old cows, Ior 3-14.

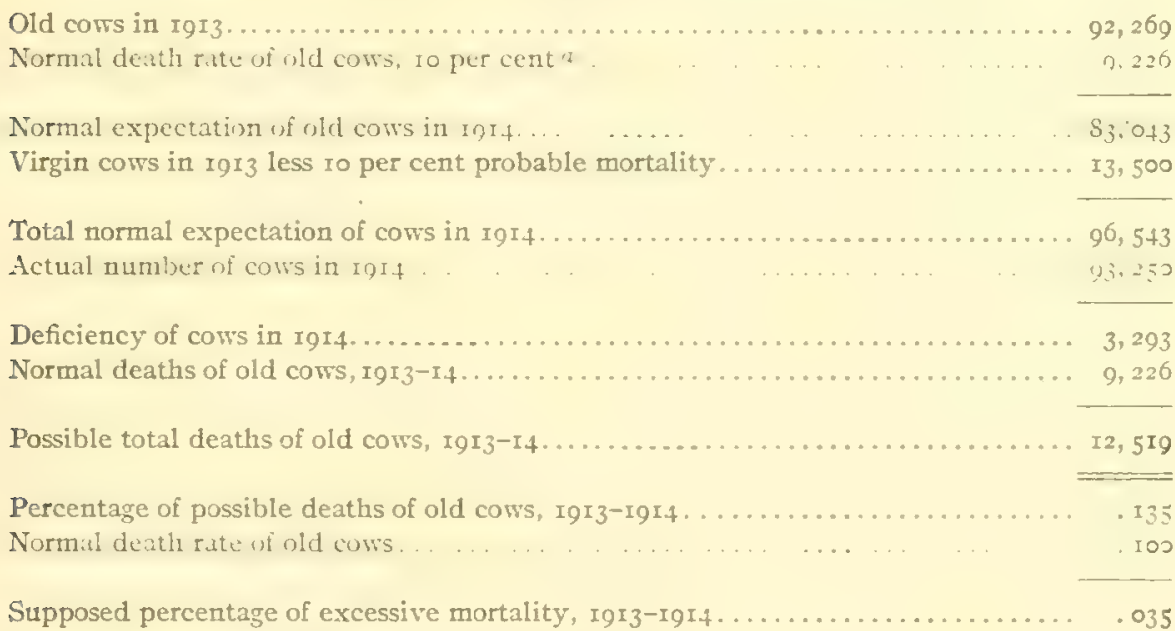

That pelagic sealing may have disturbed the death rate to the extent of $3 \frac{1}{2}$ per cent is not an unreasonable assumption, and in the absence of any other sufficient explanation this may be accepted as the principal reason for the lack of a substantial increase of cows and pups in I9I4.

Comparison of the number of pups found on the various rookeries in the three successive censuses shows certain points of interest, but conclusions drawn from them

a This is the rate due solely to old age, based on the knowledge that the average breeding life of the cow is about ro years. Some mortality of adults from other causes shou' $I$ be added for absolute accuracy, but it can not be ascertained, and is doubt. less too small to affect a calculation of this kind. 
are subject to possible unknown factors involved in the operation of pelagic sealing. The comparison of counts is as follows:

Number of pups and percentages of decrease or increase in I9I3 and in I9I4, as compared with the year before.

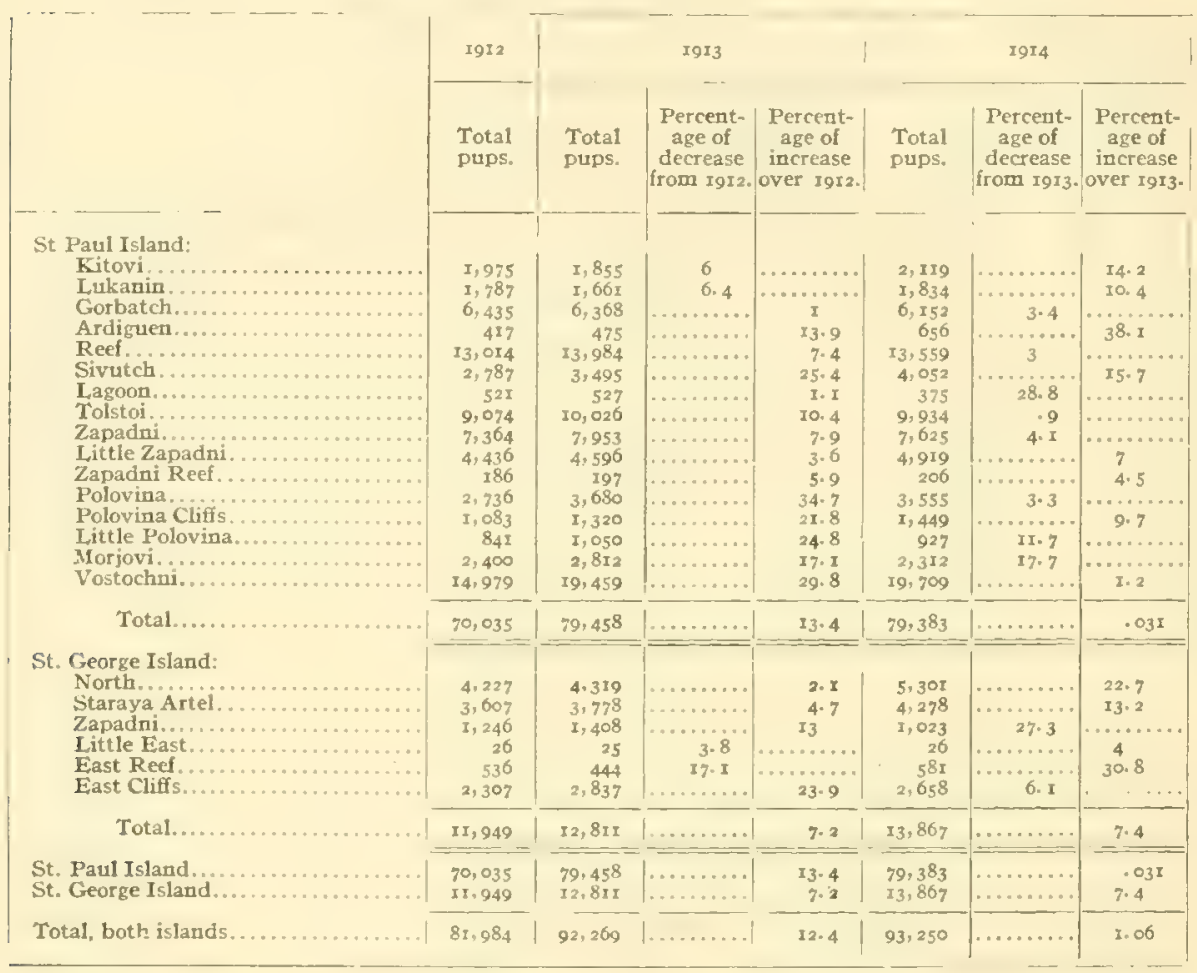

The increase in I9I3 was very general, i 8 rookeries showing an increase and only 4 a decrease. The increases on different rookeries ranged from 1 per cent to 34.7 per cent and the total increase was 12.4 per cent. In 1914 there were increases on 12 rookeries and decreases on 10, with a total increase of only r.o6 per cent. The range of variation is greater than in the previous year, running from a decrease of 28.8 per cent to an increase of $38 . \mathrm{x}$ per cent. Some rookeries which showed an increase in 1913 show a decrease in 1914 and vice versa. Kitovi, which decreased 6 per cent in 1913 , increased as much as I4.2 per cent in I9I4 and nearly the same was true of Lukanin. Polovina, which showed the remarkable increase of 34.7 per cent in I9I 3 , has 3.3 per cent decrease in I9I4, while various other rookeries show similar irregularities. The most consistent large increase is that of Sivutch or Sea Lion Rock, where there was a gain of 25.4 per cent in I9I3 and I5.7 per cent in I9I4. Ardiguen also increased well in both seasons, but its small size magnifies slight change as expressed in percentages. In the two years since I I 2 most of the rookeries show increase, but Gorbatch, Lagoon, and Morjovi on St. Paul Island, and Zapadni on St. George had fewer pups in 19I4 than in rgr2.

On the whole, the comparison of the counts on the various rookeries shows nothing more clearly than that great irregularity prevailed. There is nothing to indicate that 
increases took place on rookeries of any particular type more than another nor that decreases were due to any general cause unless it were excessive mortality of old cows produced by pelagic sealing. A point of possible significance is seen in the fact that the increases or decreases in cows on a given rookery have no definite relation to the number of bulls. In a number of instances a decrease in cows was shown on rookeries which had an increased number of bulls. Thus, Tolstoi had I20 harem bulls in 1913 and I6I in 1914. The 120 bulls of 1913 had the management of 10,026 cows, whereas the 161 bulls of I914 had only 9,934 cows, from which it is evident that the number of cows on a given rookery is not wholly dependent upon the number of bulls that are there to receive them.

\section{THE CENSUS IN THE FUTURE.}

The great element of uncertainty in all censuses thus far made is our imperfect knowledge of the percentage of young seals that naturally survive to the age of three years. Such information as we now have regarding this important matter is derived from data obtained largely in the days of pelagic sealing when unnatural conditions prevailed, making wholly reliable conclusions impossible. Under proper authority this percentage of survival can be so definitely ascertained in I9I 5 that the full strength of the herd may be estimated with a degree of accuracy sufficient for all practical purposes. With this knowledge in hand, differences of opinion as to the actual size of the herd should be reduced to a negligible minimum.

Until every possible influence of past sealing on both land and sea has disappeared and until all uncertainty is relieved regarding rates of increase and numerical proportions, it will be advisable to make an annual census. That this time has not yet arrived is evident from the results gained in I9I4, particularly the count of pups. The more regularly and carefully censuses are made now while the herd is still relatively small the less necessity there will be for such work in the future when the size of the herd will render the task more difficult and more expensive. Another census, therefore, will be required for I9I 5 and probably another for 1916. For later years, partial counts may suffice and perhaps the counting of pups may be discontinued.

As the herd grows counts will be made with increasing labor and expense, but although all future conditions can not be predicted, it is probable that the difficulties of counting harems and pups will never be quite insuperable. To continue the harem counts when the herd has reached large proportions will require improved facilities not now available, and to make pup counts at that time will involve the employment of a corps of capable men, but if necessary the work can be done.

\section{THE BREEDING OR HAREM BULLS.}

\section{STRENGTH AND VIGOR.}

The I,559 harem bulls of I9I4 showed every indication of full strength and vigor. So far as outward appearance and actions are concerned, they were normal animals in good condition as were all other classes of seals. The strain which they undergo without food during some six weeks of almost constant physical exertion and sustained sexual excitement is scarcely paralleled among animals. It is such that any weakness would be likely to manifest itself at once, and when no such weakness can be detected it must be concluded that none exists. 
The increased number of bulls, while having some effect on the average size of the harems, did not preclude the formation and successful management of some exceptionally large larems, and it is evident that an unlimited increment of bulls would not do so. Harems of large size were noted under various conditions, on large rookeries as well as smaller ones, and where idle bulls were present as well as where there were none. The bulls holding such harems, while magnificent animals, possibly superior to the average, were in no respect superior to many others in nearby positions having harems of moderate size. Harems of at least 80 cows were observed in numbers, in fact on practically every rookery. The largest single harem was noted on Zapadni rookery on St. George Island. This harem on July I 3 contained Io6 cows, and there was no doubt this was not the full total. At the close of the season the bull in charge of it was much reduced in weight, but still jealously guarded a few cows not yet served and proved so vigorous and belligerent that he could not be dislodged from his position during the counting of pups. That this bull served more than 100 cows and finished the season in relatively good condition is scarcely open to question. A similar case was noted on Gorbatch. The first harem formed here contained 6 cows on June 22 and 22 on June 26 , and rapidly increased to not less than 80 on June 30 . A few cows had already gone out to feed, so the total number of cows belonging to this harem was doubtless nearly roo even at this early date. Later in the season it grew still larger, but became so merged with surrounding harems that an exact count of cows was not possible. That it was successfully conducted is evident from the fact that the bull in charge of it was observed covering one of the few remaining cows on July 23. At this date a few bulls from other localities had concluded their labors and were sleeping in the grass behind the rookeries. These instances are sufficient evidence of the sexual capacity of the bulls. In addition, and corroborative of observations of former investigators, a single bull was noted to copulate twice within an hour and three times within 24 hours.

Further and even more conclusive evidence of the sexual capacity of the bulls is found in the average size of the harems. The 93,250 pups of 1914 were sired by the $1,+03$ harem bulls, the 105 idle bulls, and perhaps to a limited extent by the half bulls of 1913. Assuming that the number sired by half bulls is at least offset by the cows which died luring the winter, it may be concluded that 1,508 harem bulls and idle bulls in 1913 sired the 93,250 pups born in 1914 , or an average of 61.8 for each bull. The question of average harems is discussed more fully elsewhere (p. 56), but when it is considered that numerous single-cow harems are always present it is plain that many bulls must have impregnated more cows than the average. It is safe to say, therefore, that a normal bull is capable of serving 75 to roo cows in a single season.

\section{SENILE BULLS.}

Only two cases of undoubted senility were observed. One of these bulls, when first noted on North Rookery, St. George Island, was in possession of two cows near the edge of the water and some distance from the main part of the rookery. He was relatively thin, lacking in vigor, and plainly very advanced in years. He retreated on our approach like an inexperienced "quitter," and his general cowed demeanor, as well as his poor physical condition, indicated that he would not be able to maintain his position. A few hours later he was found dispossessed and dejectedly eyeing a small 5-year-old half bull 
that was actively guarding the two cows. The following day he had disappeared. The second bull of this kind, showing similar characteristics, was observed on Sea Lion Rock July 20. Among the active harem bulls a certain proportion can be distinguished as relatively old, but all maintain themselves with vigor, and it is apparent that, with rare exceptions like the ones noted above, practically all bulls with strength enough to return to the islands are still competent for harem service.

\section{ADOLESCENT HAREM BULLS.}

Many bulls not over 6 years old and a few not over 5 years conducted harems in the season of Igr4. 'The 6 -year-olds could not always be distinguished with certainty, but it was evident that practically the entire stock of this class of seals was divided between harem bulls and idle bulls. Five-year-olds with harems were comparatively few on St. Paul Island, but on St. George Island at least three were noted on East Cliffs and two on North Rookery as early as July i3. There are some observations to indicate that even 4-year-olds may be sexually capable and there is little doubt that all 5 -yearolds are. But for such animals to do harem service is scarcely desirable. Under normal conditions 5-year-old half bulls could not obtain cows until the end of the season and the break up of the harems. Their participation in the harem system early in the season can hardly be regarded as anything but an indication of a scarcity of old bulls. This, however, is not proof that the old bulls had more cows than they were capable of serving for there were old bulls with comparatively small harems not far from harems held by the young bulls. The varying character of the breeding grounds makes it impossible for a bull to move far from his original position without losing whatever advantage he may have, so cows that for any reason haul beyond the working range of the established harem bulls are subject to capture by any unoccupied bulls. Under natural conditions such cows would immediately be appropriated by the idle bulls. In the absence of idle bulls, it is evident they fall to the lot of the 5-year-olds, and so far as known are effectively served by them.

Thus, whether or not it will affect the number of pups to be born, there was in rgr4 a shortage of old bulls sufficient to permit a limited number of 5 -year old half bulls to serve as harem masters.

\section{FIGHTING OF OLD BULLS.}

The conditions in I9I4 were such as to favor a minimum of fighting. Practically all the old bulls were able to obtain at least small harems, and the idle bulls were not numerous. Moreover, the idle bulls were mostly only 6 years of age and, although fairly large and strong, lacked confidence and experience, so they were rather easily intimidated by the older animals. Early in the season before the cows arrived there was some fighting, which did comparatively little harm and which was doubtless not proportionately greater than it would be under any circumstances. On June 22 a bull was noted on Kitovi that had recently suffered the loss of one eye, and others with cuts and slashes were occasionally seen. Later, on the same rookery, an idle bull was seen to take charge of a harem while the original possessor sought to retrieve a fleeing cow, and in the onslaught which followed the interloper narrowly escaped castration.

Contrary to general popular impression, no fighting of consequence occurs over the incoming cows. The bull fights to maintain his position and only in this indirect S4512 -S. Doc. $950.63-3-1$ 
way can he be said to fight for the acquisition of cows at the time when they are arriving. Idle bulls are constantly to be seen wholly indifferent to the arrival of cows in near-by harems. Bulls in possession of harems not uncommonly attempt to welcome new cows, but in such cases the cows are very apt to return to the sea in apparent fright. In many cases, cows were observed to come quietly into a harem while its lord and master was lying asleep and blissfully ignorant of any addition to his seraglio. During the formation of the harems, the dominant instinct of every bull is not to dispossess his neighbor but to maintain his own position at all costs; and a relatively poor place is valued as highly as the more favored ones. When the height of the season arrives, with practically all cows accounted for and many of them in heat at the same time, the procreative instinct becomes stronger and bulls which find themselves without cows will then attempt to secure them wherever possible. It is evident that the majority of the bulls return each season to the same or approximately the same position as that occupied the previous year. In general, it is true also that the older bulls arrive early. Thus it follows that the less advantageous positions are left for the younger bulls. Such bulls about the rear and ends of the rookeries are constantly being menaced by the harem bulls, whether actual fighting takes place or not, and this always causes commotion. When an idle bull makes a move which is deliberately or apparently threatening, the nearest harem bull starts toward him, perhaps from the other side of his harem, and plows ruthlessly through passive cows and over struggling pups until he is near enough to cause the idle bull to retire. In the majority of cases there is no real conflict, but since neighboring harem bulls are apt to start up at the same time, the general mêlée may result in two bulls coming into such close proximity that the "bluffing" tactics are abandoned and real blows struck. Similar trouble ensues from the approach of idle bulls and bachelors at the water's edge. The large number of 3 and 4 year old bachelors in I9I 4 was the source of considerable disorder of this kind, and it is evident that even a moderate breeding reserve of these classes of males would be sufficient to haunt all the rookery fronts and rouse the antagonism of the harem bulls. Time after time a harem bull will rush through his cows merely to roar and puff at a young bachelor which has hauled partly out of the water and looked with apparent curiosity in his direction.

Even with fighting at a minimum, as at present, there is considerable unavoidable commotion on the rookeries. A particularly fruitful source is the departure of the cows to feed. When the first cows begin to go out, the harems are large, the cows closely packed, and births and copulations in progress. The bulls seem to become greatly exercised at the idea that a cow may get away without service and as soon as one makes a move, whether from a real intent to go to sea or not, the bull hastily rushes over any intervening cows and either quiets the restless one or in some way satisfies himself that she has been served. Sometimes the bull will even interrupt the service of one cow to restrain another which scems about to leave, and will do so likewise to threaten an inquisitive young bachelor. Such actions while the pups are still young and while births are undervay doubtless cause some mortality of pups. One wonders that it does not cause much more than is found upon investigation, but it is evident from this as well as from general observation that the pups are fitted to withstand an incredible amount of rough treatment. Except at the time of birth and for a few hours thereafter they may be battered about, trampled, and pushed into crevices without serious 
injury so far as the great majority of cases are concerned. Although the bulls sometimes seemed conscious of the helpless young ones and appeared to avoid trampling them, innumerable instances were noted in which they passed directly over small pups without harming them. In one case a copulation was observed during which a pup was imprisoned beneath a bull and subjected to continued mauling for nearly is minutes, after which the little fellow wriggled out apparently none the worse. It is plain, therefore, that considerable commotion is unavoidably connected with the harem system whether idle bulls are present or not; and although much of it is comparatively harmless, some fatalities are bound to result under the best of circumstances.

\section{SIGNIFICANCE OF THE INCREASE OF HAREM BULLS.}

The increase of harem bulls from 1,358 in 1912 to 1,403 in 1913 and again to 1,559 in I9I4 shows clearly that the reduced state of male life in I 912 and preceding years was at most only partly due to the killing of males on land. As stated elsewhere, tlie accessions of harem bulls in I9I4 consisted of animals that escaped the undiminished land killings of I9Io and I9I I when they were 2 and 3 years old, respectively. "Their continued survival in larger numbers than formerly is thus due to the fact that their later years were free from the effect of pelagic sealing. To some extent this justifies the belief frequently expressed that with the closest land killing possible a certain number of males would always escape and come to maturity. It can not be said, however, that it justifies land killing now at the former rate, for with pelagic sealing stopped, the increase in the number of cows would be proportionately larger than formerly.

The increase in harems in 1914 without a corresponding increase in cows shows that the number of harem bulls in immediately preceding years, if not insufficient, was at least abnormally small. That the bulls are fully capable of meeting such emergencies may not be doubted, but it is nevertheless clear that when more bulls are present the average number of cows per bull is immediately reduced. The number of cows in 1913 was almost equal to the number in 1914 , but in 1913 they were divided among $\mathrm{I}, 403$ bulls and in 1914 among 1,559 bulls. It is evident, therefore, that had 1,559 bulls been present in 19I3, all or practically all of them would have been able to obtain harems. It is apparent also that a continued increase of bulls will cause the size of the average harem to decline from year to year until it reaches a minimum beyond which no increment of bulls can reduce it.

\section{THE IDEAL PROPORTION OF HAREM BULLS.}

It may well be doubted whether it would be wise to permit such an increase of bulls as would insure a minimum average harem, for other considerations are involved; but a safe course of procedure in the management of the herd would seem to demand that the average number of cows per bull be kept as near such a minimum as possible without causing injury to the herd. Such a course may be modified as nore complete knowledge. is obtained in future years, but at present a prudent policy of approximating natural conditions recommends itself.

To accomplish a reduction of the average harem to the proportions of former years will require the preservation of a relatively small number of males and large numbers may still be killed without the slightest apprehension. This is evident when it is considered that an annual increment of only 2,000 bulls would provide for the maintenance 
of 12,000 bulis in service, and if these had an average of only 40 cows each provision would be made for a total of 480,000 cows, a number scarcely exceeded in the history of the herd.

The average number of cows per bull under approximately natural conditions can not be stated exactly, but the best evidence available indicates that it was not less than 30 nor more than 40. In the early days of American ownership it was not known that all the cows are not on land at one time, so underestimates were the rule. H. WV: Elliott, writing of conditions from i 872 to 1874 , says: ${ }^{a}$

I found it an exceedingly difficult matter to satisfy myself as to a fair general average number of cows to each bull on the rookery; but, after protracted study, I think it will be nearly correct when $I$ assign to each male a general ratio of from ${ }_{5}$ to 20 females at the stations nearest the water, and for those back in order from that line to the rear, from 5 to 12 ; but there are so many exceptional cases, so many instances where 45 and 50 females are all under the charge of $I$ male, and then, again, where there are 2 or 3 females only, that this question was and is not entirely satisfactory in its settlement to my mind.

Charles Bryant, writing of the same period, says simply, "In the average there are about i 5 females to one beach master." 8

More detailed data are available for the years 1896 and 1897 , during which the herd was considerably reduced in size, but was supplied with an excessive number of bulls, due to the suspension of lilling during the modus vivendi of I89 I to I893. In 1897 , when fairly complete counts were made, there were 4,418 harems by count and 172,288 cows by corrected estimate, ${ }^{c}$ making an average harem of 38.9 . At this time idle bulls were practically equal to harem bulls, and obviously excesive in number, so it is erident the average harem was reduced to a low figure. In view of these facts, and the knowledge that the extreme capacity of the bulls is very much greater, it is safe to say that a supply of harem bulls which provides I to every 40 cows is amply sufficient. The number in 1914 was approximately I to every 60 cows, and close observation revealed 110 evidence that all were not efficient. To have produced an average harem of 40 in 1914 would have required only 772 more harems than were found, so it is apparent that no large reserves are necessary to bring about ideal conditions in the immediate future. If it should be found in practice that the average harem can not be greatly reduced without the accompaniment of a great excess of idle bulls, action will necessarily be gorerned according to circumstances as they develop; but if an intelligent and continued effort is made to provide harem hulls in the approximate proportion of 1 to fo cows the result is certain to fulfill all the demands of a policy of conservation.

\section{IDLE AND YOUNG BULLS.}

\section{AGE AND CHARACTER.}

The so-called idle bulls were in the majority of cases bulls believed to be only 6 years of age. A few 7 -year-olds also were unable to obtain harems, but only in exceptional circumstances. It is evident that in a well-balanced herd the idle bulls would largely consist of animals relatively young. During a great excess of bulls a variable number of all ages might be found in the class of idle bulls, but the natural course

\footnotetext{
a Monogr. Seal Islands of Alaska, p. 36, I882.

b In Allen, N. Am. Pinnipeds, p. $38_{5}$, Is8o.

$c$ Obtained by multiplying the average harem of one rookery by the total number of harems and adding one-hall for error in method. Sce this report, D. 34, and Jordan and Clark, Fur-Seal Invest., I896-97, vol, I, p. 97, I898.
} 


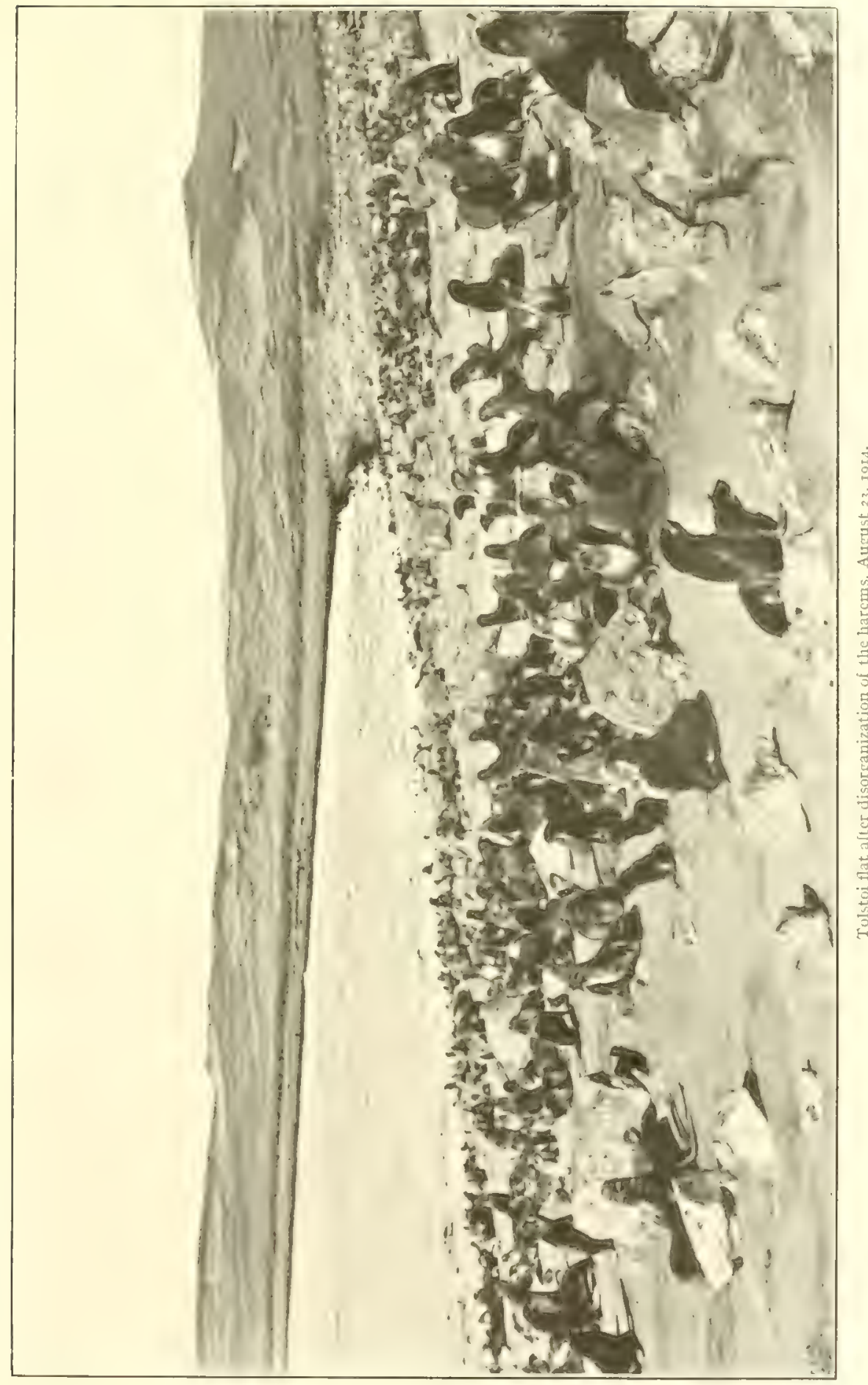



of events brings the younger animals to the less advantageous positions. The older bulls as a class are doubtless stronger and better fighters than their juniors, but their success in all cases may not be due to this so much as to their early arrival and their predilection for places previously occupied. The young bull secking his first harem is guided mainly by an instinct to secure some sort of a position on the breeding ground and wait for cows to come to him. Arriving a little late, he finds most of the good positions occupied, and unless he stumbles into a place vacant through the death of its previous occupant, he is content to take a relatively poor position and guard it as hopefully as if it were the best. Late in the season he discovers his error and attempts to get cows wherever he can find them. The old bull, on the other hand, comes early and seeks the place occupied the previous year or a similar one and is not satisfied with any other. This, with the exception of circumstances, is the general procedure which operates to make the idle bulls as a class relatively young.

Certain of the idle bulls are as tenacious of their positions as the harem bulls are and will charge at a man who comes near them with just as much ferocity and determination; others will roar at a man and grudgingly give ground as he approaches, perhaps finally retreating to the water and sitting partly submerged while they continue to puff and glower; still others take fright at sight of a man and rush pell-mell to the sea and swim off. Especially to this last class the term "quitter" has been applied and an attempt has sometimes been made to distinguish "quitters" and idle bulls. As observed in I914, there was every gradation from the undoubted "quitter" to the determined idle bull, and a large number were neither the one nor the other. Moreover, some of the most timid quitters were found continually returning to their positions and in some cases their demeanor changed as the season advanced, while a few of them actually obtained harems. It was evident that all such bulls were ready to secure harems and competent to care for them whenever opportunity permitted. Their enumeration as idle bulls, therefore, was fully justified.

Other bulls, apparently at least 6 years of age, were irregular in their movements, some being on the hauling grounds, some in the bachelor runways and at the extreme ends of the rookeries, while at all times an indeterminate number were in the water, appearing and reappearing along the rookery fronts to haunt and harass the harem masters nearest the sea. Such bulls can not be fully cnumerated and, though doubtless quite as effective reserves as the idle bulls in fixed positions, they can only be taken into account collectively with the "young bulls" or half-bulls, all of which are never on land at one time. With these exceptions, the "young bulls" consist of the 5-year-olds, the majority of which spend the early part of the season with the young bachelors. Toward the height of the season they are seen in increasing numbers about the rookery fronts, and at the first sign of relaxation of harem discipline they swarm over the breeding area. As the exodus of old bulls progresses the idle bulls and the smaller half-bulls practically take possession of the breeding ground. At this time the virgin cows appear in greatest numbers and it is assumed that they are largely served by these idle and young bulls. The young bulls, half-bulls, or 5-year-olds, are wholly unable to cope with the idle bulls, and, although in 19 It they occupied most of the space after the break-up, it is plain that they would not have been permitted to do so had a larger number of idle bulls been present. 


\section{IRREGULAR DISTRIBUTION.}

As in the case of other classes of seals, the presence of a larger or a smaller number of idle bulls on a given rookery is doubtless governed by a variety of circumstances, only a few of which can be recognized. At least it is obvious that the distribution of idle bulls is rery irregular, and a considerable number may be present about one rookery while scarcely any are found on another. It may be possible also, as observed in I9I4, for idle bulls to be present at one end of a rookery while harems are held by half-bulls at the other end. The fact that the herd as a whole includes a number of idle bulls, therefore, is not inconsistent with their complete absence and an actual shortage of harem bulls on certain rookeries. This being the case, it can not be safely assumed that no shortage of harem bulls exists unless there be idle bulls on cvery rookery. To this extent at least it is apparent that a certain number of idle bulls are desirable and necessary.

In I9I4 there were several rookeries having no idle bulls whatever and the range of variation from rookery to rookery was very great, as shown by the subjoined table:

Percentage of idle bulls on different rookeries, IgT4.

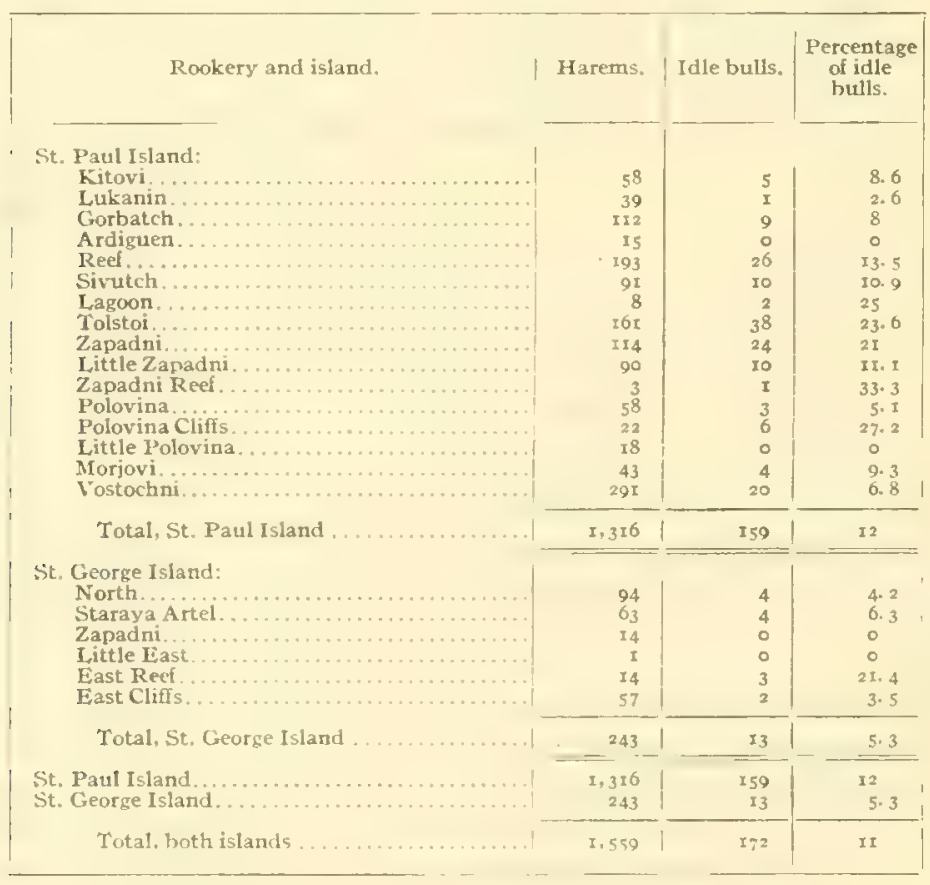

IDLE BULLS AS A DESIRABLE BREEDING ELEMENT.

The idea that the idle bull is literally a surplus or superfluous bull, only valuable as a reserve or as an indication of a sufficiency of harem bulls, seems open to serious doubt. It is quite conceivable that a moderate number of idle bulls may be an actual necessity for normal breeding. When a sufficient number of idle bulls are present, it is apparent that they are the principal, if not practically the only, agents for the service of the virgin 
cows. In the absence of idle bulls, these cows must be served either by the old bulls or by the 5-year-old half-bulls. It can not be said that any such cows ever have escaped service, but it is plain that an absence of idle bulls would be the first condition favoring its possibility. A number of idle bulls proportionate to the number of virgin cows, therefore, would be the safest guaranty that all such cows would be impregnated.

The virgin cows do not appear on the rookeries until relatively late in the season and remain on land but a short time. Apparently they come in greatest numbers at about the time the regular harems are breaking up and the old bulls retiring from the breeding areas. Although some of them are doubtless served by the old bulls, this is exceptional, for the majority of the old bulls leave each season at approximately the same time whether idle bulls are present or not. This leaves the young half-bulls free to take possession of the young cows unless prevented by the idle bulls. In I9I4, the idle bulls were sufficiently numerous to secure many of these cows, but a much greater number were seen under the care of the half-bulls. So far as known, the half-bulls are sexually as potent as the older animals, but since they would not do service under natural conditions, some doubt attaches to the adrisability of an artificial condition which permits them to act as sires. It may therefore be concluded that idle bulls as a class have a definite function in the breeding economy and that unless in excessive numbers they are a benefit to the herd.

\section{IDLE BULLS AS A MENACE TO THE HERD.}

In recent years there has been no opportunity to observe the effect of numerous idle bulls, but there can be no doubt that a large supply of idle males, including animals of 7 years of age and over, would cause increased fighting and disturbance. The extent to which this would entail increased loss of life is to a considerable degree a matter of opinion. If left to itself, the herd would undoubtedly develop an excess of bulls beyond all possible needs and one which might serve as a distinct disadvantage. It may readily be believed that superabundant male life was a factor in maintaining an equilibrium before the advent of man, but in spite of this a considerable proportion of idle bulls may not be seriously detrimental. Under present conditions the massed sections of the larger rookeries are at the height of the season as thickly packed with seals as seems possible. The harems merge one with another to such an extent that those toward the center of a given area are thoroughly shielded from any disturbances except those originating within themselves. On the flat and adjoining beach under Hutchinson Hill there were in I9I4 more than Ioo contiguous harems and 6,000 to 8,000 closely packed cows. Numerous idle bulls, if present in such a place, would have caused some extra commotion around the outskirts of this breeding ground, but the great central mass would have been practically unaffected. In a large herd a few bulls and a certain number of cows undoubtedly come to death through fighting, and a considerable number of pups are trampled and smothered, but there is no conclusive evidence that the number is appreciably more than proportionate to the size of the herd, regardless of a considerable number of idle bulls. In 1896 , when idle bulls were present in great numbers, I $3 \mathrm{I}$ dead cows and 28 dead bulls were noted, and a full count of pups was made on at least one rookery, Kitovi. So far as these figures can be compared with those of recent years, when both harem bulls and idle bulls have been at a minimum, 
no important change in the death rate is indicated. This is shown by the following table:

Mortality in relation to idle bulls.

\begin{tabular}{|c|c|c|c|c|}
\hline Year. & 1896 & I9I2 & 1913 & 1914 \\
\hline 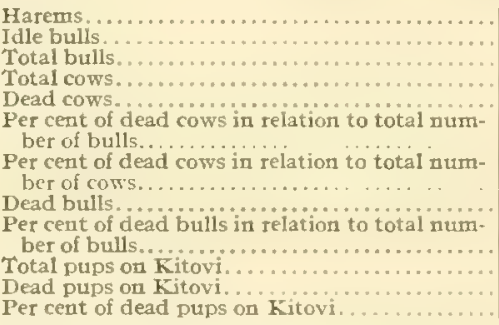 & $\begin{array}{r}4,932 \\
3,000 \\
7,932 \\
209,873 \\
131 \\
1.7 \\
.0 ; 9 \\
28 \\
\\
6,380 \\
6,049 \\
109 \\
1.8\end{array}$ & $\begin{array}{r}I, 358 \\
I 13 \\
I, 471 \\
8 I, 984 \\
37 \\
1 .= \\
.037 \\
3 \\
.204 \\
1,975 \\
37 \\
1.8\end{array}$ & $\begin{array}{r}1,403 \\
105 \\
1,508 \\
92,269 \\
30 \\
1.9 \\
.032 \\
6 \\
\\
.390 \\
1,855 \\
22 \\
1.1\end{array}$ & $\begin{array}{r}x, 559 \\
172 \\
3,731 \\
93,250 \\
18 \\
1.0 \\
.019 \\
1 \\
.057 \\
2,119 \\
47 \\
2.2\end{array}$ \\
\hline
\end{tabular}

a Estimated; see Rept. Fur-Seal Invertigatione, Ingt,-9;. rul. 1, 1. 99.

o One-hall more than formerly estimated.

c Including only those which died prior to August to to make the figures comparable with those of later years.

The above table is somewhat unsatisfactory, since pelagic sealing was going on in 1896 and the counts were made then by methods not exactly the same as those used in 1912-I9I4. Moreover, it is not possible to state what percentage of the dead was due to trampling and fighting, so it is necessary to compare those dead from all causes. Notwithstanding that the figures are less extensive than desirable, several points of considerahle interest are to be noted. The percentage of dead cows in relation to the total number of cows was greater in 1896 than in the years when idle bulls were few. In all other respects there is nothing in the figures to indicate that the percentage of death from all causes during the breeding season was any greater in 1896 than in the later years. The percentage of dead pups on Kitovi was exactly the same in 1896 as in 1912 , and even less than in I9I4. Likewise the percentage of dead cows in relation to the total number of bulls was the same in 1896 as in 1912 and less than in 1913. In 19I4, with an increase of bulls, there were fewer deaths of bulls and cows than in 1912 and I9I3.

The imperfection of the data precludes absolute proof, but so far as any conclusion is indicated by these figures it is that a considerable number of idle bulls does not produce an excessive death rate. If, in spite of these figures, it is held that an increased mortality must necessarily follow eren a moderate increase of idle bulls, the most that can be maintained is that it is likely to be relatively small and not of itself sufficient to justify apprehension. Fighting and commotion must always be a part of rookery life, and if the idle bulls have any legitimate function it need not be very great to offset the harm they may do and justify their preservation in reasonable numbers.

THE IDEAL PROPORTION OF IDLE BULLS.

What has been said in the preceding paragraphs indicates that while a great excess of idle bulls is highly undesirable, an entire lack of them is equally so and for the maintenance of a well-balanced herd a definite proportion of them is necessary. This proportion should be large enough to insure the distribution of idle bulls on all the rookeries in numbers sufficient to serve all the virgin cows. The number of virgin cows at a given 


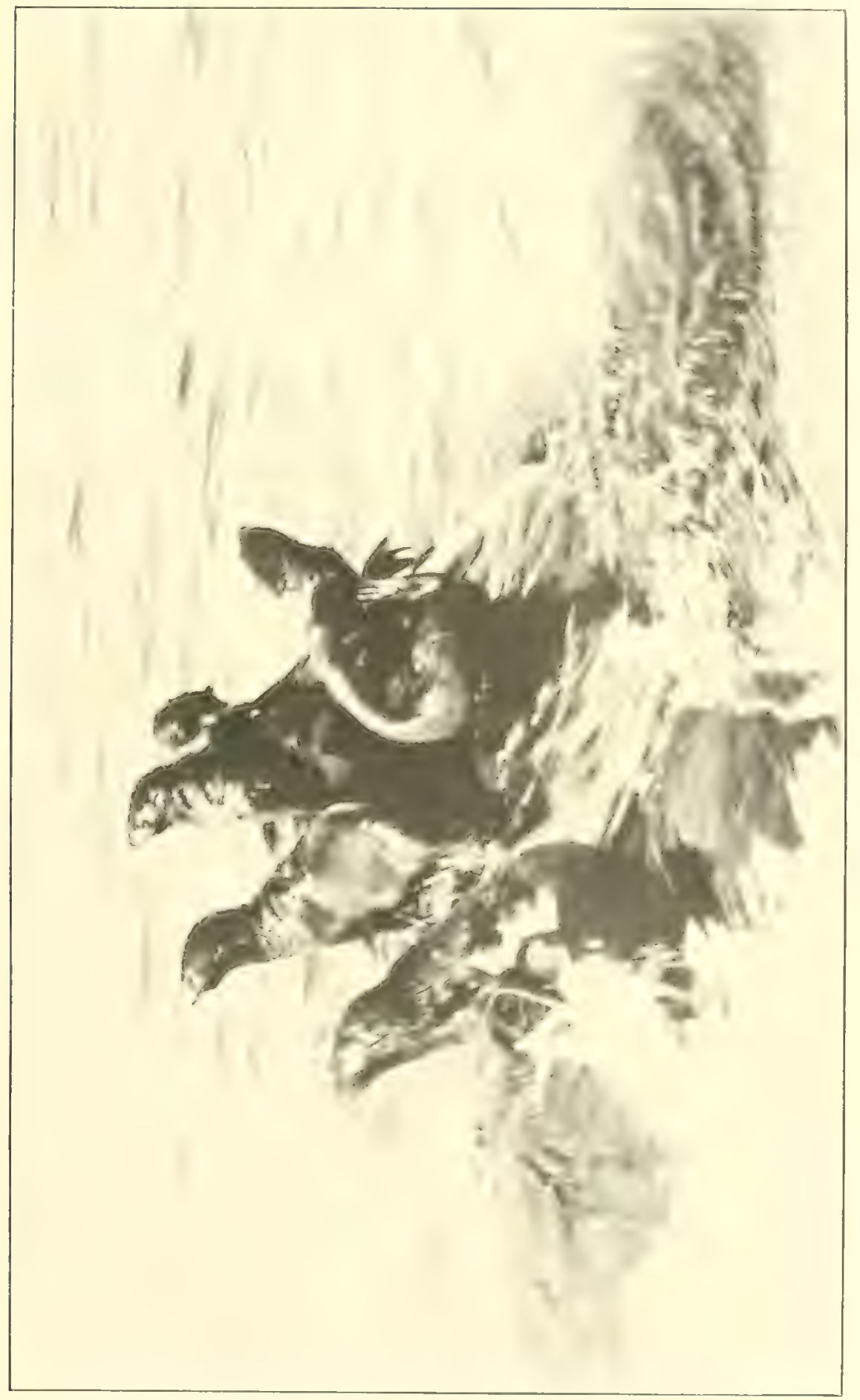



time would nomally be about one-fifth as many as the number of old cows. This would indicate that one idle bull to every five harem bulls would not be an excessive number. Although but little data are available, it seems probable that most of the virgin cows are served between July I 5 and August 5, a period somewhat shorter than that during which the old cows are held in the harems. Therefore, it may not be unfair to allow a smaller number to each bull than in the case of the old cows, and one idle bull to every four harem bulls therefore may be suggested as a theoretically ideal proportion. Reference to the table (p. 52) of the distribution of idle bulls in I9I4 shows that this proportion has nearly or quite been reached on some rookeries without effectively reducing the average size of the harems of the old bulls so it is evident that in practice it may not be possible to secure ideal proportions either of idle bulls or harem bulls. However this may be, there can be no question of the importance of striving to maintain proportions as near a theoretical ideal as circumstances will permit.

\section{THE UTILIZATION OF SURPLUS BULLS.}

To prevent financial loss, business principles demand that no large increment of idle bulls be permitted, but it is inevitable that excess may occur from time to time either as the result of well meaning restrictive legislation or on account of the liberal allowances for contingencies necessary in a carefully considered system of reserving young males. It is true that after the fourth year the pelt of the male fur seal becomes coarser and of less value than formerly, but it can not be said that it loses all its value. During the early years of the leasing system all furs were much cheaper than at present and the great abundance of seals made it natural that only the choicest should be taken for market. In later years, when the Government restricted the quota, the lessees were of course inclined to follow a similar policy guaranteeing them the largest possible profit. Therefore it is probable that they fostered the belief that skins of "wigged" males were of no value. 'The pelagic sealers, however, took seals of all classes and the records of sales in London show that "wigs" were by no means without value. Although their condition as pelagic skins was variable and doubtless below what might be expected of land-taken skins, they were often sold for good prices in lots including other grades. The best examples of lots consisting exclusively or almost exclusively of wigs in recent years are found on the sales sheet of C. MI. Lampson \& Co. for I 909 and I 9 I I, as follows:

Prices received for skins of large seals.




The average price received for land-taken skins in 1909 was $\$ 34.68$, so in general terms it may be said that wigs in that year brought at least two-thirds as much as 2 and 3 year olds. In view of these figures, it is obvious that prime skins of 5 and 6 year old fur seals would always command a price that would compensate for a considerable proportion of the revenue which might have accrued if they had been taken as 3-year-olds. Even if no figures were available, it would still be evident that the skins of young bulls must have a substantial value. The observer, seeing these fine young animals in prime condition, and knowing the growing demand for fur of all kinds and the wide range of uses to which it may be put, can not fail to conclude that the skins of young bulls would find a ready market and bring profitable prices. Therefore, while failure to kill at the proper time causes a financial loss, it does not cause a total loss. In emergencies, such as will exist in 1915 when nearly ro,000 5-year-olds will be present, it would be possible to derive at least a moderate revenue from seals of this class.

\section{THE AVERAGE HAREM.}

\section{VALUE OF THE AVERAGE HAREM.}

The average harem, as commonly considered, is the average number of old cows held in harems by old bulls in a given season. It is calculated by dividing the total number of pups (equivalent to cows) by the total number of harems, and may be obtained for a single rookery or for the whole herd. During pelagic sealing, when full counts of pups were not feasible, the average harem was used as a means of estimating the total number of cows and pups by counting pups on one or several rookeries and applying the average thus obtained to all the rookeries. Estimates made in this way, as shown by recent full counts of pups, were apparently from 30 per cent to to per cent too small (see this report, p. 34), but their comparative value is nevertheless very great. For this reason it is highly important that this information be obtained whenever it is not possible to make a full count of pups.

The average harem is of value also as an indication of the relative strength of the breeding males. Thus in 1914 an increase in harem bulls without a proportionate increase in bearing cows caused a reduction of the size of the average harem. Further reduction may be expected with further increment of bulls and regulation of the size of the average harem may be accomplished by increasing or decreasing the number of bulls.

\section{VARIATION OF AVERAGE HAREMS,}

Variation of average harems is of two kinds, that of seasons, from one to another, and that of different rookeries in the same season. From season to season the average harem of the total herd has varied in recent years within relatively small limits. Thus in 1912 it was 60.4 , in 1913 it rose to 65.8 , and in $19{ }_{4} 4$ dropped to 59.8 . During the same period it showed a net decline for St. Paul Island and a continuous rise for St. George Island. Variation on the different rookeries from year to year keeps within moderate limits in most cases, and this may be taken as some indication that, unless unduly influenced, the same set of animals repairs each year to the same rookery. In other cases, the average harem shows sudden and pronounced ups or downs which are sometimes obviously due to well-known abnormal conditions and are sometimes wholly inexplicable. A summary of average harem data follows: 
Comparison of average harems, IOI2-19I4.

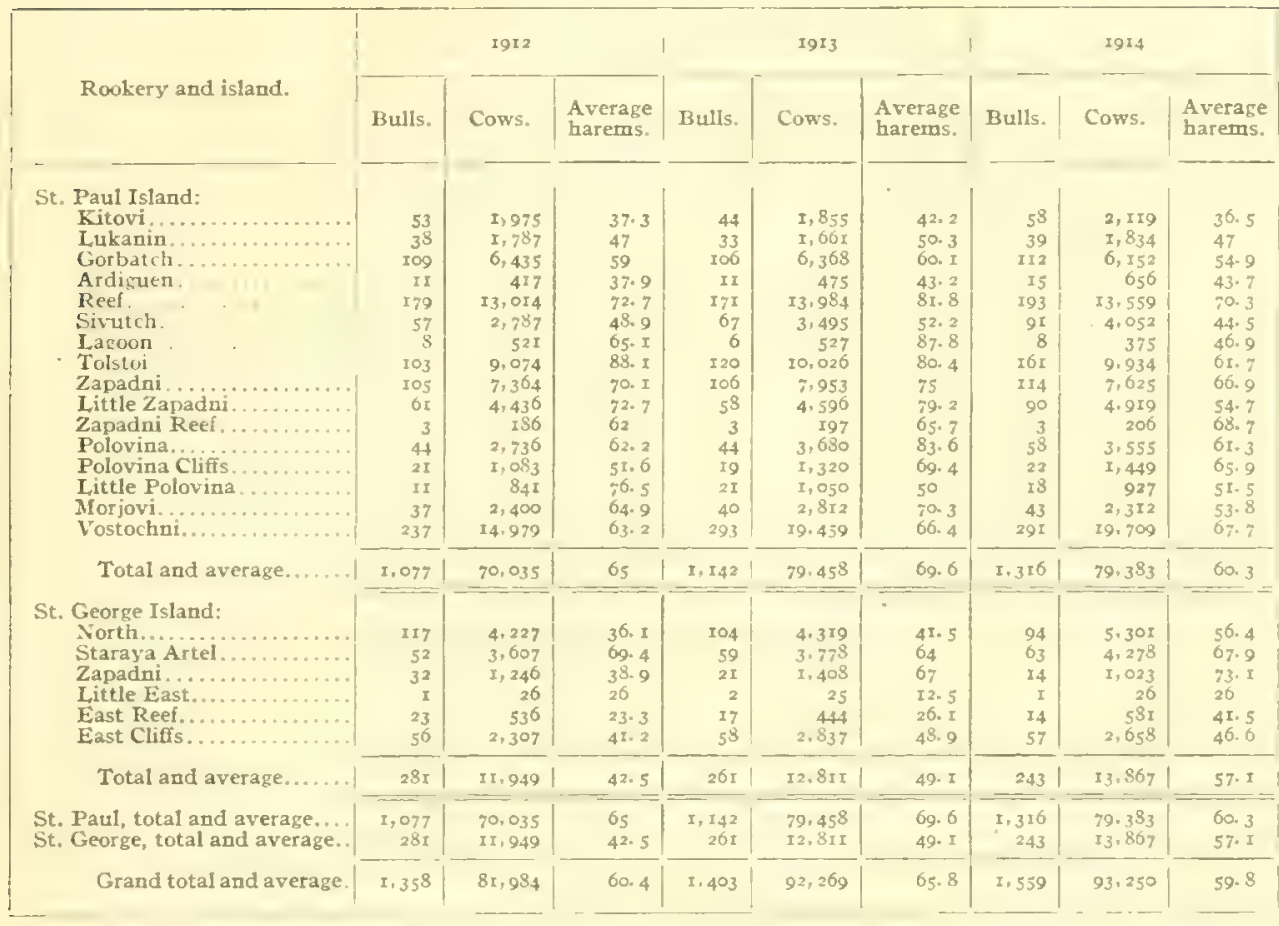

The most obvious general condition revealed by this table is the marked difference between St. Paul and St. George Island. Although only four rookeries on St. Paul show an increased average harem since 1912 , the conditions on St. George are reversed and five out of the six show an increase. This accords with field observations which make it very clear that there was a scarcity of bulls on St. George in 19r4. For the whole herd the average harem falls since I9I2 on I 2 rookeries, rises on 8 rookeries, and remains unchanged on 2 .

The variation in the averages of different rookeries in the season of 1914 ranged from 36.5 on Kitovi, St. Paul Island, to 73.I on Zapadni, St. George Island. ${ }^{a}$ Nine rookeries have an average of over 60,8 of under 50 , and 5 between 50 and 60 . Some of this rariation is cloubt less due to past conditions, especially raiding and pelagic sealing, but it is probable that conditions never have been and never will be such as to produce more than approximate uniformity in the average size of the harems on the different rookeries.

\section{THE AVERAGE HAREM AS A CRITERION OF THE CAPACITY OF THE BULLS.}

The nature of an average forbids its use as a criterion of extremes unless certain reservations are made. In some cases, an average may be the mean between only slightly divergent extremes, and thus is fairly representative; but the average harem is based upon the total number of harem bulls, including many with but one cow 
and others with more than a hundred. If the bulls are of equal strength, one is as capable of caring for a large harem as another, and it must be concluded that all bulls have the ability to serve the maximum number of cows. This maximum number is known to be more than $x 00$, and although an exact figure can not be stated it is not necessary for practical purposes that it should be. The average harem for the whole herd or for certain of the larger rookeries is of value in this connection chiefly because it substantiates the general conclusion that the maximum harem is very large. To obtain the average harem of 59.8 in 1914 , it is obvious that harems much larger than the average must have been included. The maximum average harem of some of the larger rookeries furnishes a further indication of the same sort. Thus, in 1912 the average harem of Tolstoi, a rookery of 9,074 cows, was 88. I; in 1913 the average harem of Reef, with 13,984 cows, was 81.8 ; in 1914 Reef had 13,559 cows and an average harem of 70.3 . Such figures can not possibly be interpreted otherwise than that the capacity of the bulls is far beyond their average opportunities even under present conditions.

In addition to the bearing cows, which are the only ones included in the average harem, the harem bulls have the further responsibility of at least a small proportion of the virgin cows; exactly how many can not be ascertained. If a sufficient number of idle bulls were present to insure the exclusion of the half-bulls from the breeding, the total of harem and idle bulls might be proportioned to the total of young and old cows served by each bull. Under these conditions an average might be obtained by considering the bulls of one year as sires of pups of the next, and to this extent the effectiveness of the bulls would be demonstrated wholly beyond cavil. Thus there were in 1913, according to count, I,403 harem bulls, I05 idle bulls, and 259 young bulls, making a total of 1,767 bulls and young bulls as the sires of the 93,250 pups born the following year, in I9I4. The average number of cows per bull on this basis therefore was 52.8 in I9I3. Two objections may be made to this result, (I) the number of young bulls counted did not inclucle the full stock of that class (see p. 4o), and (2) at least ro per cent of the old cows must have died between seasons. One of these objections practically offsets the other, and it would be hypercritical to dissent from the conclusion that an average of not less than 50 young and old cows was served by the combined harem bulls, idle bulls, and young bulls in 1913 .

Considering all the data on the subject of average harems, it is evident that while they fail to show the maximum capacity of the bulls they demonstrate most conclusively that the maximum is very high and that in practice it has rarely or never been reached. If any bad result has come through the reduced number of bulls on the islands in recent years, it has not been because of lack of sexual power. Possible harm through lack of opportunity by the old bulls and through participation of adolescent males in the breeding has been discussed elsewhere (see p. 47).

\section{DISTINCTIONS BETWEEN THE CLASSES OF SEALS.}

The so-called classes of seals are the natural divisions which may be made according to age and sex. For practical purposes there are seven classes of male seals and four classes of females. The classes of males are the pups, the yearlings, the 2-year-old bachelors, the 3 -year-old bachelors, the 4 -year-old bachelors, the 5 and 6 year olds or half-bulls, 
and the bulls or males of 7 years and over. The classes of females are the pups, the yearlings, the virgin cows or 2-year olds, and the bearing cows or cows of 3 years and over. The distinction of these various classes is a matter of great importance in the study of the seals and in the practical management of the herd. It is especially important to distinguish the bachelors of 2,3 , and 4 years since these are the classes most similar in general appearance and the ones from which quotas and reserves must be taken. The other classes are mostly so easily distinguished as to require no special discussion.

\section{GENERAL DISTINCTIONS.}

Certain obvious general distinctions have long been recognized. Thus, the males after the third year are so much larger than any female that no confusion is possible. Males and females of 2 and 3 years, although distinguishable by a combination of minor characteristics which are apparent to the experienced observer, have a general similarity in size and color, but they are so completely segregated during the killing season prior to August I that no attempt at careful examination of individuals is necessary. The cows keep strictly to the breeding areas during the early part of the season and the bachelors to the hauling grounds with such rare exceptions that they need not be considered. Pups or yearlings of both sexes, so far as known, are identical in general appearance, but the males and females can be readily distinguished when handled. The skinner is always aware of the sex of any seal of any age the moment he takes it in hand to make the opening cuts. Cows or bulls of advanced age are easily distinguished from those of the early years of maturity, but the exact age of a given individual can not be known except in a few cases, and it is of no practical importance that it should be. Pups in their first season are distinctly characterized by color, though, as noted elsewhere, they may become so fat at 3 months of age as to weigh quite as much or more than yearlings. Bachelors in the fifth year develop the "wig" or mane, which serves as a mark of recognition in addition to increased size. The bachelors of 2,3 , and 4 years, however, are very similar in all general respects, and can be distinguished only by size.

\section{SPECIAL METHODS APPLIED IN 1914.}

Heretofore bachelors of certain average size have been regarded as 2-year-olds, those of the next size as 3-year-olds, and those of the next as 4-year-olds. Certain seals actually or apparently intermediate between the more or less vague standards have been classified as "long 2-year-olds," "short threes," or by similar terms. The actual age of any particular seal was never known with certainty, since no seals had been marked at birth and subsequently measured as they reached different ages. In I9I4 it was possible for the first time to measure seals positively known to be 2-year-olds, since a number of that age were present bearing distinctive brands placed upon them as pups in I9I2. With these 2-year-olds as a standard of comparison it was possible to determine the characteristics of the 3 -year-olds and the 4 -year-olds. As a further and very important check upon the conclusions a large number of skulls were preserved, furnishing unmistakable evidence of the relative age of different individuals. Furthermore, the standard of distinction adopted has been the one subject to the least variation, namely, the total length of the animal. It has long been recognized by zoologists and students of classification and variation that the total length measurement of mammals is the most constant and reliable one that can be taken. This dimension is not affected 
by any temporary condition of the animal causing it to be fat or lean, but is mainly dependent upon the length of the vertebral column, which varies only within very narrow limits. As shown beyond, especially under the discussion of 3 -year-olds, the use of this measurement makes it possible to classify bachelor seals with a high degree of accuracy.

\section{THE YEARLINGS.}

Definition.-A yearling seal has been defined as an animal which has attained its second summer, or one which has completed its first migration. The great majority of the pups are born in July, but some are born as early as the middle of June and a very few as late as the middle of August. The seals of any one generation, therefore, can vary in actual age but little more than 8 weeks, and for all practical purposes this variation may be disregarded. Seals found on the islands the year following that of their birth are and in fact must in practice be regarded as yearlings during the whole of that year or from the time they arrive at the islands on the return from their first migration until they leave to begin their second journey. The same principle applies to the other classes of young seals, each simply representing one generation in the herd. It is true that a provision of the law of 1910 , which fails to use the word yearling, conditionally prohibits the killing of "any seal less than I year old." But this prohibition is expressly stated to be subject to the "authority of the Secretary of Commerce" and to the needs of the natives for food. Moreover, the subsequent law of I9I 2 provides that male seals without restriction as to age may be killed as food for the natives. Therefore it is a matter of no practical importance whether the actual age of any given yearling be slightly more or slightly less than 12 months.

It is, of course, impossible to determine the exact age of individual seals, but the limited period in which births take place affords a means of approximation. Births occur in greatest numbers from the roth to the 20 th of July. After that date they rapidly decrease, and although a few usually occur during the first week of August, they represent the merest fraction of the total number. Births as late as August ro are of very rare occurrence. Among the very few records of such cases which have been found, one on August I4 and another on August 27 may be noted. ${ }^{a}$ In I914 the latest copulation recorded was on August $2 \mathrm{I}$, the cow engaged being an old one and her pup apparently but a few days old. It is evident, therefore, that yearling seals found in July may be slightly more or slightly less than i 2 months of age, that those found early in August are mostly more than that age, while of those found after August ro the chances are thousands to one that their age exceeds the exact year.

Limited knowledge of yearlings.-During early observations of seals, it was natural to expect that the yearlings, haring but little sexual instinct and being but poorly prepared to defend themselves in the rough-and-tumble of the hauling and breeding grounds, would have little reason or desire to come to land early in the season. It was also evident from the variation in the size of the pups in the fall and from the probable vicissitudes of the first migration that yearlings would be likely to present a wider variation in size than seals of older classes. These conditions have been recognized by most students of fur seals in the past and with some corroborative observations of the yearlings themsclves, it has generally been regarded as true that the yearlings come late to 
the islands in no large numbers and associate with the pups rather than with the older seals. But exact information as to their size and characteristics has been very limited. It is probable that 2-year-olds, especially 2 -year-old females, have been mistaken frequently for yearlings not only by the agents and other white men but by the natives, who have been regarded usually as expert in distinguishing the classes of seals. An incident early in the season of 1914 indicates that this may have been the case. During a killing on July I, the chief of the natives, John Stepetin, in charge of the clubbers, was asked if any yearlings were likely to appear, and upon his replying in the affirmative he was requested to point them out. A few minutes later, a small pod of seals was driven up and the native chief announced that it contained one yearling. Through misunderstanding a motion made by the chief in pointing out this seal, one of the clubbers struck it a blow and killed it. Therefore it was carefully measured and its skull was preserved. Subsequent study and examination proved conclusively that it was a 2 -year-old and not a yearling. It was, however, approximately as small as any seal in the drive or as any on the islands at that time or for several weeks later. Neither the agents nor the natives pay much attention to seals during the few weeks just following the killing season when the yearlings really appear, so it is not unlikely that they have sometimes assumed that the smallest seals present in June and July were yearlings.

Knowledge of the movements of yearlings and of their size and weight has been based largely on assumptions which, howerer justified by obsenation and lorical probabilities, have not been demonstrated beyond the possibility of doubt by definite experiment and exact record.

Records of yearlings. - In conformity with the spirit of the law, no yearlings were killed in 1914, but records and notes made in 1913 and not as yet published were found to include much valuable data. With the object of securing exact information in regard to yearlings, 5,529 pups were carefully branded in the fall of 1912 by direction of Special Investigator George A. Clark. In I913 Mr. Clark searched for examples of these branded animals to determine the yearling type, but up to the time of his departure from the islands (August 9), he records the examination of only one, on July 24. Later in the season, the agents and school-teachers on both islands continued to search for branded yearlings and found them only in very small numbers. Since these branded animals were the only undoubted yearlings upon which observations ever were made, the notes of the agents and school-teachers in the fall of 1913 are highly important. Prior to the month of August, as shown by the field notes of G. A. Clark, only one clearly branded yearling had been seen, on July 24, and during the remainder of the season until November I I only nine more were recorded. The very small number found led to the contention that many of the pups of I9I2 must have succumbed to the branding. Although this may have been a matter of uncertainty in 19r3, the large number of branded 2-year-olds which appeared in 1914 shows conclusively that it was not founded in fact. As indicating the thoroughness of the search for branded yearlings in 1913 , the following notes of Mr. A. G. Whitney, school-teacher on St. Paul, are of interest:

August I0. Spent an hour in the aftemoon watching the seals at Kitovi from fox cairn at Rock 8. Many cows and pups hauled back to edge of grass, and a hundred or more bachelors on the knoll at Rock Io. A yearling, with a perfect $T$ brand, playing with the pups and scampering about among the dozing cows. This yearling, scarcely larger than the huskiest pups, and although slenderer and more alert and agile, apparently no heavier than they. 
August I6. Hation reported three branded yearlings in the food drive made to-day.

August 27. Went out to Gorbatch (Rock I4) just before dark to observe the mass of seals there. Noted a number of very small seals, undoubtedly yearlings, among the cows and pups at upper edge of herd.

September 9. One branded yearling seen on Kitovi.

October I3: After closing school, I spent an hour and a half with Hatton searching for branded yearlings on Gorbatch, Ardiguen, and Reef, without success.

October I4. This being a school holiday, I spent all day hunting for branded yearlings. Hatton and two natives accompanied me. With glasses we thoroughly scanned every foot of rookery on Gorbatch, Ardiguen, Reef, Kitovi, Lukanin, and Tolstoi. Observed but one branded yearling (at Rock 2 , Gorbatch), which we were unable to catch.

October I7. After school, searched until dark for branded yearlings with Hatton and two natives on Gorbatch, Ardiguen, and Reef. The natives insisted that the yearlings are to be found among the bachelors, and never among the cows and pups. Although I knew better, we decided to cull over the bachelor herd (about 200) on Reef. A few possible yearlings were among them, but no brands. With our glasses we carefully worked over every bunch of seals along the rookery fronts.

October IS. As it was Saturday, Hatton and I spent the whole afternoon looking for branded yearlings. Hunted over Gorbatch, Ardiguen, and Reef carefully. Found but one brand, at Rock 2, Gorbatch, the same place where the one was seen October 14.

October i9. Spent half a day with a native searching for branded yearlings on Gorbatch, Ardiguen, and Reef, and then Kitovi and Lukanin. Found but one, at Lukanin, which we tried to snare, but he got away from us. This one was hauled up aroong a mass of cows and pups, and frisking about, as usual.

October 24. Spent the late afternoon on Reef Peninsula. Found a finely-branded yearling just in front of "Old John Rock" on Gorbatch, among the cows and pups.

November 4. Took charge of a "food-drive" at Northeast Point and attempted to procure branded yearlings. In a drive of 386 seals from a herd of a thousand or more near Sea Lion Point, there were no branded yearlings and scarcely any seals small enough to have been yearlings.

After the killing this morning, I took two natives and returned to the rookeries to search again for yearlings. Only 50 bachelors hauled out where we drove from last evening and these all threeyear-olds or older. Went to bluff at front of Hutchinson Hill and looked over the big mass of cows and pups there for half an hour. Saw no branded yearlings, but a dozen or more very small seals that I am sure were yearlings scattered along the edges of the herd, mostly on the sandy area just in front of the bluff.

November 10. A drive was made from Reef, but it contained no branded yearlings, out of a total of 400 seals driven.

November II. While on a trip after the reindeer, Hatton saw one branded yearling at Polovina Rookery.

The total number of branded yearlings noted in I9r3 on St. Paul Island may be summarized as follows:

Branded yearlings seen on St. Paul Island, IgI3.

\begin{tabular}{|c|c|c|c|}
\hline Date. & Rookery. & $\begin{array}{c}\text { Number } \\
\text { seen. }\end{array}$ & Observers. \\
\hline July . & Reef. & I & \multirow{8}{*}{$\begin{array}{l}\text { G. A. Clark, W. I. Lembkey, and } \\
\text { A. G. Whitney, } \\
\text { Mr. and Mrs. A. G. Whitney. } \\
\text { P. R. E. Hatton. } \\
\text { A. G. Whitney and P. R. E. Hatton. } \\
\text { Do. } \\
\text { A. G. Whitney. } \\
\text { Do. } \\
\text { P. R. E. Hatton. }\end{array}$} \\
\hline A山工. I & Kitovi........ & I & \\
\hline If & Reeí....... & $i$ & \\
\hline Uct. I & Gorbatch & I & \\
\hline I & Lukauin & 1 & \\
\hline$\therefore \quad 2$ & Gurbatch & I & \\
\hline \multirow[t]{2}{*}{ Now. I } & Foluvins. & I & \\
\hline & Total & Io & \\
\hline
\end{tabular}


On St. George Island, a much larger number was seen, the total being 74, but here, as well as on St. Paul, it was impossible to be certain that some animals had not been counted more than once, so the total is a maximum. The observations on St. George Island, as shown bv the notes of Messrs. Proctor and Hanna, were as follows:

Branded yearlings seen on St. George Island, IOr3.

\begin{tabular}{|c|c|c|c|c|}
\hline Date. & & Rookery. & $\begin{array}{c}\text { Number } \\
\text { seen. }\end{array}$ & Observer. \\
\hline $\begin{array}{l}\text { Aug. } \\
\text { Sept. }\end{array}$ & $\begin{array}{r}16 \\
26 \\
30 \\
4 \\
4 \\
6 \\
13 \\
17 \\
18 \\
21 \\
26 \\
5 \\
10 \\
25\end{array}$ & 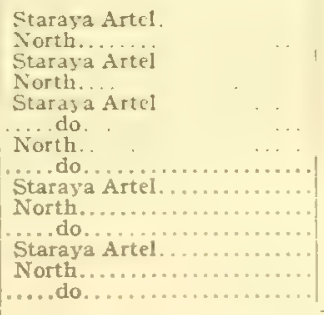 & \begin{tabular}{r|}
2 \\
2 \\
2 \\
2 \\
1 \\
2 \\
1 \\
3 \\
5 \\
4 \\
3 \\
10 \\
12 \\
25 \\
\end{tabular} & \multirow[t]{2}{*}{$\begin{array}{l}\text { A. H. Proctor. } \\
\text { G. D. Hanna. } \\
\text { Do. } \\
\text { Do. } \\
\text { Do. } \\
\text { Do. } \\
\text { Do. } \\
\text { Do. } \\
\text { Do. } \\
\text { A. H. Proctor. } \\
\text { G. D. Hanua. } \\
\text { A. H. Proctor. } \\
\text { Do. } \\
\text { Do. }\end{array}$} \\
\hline & & Total St. George Island - I & 74 & \\
\hline
\end{tabular}

Efforts to obtain specimens of branded yearlings and records of weights and measurements on St. Paul Island were unsuccessful, but on St. George three of the animals were secured and two others obviously of the same age, but unbranded. These were measured and weighed in the presence of Agent Proctor by MIr. Hanna, who is an experienced zoological collector accustomed to measuring animals. The data obtained and certified to by Messrs. Hanna and Proctor follow:

Measurements and weights of male ycarlings, St. George Island. a

\begin{tabular}{|c|c|c|c|c|}
\hline Date. & Length. 8 & $\begin{array}{l}\text { Weight of } \\
\text { animal. }\end{array}$ & $\begin{array}{l}\text { Weight of } \\
\text { skin. }\end{array}$ & \\
\hline $\begin{array}{l}\text { I9I3. } \\
\text { Aug. } 16 \\
\\
\text { Nov. } 5 \\
\text { Oct. } 51 \\
\end{array}$ & $\begin{array}{c}\text { Inche's. } \\
37 \\
35^{3} / 8 \\
36 \\
342 / 8 \\
35 \% 14\end{array}$ & $\begin{array}{cc}L b s & \text { oz. } \\
39 & 4 \\
37 & 8 \\
41 & 12 \\
39 & 15 \\
33 & 10\end{array}$ & $\begin{array}{rr}\text { Lbs. } & a_{2} \\
4 & 6 \\
3 & \mathrm{I3}_{3} \\
c_{5} & \mathrm{II} \\
c_{5} & 2 \\
c_{4} & \mathrm{I3}_{3}\end{array}$ & $\begin{array}{c}\text { Branded. } \\
\text { Do. } \\
\text { Do. } \\
\text { Not branded. } \\
\text { Do. }\end{array}$ \\
\hline
\end{tabular}

a Since these were taken after Aug. Io, the assumption is justified that they were from a few days to several weeks more than Is months of age.

$b$ Length of animal from tip of nose to root of tail, taken with tapeline before skinring.

$c$ This weight is inclusive of the skin of the bead; the other weights are of skins prepared in the usual manner, without the head skin or "mask."

Although yearlings may have been recognized and measured in the past, these figures are the first and only available ones based on the examination of seals of positively known age. The weights of the two skins taken in the usual manner are well below 5 pounds, the minimum prescribed by the Government regulations for killings in past years. The others weighed somewhat more, owing to the inclusion of the headskin or "mask," which is ordinarily left on the carcass. Such a mask from a skin of only 3 pounds $83 / 4$ ounces total weight was weighed August i 8 , I 9 r 4 , and found to weigh $3 \frac{3}{4}$ ounces, or 6.2 per cent of the total weight. With allowance for this extra weight it is seen that even the skin taken November 5, and therefore from an animal of some i 5 months of age, only slightly exceeded 5 pounds, and all the others were less than that.

$$
84512^{\circ}-\mathrm{S} . \text { Doc. } 980,63-3-5
$$


The total body weights of these yearlings, taken immediately after killing and before bleeding or skinning, are interesting in comparison with weights of pups taken late in the season. They indicate that after the pups leave the islands, fattened by an easy life and ample nourishment from their mother's milk, they lose weight, and many of them may actually return to the islands the following summer weighing less than when they left. Under instructions to weigh six of the smallest pups and six of the largest to be found on November 17, I914, Agent Fassett submitted the following results: Average of smallest four weighed $25 \frac{9}{10}$ pounds; average of next smallest four, $33 \frac{1}{10}^{2}$ pounds; average of largest four, $48 \frac{8}{10}$ pounds. Individual weights, recorded in pounds, were as follows: $24 \frac{3}{4}, 251 / 2,253 \frac{1}{4}, 273 / 4,423 / 4,431 / 2,491 / 4,513 / 4$. The average weight of the four smallest and the four largest is 37.3 pounds, which may be taken as a fair average for November pups; this is only slightly less than that of the yearlings. The great variation in the weight of gray pups is doubtless due in part to early or late birth, but it is evident that this is largely compensated during the first long hard winter at sea, when the weaklings succumb and general vigor rather than mere weight determines survival, so that on the return to the islands the yearlings as a class show comparative uniformity.

Moiements of ycarlings. - The observations of branded yearlings in 19r3, particularly those of Mr. A. G. Whitney, who has kindly submitted his notes for examination, show that yearlings first appear in very small numbers late in July, and that they are seen in greater numbers in August and later months. They are seldom found on the hauling grounds with the bachelors, but prefer the areas occupied by the cows and pups, being found most frequently near the shore engaged in play with the pups, which they do not greatly exced in size. All specimens taken were of the male sex. Observations made in $191+$ confirm those of 1913 in all important respects. Although no branded yearlings were present in 19I4, the identification of seals of this class was rendered comparatively certain by the knowledge of the observations made the previous year, and especially by the presence of known 2 -year-olds with distinctive brands, which were practically always available for comparison. During the entire month of July the hauling grounds were repeatedly scrutinized for yearlings, but at no time were any seals seen that were smaller than the known branded 2 -year-olds. In the same way all food drives from July i to August is, in which seals to the total number of 5,105 were passed in review in small pods under close examination, showed nothing smaller than 2-year-olds. The first yearlings were observed August 17, and after that date others were seen frequenty. Of those seen, however, only two were among the bachelors, and even these may have been frightened away from the margin of a breeding area by the natives in rounding up the bachelors. In riew of these facts it seems highly improbabie that yearlings ever resort to the hauling grounds in numbers, and it is practically conclusive that during the killing season, which ends July $3 \mathrm{I}$, they seldom come to land at all.

Observations of yearlings made in 1914 are indicated by the following extracts from the field notes of W. H. Osgood:

August 17. Started at 7.I5 a.m. for Northeast Point with Preble, Macoun, Hanna, Ball, and four natives. Macoun stopped to botanize at Polovina. Went out (on Vostochni Rookery) and drove bachelors for branded 2-year-olds and clipped 3I; also saw one St. Paul return and one St. George return. Counted pods to a total of 2,945 , and fully $x, 000$ got away into the water and elsewhere, and 
were not driven. Not the least doubt that there were over 4,000 bachelors hauled; many were in with the cows and could not be herded. In all this number of seals only two were seen that by any possibility could have been yearlings. These Hanna thitiks undoubtedly were yearlings, and he was the only one of the party that ever had seen any before. I was well enough convinced of it, for they were obviously smaller than the 2-year-olds, the size of which is, of course, very well fixed in our minds after all the branded ones we have observed during the summer. Only two in a drive of practically 3,000 seals, however, shows that they are on land in very small numbers, and I am positive we have not seen any earlier in the season.

August 20: Went to Tolstoi and watched seals. * * * Saw two seals (among the cows) that appeared to be yearlings.

August 2I: This afternoon went to Gorbatch for a short time and found many bachelors on the "Parade Ground," perhaps eight or nine hundred, including a number that were hauled out on the plateau extending between Gorbatch and Reef. Was rather surprised to note a copulation near Rock I4. The bull was an old harem master and the cow not very young. Her pup was quite small, evidently only a few days old. Saw a couple seals I think were no doubt yearlings (near Rock I4).

August 23: On Lukanin, saw a very small yearling not much larger than one of the largest pups.

August 24: With a little search, yearlings can be found on any of the rookeries now.

August 25: Went to Kitovi. * * * Saw a number of yearlings ( 15 or 20) along the edge of the water playing with the pups and with each other. Went to Tolstoi again in the afternoon. I,arge hauling of bachelors on beach. Saw a branded 2-year-old cow among them and photographed her at short range with a 3 -year-old bachelor that was paying her attention. Saw two or three yearlings near the water's edge with the pups. Preble tells me he saw at least a dozen among some pups at the edge of the water at Zapadni to-day. I don't believe they associate with the bachelors much more than the pups do.

August 28: Went over Reef, Ardiguen, and Gorbatch looking especially for yearlings and crossbranded 5-year-olds. * * * Saw a couple yearlings on Gorbatch and a half-dozen on Reef, in both cases associated with the cows.

\section{THE 2-YEAR-OLDS.}

Twa-year-old males.-Early in the season of 1914 seals began to be noted in the food drives having the clearly marked $T$ brand on the top of the head. These were animals branded as pups in 1912 and therefore were undoubted 2-year-olds in I914. As yearlings they had been noted in 191.3 in small numbers and only late in the season, but as 2-year-olds in 1914 they appeared as early as June 12, and soon became fairly common. As many as 32 were recorded in a single food drive of only 566 bachelors on July 25 on St. George Island. Throughout the period from June 22 to August 28 failure to find at least several of these branded 2-year-olds on any hauling ground was a rare occurrence. The brands were clear and distinct and easily recognized, making it possible by the use of field glasses to note branded animals at a distance of oo yards or more and to compare them with the other bachelors hauled without any disturbance of the herd. Allowing the ustual deductions for natural mortality, not over 1,20o males of the total branding of 5,529 pups of both sexes should have survived to the age of 2 years. Therefore it was not to be expected that any large number of them would be seen at any one time or place. However, an effort was made to keep a definite record of those which appeared. In order that none should be counted twice, the branded animals were caught and marked by clipping the hair from one side of the head and no record was kept of any except those so marked. Owing to pressure of other matters, it was not possible to make more than two special drives for this purpose, so the seals marked and recorded were for the most part limited to those appearing in the food drives. Moreover, through misunderstanding of instructions, the work was not continued through August and September by the agent and was not resumed until late in October and 
November, when a large proportion of the herd had left the islands. Nevertheless, a total of 315 was recorded, and it is evident that many more were present at times when no enumeration was made.

During the season, I, 3 branded 2-year-old males were killed at food killings and subjected to special examination. Three others taken in November have been reported upon by Agent Fassett. The data obtained from these examples are given below:

Measurements and ucights of 2-jear-old males.

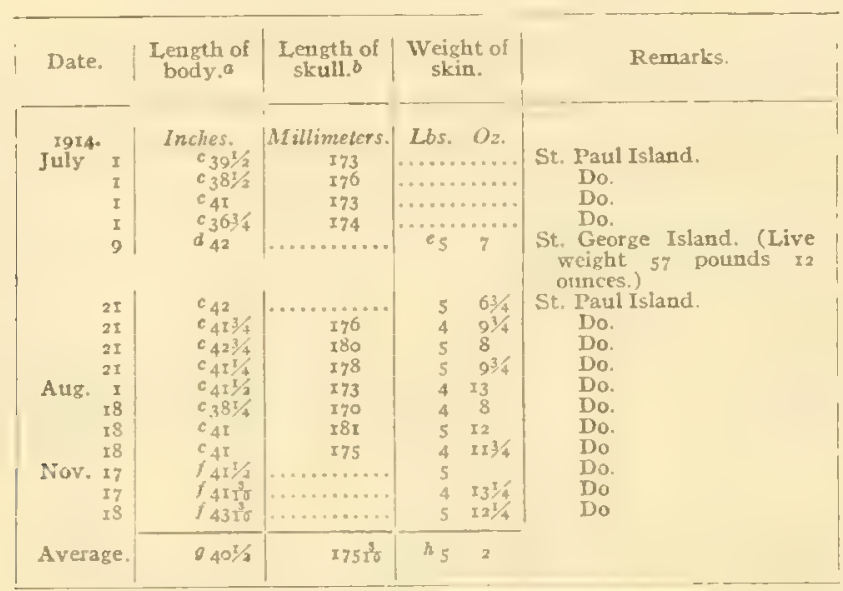

a From tip of nose to root of tail.

c Measured by WV. H. Osgood, G. H. Parker, and E. A. Preble.

d Measured by G. D. Hanna and A. H. I'roctor.

eIncluding skin of head.

f Mreasured by G. D. Hanna and H.C. Fassett.

$f$ Measured by $\mathbf{G}$. D. Hanna and $\mathbf{H}$.

$h$ Light skins taken July $2 \mathrm{I}$-August 18.

Two-year-old females. - The 2-year-old females begin to land at about the height of the season or just before the harems of old cows have broken up. They become more numerous after the break-up but are never seen in large numbers. Some of them join the regular harems and remain for perhaps two or three days, but as a rule they do not stay long in one place. In a few cases, small harems composed exclusively of 2 -year-olds may be seen but this is exceptional. Probably many of them are served near the water and never reach the rookery ground beyond. Although not always distinguishable with certainty from young cows of three or perhaps four years, they have certain characteristics which would doubtless be recognized by an experienced observer in practically all cases. They are generally very fat and sleek and seem relatively short-bodied with short front flippers, very light-colored breasts, and short dark whishers. These characters are not absolutely distinctive, but when combined with observation of the general appearance and actions and the indifference to the pups, they serve to make the identification of the z-year-old female fairly certain. These females enter the rookery ground with obvious hesitancy; their whole demeanor is that of inexperience and coyness, and they take flight at the slighest alarm. A few of them occasionally stray to the hauling grounds, and when once there sometimes persist in remaining until literally driven into the sea by the unwelcome attentions of the younger bachelors. During the season of 1914 , with one exception, the only females found in drives were 2 -year-olds. 


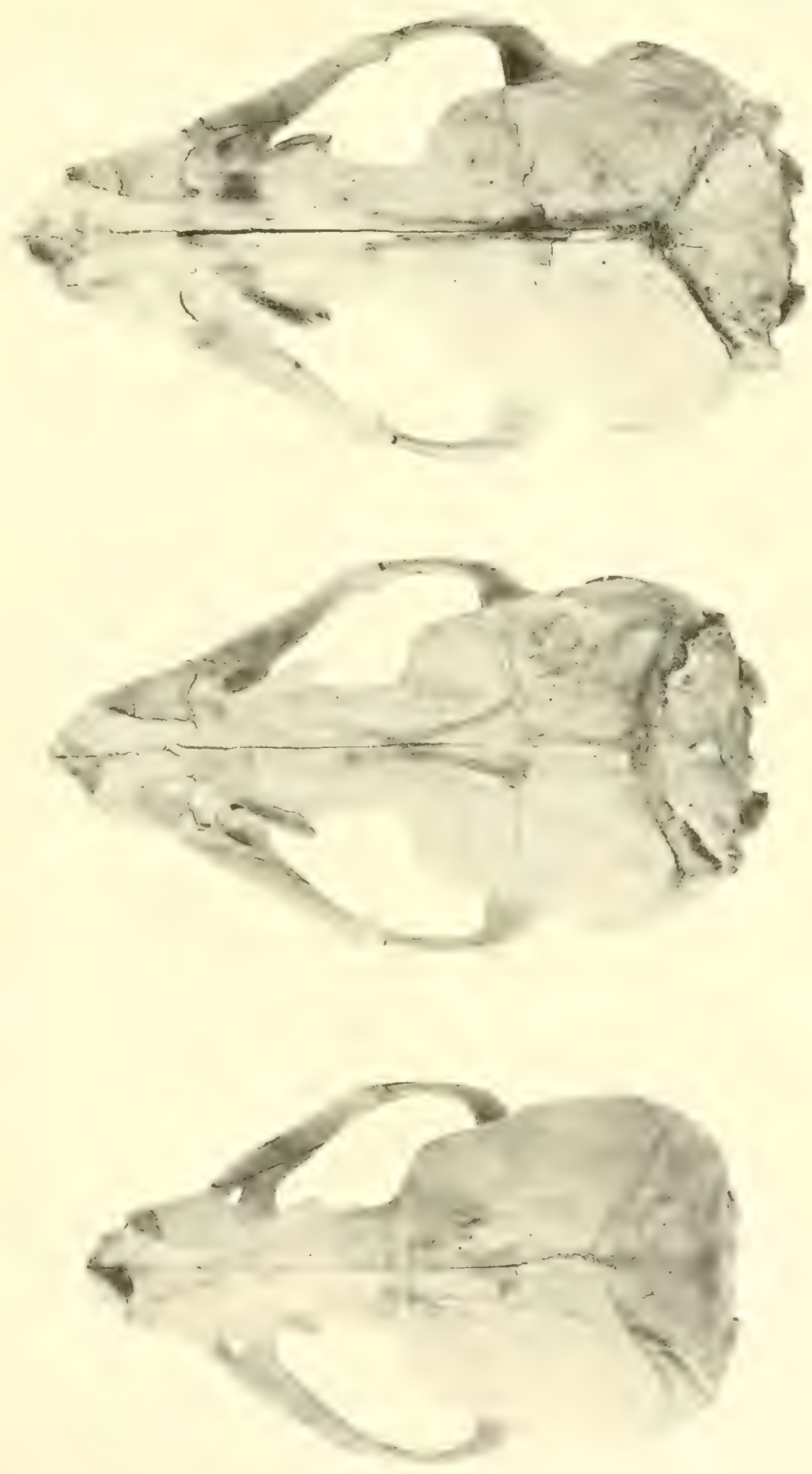

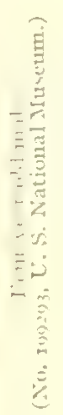

$r$
r

送 

Although branded 2-year-old males were seen in numbers in 1914, females with brands were observed in only Io instances, probably because the females remain on land but a short time. The first branded females were seen on Polovina on July 19. In company with some 20 others apparently of the same age, three of these branded animals were observed on a gravel beach beneath a low bluff at the north end of the rookery. They were in charge of a small 5 -year-old bull who made a futile effort to hold them and then followed as they all rushed into the sea. During the next ro days a few females, believed to be 2-year-olds, were seen but none branded. On August I, in a drive from Reef rookery, a branded female was accidently killed. On August i a branded female was noted near Rock $\mathrm{I}_{4}$ on Gorbatch wandering over the breeding ground obviously unattached to any particular place. Another seen on Reef August I 3 was among some older cows apparently held by an old bull, but, as the old cows made for the water, the bull followed and a young bull quickly made advances to the 2-year-old cow which remained. On the Tolstoi sands August 25 a branded cow was found among the bachelors being harassed by a 3 -year-old whose attentions were vigorously resented, the cow tumbling about plainly seeking a place where she might he undisturbed. Still later, on August 28, two branded cows were seen playing together in the irregular mass of cows, pups, and roving bachelors on the breeding ground of Reef Rookery. Late in the season, on November $I_{7}$, as reported by telegraph, a branded 2 -year-old female was accidently killed in a food drive from Tolstoi rookery. The sizes and weights of the 2-year-old females which died through overheating or by accident in drives in I9I 4 are as follows:

Measurements and weights of 2-year-old females.

\begin{tabular}{|c|c|c|c|c|}
\hline Date. & Length. & $\begin{array}{l}\text { Weight of } \\
\text { skin. }\end{array}$ & $\begin{array}{c}\text { Live } \\
\text { weight. }\end{array}$ & Remarks. \\
\hline $\begin{array}{r}\text { I9I4. } \\
\text { Aug. I } \\
\text { I8 } \\
\text { I8 } \\
\text { Nov.I7 } \mathrm{e}\end{array}$ & $\begin{array}{c}\text { Inches. } \\
38^{3 / 4} \\
39 \\
38 \\
45^{1 / 4}\end{array}$ & $\begin{array}{rc}\text { Lbs. } & 0 z . \\
3 & 14 \\
\ldots . & \cdots \\
3 & 5 \\
5 & 7\end{array}$ &  & $\begin{array}{l}\text { Branded, } \\
\text { Unbranded.a } \\
\text { Do. a } \\
\text { Branded. }\end{array}$ \\
\hline
\end{tabular}

a The determination of the age of the unbranded animals is made positive by exanination of the skulls which were preserved and compared with those of the branded animals.

$b$ Although no other weights of 2 -year-old females were obtained, it was evident that this was an exceptionally small example; until its skull was examined it was thought to be a yearling.

c Measured and weighed by $\mathbf{H}$. C. Fassett.

\section{THE 3-YEAR-OLD BACHELORS.}

The presence of numerous branded 2-year-olds of known age in I9I4 made the identification of the 3 -year-olds comparatively certain. Owing to the importance of this class as the one from which killings and reserves are taken, a special effort was made to determine its characteristics. With this end in view, a large number of supposed 3-year-olds killed for food were carefully measured and their skins weighed. In addition the complete skull of each was preserved and tagged with a number corresponding to the number attached to the skin. These skulls were then brought to the National Museum and there prepared for study. In the same way, skulls were preserved of the branded 2-year-olds taken and of a small number regarded by the natives as 4-year-olds, 5-year-olds, and 6-year-olds. Using these skulls as a check on the measurements taken in the field, it was possible to determine with a high degree of 
accuracy the age of any particular seal, to test the judgment of the natives, and to learn the range of variation in size among seals of a given class. Thus, if a supposed 3-year-old showed a small body measurement it was possible to examine its skull and compare it with that of a known 2-year-old and so lean whether it was in reality a small 3-year-old or a 2-year-old mistaken for a 3-year-old. As the combined result of field observations and measurements and the study of skulls and teeth, it was found that the total length of 3 -year-old bachelors is subject to but little variation, and that the natives are able to distinguish seals of this class with a very small percentage of error.

During a food killing on July I, 1914, at which the native clubbers were instructed to proceed as usual and kill only 3 -year-olds, 37 seals taken at random as they were killed were carefully measured with a steel tape and their skulls tagged and preserved. Thirtyfive of these proved to be undoubted 3 -year-olds, one was a 2 -year-old, and one was larger than the others and may have been a small 4 -year-old. The total length varied from 45 to 52 inches and in 71 per cent of cases it was from 46 to 48 inches. At a later killing on August 10 , 61 seals were measured in similar manner, using calipers instead of tape, which gave a slightly smaller result in each case but the same telative uniformity prevailed. One of the $6 \mathrm{I}$ proved to be a 2 -year-old and the remaining 60 were undoubted 3 -year-olds. The length measurement varied from $42 \frac{1}{2}$ to $5 \mathrm{I}$ inches and in 93 per cent of cases was from +4 to 49,2 inches. Such uniformity is not found in the weight of the animals, which may be fat or lean, nor in the weights of the skins, which vary according to the amount of blubber removed. It is found in the skulls, however, and these serve to corroborate the accuracy and significance of the length measurements. The seals of any two generations differ from each other as a class by not less than ro months in age, and since in the males there is a rapid growth from 2 until 6 years of age, it is evident that differences due to age are likely to be more pronounced than those due to individual variation. A study of skulls proves this to be the case, and with rare exceptions the age of any given skull may be determined upon the basis of growth characters familiar to students of osteology. With the skull, as with the animal, the length measurement is the principal reliance, although other characters are considered. The skull of a newly born pup is short with a broad flattened braincase having no bony ridges or prominences; the facial part of the skull is relatively undeveloped and the teeth are just beginning to appear. In the 2-year male these conditions in general still prevail, although the bone has thickened and the skull become more lengthened. In the 3 -year-old a more definite lengthening has taken place, the braincase is higher and relatively narrower, and ridges and prominences begin to show. This process is carried farther in the 4-year-old and in succeeding years until in the old male the skull which began smooth and flat becomes relatively high with various prominences and a high bony ridge extending lengthwise over the top of the braincase. (See pl. Ix and $\mathrm{x}$.)

The data obtained from the 3-year-olds measured on July I, 1914, of which all the skulls were preserved, are as follows: 






FUR SEALS AND OTHER LIFE, PRIBILOF ISLANDS, I 9 I4.

Measurements of 3-year-old males, with weights of skins, St. Paul Island, July I, IOI4.

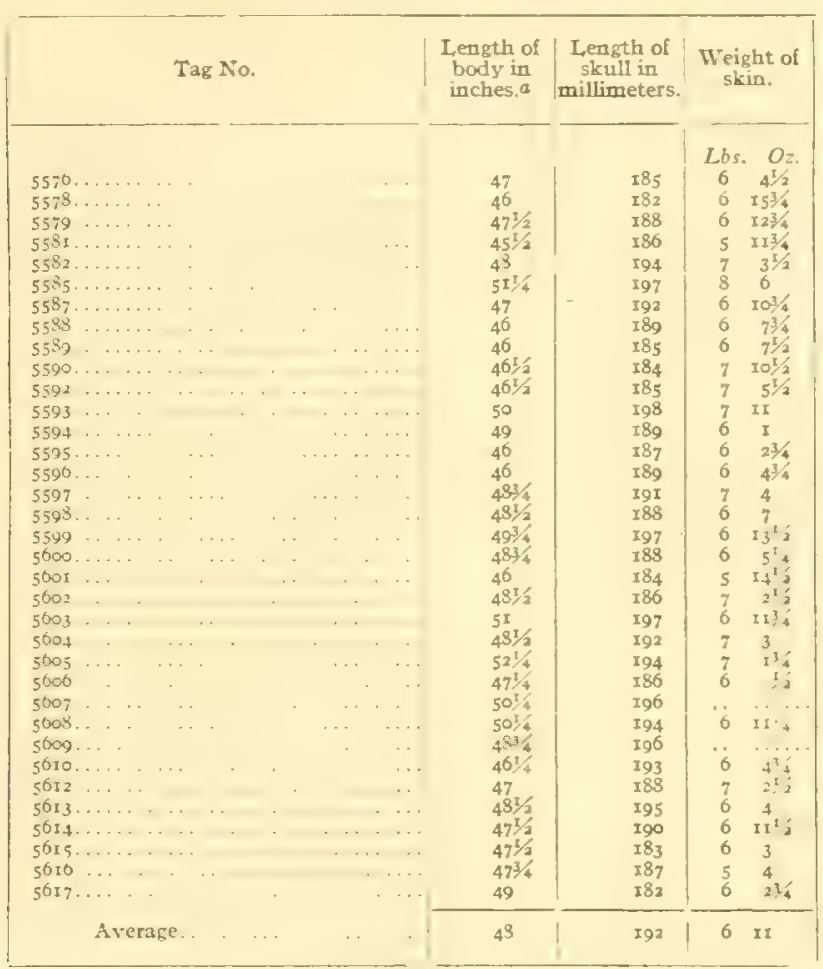

a These measurements were taken with a steel tape stretched over the back of the animal from the tip of nose to the root of tail. Measurements taken with calipers give slightly smaller figures.

\section{THE 4-YEAR OLD BACHELORS.}

The 4-year-olds associate with the younger bachelors on the hauling grounds, and though some of them may be distinguished by their dark breasts and occasionally by an incipient "wig," as a class they differ from the 3-year-olds mainly in slightly increased size.

Only a few 4-year-olds were killed in 1914, and most of these had their skulls so badly shattered that they were not preserved. The data as to 4 -year-olds, therefore, are somewhat meager. In the case of five examples they are as follows:

Measurements of 4-year-old males, with weights of skins, ror4.

\begin{tabular}{|c|c|c|c|}
\hline Tag No. & $\begin{array}{l}\text { Length of } \\
\text { animal in } \\
\text { inches. }\end{array}$ & $\begin{array}{l}\text { Length of } \\
\text { skull in } \\
\text { millimeters. }\end{array}$ & $\begin{array}{l}\text { Weight of } \\
\text { skin. }\end{array}$ \\
\hline 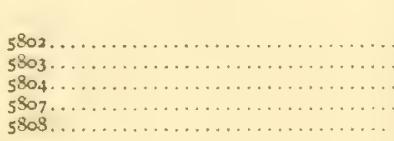 & $\begin{array}{l}58 \\
53^{1 / 2} \\
57^{1 / 4} \\
56^{1 / 4} \\
52\end{array}$ & $\begin{array}{l}202 \\
205 \\
208 \\
207 \\
204\end{array}$ & $\begin{array}{rr}\text { Lbs. } & \mathrm{Oz} . \\
8 & 13 \frac{1}{4} \\
8 & 3 / 4 \\
9 & 5 \\
8 & 41 / 4 \\
8 & 814\end{array}$ \\
\hline
\end{tabular}




\section{SUMMARY OF MEASUREMENTS.}

In view of the foregoing, it is evident that bachelor seals of various ages can be distinguished with a high degree of accuracy; that the difference between them is best expressed in the total lengtl of the animal taken before it is skinned; and that weights, either of animals or of skins carrying varying amounts of blubber, are unreliable as a criterion for age. As stated elsewhere, therefore, it is desirable that the classification of seals killed be made upon the basis of measurement rather than weight. It should be said, also, that the native clubbers are able to distinguish seals of different ages with very few exceptions, and that a system of measurement in the field would tend to increase their efficiency and reduce their mistakes to a minimum. The measurements made in Igrt may be subject to slight revision with further experience and practice, but in general it seems safe to state that, with possible rare exceptions, yearlings have a body length between 34 and 37 inches; 2 -year-olds between 37 and 43 inches; 3 -year-olds between 43 and 52 inches, and 4 -year-olds between 52 and 59 inches. The data on the several classes are summarized below:

Condensed measurements of young males.

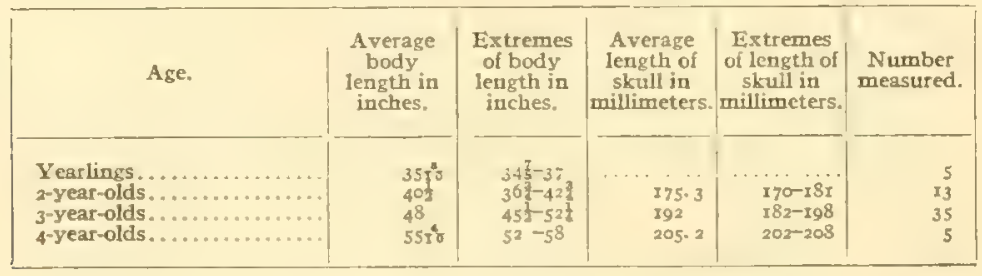

\section{MORTALITY OF SEALS.}

\section{DEATH OF PUPS ON LAND.}

In making the pup count between July 29 and August 5, the number of dead pups, as well as of live ones, was regularly recorded. When the rookeries were on a narrow stretch of beach, the dead pups were enumerated as they were passed over in counting the live ones. Where the rookeries spread out over extensive areas, however, these areas were examined for dead pups after the live ones had been comted. In the following table are given the total numbers of pups, the numbers of dead pups, and the percentages of dead pups in 1914 for each rookery on the two islands as ascertained at the time of the count of pups, July 29 to August 5. 
Mortality of pups, summer of 1914 .

\begin{tabular}{|c|c|c|c|}
\hline Rookeries. & $\begin{array}{l}\text { Total of } \\
\text { pups. }\end{array}$ & Dead pups. & $\begin{array}{c}\text { Percentage } \\
\text { dead. }\end{array}$ \\
\hline \multicolumn{4}{|l|}{ St, Paul Island: } \\
\hline Kitovi. . & 2,119 & 47 & 2.2 \\
\hline L,tukanin..... & $I, 834$ & 73 & 3.9 \\
\hline Gorbatch... & 6,152 & 85 & 1. 3 \\
\hline Ardiguen & 656 & II & I. 6 \\
\hline Reef $\ldots . . . \ldots \ldots \ldots . . . . . .$. & 13,559 & 206 & I. 5 \\
\hline Sivutcli.......... & 4,052 & 68 & I. 6 \\
\hline Lagoon... & 375 & 2 & .5 \\
\hline Tolstoi. & 9,934 & 174 & 1. 7 \\
\hline Zapadui........ & 7,625 & I26 & I. 6 \\
\hline Iittle Zapadri. & 4,919 & 79 & I. 5 \\
\hline Zapadni Reef......... & 206 & 3 & 1. 4 \\
\hline Polovina...... & 3,555 & $7 I$ & 1. 9 \\
\hline Polovina Cliffs.... & $I, 449$ & 18 & I. 2 \\
\hline Little Polovina... & 927 & $x 7$ & 1. 8 \\
\hline Morjovi......... & $2,3 \times 2$ & 44 & 1. 8 \\
\hline Vostochni. & 19,709 & 499 & 2. 5 \\
\hline Total.. & 79,483 & $x, 523$ & I. 9 \\
\hline \multicolumn{4}{|l|}{ St. George Island: } \\
\hline North.... & $5,30 \mathrm{r}$ & II2 & 2. I \\
\hline Staraya Artel. ......... & 4,278 & 63 & I. 4 \\
\hline 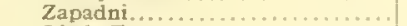 & 1,023 & 8 & .7 \\
\hline Little East.............. & 26 & I & 3.8 \\
\hline East Reef... & $5^{8 I}$ & 5 & .8 \\
\hline East Cliffs & 2,658 & 3 I & I. I \\
\hline Total.. & 13,767 & 2201 & I. 5 \\
\hline Grand total ................ & 93,250 & $I, 743$ & 1. 8 \\
\hline
\end{tabular}

It will be seen from this table that the mortality of pups up to about August 5 was 1.8 per cent of the total number born and that no rookery diverged far from this percentage. The highest death rate was on Lukanin, 3.9 per cent, and the lowest on Lagoon, 0.5 per cent. These figures show conclusively that during the season of I9I4 there were no noteworthy epidemics of any kind among the pups.

The dead pups were usually found on the rookery grounds, and often gave evidence of having been dead several weeks. Some few, particularly on Reef and on Tolstoi, had been dragged away by the foxes and their remains were found at the mouths of the fox burrows on ground adjacent to the rookeries. As there was no evidence of any epidemic, the dead pups were not especially examined. It is probable, as Marsh has pointed out (Science, vol. 36, p. 397, 1912), that starvation, asphyxia neonatorum, and crushing by rocks and landislides are the chief fatal accidents of early life, and that uncinariasis is the principal fatal disease of this period. In a report made by Marsh in rgra to the Department of Commerce and Labor on the causes of death of 175 pups examined in that year, $8 \mathrm{x}$ ( 46 per cent) were believed to have died of starvation, 24 (I4 per cent) of asphyxia neonatorum, ig (I i per cent) from accidents due to landslides, etc, and 12 ( 7 per cent) to uncinariasis. These four causes were believed to be the chief occasions of death among the young pups in the season of 1912. Since the death rate in that season was estimated at 1.2 per cent of the total number of pups bom, and since in 1914 this rate was much the same, I. 8 per cent, it seems probable that the causes of death already enumerated have continued to act in 1914 as in 1912.

An inspection of the table will show, as already pointed out, considerable uniformity so far as the death rates of the various rookeries are concerned. The chief divergences in the direction of larger numbers are to be seen in Little East Rookery on St. George, and in L,ukanin and less so in Vostochni on St. Paul. In Little East Rookery the condition is a mere accident due to the small total number of pups present and in Lukanin, 
which shows the most considerable divergence of all, the increase is scarcely noteworthy. In Vostochni a state of affairs was observed which may explain its slight excess.

In this rookery there has always been a very large area between Hutchinson Hill and the sea covered with a relatively enormous aggregation of harems. At the height of the season and later, this area has upon it a dense population of pups. On its sides are extensive hauling grounds for bachelors, with runways leading to the sea. Pups may stray to the ground occupied by the bachelors, become lost, and eventually die of starvation or of mistreatment from the bachelors, for the latter were often seen mauling pups and even attempting to copulate with them. Since not a few of the dead pups. recorded for Vostochni were found well within the hauling grounds, some of them bearing the tonthmarks of the bachelors, it is highly probable that they met their deaths in the way indicated and thus Vostochni may have suffered in this respect somewhat more than most of the other rookeries. Large numbers of bachelors close to aggregated harems certainly afford, as just indicated, unfavorable conditions for pups, though as a cause for their death, this condition is not to be compared in the number of victims that it claims with such other causes as starvation, asphyxia neonatorum, etc.

\section{DEATH OF YOUNG SEALS AT SEA.}

The first year is universally considered as the most fatal in the life of seals, the loss during this period by natural causes, though necessarily unknown, being assumed to be 50 per cent. Since the loss from all causes during the first month or so of life, before the animal has learned to swim, is seen to amount to less than 2 per cent, it follows that other and very potent causes must operate.

During the few weeks following the time the animals have learned to swim, deaths from starvation must continue to form a considerable proportion of the total loss. The young animals now wander farther and farther from the spot where they were born, and by late August may be found in numbers at a distance of a mile or more from any breeding place. It necessarily follows that the mothers, on retuming from feeding, must experience increasing difficulty in finding their offspring, and the conclusion is unavoidable that some are never found and are thus deprived of the natural means of subsistence. Little is known regarding the time when the young seals first learn to shift entirely for themselves. Although they may pick up a small amount of food while paddling about the shores in the early autumn, it is not likely that they actually leam to fish until they leave with the older seals on their first migration. The search for dead pups in early fall has always resulted in a considerable addition to the number of dead as taken at the time of the regular count.

While the young pups are still about the islands in autumn many are destroyed by killer whales (Orca gladiator), which are frequently observed singly or in small schools cruising about in front of the rookeries and are known to prey especially on the pups. The following actual records of killer whales observed about St. Paul Island in autumn, selected from a large number of observations taken from the island log by the late Dr. Hahn, indicate to some degree the part played by them in the destruction of young seals. A large school of killers was seen near East Landing on October 21, 1875, and five near the same place on September 2I, 1891; one seen off Reef Rookery on December 2, 1902, was playing havoc with a band of seals; fragments of both cows and pups, the work of killer whales, were found strewn along the beach at Northeast Point on November 6, 1904. In the autumn of 1907 killers were reported on numerous occasions, 
and native watchmen at Northeast Point and Polovina reported considerable destruction. A killer 24 feet long was stranded at Northeast Point on December r6, Igo8. On November 1, I913, G. Dallas Hanna observed three killers close to the reef near the village of St. George preying on the seal pups. Two of these came so close to the bluffs that he was able to hit them with a rifle and killed at least one.

These records indicate that killer whales are by no means uncommon about the Pribilofs. The stomachs of two killers examined by Capt. Bryant contained, respectively, I8 and 24 seal pups, ${ }^{a}$ and it is certain that the total number of young seals killed by them must be very great.

\section{DEATH OF ADULT SEALS.}

Regarding the death of seals at sea from natural causes little is known from actual observation. Deaths from old age usually take place at sea and probably result mainly from the animals being unable because of infimity to procure food. There is good reason to suppose that a very considerable loss of adults is caused by killer whales. The fact that these destructive animals are frequently observed about the Pribilofs at the time of the arrival of the main body of the seals strongly suggests that they attend the seal herd on its migration. Entries from the St. Paul journal before referred to show that many killers were seen on June 6,1877 , and several seals bearing evidence of having been attacked by them were observed; many were observed between St. Paul and Walrus Island on June 6 and 8, I88r; they were numerous May I5, I884, and May I9, I886, and on the latter date both the seals and sea lions were taking to the shore at Northeast Point to escape them; many were seen close to shore on May 28, I888, and an entry of May 3I, I889, asserts that the natives reported killers more numerous that spring than at any time within their memory. On June I, I 894, a school of these whales was killing seals at Kitovi and near East Landing, and several were shot with rifles. Other records of killers, in some cases accompanied by the specific statement that they were preying on seals, occurred under the following dates: May 22, 23, and 26, I900; May 5, I903; July I8, 1902; and June 6 and 2I, 1910. That the old bulls do not suffer much from their attacks is suggested by an entry under date of May 24, 1900, when two killers were observed near the shore, while the bulls rolling about in the water near them were not attacked and showed no fear. On the other hand large seals and even sea lions have been known to take to the land to avoid them. Writers on the habits of killers speak particularly of the destruction waged among seals by these roracious animals. There is, of course, a certain proportion of deaths among the older seals, principally the breeders, while they are on the islands. Deaths of bulls occur rather rarely from fighting, though in the event of a great excess of males this factor might be an important one. Under conditions as observed in I9I4 no evidence of any mortality from this cause was found, though several bulls were badly injured by their fellows. In the case of the single bull found dead during the summer no specific cause of death could be ascertained.

Among the cows, deaths during the breeding season are mainly from two causesfrom the accidents of birth and from the injuries inflicted by the bulls in contending for supremacy. Mortality from these causes has been elsewhere discussed (p. 54). In general, the condition of the cows found dead at the time of the counting of pups is such that the specific cause of death is not apparent. 


\title{
THE EFFECT OF PELAGIC SEALING.
}

\author{
LOSSES DUE TO PELAGIC SEALING.
}

The effect of pelagic sealing has been the subject of much discussion to which reference is not nccessary at present. This form of sealing, insignificant at first, began to be important about $\mathrm{r} 850$ and continued until effectively stopped by international agreement in I III. The total loss to the herd directly or indirectly due to pelagic sealing can never be known. The records show that in Bering Sea and on the Northwest coast during the period from I 880 to I9I I approximately 900,000 skins were secured and marketed by the pelagic sealers. When it is considered that from three to five seals were killed for every one retieved and that a large percentage were females whose unborn pups perished with them and whose pups on land were left to starve, it is plain that the total losses ran well into the millions. In every senson since I 890 the recorded pelagic catch exceeded the land catch, so that during this period of steady decline of the herd even the primary losses due to pelagic sealing were greater than those of land killing.

\section{INFORMATION TO BE GAINED FROM THE CESSATION OF PELAGIC SEALING.}

The present importance of a consideration of the effects of pelagic sealing lies in the contrast between present and former conditions. Now, for the first time during American ownership the herd is increasing and an opportunity is afforded for studying its behavior under approximately natural conditions. In previous times practically all efforts for knowledge of the numbers and movements of various classes of seals, all data as to rates of increase or decrease, and all measures looking toward regulation of killing and reserving of breelers were subject to the unknown and uncontrolled factors contributed by pelagic sealing. With pelagic sealing stopped, the time has arrived for a thorough study of the problems hitherto in question solely or chiefly because of the existence of pelagic sealing. The most important of these relate to the percentage of survival to killable size and to the reserving of males for breeding. After the thorough demonstration of the evils of pelagic sealing and after all the effort expended to abolish it, legislation or regulations which perpetuate some of the very obstacles against which we have been contending should be aroided so far as possible. While the cessation of pelagic sealing is principally a matter of congratulation because it insures the preservation of the herd, it is evident that our immediate practical benefit from it is the opportunity it pernits for obtaining information which will be absolutely essential in conducting land operations in the future. Thus far we have only partially taken advantage of this opportunity by obtaining full counts of pups in 1912, 1913, and 1914. The information thus obtained has been of great value, but a further use for it of the highest importance will appear in 1915 and 1916 , when it might be applied in connection with liberal killing and reserving to determine the percentage of male seals which naturally survive to killable age. This information in regard to the males could then be applied to the females which doubtless survive in approximately the same proportions. Thus it would be possible at an early date to have for future guidance certain very definite data as to natural death rates and percentages of increase of great importance in the management of the herd. 


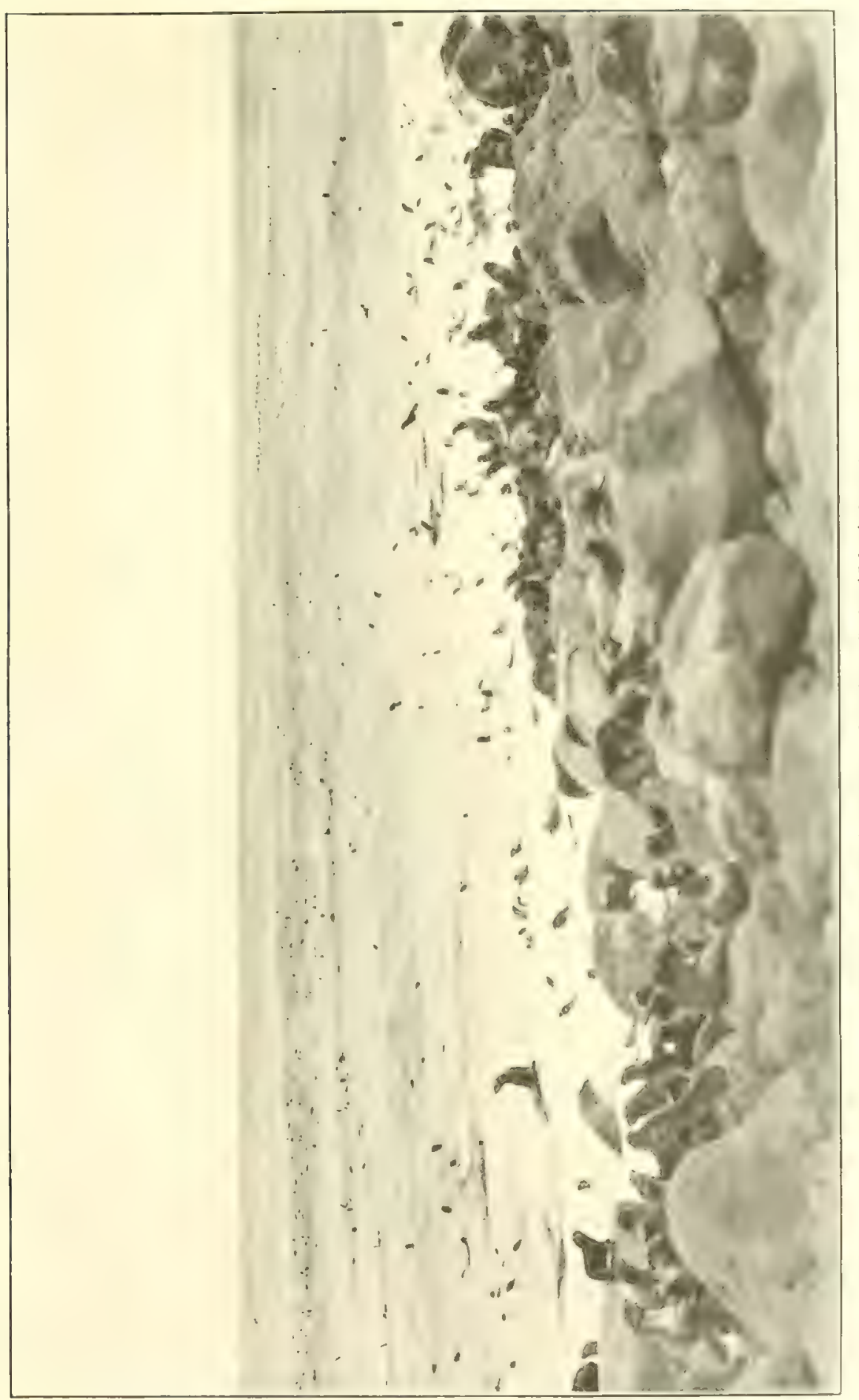



EFFECT OF PELAGIC SEALING STILL EVIDENT.

The treaty abolishing pelagic sealing became effective December 15 , I9II. Therefore, killing at sea was going on in the summer of IgI $\mathrm{x}$, and although only I4,5I I skins were taken, and these may have included animals from the Russian and Japanese herds, the usual failure to retrieve all seals killed and the starvation of pups as the result of the death of their mothers must have made the losses to the herd much greater than the recorded catch. Since I 9 I I no seals have been taken at sea except the negligible few speared from canoes by natives according to law. The patrol of the fleet of revenue cutters has been continued but no sealers or marauders have been detected. The nature of pelagic sealing was such that it could not fail to leave the herd in a very abnormal condition. The number of seals killed and the proportions of different classes taken at sea were necessarily quite fortuitous. Young cows, old pregnant cows, bachelors, and even old bulls were killed indiscriminately. It is possible that some of the resulting irregular proportions may have had chance compensation from year to year, but there can be little doubt that the cessation of pelagic sealing left the proportions of young and old breeding seals in far from normal condition. The breeding life of the bulls is 7 to 8 years and of the cows ro to II years. This being the casc, and other things being equal, about one-sixth of the bulls and about one-tenth of the cows would die each year of old age. The proportion of each age from the youngest to the oldest would be evenly graded and refiable calculations of the general rate of increase conld be deducted from the birth rate and the death rate.

It is evident that these proportions can not be reestablished until all the seals subject to pelagic sealing have died and been replaced by others. This will require I 2 to I4 years, although approximately natural conditions may be expected somewhat sooner. Seals born in $19 x$ I will be 12 years old in 1923 and the death rate among breeding females will then be practically normal. That abnormal conditions prevail at present is evident from the lack of a substantial increase of breeding cows in Igr4 which can not be satisfactorily explained except on the assumption of an excessive death rate among old cows due to pelagic sealing in former years. This has been referred to elsewhere (see p. 43).

Although the effect of pelagic sealing on the breeding herd will linger for years, it can have only a slight and indirect influence on the abundance of young male life. The combined effect of no killing at sea and very limited killing on land in the three seasons since IgII has already produced an overabundance of young males. The proportion of these that will be needed in later years as breeders is no greater than it would be if there had never been an undue reduction of male life. The preservation of more than this proportion, therefore, is no more justified now than it ever would have been or ever will be. Although the birth rate may fluctuate for some years as the result of irregular mortality of old cows, a reservation of males for breeders based on a regular increase of cows could not fail to be ample since none of the males so reserved would be old enough to go out of service before normal conditions were restored. So far as the effects of pelaric sealing are concerned, therefore, killing and reserving of males need not be postponed. 


\section{PELAGIC SEALING INDIRECT CAUSE OF CLOSE LAND KILLING.}

Examination of the records and chance interrogation of various individuals formerly connected with sealing make it clear that pelagic sealing, with its reckless and piratical methods, may have indirectly affected the sincerity and morale of land sealing. The conditions were such that it could scarcely be otherwise, and those in charge of the land operations can not be justly criticised for it. If there had been no pelagic sealing, the lessees would have clesired to perpetuate the herd quite as much as the Government, but when it was merely a question whether the lessee or the pelagic sealer got the seal, it was to be expected that the lessee would take practically all he could get. As it then appeared, the herd was doomed any way and the preservation of a seal on land was no guarantee that it would not immediately be killed at sea. Thus, even if close killing on land he admitted, it is evident that pelagic sealing was to a considerable extent responsible for it. 'This form of killing may therefore be credited with even more than its direct drain on the herd. It has been almost the sole cause of trouble. It is inconceivable otherwise that prudent business men, such as constituted the leasing companies, would have allowed their own interests to dwindle by the goose and golden egg method; and of course their agents were thoroughly familiar with at least the main features of the brceding habits of the seals and able to appreciate the futility of efforts at protection on land while wholesale destruction went on at sea.

\section{THE EFFFCT OF LAND SEALING.}

The effect of land killing is irretrievably involved in that of pelagic sealing. All things considered, it is difficult, if not practically impossible, to show that any land killing during American ownership has been "excessive." The killing of gray pups for food of natives, as practiced to some extent during the period of the first lease, was wasteful, but even this did not include females. The killing of males on land until I9I I has served to reduce the catch at sea and in itself may not have produced any shortage of breeders. The reduction of land killing in I $\$ 92$ and I 893 produced a surplus of old males in 1896 and 1897 , but was accompanied also by a large increase in the pelagic catch, and it is evident that a continued cessation of land killing at that time would only have caused the pelagic sealers to redouble their efforts, and the herd would have continued its decline. In the six years from 1890 to 1895 the number of seals killed on land was 80,482 ; during the same period pelagic sealers took 295,965 and caused the death of at least several times as many more. In every year thereafter until IgI the pelagic catch exceeded the land catch. Under such conditions, the effect of any limitation of land killing was problematical. The system of reserving males for breeding purposes inaugurated in 1904 and continued until I9I 2 had its objectionable features, since certain animals rescrved in one season may have been killed the next, but in spite of this it might hare been effective but for pelagic sealing. This is evident from the increased number of bulls in I9I3 and 1914, due to the reserves of rgro and Igr. That the reserves of former years did not produce a like number of bulls at the proper time was beyond doubt due to the effect of pelagic sealing. If larger reserves had been made, it is questionable whether they would have accomplislued more than an increase in the pelagic catch; certainly a proportionate increase would 
have resulted. Therefore, there were no sound economic reasons for making large reserves.

The quotas killed in the decade preceding the abolition of pelagic sealing would not have affected the breeding strength of the herd if they had not been accompanied by the drain of pelagic sealing. It is obvious, therefore, that equally large, or even larger quotas might be permitted in the absence of pelagic sealing with periect affety. Remembering the great increase of bulls which followed reduced land killing in isge and IS93, when pelagic sealing was practically at its height, it is impossible to believe that the reduced killings from 1912 to 1914 , with no pelagic sealing whatever, will not produce an overstock of bulls proportionately much greater than that of i 896 and is 87 .

So far as the present management of the herd is concerned, land killing in the past only serves to show that relatively large quotas may be taken. With pelagic sealing abolished, uncertainty in many directions ceases, and action should be governed by the number of seals actually found on the islands. The number to be killed or reserved is wholly a matter of proportions, and all the old ideas of fixed quotas and definite numbers should be discarded forever. These proportions are not the same as they would have been during pelagic sealing, and all that can be said is that in working them out under the new conditions, we are likely to find it possible and advisable to kill on land at a higher rate than when land killings were more than duplicated at sea. The effect of the reduced hillings of the last three seasons is to be seen on the islands now by the most castial observer. Young male seals of four years and under are filling the hauling grounds again. According to the estimates, which are ultraconservative, the bachelors in 1914 were as follows: Yearlings, 23,067; 2-year-olds, 17,$422 ; 3$-year-olds, I3,880; 4-year-olds, 9,939; and 5-year-olds, I,658; a total of 65,966 young male animals. If only half of them lived, they would provide service for eight years for $9 \$ 9,490$ cows at the low ratio of I bull to 30 cows. Of course, the cows can not reach such numbers for many years, so it is evident the reduced killing of the last three years has already provided a great excess of males.

\section{THE MANAGEMENT OF THE HERD.}

\section{THE GENERAL POLICY.}

Since the ratification of a treaty between the United States, Great Britain, Japan, and Russia effecting the complete cessation of pelagic sealing the managenent of the Pribilof seal herd is no longer to be viewed in the light of past conditions except as they are corroborated by the findings of the present. The way is now clear for the adoption of definite policies, for the acquisition of all necessary information, and for the development of a systematic and bucinesslike management worthy of and creditable to the Govemment of the United States.

Although sentiment might prevent the absolute extinction of the fur-seal herd, its preservation is principally possible because of its value as the source of an important commercial product. It is doubtful if it could be preserved at all were it not plain that conservation guarantees infinitely larger profits than immediate destruction. Those interested in the preservation of wild life from scientific or esthetic motives are fortunate when the very ends they desire are supported by strong economic reasons. 
In the case of the fur seals it is particularly evident that the only way to insure the growth and continuance of this wonderful display of mammalian life is to advocate a policy involving the taking of life. Scientist, conservationist, sentimentalist, or legislator, therefore, should view the managment of the fur-seal herd almost solely from a practical business standpoint.

Laying aside all irrelevant matters of the past and considering the seal herd only as a piece of property to be prudently exploited, we find that simple business principles demand answers to three questions. First, what is the nature and extent of our property? Second, what is the largest annual yield that can be taken from it consistent with absolute safety? Third, what immediate provision should be made for the management of the business?

\section{THE NATURE AND EXTENT OF THE PROPERTY.}

This subject involvès much of the matter in the present report and requires only brief consideration in this place. To those familiar with the seal herd during periods of expansion, it may seem small at present, but the observer who sees it now for the first time can not fail to be convinced that it is still a large and exceedingly valuable property. It is true that the herd was once vastly larger than at present. It is true also that the past killing of seals at sea was both reckless and disastrous. But the past is gone and the injection of its issues into the present only serves to obscure the real vital matters which need present consideration. Of the present we know that we have a herd of nearly 300,000 seals under practically complete control on both land and sea. This herd includes not less that y3,oon breeding females producing I young annually, half the young being males and half females, and at most only I male to 35 females being required for breeding. A large supply of males from 2 to 5 years of age is already present and a large revenue from the taking of the surplus is assured. Without attempting an exact calculation, it is evident that the productive capacity of the seal herd is equal to that of an enterprise representing an invested capital of at least ten millions of dollars. As such it is worthy of the highest effort for efficient administration.

\section{MANAGEMENT BASED ON PRINCIPLES EMPLOYED WITH DOMESTIC ANIMALS.}

The fur seal is a highly polygamous animal almost wholly controlled by man during the breeding season. It has been subjected to man's disposition for more than a century and shows no tendency to change its habits as a result of his interference. Seals may be driven up, counted, caught and examined, branded, or killed even more easily than range cattle or horses. After being driven they return to their accustomed resorts as if nothing had happened. Except that they have not yet been improved by man, they are scarcely more to be regarded as wild animals than the majority of our domestic species. Their numbers, their breeding, and to some extent their ailments are subject to the control of man. The sexes are born in equal numbers, and a large proportion of the males are superfluous for breeding purposes. It is obvious, therefore, that these superfluous males moy be utilized by man just as in the case of domestic animals and that the principles involved are those successfully employed by breeders of live stock. 
BULL. U. S. B. T', IgI4.

PIATIS XII.

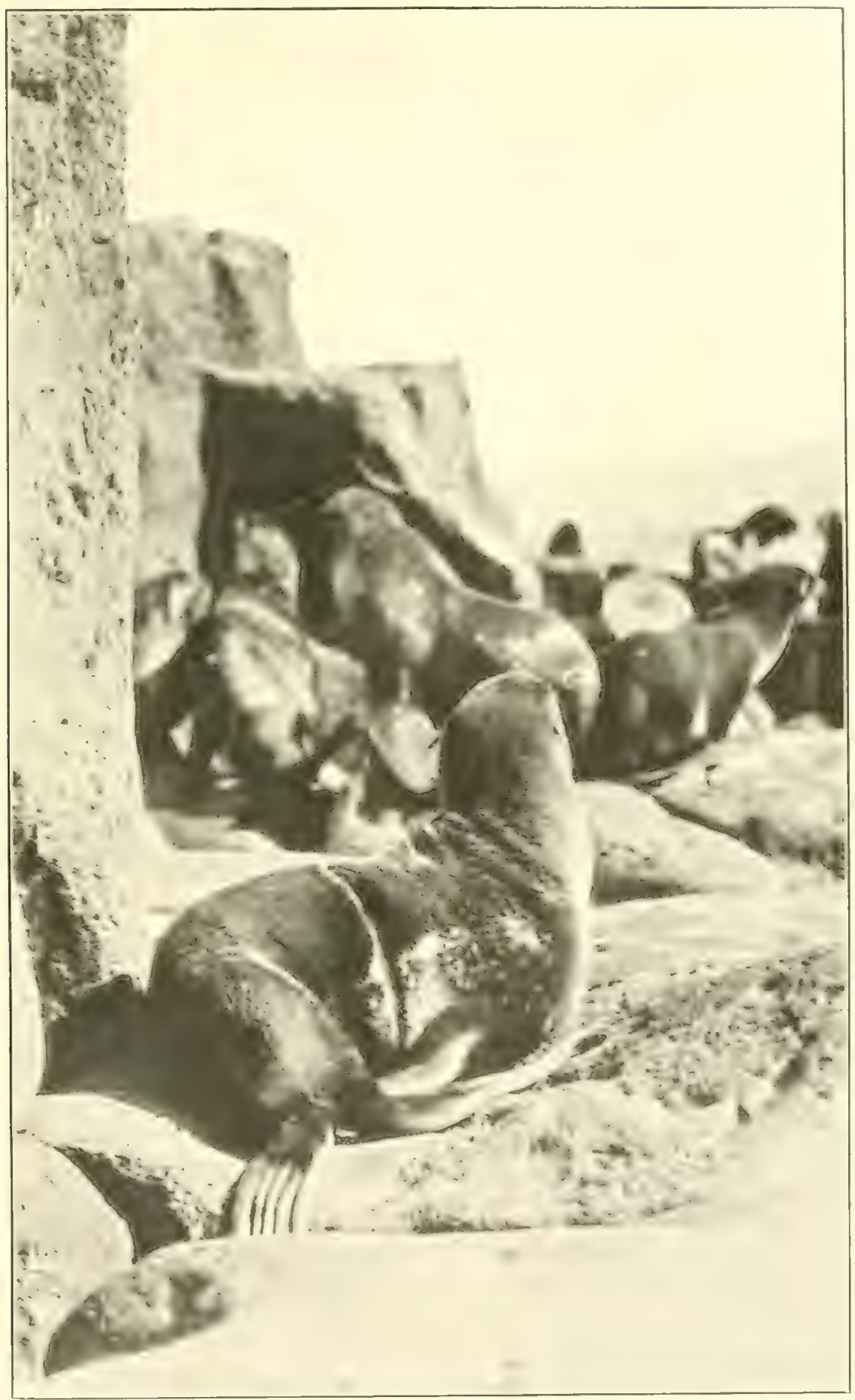

Lianded cow, nrobably iz years of age, I itovi IRoukery, August 23, 194. 



\section{REQUIREMENTS OF A RESERVING SYSTEM.}

The requirements of a system of management for the seal herd, therefore, may be stated in their simplest form as only two: ( $I$ ) The preservation of those males needed as breeders, and (2) the utilization by man of those not needed as breeders. To put these requirements into effect, however, involves the determination of the total number of seals, the proportions of various classes, the death rates from natural causes, the age at which the surplus should be taken, and the method of marking or branding to insure the permanent preservation of the reserves. Some of these matters may be decided upon the basis of data now available, but in regard to others it is still necessary to estimate. The prime requisite for a well-grounded system of reserving males is a better knowledge of the natural rates of increase than we now possess. Liberal allowances for supposed mortality answer the demands of conservatism in estimating the size of the herd and the relative strength of different classes of seals, but, as shown in the discussion of the census of I9I 4 , the estimates are largely based on data obtained during pelagic sealing when natural conditions were greatly disturbed. From one point of view these estimates are entirely safe guides, since they are conservative enough to be well within the facts, but with better data within reach there is no justification for using them longer than necessary. The percentage of survival to the age of 3 years can be determined in a single season by the simple process of setting aside a reserve of 3 -year-old males and then killing all the remaining animals of that class. This should be done in I9I5, not only because the information is needed as soon as possible, but because the conditions at that time will be particularly favorable. In the first place, the total number will be smaller than in later years and therefore easier to handle. Moreover, the number of pups born in I9I2-the 3-year-olds of I 9 I 5 is known from an actual enumeration, while some 5,500 of these pups were given permanent brands in 1912 and a record was kept of the few killed as 2-year-olds in I9I4. The presence of a certain number of these branded animals, which will be 3 -year-olds in 1915 , will make it possible to determine with great exactness the characteristics of the 3 -year-olds and would greatly facilitate the restriction of killing and reserving to that class. Such favorable conditions will not occur soon again, and even to approximate them in 1918 would require a needless repetition of the branding done in 1912.

\section{CONFINEMENT OF KILLING AND RESERVING TO ONE CLASS.}

Various considerations indicate that at present and at least for a few years to come killing and reserving should be mainly confined to one class-the 3 -year-olds. In former years the seals taken included those of 2,3 , and 4 years of age. The twos and threes are of practically the same quality, but the threes being larger, usually command a higher price. The fours, although still larger, are not as uniform as to quality, and although they still have good values it is eqvidently poor economy to allow them to reach that age before being taken. In the past the market has sometimes shown a special demand for the sizes yielded by z-year-olds, and if it should be found profitable in future to cater to such a demand it may be done at least to a limited extent when our knowledge of proportions and rates of increase is more definite than at present. In general, however, the 3 -year-olds yield the skins of highest quality and value, and while the herd is comparatirely small and methods are being perfected these only should be taken.

S4512ㄴ.S. Doc. $98063-3-6$ 
It is obvious that the breeding reserves should be made annually from a single class or generation of seals. They should also be from a class not previously subjected to killing and to one as advanced in years as possible, in order that there may be a short interval between the age of reservation and the age of harem service. The 3-year-olds meet these conditions better than any other class. Furthermore, if 3 -year-olds be reserved it will then be pesible to take any unbranded f-year-olds with safety, and thus the chances that any surplus males may come to maturity will be minimized.

\section{THE METHOD OF MARKING RESERVES.}

To insure their continued preservation as breeders, it is evident that nothing less than a permanent brand will suffice for marking reserves. The temporary mark used in previous reserves and made by clipping a patch of hair from the head is objectionable because it disappears in a few months, making it impossible to distinguish the reserves when they become 4 -year-olds and older. If a permanent brand were given the reserves for a period of years with some slight distinctive variation from year to year, it would soon become possible to determine the relative ages of the stock of harem bulls. The brand should be made on the head or neck with a hot iron or some device for producing the same result. Brands on the body can not be distinguished readily on the killing field, whereas those on the head or neck are easily seen at all times. The practicability of branding on the head and neck has been demonstrated by the branding done in 1912. This consisted of brandins on the head some 5,500 pups and about 300,3 -year-olds. They were seen in such numbers in $101+$ as to indicate that the branding was successful. Although no exact enumeration of them was made, 5-year-olds with brands were seen throughout the season on practically all the rookeries, and when the small number originally branded is considered it is evident that practically all survived. Moreover, it is plain that if young pups survive a brand on the head there can be no risk in placing a similar brand on large vigorous 3 -year-olds. Lntil methods of branding are perfected and the natives instructed in them, branding operations should be conducted by someone experienced in such work. In fact since natives can not be depended upon and since previous branding has been done by persons no lonere available, a special employee should be detailed for one or more summer seasons with instructions to investigate the subject of branding thoroughly and establish methods and apparatus for future use.

\section{THE PROPORTION OF MALES TO BE RESERVED.}

As shown elsewhere (see p. 49), the ideal number of harem bulls would be such as to provide them in the proportion of I to fo bearing cows, while at the same time idle bulls should be precent in the proportion of I to so virgin cows or approximately I idle bull to $t$ harem bulls. If these proportions could be maintained, there would never be any question as to the sufficiency of males. It is too much to hope that such exact proportions would in practice be possible, but it is believed that a consistent effort to keep as near as possible to these proportions would serve all practical purposes.

Since reserves must be made at the beginning of the season before the harems are formed and before the size of the herd can be determined, the size of the reserve must depend upon knowledge of conditions the previous year. Furthermore, since the reserves will not enter the stock of bulls for at least thee years the size of the reserve in a given season will bear some relation to the reserves of the three preceding years. Therefore the 


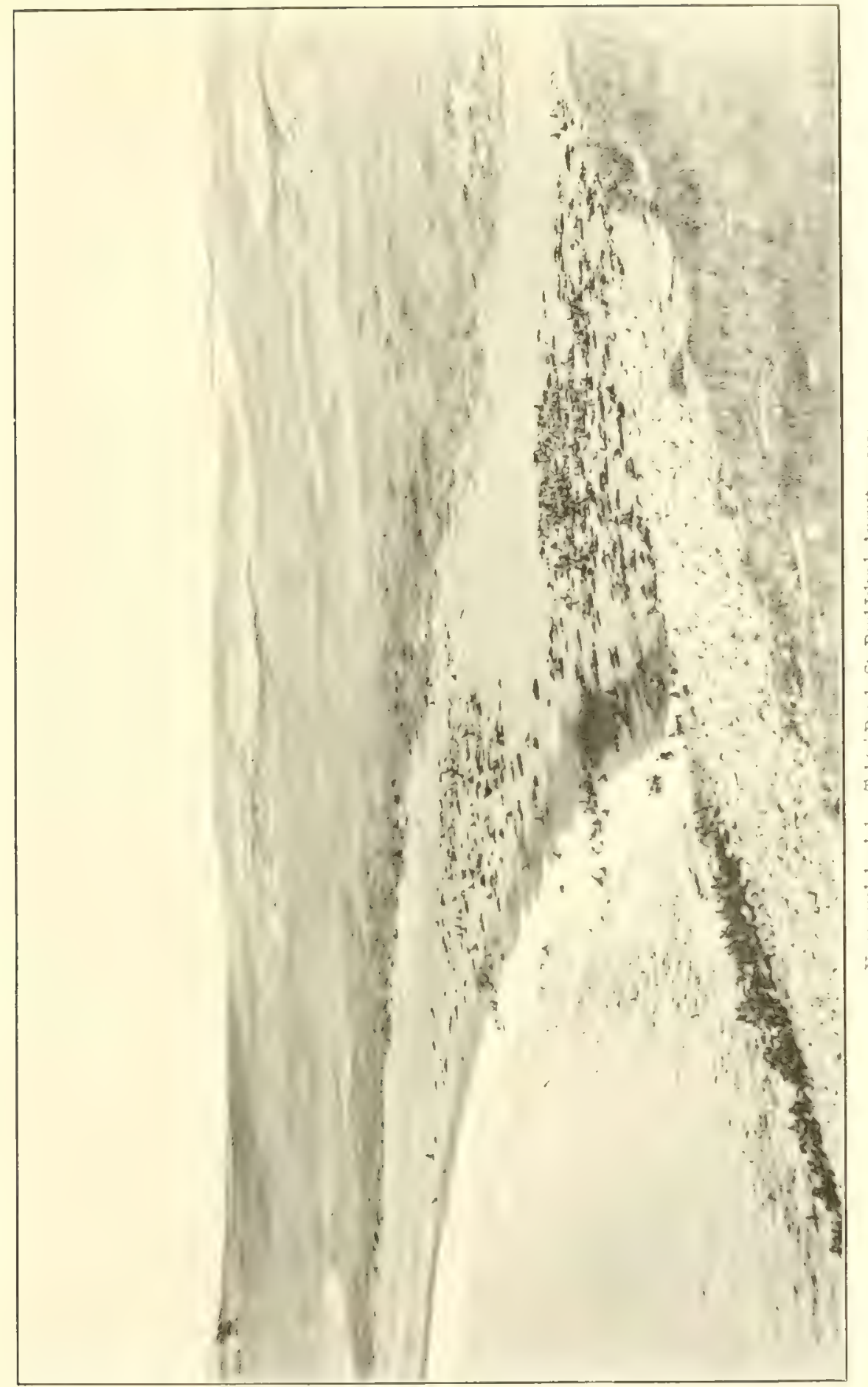



size of the reserve should increase from year to year at a rate proportionate to the rate of increase of the cows. After a few years of experimentation this rate could be determined. To indicate our present knowledge of rates of increase and to serve as a guide to be used according to circumstances in making reserves, the following tables lave been prepared. Although they furnish a forecast of possible future conditions, this is not their primary purpose, and it is hoped that they will be regarded less as predictions than as demonstrations that whatever the rate of increase the reserve of males should be relatively small.

TABLE No. I.-Estimated minimum number of females, I0I4-1926.a



a Based on assumed mortality of 50 per cent in first year, 25 per cent in second year, 10 per cent in third year, and 12 per cent annually thereafter; annual rate of increase of cows 5 per cent to 6 per cent.

Based on actual count of pups.

TABLE No. 2.-Estimated maximum number of females, I0I4-1926.a

\begin{tabular}{|c|c|c|c|c|c|c|c|}
\hline & & 1914 & 1915 & 1916 & 1917 & 1918 & I9I9 \\
\hline \multicolumn{2}{|c|}{ 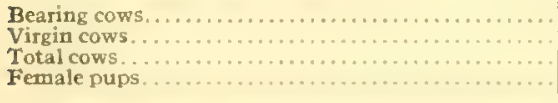 } & $\begin{array}{r}93,250 \\
24,255 \\
117,505 \\
46,625\end{array}$ & $\begin{array}{r}105,755 \\
27,681 \\
133,436 \\
52,877\end{array}$ & $\begin{array}{r}120,093 \\
27,975 \\
148,068 \\
60,046\end{array}$ & $\begin{array}{r}133,26 x \\
3 x, 726 \\
164,987 \\
66,630\end{array}$ & $\begin{array}{r}148,488 \\
36,027 \\
184,515 \\
74,244\end{array}$ & $\begin{array}{r}166,064 \\
39,978 \\
206,042 \\
83,032\end{array}$ \\
\hline & 1920 & 1921 & 1922 & x923 & I924 & I925 & 1926 \\
\hline 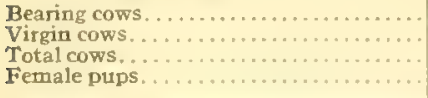 & $\begin{array}{r}285,438 \\
44,546 \\
229,984 \\
92,719\end{array}$ & $\begin{array}{r}206,986 \\
49,819 \\
256,805 \\
103,493\end{array}$ & $\begin{array}{r}231,125 \\
55,631 \\
286,756 \\
115,562\end{array}$ & $\begin{array}{r}358,080 \\
62,095 \\
320,175 \\
129,040\end{array}$ & $\begin{array}{r}288,158 \\
69,337 \\
357,495 \\
144,079\end{array}$ & $\begin{array}{r}321,746 \\
77,424 \\
399,170 \\
160,873\end{array}$ & $\begin{array}{r}359,253 \\
86,447 \\
445,700 \\
179,626\end{array}$ \\
\hline
\end{tabular}

a Based on assumed mortality of 40 per cent in first two years and ro per cent annually thereafter; annual rate of increase of cows it pet cent to 12 per cent.

TABLE No. 3.-Estimated mean number of bearing and virgin con's, ror 4-1926.a

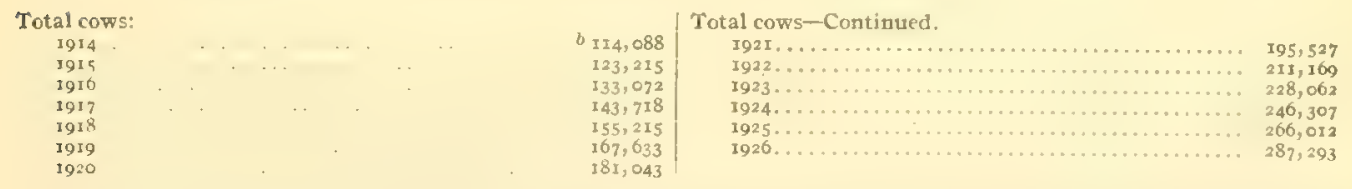

c Based on a rate of increase of 8 per cent per anum, this being the approximate mean between the rate of the minimum estimate and the rate of the maximum estimate.

$b$ Mean between maximum and minimum estimates. 
TABLE No. 4.-Estimated minimum number of males, 19I4-1926, under operation of law of I9I2."

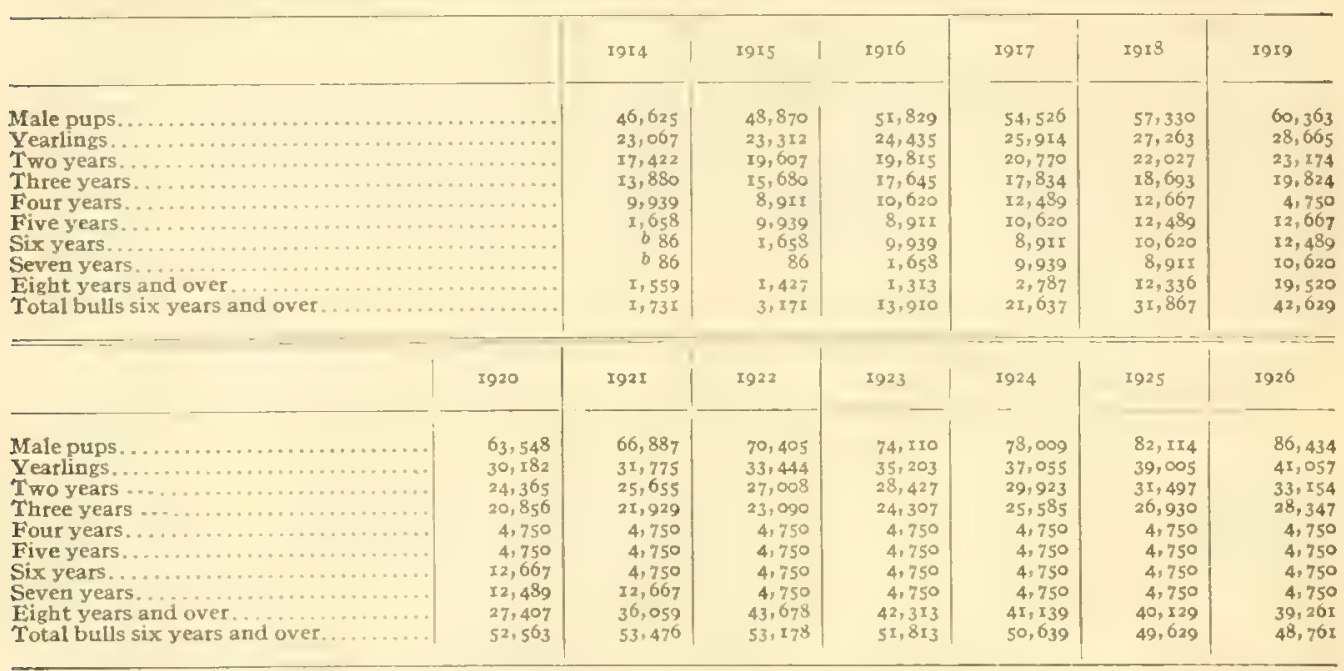

a Based on assumed mortality of so per cent in first year, is per cent in second, so per cent in third, 5 per cent in fourth, and 14 per cent annually after eighth; with allowance also for food killings of 4,500 3-year-olds in 1914, I915, I9I6, and 1917, and reserves 5.000 per annum aiter 1917 .

TABLE No. 5.-Harem and idle bulls and annual increments required under various estimates at ratio of I bull to 35 cores.

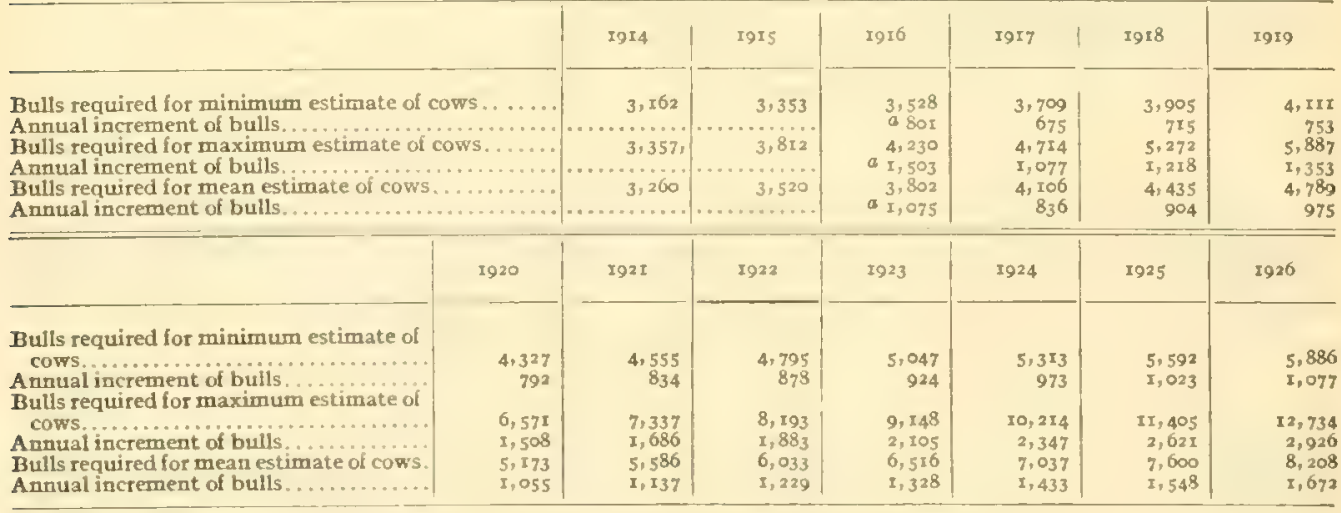

an the basis of $3,27 \mathrm{x}$ bulls which it is estimated will be present in Igrs.

TABLE NO. 6.-Comparison of results of present law, and of a reserving system based on an estimated mean rate of increase of cows.

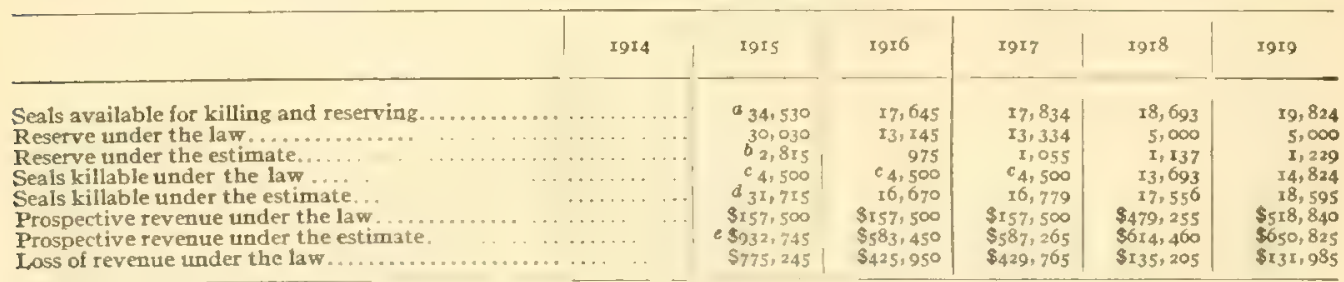

Includes 9,939 5-year-olds, 8,915 4-year-olds, and I5,680 3-yrear-olds.

8 Includes $x, 075$ 5-year-olds to supply the required increment for 1916,836 4-year-olds for that of $19 \times 7$, and 9043 -yeat-olds for that of 1928 .

c Food requirement only.

$d$ Assuming that surplus 4 and 5 year olds were killed in zors and only 3 -year-olds thereafter.

c Allowing in average price of $\$ 85$ for 5 -year-olds and $\$ 35$ for 3 and 4 year olds. 
TABLE NO. 6.-Comparison of results of present law, and of a reserving system based on an estimated mean rate of increase of cows-Continued.

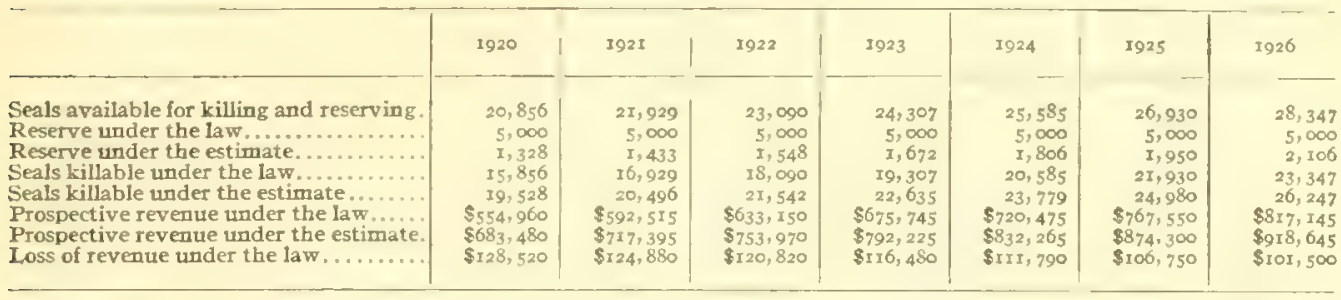

Remarks: Approximate annual rate of increase of reserve, 8 per cent. Total revenue under the law, $\$ 6,232,135$. Total revenue under the estimate, $\$ 8,947,025$. Total prospective loss of revenue, $\$ 2,708,890$.

TABLE No. 7.-Bulls provided by law in excess of requirements of maximum, minimum, and mean estimates of cows.

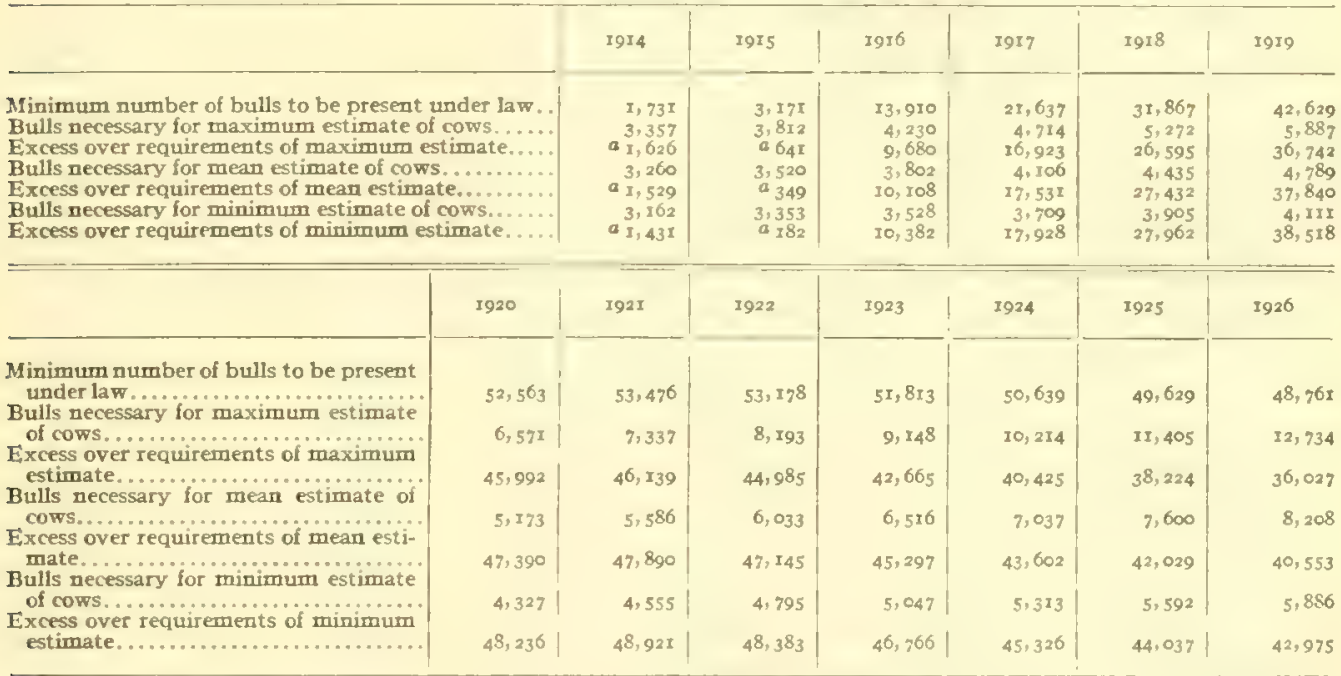

a Deficiencies. These will exist in 5935 under any circumstances and merely indicate the possible extent to which $5-y$ ear-olds might participate in the breeding.

Tables Nos. I, 2, and 3 give minimum, maximum, and mean estimates of cows from I91 4 to 1926 , using as a basis the actual number of cows and pups found in 1914 and progressively applying a very high death rate for the minimum estimate, a low rate for the maximum, and striking an approximate average for the mean between the maximum and the minimum. Table No. 4 shows primarily the number of young male seals which would be present from I914 to 1926 under a high death rate and a slow increase of breeding cows. The number of bulls which would result from the operation of the law of $19 \mathrm{r} 2$ is then obtained by making allowances for food killings of 4,500 three-year-olds per annum until I9I7 and for reserves of 5,000 per annum thereafter.

Table No. 5 shows the total number of bulls which would be necessary to provide I bull to 35 cows under the various estimates. Thus, under the minimum estimate there would be a total of 123,473 cows in 1916 . Dividing this by 35 gives 3,528 , the number of bulls to be required in that icar. After obtaining the number of bulls recpuired for each year, the increment from yerr to year is obtained by allowing for deaths of 44 
per cent per annum, which is about 2 per cent more than results from natural termination of life. Thus if 3,528 bulls were present in 19 I 6,86 per cent, or 3,034 , would be assumed to survive to 1917 , and therefore an increment of 675 bulls in 1917 would be necessary to make the total requirement of 3,709 bulls for that year. From this table it is seen that even for the maximum estimate of cows, only 12.734 bulls would be needed in 1926 and the annual increments would be very small, not exceeding 2,000 until 1923 . Under the mean estimate, which is a much more reasonable one, scarcely more than 8,000 bulls would be needed in 1926 , and the increment would not exceed I,500 until 1925. Therefore, no reserve of over I,500 would be necessary until 1922.

In Table No. 6 is shown the result of a reserving system based on the estimates of the preceding tables and compared with the results to be expected under present law. The results thus indicated are decidedly conservative, and it is highly probable that smaller reserves would suffice, but as a guide for action it is desirable that all reasonable provision be made that the supply of bulls be ample. Therefore, under the system proposed in this table, it is intended that there shall be at least I bull to 35 cows. That this can not fail to result is evident when it is noted that this ratio is maintained in a calculation in which the bulls are assumed to increase at a slower rate than the cows. It would be quite fair to state the requirements of the minimum estimate of cows, since the males to be killed represent a minimum, but in order to allow for all possible contingencies the mean estimate of cows is used. The maximum estimate need not be considered, except as an indication that under the most extreme and improbable increase of cows the number of bulls required would still be small as compared with that provided by law.

In order to establish a rational reserving system at once and to prevent loss of revenue, all surplus 5-year-olds and 4-year-olds should be killed in I9I5. Thereafter, reserves would be made from the 3 -year-olds and would increase from year to year at the rate of 8 per cent. Referring to Table No. 5 , it is seen that an increment of $\mathrm{r}, 075$ bulls would be needed in 1916 , the increment in that year being relatively large owing to the present shortage as compared with an ample allowance. This increment will be supplied by the 5-year-olds of 1915 , of which all but 1,075 , therefore, might be killed. In 1917 the increment would be 836 to be supplied from the 4 -year-olds of 1915. The following year, I918, would require $90+$ new bulls, and this determines the size of the reserve of 3-year-olds in 1915. In 1916 the reserve of 3-year-olds would be 975 , and subsequent reserves would increase at the same rate. The size of the reserve in any given season would be $S$ per cent larger than the reserve of the previous year or approximately 22 per cent of the number of harem and idle bulls which were present the preceding year.

Table No. 6 shows also the estimated revenue to be derived under the proposed reserving system in comparison with that which might be expected under present law. It is seen that a prospective loss of more than three-fourths of a million dollars is indicated for the year 1915 , from which it is apparent that immediate action is necessary. The total loss indicated for the I2 years from I9I 5 to 1926 , inclusive, is $\$ 2,708,890$, or an average of $\$ 225,742$ per annum. Of this loss only 70 per cent, or $\$ 1,896,223$, would be suffered directly by the United States, since 3 o per cent, or $\$ 812,667$, would fall upon Great Britain and Japan. These losses are computed on the basis of a price of $\$ 35$ per skin, which is the approximate average price received during 
the last ro years. It is, of course, impossible to predict the future state of the fur market, but with an annual output of considerably less than 30,000 skins it is more likely that this figure would be exceeded than otherwise.

Table No. 7 makes comparison of the number of bulls of six years and over which would be present under the law and the numbers which would be required for the various estimates of cows. It is seen from this that on the basis of the mean estimate of cows, although there would be a slight deficiency of bulls in 1915, this would suddenly change to a large excess of over 10,000 in 1916 , which would increase to a surplus of 47,890 in I 921 and maintain a high excess of over 40,000 until I926. Even the requirements of the maximum estimate are greatly exceeded by those of the law, the excess of bulls in this case being 9,680 in $1916,46,139$ in $192 \mathrm{I}$, and 36,027 in 1926 . If comparison is made with the minimum requirements, the excesses are still greater, and it is evident that the operation of the law provides for an excess over any rational estimate that could be made. Using the minimum estimate of cows, and therefore simply assuming an equal rate of increase of males and females but with allowance for the killing permitted by law, it appears that in I 92 I there would be 159,428 cows and 53,476 bulls, or exactly three cows for each bull. It is apparent also that the 53,476 bulls of I I II, at the conservative ratio of I to 35 , would be sufficient for I,87I,660 cows, or more than seventeen times the number living in 19I4. Such an increase of cows is, of course, impossible.

Comparisons need not be multiplied, but it may be repeated that the above tables have not been constructed for the purpose of predicting by exact figures the future growth of the herd, but for demonstrating that the effects of the law and of a limited reserving system, estimated by the same method, are very far apart. It is confidently believed that a reserving system based on the principles above outlined might be undertaken at once with perfect safety. Although the exact percentages shown by the foregoing tables may need alteration as new information is obtained, there is not the slightest danger that any shortage of males would result from their adoption for immediate practice. It is therefore plain that in I9I5 all males of 3 , 4, and 5 years of age might be taken with the exception of reserves of approximately I, IOO 5-yearolds, 850 4-year-olds, and 900 -year-olds, and that subsequent reserves of 3 -year-olds need to increase at no greater rate than 8 per cent per annum.

\section{METHODS OF DRIVING, KILLING, AND CURING SKINS.}

The main methods now practiced are the results of the experience of many years. To those studying the matter from a viewpoint free from the restrictions imposed by long custom, however, many improvements suggest themselves, mainly in regard to details which have been handed down from a period when modern transportation methods were unknown and the time of laborers considered of little moment, or those which have been demanded by temporary exigencies no longer existent.

\section{NEED FOR SHORTER DRIVES.}

The seals are forced to carry their skins and meat and most of the butchering is done close to the villages, entailing more or less annoyance from the presence of the decaying offal. Furthermore, the seals are driven distances varying from one to several 
miles, involving much delay and the possibility of injury from overheating. Inder this method no killing can be done on warm or dry days, since the seals can not travel far unless rain or heary dew is present. It sometimes happens that sereral days will pass without weather conditions which permit driving. On many other occasions drives have to be abandoned before the killing grounds are reached because of sun or lack of moisture.

The main difficulty opposing the location of killing grounds nearer the rookeries, which would do away with much of the necessity of waiting for favorable weather conditions, is the absence of roads. Although draft animals have been used on St. Paul Island for many years, there is only one road-that connecting Jortheast Point with the village. Teams are sometimes driven to Zapadni, but the road is scarcely passable and the journey involves so much discomfort and such flagrant misuse of the animals and rehicles that it is seldom undertaken. Reef Rookery, from which most of the seals killed during the last few years have been taken, though only a mile from the village, is not reached by road nor by trail worthy of the name. The seals are therefore driven by indefinite routes to the killing ground close to the village and thence the meat and skins are hauled by wagon to the storehouses. A road would allow the animals to be killed nearer the hauling ground, and the expenditure of a little more time and energy would pernit the transportation of the meat and skins the whole distance by wagon.

KILLING.

It is believed that the present method of killing is effective and as humane as is possible and that no change is necessary or desirable. The seal selected to be killed is stunned by a blow on the head from a heary club and while unconscious is stabbed in the heart and bled. The method is thus at least as humane as that followed in slaughtering domestic animals for food.

\section{FEMALES AND OLD SEALS IN DRIVES.}

In making drives from the vicinity of the breeding rookeries it sometimes happens that a few females are included. These are almost always detected and liberated, but occasionally one is accidentally killed. This may happen from the inability of the clubber to judge of the sex of the animal when only the head is risible or by the animal's receiving a blow intended for another individual. In spite of all care, an occasional accident of this kind in killing thousands of seals is unaroidable. During June and early July cows are seldom included in the drives, but after the last of July, when the vigilance of the harem bulls has becone relixed, the bachelors encroach somewhat on the breeding grounds, and if drives are made then a few cows are likely to be included. About this time, howerer, the stagey scason begins and so many of the shins become worthless that killing is wasteful and should be stopped altogether. July in should mark the close of the sealing season.

During June and July in the season of 19 I t ten food drives were made on the Pribilof Islancls. The only cow which appeared in any of these drives was a virgin female accidentally killed on St. George Island on July 25 . After August I, howerer, a few cows were noted in almost every drive, and though only three were killed (by accident) several others succumbed to overheating and trampling. The cows, especially the 


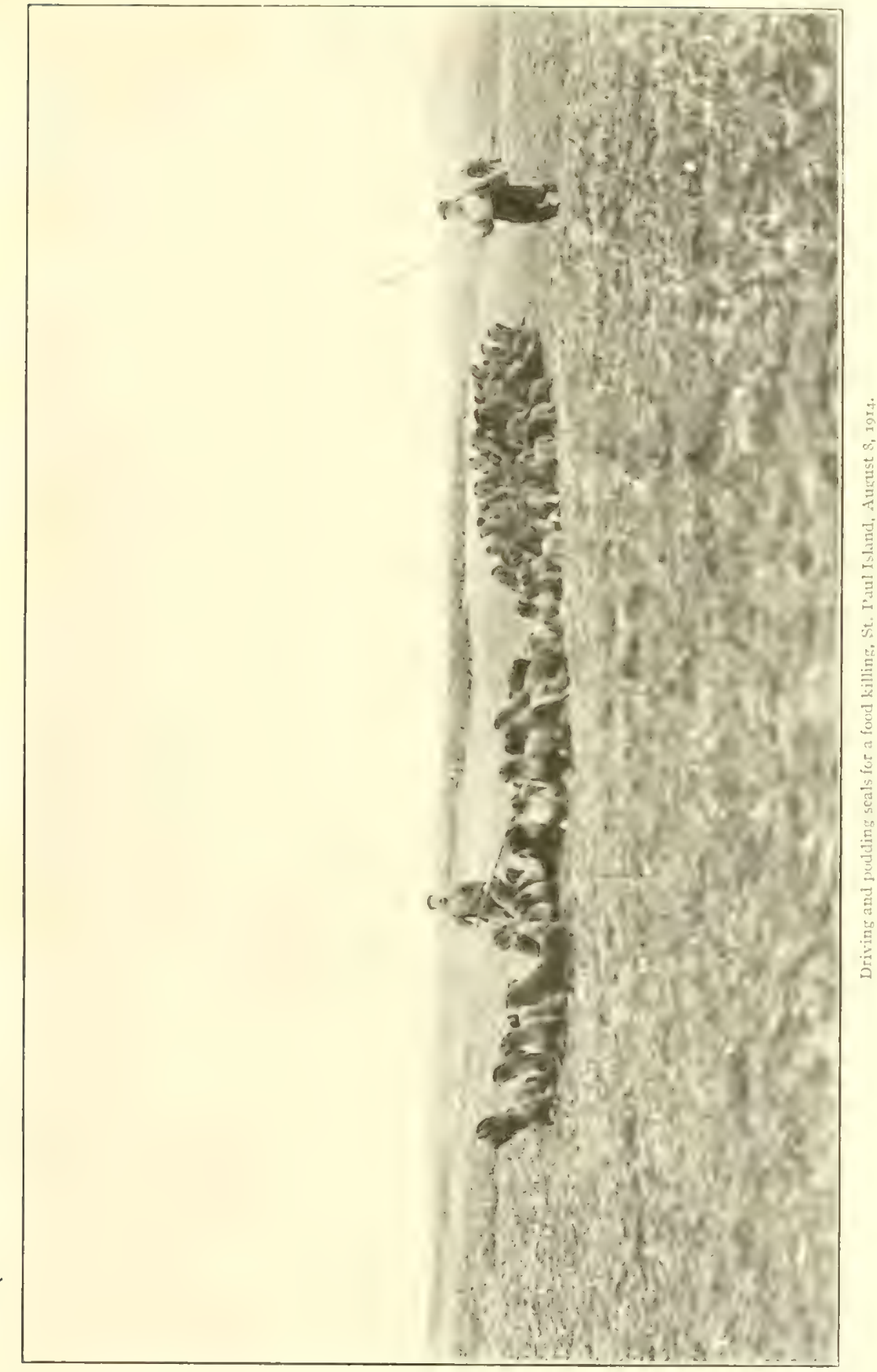



young 2-year-olds, are much less able to withstand the pressure and buffeting of the drive than the bachelors, and they are often detected by their distressed appearance as compared with the males. The presence of cows in the drives has evidently been regarded as a matter of seriousness in past years, for it is noted with considerable regularity in the agents' daily journal or "log." The records are far from complete, but the following compilation of them made by naturalist W. L. Hahn is of considerable interest:

\section{Extracts from St. Paul log regarding cows in drives.}

1879. (?)

October 29, first drive of pups was made from Lukanin, among them many females. Orders were given to examine each separately before it was killed. The Government agent believed that formerly pups had been selected on account of size-not sex.

August 28, 2 females killed by accident.

October 7,2 females killed by accident.

October 20 , io females killed by accident.

November 13 , in a food drive it was found that several-probably 8 or to-female seals had been killed by accident.

1897.

November 12,2 cows were accidentally killed in a drive.

1902.

July 24, I3 cows appeared in a drive at Zapadni.

July 29, 6 cows in a drive from Zapadni.

August 9, I large and 7or small seals were dismissed from a drive, a large part of them being cows.

1903.

July 24, I cow dismissed from drive from Zapadni.

July 27,2 cows dismissed from drive at N. E. Pt.

July 29, I cow dismissed from drive from Tolstoi.

July 30, 2 cows dismissed from drive from Reef.

July 3 I, I9 cows dismissed from drive from N. E. Pt

1904.

July I, 3 yearlings (?) appeared in the drive at N. E. Pt. A large one was knocked down and proved to be a female. It weighed 34 pounds before it was stuck, and the skin weighed 3 I/ pounds.

August 9,25 cows appeared in a drive from Reef and Gorbatch. A pronounced falling off in the number of cows appearing in drives is noted this summer.

1905.

June 23,32 pregnant cows were dismissed from a drive of about 600 seals at N. E. Pt.

June 30,8 cows were dismissed from a drive at N. E. Pt.

July 26 , I7 cows were dismissed from a drive at N. E. Pt.

July 28,75 cows were dismissed from a drive from Zapadni.

July $3 \mathrm{r}, 32$ cows were dismissed from drive from Reef.

August 10, 97 cows were dismissed from food drive from Reef.

1906.

July 28,4 cows were dismissed from drive from Polovina.

1907.

October 31,40 pups and II 6 cows appeared in a food drive from Reef Rookery. 
1908.

October 20 , few cows in the drive from Reef.

October 29, only a few cows in a drive from Tolstoi.

1909.

July 30 , to cows dismissed from drive from Zapadni.

July 31,4 cows in drive from Reef and Gorbatch.

October 20, 34 pups and a large number of cows were dismissed from a food drive from Tolstoi.

November I, 45 cows were dismissed from food drive from Reef.

November 13, 52 cows dismissed from food drive at Northeast Point.

The great majority of these records relate to dates very late in the season; in fact, only three are earlier than July 24. Two of these are June records and undoubtedly refer to drives improperly made from a breeding ground. It is evident that with careful driving prior to Ausust $\mathrm{I}$ there is little danger to the females, but that later in the season even small food drives are made at considerable risk. If a system of cold storage of meat were installed on the islands and the worling force of men trained to high efficiency, all killing might well be confined to the months of June and July.

Owing to the fact that few seals have been killed since I9II, a large number of five and six year old seals now haul out with the younger bachelors and are included in the bands of seals which are driven to the killing grounds. These large seals are a source of considerable delay and annoyance and some danger. It is always possible to eliminate a part of them, as they travel more slowly than the younger animals and may sometimes be left behind. Some, however, refuse to be discarded, and as the younger seals show a tendency to rally around the-larger ones, it always happens that some remain with the drive. Since they travel slowly, the speed of the entire company must be accommolated to their gait, and the younger seals are trampled and hampered and fatigued by their unwieldy companions. Some of the larger seals which are thus included in the drives become very vicious. There are instances of sealers being seriously injured by the sudden attack of one of these stubborn animals.

Within the next few years, unless some means are taken to reduce the number of these large seals, they will become sn abundant that driving will be a matter of difficulty.

\section{THE SEALING SEASON.}

The season during which commercial killing is possible is short. The bachelors are most numerous at the same time that the breeding animals are at their height of abundance-from the last of June to the end of August. The so-called "stagey" season, when the animal is moulting, begins about the Ist of August, and this reduces the effective period of greatest abundance to about one month. In order to take the fullest advantage of the short season it is necessary to begin before the time of greatest abundance. In past years the bulk of the catch was taken between the middle of June and the zoth of July, though a few were killed in late May and a few up to the last of July. This very short season necessitates that every possible facility for effective work be provided. Even under the best conditions days will frequently occur during which it will be impossible to work to advantage, and this emphasizes the need for thorough preparation, so that the favorable days may be utilized to the fullest extent. 


\section{SKINNING.}

The seals after being killed are laid in rows far enough apart to allow each skinner to work on his subject without impeding the movements of his neighbor. An incision is first made from vent to throat; continuous with this cut, incisions are made around the head in front of the ears, and around the base of the hind flippers; a cut is also made around each fore flipper close to the body. Beginning at the middle of the ventral cut the native then rapidly separates the skin from the body, holding the skin slightly stretched and cutting through the subcutaneous layer of blubber with rapid, sweeping strokes. Each fore flipper is worked out of the circular cut at its base, and the remainder of the skin, after being separated from the body, falls free of head and limbs. The result is an ovate pelt with two circular holes where the fore flippers were removed.

The skin of the head from the ears forward, known as the mask, has customarily been left on the carcass and allowed to waste. It is probable that these masks include enough good fur to give them a substantial value. They are easily removed and preserved and have sometimes been taken as perquisites by the natives, who have sold them for small sums to the natives of Unalaska and to chance visitors to the Pribilofs. The value of these masks should be investigated and if it be found profitable, as seems likely, they should be regularly taken and marketed.

A layer of fat from one-fourth to one-half an inch in thickness is left on the skin. This is allowed to remain and helps to keep the skin in the moist flexible condition desirable for its proper dressing. The process of skinning requires much skill and care. A chance cut greatly reduces the value of the skin; too much blubber may result in imperfect curing and consequent loss; while a dearth of blubber may allow the skin to become dry, which interferes with the process of dressing. Some of the more expert of the natives are able to skin a seal in two minutes, but the average time is longer. To retain the desired degree of skill it is, of course, necessary that the work be kept up. It is evident that the suspension of killing during the past few years has already resulted in considerable loss of skill, even among the experienced men, while the younger men have had practically no opportunity to acquire efficiency.

\section{CURING OF SKINS.}

The method of curing the skins has been detailed so often that only a brief description is necessary. After being allowed to cool on the ground so that the animal heat is lost, the skins are taken to the salt house where they are numbered and weighed individually, and recorded. The process of weighing consumes a great deal of time and should be discontinued, as under Government management it serves no useful purpose. A simple system of flesh measurements, as explained beyond, should be substituted. The skins are then laid flat, fur side down, and having been carefully spread to guard against the persistence of folds or wrinkles, are covered with salt. Successive layers of skins, each well salted, are placed in the bins or "kenches" until the entire catch of the day is cared for. In this state they are allowed to remain a week or ten days, when they are shaken clear of salt and are examined critically to make sure that all parts of the skin hav"e been cured. They are then repacked in a compact pile, called the "book," the process being similar to that of the original salting, but less salt being used. Here they remain until such time as they are to be shipded, when they are tied into bundles, each containing 
two skins placed flesh to flesh, with a small quantity of salt between to keep the skins moist and pliable. Much of the salt now in the bins or kenches has been in use so long that it has become so coated with dirt and grease that its solubility and consequent curing power is considerably lessened. Unless this old salt can be freed from the foreign matter which accompanies it, much of it should be thrown away. It is believed also that the substitution of a finer grade of salt, which would be more easily soluble, might have advantages. It may be possible to cleanse and reduce to finer grains some of the salt now on hand. This amounts to many tons, and by utilizing the native force, the expense and trouble of actually replacing it may be avoided.

\section{NEED OF COMPETENT SUPERVISION.}

It is evident to any one who has observed a gang of the natives at work that they need constant and intelligent supervision. Left to themselves they are rather careless and indifferent. This is in part due to their natural lack of care for detail, and partly to the fact that they have fallen behind in efficiency because of the decline in the amount of sealing. It was noticed that in making drives they allowed the seals to travel in too large bunches, resulting in an excessive amount of trampling. This fact being recognized, a drive made under special direction was managed differently. The seals were drawn out into a long line, only a few abreast, and a much longer drive than usual was made with decidedly less distress and, according to the natives, in the quickest time on record. In some of the illustrations of driving as practiced during the days of extensive killing, the seals are represented as being driven in this way, and it is probable that the carclessness observed in 1914 represents merely a lapse from a method formerly recognized as efficient and proper.

\section{MEASUREMENTS VERSUS WEIGHTS.}

It lias long been the custom in selecting seals of the proper age for killing, to rely on the weight of the skins as a criterion. Those below a certain weight were considered 2-year-olds; those above this weight and below another higher weight were considered 3 -year-olds, and so on. The uncertainty of this method, and the impossibility of confining the killing strictly to certain ages by its application has been amply demonstrated. Measuring the skins also has been found to be very unreliable because of the extreme flexibility of fresh skins. The large amount of variability in the weight and measurements both before and after salting has been demonstrated repeatedly. The fact that neither the weight nor the measurements of a skin can be taken until it is removed and all connection in the minds of the sealers between a particular skin and the seal from whose body it was taken is necessarily lost, must always remain an insuperable argument against its practicability. It should be stated, moreover, that the confinement of killing to particular classes of seals in the past has been due more to the judgment of the clubbers than to the system of weighing skins.

Under complete Government control there can be no temptation to take animals below the prescribed age, and the time-consuming system of individual weighing should be abandoned. Notes made in 1914 show that the process of weighing roo skins takes two men about one hour. As before stated, this necessarily has to be done at a time when every consideration of economy demands that the skins on hand be placed in the salt as cquickly as possible, and thus it interferes greatly with the proper utilization of the services of the working force. 
The measurements of the seals of a given age are much more uniform than the size or weight of the skins. The most important measurement and one that is easily taken is the length from the end of the nose to the root of the tail, and the idea was conceived of using this measurement as a standard for judging the age of seals killed. It was found entirely practicable to take this measurement for each one of the seals without delaying the progress of the work as they were laid out in rows preparatory to skinning. The most satisfactory method of measuring is by means of calipers similar to those employed in measuring timber. The one used experimentally was made by fitting a fixed and a movable arm to a rod marked for feet and inches. Even with this improvised instrument it was found practicable to ascertain the length of the animal easily and quickly. As explained elsewhere, a large number of skulls of seals killed in the food drives were preserved. Some of these were of seals branded as pups in Igr 2. These specimens of known age, studied in connection with the flesh measurements and the weight of the fresh skins, serve as a basis for comparison with the older seals. The specimens include also a large series of 3 -year-olds and a few older seals. It was thus possible to ascertain the approximate size of the seals of different ages. Owing to the fact that there is a range of nearly two months in the actual ages of the seals of a given class, and because of the range of individual variation, there is a small percentage of animals whose age can not be absolutely determined even by careful examination. A careful study of the data at hand, however, convinces that this proportion is probably not greater than $\mathbf{I}$ in 50 and may be regarded as negligible. To show how much greater is the variation in the weight of the skins of seals of a given age, compared with the total length, the data regarding a killing of 6I seals made on August ro may be briefly discussed. These seals were selected with ordinary care by the natives as being 3-year-olds. Before they were skinned the length of each animal from the tip of the nose to the base of the tail was taken with calipers and this measurement was recorded against the tag number of the skin. Ten skulls selected at random from the lot were saved for examination. Each skin was then weighed before being salted.

Of the $6 \mathrm{I}$ seals, 56 ranged from 44 to $49 \frac{1}{2}$ inches in length. Of these, 8 measured 44 to $44 \frac{1}{2}$ inches; Io, from 45 to $45 \frac{1}{2}$ inches; 12 , from 46 to $46 \frac{1}{2}$ inches; 8 , from 47 to $47 \frac{1}{2}$ inches; Io, from 48 to $48 \frac{1}{2}$ inches; 8 , from 49 to $49 \frac{1}{2}$ inches. Of the remaining 5 seals, I (probably a 2 -year-old) measured $f$ inches, and the skin though fat weighed only 5 pounds and 1 ounce; one measured $42 \mathrm{I} / 2$ inches, and 2 measured 43 inches; the remaining one measured $5 \mathrm{r}$ inches and since its skull was that of a 3 -year-old it doubtless represents the maximum size for this class.

Regarding the weight of the skins of the 56 animals ranging in total length from 44 to $49 \frac{\mathrm{T}}{2}$ inches, every one of which was certainly a 3 -year-old, the lightest weighed 5 pounds $6 \frac{\pi}{4}$ ounces, and the heaviest 9 pounds $10^{1} / 4$ ounces. The variation in measurements was thus only I I per cent of the maximum, while the variation in the weight of skins was 44 per cent of the maximum. The 12 skins from animals of practically the same length- 46 to $46 \frac{1}{2}$ inches-ranged in weight from 5 pounds $6 \frac{1}{4}$ ounces to 8 pounds $5 / 4$ ounces.

An incident showing how little dependence can be placed on the weight of skins as a criterion for age occurred on August 6, when a skin weighing I I pounds $73 / 4$ ounces was noticed to bear an excessive amount of hesh, probably having been skinned by an inexperienced native. After being divested of the superfluous muscle and fat, it was found to weigh 9 pounds $I I 3 / 4$ ounces, a difference of $I 3 / 4$ pounds. 
From a careful study of these and other data, it is believed that the present practice of weighing each skin should be discontinued and that a check complying with all reasonable requirements may be made by the use on the killing field of calipers by means of which the seals may be rapidly measured by the person in charge. Seals between 42 and $5 \mathrm{I}$ inches in body length may be considered as 3 -year-olds with but little chance for error. If it is found that seals under or over the proper size are being killed, the fact can be immediately and graphically impressed on the minds of the working force. If desirable, skins of seals departing from the standard may be tagged in the field and a record made of the size or weight, but even this does not seem necessary. It is believed that the real object-the securing of skins of a uniform class-will be accomplished by this method with a minimum of effort, with no waste of valuable time, and with much more accuracy than has been possible under the methods formerly in use.

\section{TAGGING OF SKINS.}

The affixing of a leather tag bearing a serial number to each sealskin as a mark of authentication, while it affords a help in recording weights or measurements, does not seem necessary. A tag can, of course, be removed at will and either thrown away or attached to another skin, and therefore does not certainly identify any particular one. Furthermore, it is not practicable to dress the skins without removing the tag. It is therefore necessary to replace the leather tag by pricking in the skin a number or symbol which can by no process be obliterated or hidden, and which, while the skin remains intact, must constitute a distinctive mark.

In view of these facts it seems that the small advantage gained by the system of tagging each skin does not justify the expense and trouble involved, especially if the troublesome and misleading process of recording the weight of each skin be abandoned.

The authentication of the Pribilof Island sealskins will be rendered a matter of certainty by pricking on each skin the letters $\mathrm{P}$ or $\mathrm{G}$, followed by some number or symbol to express the year of capture; e. g., P-I5 or G-15, to express St. Paul or St. George, 1915. This process of pricking can be effected by a single motion with a small hand instrument as the skins are counted into the salt house preparatory to curing, and the mere recording of the number of skins taken at a killing or during a season can be done as readily as under the present laborious system. As before stated, certain skins which for any reason require special marks may be tagged as at present.

\section{PRACTICAL IMPROVEMENTS NEEDED.}

\section{PRESENT UNIMPROVED CONDITION OF PLANT.}

It is evident to anyone considering the matter from an unprejudiced standpoint that many improvements are needed in order that the work of sealing, the principal business of the islands, may be more effectively accomplished. The Pribilof Islands, with their herds of fur seals greatly surpassing in number and value any others in the world, constitute a plant equivalent to a private business with an investment of millions of dollars. It is plain that such a business deserves to be put on the most efficient working basis possible. The need of a larger administrative force on the islands and of improvements in some of the methods of the actual work of sealing or of the other 
industries more or less directly concerned are treated elsewhere. Under the following heads will be considered particularly the needed improvements and changes of a more or less mechanical nature.

\section{REFORMS CONTEMPLATED BY LESSEES.}

The desirability of making certain of the improvements recommended in the present report has been repeatedly pointed out in past years, even before the taking over of the sealing business by the Government. Various improvements were contemplated by the later lessees toward the close of their occupation, but the uncertainty of the renewal of the lease prevented active steps for their adoption. Since the abandonment of the system of leasing, little progress has been made in improving the plant or in instituting useful changes. This has been due partly to the death or serious illness of valuable members of the island force and partly to the results of the agitations which have beset the general administration of affairs. The prevailing impression that the seal herd was reduced to very small and unimportant proportions also contributed to inaction.

\section{BETTER METHODS OF TRANSPORTATION NEEDED.}

One of the most important of the improvements needed is the installation of better facilities for transportation. These may be considered under two heads: (I) Facilities for traveling and moving supplies on the islands, and (2) the transportation from the United States to the islands of the necessary supplies and the moving of the annual catch of seal and fox skins to market.

Roads and trails. - A pressing need is the establishment of better facilities for reaching Northeast Point from the village. It is believed that the construction of a tramway to be traversed by a small gas engine would prove most satisfactory. It would be about I2 miles in length and would connect some of the most important hanling grounds with the village, where the only feasible landing places are located. A spur road about + miles long would reach Zapadni and would thus allow prompt access to all the important parts of the island. In the event of a raid on the rookeries, prompt action would be of the highest importance, while the moral effect inspired by a state of preparedness might go far in preventing such an occurrence. A wagon road, much of which is deep in sand, now connects the extremities of the island, but under present conditions travel by mule team is scarcely faster than progress on foot. In the days of active commercial sealing nearly one-third of the skins from St. Paul Island were taken at Northeast Point, and as the facilities for landing there are very poor, the importance of a ready means of hauling the skins to the village, when sealing is resumed, is apparent. The installation of a tram road would also provide for the prompt delivery of the sealing force at the scene of their labors whenever a killing was planned and the skins secured could be promptly transported to the main salt house and there cared for more economically than at Northeast Point. This road would also serve as an important aid in properly distributing seal meat intended for the foxes or for other purposes.

Whether or not a tram road to Northeast Point is installed, the construction of a number of shorter roads on both islands is important. One from the village of St. Paul to Reef Rookery is highly desirable, as it would permit killing near the rookery and would do away with the killing ground now situated at the edge of the village. Foot 
trails to the various rookeries near the village may also be laid out at a trifling expense, and would allow ready access by foot or horseback for purposes of inspection and study.

On St. George Island no draft animals are now used, but the construction of a road connecting Garden Cove with the village seems important. It often happens that a landing can be made at Garden Cove when none other is possible, but this place can not be used for the landing of general supplies because of the lack of any means of transporting the goods to the village, a distance of about 3 miles. Because of this it is sometimes impossible to land urgently needed merchandise. A foot trail now connects these places, and another facilitates travel to Zapadni, 5 miles from the rillage. There are trails to North and Fast ronkeries also, but they need improvement. A road to Staraya Artel, at present the most important hauling ground on the island, also seems desirable. The seals are now driven to the village, a distance of about $2, \frac{1}{2}$ miles, and a road would do away with the necessity for this long drive.

The importance of a better system of transportation in connection with the problem of distributing fox food has been referred to in the account of that animal. The fox herds represent very valuable possibilities, and it is important that their needs be fully considered.

Supply ship.-For the transportation of the supplies needed for the Pribilof Islands the charter of a ship of approximately $r, 000$ tons is necessary. For the Homer, which has been employed for several seasons on this work, the average cost for the past four seasons was a little over $\$ 2 \mathrm{I}, 000$. The cost of the Melville Dollar for the season of I914 was a little over $\$ 18,000$ for 59 days, or slightly over $\$ 300$ per day. It would seem that an annual expenditure of this amount would justify the acquisition by the Bureau of Fisheries of a ship to be used chiefly or entirely for the Alaskan service. Two trips to the islands should be made; the first with the opening of narigation and another as late in the autumn as the weather conditions allow.

The landing of cargo on the Pribilof Istands is a matter of considerable difficulty. There are no wharves nor even harbors on either island. A ship must lie at some distance offshore in such place as affords the best shelter under the prevailing condition of the wind. It frequently happens, under stress of weather conditions, that the place most favorable for landing cargo has to be abandoned while the ship weathers out the storm in some more favorable spot. All cargo must be landed in the native boats called bidarras, which are made by stretching a cover of sea-lion shins over a wooden framework. In spite of the increasing difficulty of procuring enough shins suitable for this purpose, the use of the native boats has been continued. They have the distinct advantage of being so constructed that they stand the buffeting against the sides of the ship without injury. They can carry only about 5 tons, however, so that the landing of the cargo of approximately soo tons necessitates a great many trips, even with the use of two boats. During the season of $19 \mathrm{I}_{4}$ the ship was detained 9 days at St. Paul and I2 days at St. George at a cost of $\$ 300$ per day in landing the cargo. It is evident, in view both of the growing scarcity of the sea lions and of the objections to the use of the skin boats, that some substitute for the latter must soon be found.

In many places cargoes are landed by means of a car running on a cable which is stretched between the anchored ship and a high point on the shore. Steps should be taken to ascertain whether this or some other efficient method can not be used on the Pribilof Islands. 


\section{COLD-STORAGE PLANTS.}

With the resumption of sealing on a commercial scale and with better methods of local transportation, it is believed that the establishment on each island of a small coldstorage plant would be a wise and economical project. The great quantities of seal meat, above what can be used by the natives and to support the fox herd, should not be allowed to go to waste. Cold storage would not only provide for preserving the winter supply of meat for the natives and for the fox herd, but would allow the surplus to be economically utilized for other purposes. There are on the Aleutian Islands and elsewhere in northern Alaska many communities of natives which have been reduced to actual want through the cessation of sea-otter hunting, the extirpation or reduction in numbers of other animals formerly relied on, or from the desertion of routes of trade which formerly brought them employment. The partial or entire support of some of these people must eventually be borne by the Government. Unalaska was formerly the center of a prosperous sea-otter trade, and later the scene of much activity by reason of its being a stopping place for vessels bound for northern Alaska, but is now of little importance as a port, and its inhabitants are much reduced in circumstances. To such a community a portion of the seal meat which might be wasted on the Pribilofs, only 200 miles away, would be of the utmost importance. It is also by no means unlikely that a market for a quantity of the surplus meat, which is very nourishing and not unpalatable, might be found among the poorer classes in the cities of the west coast of the United States.

A further important advantage to be gained by the use of cold storage would be found in the possibility of limiting the driving and killing of seals to the season when females are not associated with the young males. The accidental and very undesirable killing of even a few cows might thus be almost entirely avoided.

\section{ROOKERY IMPROVEMENTS.}

Some work in improving the ground on several of the breeding rookeries should be done. This is a matter which has been frequently discussed, but very little has been accomplished. The perpetuation of the series of marked rocks to facilitate the taking and recording of observations is also important.

Marked rocks.-On each of the rookeries is a series of rocks marked by numbers put on with white paint, the work of the Coast and Geodetic Survey. These rocks serve as landmarks for locating and recording the harems and the boundaries of hauling grounds. Many of the numbers, from long exposure to the weather, are becoming obliterated and in some cases can no longer be deciphered. Since these marked rocks have figured in the records of observations for several years, it is very important that they be repainted when necessary.

Observation stations. - In some of the more crowded rookeries it is very difficult to count the harems, and as it will be desirable to count them for several years at least, a few observation stands should be built. They may be towers of rock a few feet in height, and in some cases will need to be connected with the rear of the occupied space by lanes protected by walls of rock which afford a safe path through the rookery mass. At present Reef Rookery is most in need of these observation towers. In 1914 it was S4512 -S. Doc. $950,63-3-7$ 
difficult to count the harems there, and if the breeding area is increased in future years, as is almost certain, it will be impossible to make an accurate count without their aid. An inclosed station on Gorbatch for the accommodation of visitors to the islands also would serve a useful purpose, since it is now difficult to carry out the regulations in regard to the inspection of the seals by persons landing on the islands for a few hours and desiring to see the seals.

Improvement of ground.-Although the breeding ground preferred by the seals is decidedly meven in character, some of the occupied areas are so rough that the cows and pups are exposed to considerable discomfort and danger. Small hollows between bowlders afford refuge to the pups and protect them from trampling, but where deep cavities occur pups and occasionally cows may be unable to escape from them and may perish. These cavities are a source of great annoyance also in the work of counting the pups, as it frequently happens that several dozen must be pulled bodily from a cavern before any idea of their number can be gained. Certain stretches on Lukanin, Gorbatch, and Tolstoi are particularly troublesome.

By blocking the entrances to the larger cavities and by filling the smaller ones with loose bowlders the rookery grounds can be greatly improved. A few days' work with a gang of men would give good results. It would be advisable to do as much of this work as possible in the spring before the arrival of the bulls in order that the animals of that season might benefit by the improvement.

On Polovina Rookery there are a number of cares in the soft bank, evidently formed by the action of the waves during the storms of winter, which become packed with the little pups. Nearly a hundred were taken from one of these caves during the pup counting of I9I4. As these soft banks are constantly crumbling, there is always danger of some of the little creat ures being buried by the slipping of a part of the bank. These places should be inspected each spring, and such portions of the bank as seem dangerous should be cut down. The likelihood of haring to pave sandy areas which in the past have been affected with Uncinaria should not be lost sight of. While no evidence of this pest was found in 1914 , it may recur at any time. Areas which were especially favorable to the spread of the plague have been improved from time to time by being partially covered with rock, and this treatment appears to have borne good results. Close watch should be kept, and at the first evidence of the recurrence of the pest the affected places should be partially or completely pared. The shrinking of the rookery areas in late years has naturally led to the abandonment of some of these affected spots, but with the increase of the herd they will doubtless be reoccupied and may again become serious sources of mortality.

\section{THE EFFECT OF EXISTING LAWS.}

Among the matters to which special attention was directed in the instructions for the investigation of $191+$ was "The strength of the surplus male life in relation to the close-time provisions of existing law and to treaty obligations."

The most recent law affecting the seal herd, and the one under which it is chiefly administered, became effective August 24, 1912. It provides that all killing of fur seals be suspended for a period of five years, except the limited number of male seals needed as food for the natives. It further provides that not less than 5,000 males shall be reserved for breeding in each year after the resumption of killing until r926, 
and thus prescribes by exact figures the nature of the management of the herd for a period of 14 years, or until the expiration of the international agreement by which pelagic sealing was stopped. The text of the law relating to these important provisions is as follows:

SEC. II. That from and after the approval of this act all killing of fur seals on the Pribilof Islands, or anywhere within the jurisdiction of the United States in Alaska, shall be suspended for a period of five years, and shall be, and is hereby, declared to be unlawful; and all punishments and penalties heretofore enacted for the illegal killing of fur seals shall be applicable and inflicted upon offenders under this section: Provided, That this prohibition shall not apply to the annual killing on the Pribilof Islands of such male seals as are needed to supply food, clothing, and boat skins for the natives on the islands, as is provided for in article eleven of said convention; the skins of all seals so used for food shall be preserved and annually sold by the Government, and proceeds of such annual sales shall be covered into the Treasury of the United States: Provided further, That at the expiration of the said five years' suspension of all commercial killing as above provided, said killing may be resumed under authority of the Secretary of Commerce and Labor: Provided, however, That the number of three-yearold males selected from among the finest and most perfect seals of that age found on the hauling grounds to be reserved for breeding purposes, in each year ending August first, shall not be fewer than the following: In nineteen hundred and seventeen, and in each year thereafter until nineteen hundred and twenty-six, inclusive, five thousand.

\section{THE LAW EFFECTIVE FOR LONGER THAN INTENDED.}

This law, which was introduced in the House of Representatives on February I5, 1912 , was pending during the sealing season of 1912 , and, in the expectation of its passage at an early date, operations were limited until its final provisions should become known. This did not occur until the season had closed, the result being that although the law was not in force during that season the effect was the same, for only 3,764 seals were killed, a number scarcely sufficient to supply meat for the natives. Thus the close-time provision of the law was in effect increased from five to six years, and in actual practice the law will operate one year in excess of its intent.

\section{AS A BENEFICIAL MEASURE THE LAW HAS SERVED ITS PURPOSE.}

At the present time, therefore, commercial killing has been suspended for a period of three seasons, though the law has actually been on the statute books but two years. What has been accomplished in these three scasons is of the highest importance. The law is entitled "An act to give effect to the convention between the Govemments of the United States, Great Britain, Japan, and Russia for the preservation and protection of the fur seals and sea otter which freguent the waters of the North Pacific Ocean, concluded at Washington July seventh, nineteen hundred and eleven." Obviously it was a conservation measure, and now, after three years, it may be inquired how far its intent has been fulfilled.

In 1912 , when the law was under discussion, conditions were very different from those at present. At that time pelagic sealing had just been stopped, the herd was at a low ebb, male life was greatly reduced, the real or supposed evils of former systems of management were fresh in mind, and conflicting opinions were freely expressed as to the fate of the seals. The ultimate needs of the herd were obscured by the complicated and special nature of the subject and by its long, involved history, in which almost all important points were rendered elusive by the uncertain factors contrihuted by pelagic sealing. Under these circumstances it was inevitable that the law as finally 
passed would be something of a compromise except as to its main feature, which was that the seals receive immediate and practically unqualified protection.

In I9I4, after three years without pelagic sealing and without commercial hilling on land, the herd is found to be in flourishing condition, the stock of breeding females appreciably increased, an ample supply of breeding males assured, and a large surplus of males immediately impending. To produce such conditions was doubtless the main object of the law, and it is evident that as a purely protective measure the law up to the present time has been successful and beneficial. This improvement in the herd, however, seems to indicate that at least certain provisions of the law no longer accord with its intent.

\section{EVILS OF LEASING SYSTEM NOT POSSIBLE UNDER GOVERNMENT MANAGEMENT.}

The herd is now beyond the danger point, and with full govemmental control, protection of the seals and conservative management would be assured without special restrictions. Departmental officers having discretionary power, and even agents on the islands, could have no possible incentive for furthering any interests other than those of the Government itself. A law restricting hilling does not guard against the cupidity of any private individual or any Government employer, because under the new system no one can gain by excessive killing. Under private leasing, whether or not irregularities existed, it is conceivable that the system might have offered temptation to dishonest parties; but under full governmental administration circumstances can scarcely be imagined in which individual officers could derive personal profit at the expense of the Government's interest. Detailed regulations influenced by real or supposed injurious practices of the past, therefore, are entirely unnecessary at present. The general laws against official misconduct cover practically every possible contingency.

\section{FLEXIBLE REGULATIONS DESIRABLE.}

The nature of sealing as a business is such that restrictions of a fixed and absolute character are highly impractical. Living animals subject to the ravages of disease, to the inroads of natural enemies, to the vicissitudes of an unusually stressful existence, and to the varying results of peculize breeding habits can not be successfully managed under inflexible rules laid down long in advance. The establishment of close seasons for game animals, especially those of the deer family, is quite a different matter from the restriction of killing of fur scals. A comparison of fur seals with American elk, caribou, or prong-horned antelope in this connection would scarcely be made by any one having first-hand knowledge of the nature and habits of the seals as well as of the game animals. If all the elk, caribou, or antelope living came annually to a Government reservation where they could be enumerated and proportioned as to age and sex, there would be no reason to prohibit the killing of males not needed as breeders.

Among wild animals the fur seal is unique in many respects. Although not actually under domestication, it is by nature and habits almost strictly comparable to a domestic animal, and the principles governing its management should unquestionably be those employed by breders of live stock. Rigid rules of procedure, therefore, are as inadvisable in the case of the seals as they would be with horses, cattle, or sheep. So far as possible, regulations should be sufficiently elastic to take adrantage of conditions as they 
arise. The number of males which should be killed or reserved can not, in the nature of the case, be absolute. It is not and never can be a fixed number, and the only possible way in which it can be stated in advance is in relative terms. That is, the number to be killed or to be reserved in any given season depends upon the number that are present in that season and upon the relation which the number of males of certain ages bears to the number of females. With pelagic sealing abolished, these numbers and proportions can be determined with all reasonable accuracy. Whether the herd be large or small, diminishing or progressing, good management demands discretionary power in the lands of responsible officers in order that action may be governed by circumstances. Inflexible rules applied to living animals are dangerous under any circumstances and in the case of the seals are no more necessary nuw than they will ever be. The relative proportions of males and females should be the same in a herd of a thousand seals as in one of a hundred thousand or a million, and in any case it is wholly a matter of proportions, not of fixed numbers.

\section{RESERVES UNDULY LARGE.}

The subject of reserving males for breeding has received careful consideration in the present report. It has been recognized that the number of bulls in recent years may have been inadequate, and it has been concluded that in the future a much larger supply would be desirable, even to the point of having somewhat more than the requirements of a most conservative ratio of males to females. But the reserves of the law go far beyond the needs determined by a careful investigation of present conditions.

Aside from the close-time provision of existing law, which in itself provides more males than necessary, the subsequent reserves of 5,000 per annum are excessive. After thorough and unprejudiced investigation it is found impossible by argument or calculation to justify such large reserves. As shown elsewhere (p. 82), the close-time and the later reserves will produce an enormous supply of males unwarranted by any policy, unless it be one of permanent cessation of killing for sentimental reasons. Such a policy is, of course, impractical, for it wonld mean a return to pelagic sealing, which is brutal in the extreme, whereas land killing is quite as humane as the killing of domestic animals for food. This great excess of mules would doubtless cause some increased fighting and consequent mortality detrimental to the herd, but laying this aside as of minor importance, it is evident that a great waste is involved. The money loss alone during the period affected promises to be very large, not less than $\$ 2,700,000$ by most conservative estimates.

It should be stated that if these reserves were liberal merely to provide for emergencies or errors in estimates, no objection to them could be urged. But they are much more than liberal, since they provide not twice as many but several times as many as a very conservative ratio of males to females would require. In the end it is believed they would produce a stock of some 50,000 bulls where less than 10,000 would be a liberal allowance. That is, if bulls and cows increase at the same rate, the law provides for a herd in $192 \mathrm{I}$ in which there would be one bull for every three cows, instead of one to forty, the a reasonable ratio. 


\section{MATTERS FOR SPECIAL DISCRETIONARY POWER.}

Emcrgency action.- The concurrent action of the law of 1912 and the previous law of April 21, r910, places such restrictions on the killing of seals that eren in cases of urgent necessity action could not legally be taken.

The clauses bearing particularly upon this matter are as follows:

ACT OF APRIL 2I, 1010.

Sre. 6. That section nineteen lundred and sixty of the Revised Statutes of the United States and section one hundred and seventy-seven of the act of March third, eighteen hundred and ninetynine be amended to read as follows:

It shall be unlawful to kill any fur seal upon the Pribilof Islands, or in the waters adjacent thereto, except under the authority of the Secretary of Commerce and Labor, and it shall be unlawful to kill such seals by the use of firearms or by other means tending to drive the seals away from those islands; but the natives of the islands shall have the privilege of killing such young seals as may be necessary for their own food and clothing, and also such old seals as may be required for their own clothing and for the manufacture of boats for their own use; and the killing in such cases shall be limited and controlled by such regulations as may be preseribed by the Secretary of Commeree and Labor.

SEC. 7. That section nineteen hundred and sixty-one of the Revised Statutes of the United States and section one hundred and seventy-eight of the act of March third, eighteen hundred and ninetynine, be amended to read as follows:

It shall be unlawiul to kill any female seal or any seal less than one year old at any season of the year, except as above provided; and it slall also be unlawful to kill any seal in the waters adjacent to the P'ribilof Islands, or on the beaches, clifis, or rocks where they haul up from the sea to remain; and every person who violates the provisions of this or the preceding section shall be punished for each offense by a fine of not less than two hundred dollars nor more than one thousand dollars or by imprisonment not more than six months, or by both such fine and imprisonment; and all vessels, their tackle, apparel, and furniture, whose crews are found engaged in the violation of either this or the preceding section shall be forfeited to the United States.

ACr OF AUGUST 24. I0I2.

SEc. II. That from and after the approval of this act all killing of fur seals on the Pribilof Islands, or anywhere within the jurisdiction of the United States in Alaska, shall be suspended for a period of five years, and shall be, and is hereby, declared to be unlawiul; and all punishments and penalties heretofore enacted for the illegal killing of fur seals shall be applicable and intlicted upon ofienders under this section: Provided, That this prohibition shall not apply to the annual killing on the Pribilof Islands of such male seals as are needed to supply food, clothing, and boat skins for the natives on the islands, as is provided for in article eleren of said convention: * * *

From this it appears that in the event of a sudden epidemic of disease or in any other cmersency requiring immediate and perhaps drastic measures, no oflece would have authority to kill female seals. The provision against the use of firearms has a similar effect since conditions may arise making it advisable to kill certain animals, as vicious old bulls, which can not be put to death by the usual methods. In addition, ordinary humane action in the case of wounded or in jured seals is probibited. Pups or cows may be found mortally wounded by the bull or by falling rocks, but under the law they can not be put ont of their misery and must be allowed to suffer a lingering death. Several cases of this kind occurred in the season of 1914 . Under present conditions there are no alvantages ganed by these provi-ions of the law. The agents ane not and can not be under any temptation to permit unnecessary killing of females or young, but exen if they should be, the matter could be gerernd by regulations limiting regular killings to seals from the hauling grounds and to the season ending July $3 \mathrm{I}$. 
Annual sale of skins.- In section II of the law of 1912 it is provided that "the skins of all seals so used for food shall be preserved and annully sold by the Government." A further provision of the same section relating to the disposition of skins obtained from commercial lillings and from the Governments of Great Britain and Japan utites that "all skins which are or shall become the property of the United states from any source whatsoever shall be sold by the Secretary of Commerce and Labor in such market, at such times, and in such manner as he may deem most advantageous." 'Thus at least food skins taken during the five-year period of restricted killing are to be sold annually, and by construing the first provision of the law as governing the second, the same course will be necessary with all skins taken in the future.

Obviously it would be to the interest of the government to be able to take advantage of the best market conditions in all cases. A temporary depression, such as that caused by the European war, would make it advisable to postpone the sale to a more favorable date, but under the present laws this can not be done without special authority from Congress. ${ }^{a}$ 'The sale has usually been conducted in December or January. The time between the shipment of the skins and the sale may be so short that conditions are likely to arise making it desirable to postpone the sale for several months. Even slightly depressed market conditions during the restricted period allowed for the sale might cause serious loss.

Specimens for scientific purposes.-The laws make no provision for the preservation of specimens of the fur seal for scientific investigation or for exhibition in public museums. It is altogether probable that in the future management of the herd practical problems will arise which can not be settled except by research involving the killing of certain seals, including some proportion of fenales and young. Such problems may relate to breeding and reproduction, to ascertaining the cause of disease, or to various other matters. Although of technical nature, they may be of great economic importance, and failure to provicle for them may result in lare financial loss. During the investigation of $19 \mathrm{I}$, the lemal prohibition arainst killing females proved embarrassing, and certain matters which otherwise night have received attention were therefore disregarded. The preservation of specimens of the fur seal in public museums is surely worthy of consideration because of the educational service to the public. Many of our museums have very few or no specimens of the fur seal, and even in the United States National Museum, where such an important and interesting animal should be well represented, the specimens are old and imperfect. Under the law, even the shins of seals that have died from natural causes and which may have only trifling money value, must be sold like any others.

It is plain, therefore, that a provision which would place the killing of seals for scientific or educational purposes within the discretion of a responsible oflicial would be very desirable.

\section{EFFECT OF RESTRICTED SEALING ON THE FOX HERD.}

The blue foxes of the Pribilof Islands constitute an important and valuable asset. Undue restriction of sealing not only causes a reduced revenue from the seals but

a This was found necessary in December, Ig:4, when a joint resolution to postpone the sale of fond skins for that season was introduced in Congress. Such action would have been unnecessary if the time of sale had been within the discretion of a respon. sible official. 
involves an additional loss through its effect on the foxes. As shown in the special discussion (p. I06), the decline of the output of fox skins has been coincident with the reduction of seal killing and is due to the lack of a sufficient supply of seal carcasses upon which the foxes are dependent. This decline has progressed more rapidly since the limitation of sealing imposed by the law of 1912 until at the present time the fox industry is in a highly undesirable condition, the animals being greatly reduced in number and the stock deteriorated in quality and vigor. The resumption of sealing on a larger scale would provide means for the upbuilding of the fox herd; otherwise prompt measures of some other sort will be necessary. The main problem is one of food supply, and owing to the isolation of the islands and the poor facilities for communication the securing of fox food other than seal meat is beset with difficulties. Therefore it is desirable that seal meat be provided for then at the earliest possible tine; that is, as soon as the condition of the seal herd will warrant it. That this time has already arrived is evident from the general results of the investigation of 1914 , and while no consideration of the foxes should be permitted to jeopardize the sealing interests it is to be remembered that with the good condition of the seals assured the foxes are capable of producing a revenue not to be ignored.

In former years, without any attempt at careful management, more than $\mathrm{I}, 000$ fox skins were taken annually on St. George Island alone. Such an output, at the prices prevailing in recent years, would have realized a revenue of $\$ 40,000$ to $\$ 50,000$ per annum. That an equally large or a larger revenue may be obtained in the future is scarcely to be doubted if proper measures be taken now.

\section{THE TREATY.}

The treaty effective December 5, I9 I, between the United States, Great Britain, Japan, and Russia is essentially an agreement by which the foreign nations relinquish their right to take seals on the high seas in exchange for a share in land sealing to be conducted by the United States. The main assumption of the treaty is that the decline of the herd has been caused by pelagic sealing and not by land sealing, a conclusion formed and agreed upon by the joint conference of British and American experts after the investigation of 1896-97. The Governments of Great Britain and Japan paid large sums to retire their sealing fleets, obviously expecting to be reimbursed in the near future by their I 5 per cent share of land sealing. The United States is granted the right to suspend land sealing under two conditions: (r) To protect and preserve the seal herd, and (2) to increase its number. The statements of the treaty in regard to these provisions (Sen. Doc. No. 75, 62d Cong., Ist Sess.) are as follows:

ART. X, page 7, lines I5-22: Provided, however, That nothing herein contained shall restrict the right of the United States at any time and from time to time to suspend altogether the taking of sealskins on such islands or shores subject to its jurisdiction, and to impose such restrictions and regulations upon the total number of skins to be taken in any season and the manner and times and places of taking them as may seem necessary to protect and preserve the seal herd or to increase its number.

ART. XI, page 8, lines 25-32: If, however, the total number of seals frequenting the United States islands in any year falls below one hundred thousand ( 100,000 ), enumerated by official count, then all killing, excepting the inconsiderable supply necessary for the support of the natives as above noted, may be suspended without allowance of skins or payment of money equivalent until the number of such seals again exceeds one hundred thousand (IOO,, 00 ) enumerated in like manner. 
Without attempting to interpret these sections of the treaty, it may be stated that a number of American experts and officials, both scientific and legal, have expresseci the opinion that the right to suspend land sealing depends upon the need of the herd for protection and that unless this need can be demonstrated land sealing should go on under no limitation except that required for the preservation and growth of the herd. If this opinion be sound, the important question is, Does the herd need protection to the extent of continued suspension of land killing? Even assuming to the full that the herd did need protection when the law of 1912 was enacted, this nevertheless does not relieve us from the obligation of demonstrating that it still needs it now after three seasons without commercial sealing. No such necessity can be demonstrated. The condition of the seal herd in I $9 \mathrm{r}_{4}$, as set forth in this report, is such that resumption of commercial sealing on a moderate scale in I9I 5 could be undertaken with confidence that the protection and growth of the herd would not be jeopardized in the slightest degree. The inference is clear, therefore, that unless sealing be resumed agitation will be continued and the integrity of a most desirable treaty endangered.

\section{EARLY SOLUTION OF PRACTICAL PROBLEMS IMPORTANT.}

At the time the law of 1912 was enacted, there were certain important practical problems regarding the seals which hitherto had remained unsolved owing to the existence of pelagic sealing. The treaty of I 9 I I had abolished this form of sealing, opening the way for the solution of these problems. The law, however, was and still is an effectual bar to the elucidation of these vital matters. The principal points to be determined as prerequisites of sound and systematic management relate to distinguishing seals of different ages and to ascertaining the number or proportion of males that naturally survive to the age of 3 years, these forming the class from which both killings and breeding reserves are drawn. As shown elsewhere, the conditions for obtaining this information will be particularly favorable in 1915 . The number of pups bom in I9I 2 is known, and certain of these which will appear as 3-year-olds in I 915 carry permanent brands which will greatly facilitate the confining of killing and reserving to that class. Therefore, it would be possible to determine fully the characteristics of the 3 -year-olds as a standard for future use; and by setting aside a liberal breeding reserve and killing the remainder the total stock remaining from the pups born in 1912 would be leamed. Such favorable conditions could not be obtained again until I9I 8 and then only by repeating in 1915 the branding of pups which was carried out at considerable labor and expense in 1912. Therefore it is highly desirable that the work be done in I9I5.

\section{GRADUAL DEVELOPMENT OF EFFICIENCY NECESSARY.}

The long-continued ravages of pelagic sealing and the publicity which they gained during the protracted agitation against it, combined with charges of excessive land killing and the undisputed fact that the seal herd was reduced to a fraction of its former size, produced a general impression that the number of seals remaining was only a mere handful, or in fact that the herd was on the very verge of extinction. The total suspension of commercial killing by the law of 1912 has added to this impression and circumstances have caused an interruption and abandonment of continuous policies, a reduced and partly temporary persunnel, and general conditions favoring inaction only 
justifiable on the assumption that since there are few seals and but little lilling, the requirements of the situation must be few and unimportant. The actual conditions, as disclosed by the investigation of 1914 , are quite the contrary. Never during American ownership has the situation demanded more careful consideration, more numerous and capable employees, or more liberal financial support.

The seal herd is small only by comparison. Actually it is large and growing rapidly. The business of managing it will involve the handling of a product yielding an annual income equivalent to that of a business enterprise with an investment of at least ten millions of dollars. Extensive preparation and careful study are necessary to avoid large financial loss not only at present but in the future. The native men who do the sealing are losing their former efficiency. The younger ones, of whom much will be required in the future, are gaining but little experience and training and it is plainly evident that a sudden resumption of killing on a large scale a few years hence would find them unequal to the task. The duties and responsibilities of the agents and officials resident on the islands are of a special nature and they too need time and opportunity to grow with the business. Suitable men to fill these positions can not be had for the asking but must be selected with care and trained by experience. Men with special training also are needed for special purposes-to plan and execute general improvements, to build roads and trails, to provide better housing, sanitation, and education for the 300 natives of the islands, to study the possibilities of new industries and economies, the utilization of by-products, and the development of general efficiency-in short, to provide means by which the Pribilof Islands shall be a source of profit, satisfaction, and pride to the Goverument.

Failure to undertake many needed reforms and to develop efficient and systematic management is to a considerable extent due to the continued suspension of land sealing and it requires no lengthy argument to show that the sooner the Gorernment resumes land sealing, the principal business of the islands, the sooner will it be possible to institute reforms of all kinds and to provide a basis for permanent efficiency.

\section{CONCLUSIONS.}

Conclusions regarding the effect of existing laws, especially the law of 1912 , as seen in the light of conditions in 1914 , may be summarized as follows:

(I) The law effects a suspension of sealing for six years instead of five and sealing has now been restricted for three years.

(2) The benefits of the law as a protective measure have now been attained, the seal herd being past the danger point.

(3) The law guards almost wholly against practices which may have been possible under the leasing system, but which can not occur under full Government management.

(4) The law is a rigid measure imposing fixed restrictions on the management of living animals subject to natural vicissitudes, whereas in the nature of the case reasonable elasticity is required to meet conditions as they arise.

(5) Under the law, no one has discretion to permit the killing of seals in emergencies or exceptional circumstances to prevent the spread of disease, to avoid suffering, to provide material for scientific study, or to obtain specimens for museums and other educational institutions. 
(6) By provision for the annual sale of skins, the law makes it difficult to regulate the time of the sale to market conditions. Moreover, a small output of skins during the suspension of commercial sealing may cause the demand for them to diminish, and a sudden large supply upon the resumption of sealing is likely to meet with reduced prices.

(7) The blue fox industry, capable of yielding $\$ 50,000$ or more per annum, is reduced to small proportions through lack of seal meat for food.

(8) The continued suspension of sealing and the subsequent reserves provided by law will create a large excess of males, and failure to take and market their skins at the proper time will cause an estimated minimum loss of $\$ 2,700,000$.

(9) A part of this loss falls upon Great Britain and Japan, to each of which we are by treaty bound to deliver 15 per cent of the annual take under commercial sealing.

(ro) The suspension of sealing prevents the immediate determination of the proportion of seals which naturally survive to killable age, a most vexed and vital matter, which must be settled before any explicit regulations based on sound principles can be formulated.

(I I) The development of general efficiency for the future managment of a very large and profitable business, the training of both white and native employees, the installation of modern methods, and the numerous preparations necessary for adaptation to new conditions are largely dependent upon the resumption of active sealing at the earliest possible date.

(12) The law now offers no compensations for its many disadvantages. It has served a purpose as a remedy for a shortage of male life, but though a shortage existed when the law was enacted it does not now and will not in the future, whether the law be in effect or not.

\section{THE FOXES.}

\section{GENERAL CONSIDERATIONS.}

The foxes of the Pribilof Islands belong to a group ordinarily known from their circumpolar habitat as arctic foxes and considered as forming a genus distinct from other foxes. The animals of these islands have become slightly differentiated by long insular isolation from their relatives inhabiting the other parts of the north, and bear the name Alopex pribilofensis (Merriam).

The so-called white and blue foxes are not different species but merely represent two color phases of the same animal, the white being the winter coat of the normal phase, which in summer is characterized by a brown back and shoulders and tawny sides. The blue fox is the abnormal dark color phase, sooty gray in summer, and bluish gray in winter. This sooty phase is found practically throughout the range of the animal, at least in America, but is usually much less abundant than the ordinary phase and in some sections is so rare as to be practically unknown.

On the Pribilof Islands, however, the sooty phase so outnumbers the ordinary phase as to be practically the normal state. According to old accounts, blue foxes only were found on the islands when they were first discovered, and the white ones came (presumably on the ice) a few winters afterwards. This is probably an error, as it is much more likely that the white were present at first but were overlooked until their white winter condition forced itself on the attention of the discoverers. It is undoubtedly true, however, that foxes do occasionally reach the islands from the north on the pack ice, 
and as these would probably come from regions where the normal phase predominates it is likely that the majority of such immigrants would be white. Such infrequent arrivals, however, can have had but little effect of any kind on the Pribilof herd within historic times.

Because of the beauty and rarity of the blue fox its value has always been much greater than that of the white. Until very recent years the white skins were worth very little, but the growing scarcity of all kinds of fur has resulted lately in a great increase in their value.

During the continuance of the leasing system the companies paid to the natives a certain price for taking the skins and sold them in the best markets, the Government deriving no benefit from the transaction. Since the discontinuance of this system in I9Io the same methods have been followed by the Government, which now derives a revenue from the animals. The gross proceeds of the catch of the winter of $1910,37 \mathrm{I}$ blue and 20 white skins, were $\$ I 6,563.55$; the expenses of marketing were $\$ I, 466.92$. The net price received was thus about $\$ 40$ each for the blue slins and $\$ 6$ each for the white. Of the skins taken in I9I I, I 2 blues netted over $\$ 50$ each, and the whites about \$1 3 each, while an exceptionally fine lot of $3 \mathrm{I}$ blue fox skins brought a gross return of \$I I each. Of those taken in 1912,13 brought slightly less on the average, a little under $\$ 40$ each for the blue and about $\$ 11$ each for the white. One lot of 6 fine blue skins brought an average gross price of $\$ 158$ each. The net proceeds to the Government from the sale of fox skins for I910-II were \$15,096.58; for I9II-12, \$20,505.I7; and for I9I2-13, ahout $\$ 16,000$. It is plain that an industry which even in its present depleted state has yielded this revenue deserves to be brought up to a higher state of efficiency.

\section{FORMER ABUNDANCE.}

According to the old records, foxes were present on the Pribilof Islands when they were furst visited, but regarding their numbers in early times we know very little. During the period from $18+2$ to 1860 , inclusive, the Russian-American Co. took from the Pribilofs an average annual catch of $I, 829$ foxes; more than two-thirds of these came from St. George. From I86I to I870 the complete figures are not available. From i 87 I to 1890 a total of 24,792 skins was taken from both islands; 20,412 of these came from St. George, an annual average of $\mathrm{I}, \mathrm{O} 20$ skins. During all this time practically no attention was paid to the care of the foxes, which subsisted mainly on the birds and on the bodies of the seals which had been left on the killing fields.

\section{DECLINE FROM LACK OF FOOD.}

About 1890 the number of foxes begun to show a marked diminution, undoubtedly die to the smaller quota of seals killed. Within the next few years, during the modus vivendi, the catch of seals being limited to the food requirements of the human inhabitants, the foxes suffered further reduction in numbers. During the period from 189 r to I 900 the total catch for both islands was only 6,245 skins. The decline being attributed to over-trapping, no foxes were killed on either island during the winters of $I S 9 I-2$ and $1894-5$, and the season of $1898-9$ was marked by a suspension of killing on St. Paul. But the scarcity of food rather than excessive killing gradually becoming recognized as the real cause of the decline, the special feeding of the animals was taken up in 1896 , 
and has been carried on in a more or less systematic way ever since. This matter is elsewhere discussed.

In marked contrast to the numbers taken on the Pribilof Islands during the middle and latter part of the last century, the lessened number yielded during the last two decades is of interest. The figures have been compiled from various authentic sources.

Number of foxes taken on Pribilof Islands, I800-I9I3.

\begin{tabular}{|c|c|c|c|c|c|c|c|c|c|}
\hline & \multicolumn{3}{|c|}{ St. Paul. } & \multicolumn{3}{|c|}{ St. George. } & \multicolumn{3}{|c|}{ Pribilof Islands. } \\
\hline & Bitue. & White. & Total. & Blue. & White. & Total. & Blue. & White. & Total. \\
\hline I $19,0-6, \mathrm{t}$ & 0525 & & $(b)^{525}$ & 233 & & $\left(\right.$ (i.) ${ }^{793}$ & I, 313 & & $1,3 \pm S$ \\
\hline$I \operatorname{lin}_{2}-93$ & 330 & 37 & 373 & 6.3 & & 928 & $I, 264$ & 37 & 1,301 \\
\hline 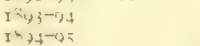 & 213 & $=7$ & $=24$ & ८५: & Ii & $\left(b^{57 I}\right.$ & $\begin{array}{r}770 \\
8\end{array}$ & 45 & $\begin{array}{l}8 \mathrm{II} \\
{ }^{8} \mathrm{~S}\end{array}$ \\
\hline 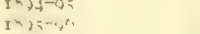 & 253 & 14 & 27 & $c+3$ & . & 33 & $c_{23} 3_{9}$ & 13 & 307 \\
\hline $12,0-2-$ & 212 & 9 & 223 & $54)^{-}$ & $\ldots$ & 497 & $c_{7 I I}$ & 9 & 720 \\
\hline$I^{4},-,-y 4$ & $I ;)_{i}$ & is & 107 & 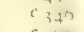 & & 346 & $c_{495}$ & 18 & $5 \pi 3$ \\
\hline I & & & (b) & $c_{3 n t}$ & . & 386 & $c_{386}$ & & 380 \\
\hline In $I 1+$. & $27:$ & -3 & $2 ?$ & ${ }^{2}+1 ;$ & & $4^{\mathrm{IS}}$ & $c 663$ & 23 & 695 \\
\hline $1,300-1.51 \ldots$ & I $5:$ & I & $1 \leqslant r^{\prime}$ & $c_{+11}$ & & $44 I$ & $c_{596}$ & I & 597 \\
\hline $\mathrm{I} x \mathrm{~N}-2 \quad \ldots$ & $I_{1} K_{3}$ & ; & t:? & $r_{2}+r^{2}$ & & 246 & $c_{409}$ & 7 & 416 \\
\hline $1902-; \quad \ldots \ldots$. & $\therefore$ & $\therefore$ & 238 & \& 511 & $\cdots$ & $5 x I$ & $c_{739}$ & Io & 749 \\
\hline $190 ;-4$ & $x=$ & 5 & 20 & $4 \times 1$ & $: 5$ & 501 & 501 & 20 & 521 \\
\hline $\mathrm{ISO}_{4}^{-2}=$ & 31 & 2 & $d_{33}$ & 2 the & If & 272 & 293 & 12 & 305 \\
\hline $100<-4$ & (3) & & (b) & $4+5$ & $1:$ & 4 So & 468 & 12 & 480 \\
\hline 12000-? & $\ldots \ldots$ & . & (b) & $3+2$ & 5 & 374 & 360 & 8 & 374 \\
\hline 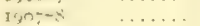 & .. & & (3) & 434 & \& & $44^{6}$ & 438 & 8 & 446 \\
\hline 105-4 & $\ldots$. & & (i) & $3 \times 7$ & 10 & 377 & 367 & To & 377 \\
\hline I $00-10$ & (is) & in & $C_{1}=5$ & $\therefore 2$ & ro & 223 & $36 \mathrm{r}$ & 46 & 407 \\
\hline IT) & 131 & $=0$ & IदI & 247 & I & $24 \mathrm{I}$ & $37 I$ & $2 \mathrm{I}$ & 392 \\
\hline IYII-I: & $x(n)$ & 27 & $\mathrm{~J} 30$ & 275 & 2 & 277 & 384 & 29 & 413 \\
\hline $1912-13$ & 143 & 30 & 173 & 202 & I & 263 & 405 & $3 \mathrm{I}$ & 436 \\
\hline 11,$1 ;-14$ & $I=0$ & $\therefore 5$ & $: 75$ & 100 & I & 107 & 256 & 26 & 282 \\
\hline
\end{tabular}

a Including to pairs blue foxes sold for breeding purposes.

It will be noticed that a few skins have been taken on Otter Island. In former years this island, situated about 6 miles southward from St. Paul, maintained a considerable herd of foxes. In December, I875, according to the St. Paul records, 60 foxes were taken. In December, I 894 , a trapping party took 8 foxes and was supposed to have depopulated the island. No more appear to have been taken there until the winter of 1904-5, when 33 were killed. In December, 1909, I9 blue foxes and I white one were taken there.

During our visit to Otter Island in July, I9r4, we looked carefully for foxes, but saw no traces. This island has large colonies of breeding birds and would support a good number of foxes during the summer, but the natural supply of food in winter is apparently not sufficient. In former times a few fur seals bred there, and the bachelors hauled out in some numbers. Although none seem to have been killed there, the animals dying from natural causes may have afforded some food, which, added to what was obtainable on the beaches, permitted numbers of the foxes to survive the winter. That they were never in a prosperous condition is indicated by the fact that the skins taken there have always been reported as inferior. Unless seals should again resort to Otter Island in numbers sufficient to warrant killing for the skins, so that winter provision could be supplied, it will probably be unwise to encourage the foxes to increase there. Although there are none there at present, a few are likely to reach there from St. Paul whenever the pack ice occurs in quantity. 
On one occasion, on June I I, I892, a fox was found on Walrus Island. Its activities had prevented the birds from beginning to nest, and it was shot. On June 27, when the island was next visited, a boatload of eggs was gathered.

\section{DISEASES.}

The main cause of the decline of the fox herd, lack of food, has been sufficiently discussed. Some dininution due to disease has taken place, but apparently there has never been any serious epidemic. Deaths of occasional individuals occur from tuberculosis, hemorrhage, or other affections of the kidneys, and ulcers of the stomach or intestines. Mange, or a similar disease, has appeared at infrequent intervals, and has undoubtedly caused the death of many. It was prevalent on St. George in I9r4.

Under this head cannibalism, although undoubtedly due entirely to lack of proper food, may be considered. It has caused a serious loss on a few occasions, the most notable occurring on St. George in the autumn and winter of 1913-14, when several hundred were estimated to have perished from this cause. At this time the foxes were being supplied plentifully with salted food. This apparently had been imperfectly freshened and was not relished by the animals. It is certain that salt is injurious to foxes, and it is not unlikely that the eating of salted food induced a diseased condition similar in effect to scury, and that the craving for fresh meat led to cannibalism. During the spring of 1914 the number of foxes observed was unusually small, and many were in poor physical condition.

FOOD.

Seal meat.-Under the conditions prevailing for many years on the Pribilof Islands, while large numbers of seals were killed every season, the thousands of bodies which were left on the killing fields constituted the main source of food for the foxes. To this abundance the islands owe their eminence as a fox nursery. During the few years immediately following 1890 , coincident with a reduced catch of seals, a great diminution in the rumbers of foxes on both islands was apparent, and although for several years only a few animals were killed the numbers continued to remain at a low ebb. Although other factors have contributed to their continued scarcity, there is no doubt that the main cause has been the lessened quantity of seal meat available. Formerly no special care was taken to preserve the meat, the bodies being merely left on the killing grounds to be disposed of by natural processes, and the foxes securing their share as best they could. But when it became ericlent that the diminution in the fox herd was due to the reduced kill of seals, steps were taken to provide the animals with salted food of rarious hinds, and seal meat was used as far as available. The subject of most effectively utilizing surplus seal meat for fox food is elsewhere discussed.

During the summer and early autumn the bodies of young seals dying from natural causes on the breding rookeries are eagerly devoured bv the foxes being eaten on the spot or dragged to the dens for the young.

Birds and eggs.-The foxes of the Pribilof Islands seem to prefer birds to any other food. The greater abundance of birds on St. George seems to have been the direct cause of the larger number of foxes taken on that island. During the spring and summer the remains of birds, which are found about the burrows of the foxes in large numbers, testify to the fondness of the animals for this food. The foxes are adept climbers and make their war ahout clifts which appear absolutely inaceessible to a quadruped. Nany gulls, 
puffins, murres, and other cliff-nesting species are secured by the foxes in this way. But the bird most commonly eaten is the least auklet, the smallest sea bird found on the islands. These occur literally in millions and are especially numerous on St. George. From the time of their arrival in early May they are pursued relentlessly by the foxes which are easily able to secure them owing to their habit of nesting in large colonies in subterranean cavities on the bowlder-covered beaches and ridges. So numerous are the birds, however, that the foxes seem to cause no appreciable diminution in their numbers. During the nesting season the eggs of various birds are eagerly and successfully sought by the foxes. Though it is probable that eggs of practically all the breeding species are secured, those of the murres furnish the bulk of this form of subsistence. The foxes store large numbers by burying them singly in the mossy tundra in the vicinity of the breeding grounds of the birds. These spots are later visited and the eggs are eaten on the spot or carried to the young.

After the departure of the bulk of the birds in the autumn, the foxes derive but little benefit from those remaining. An occasional dead bird or an egg orerlooked during the time of abundance, or an unfortunate migrant or winter visitor is picked up, but as a source of food in winter, the birds are of little value. Out of about 40 stomachs of foxes examined by A. G. Whitney at St. Paul village late in November, I9r3, feathers or other remains of birds were found in if cases, but they probably represented only a small amount of nourishment.

Miscellaneous food.-The various invertebrates and other forms of marine life are of great importance as food during the winter, and are of course utilized to some extent at other seasons. Of about 40 stomachs of foxes examined at St. Paul village in late November, 1913, tunicates were found in five cases, and the remains of a fish in one. Grass or other vegetable matter of little nutritive value, but chiefly indicating that the animals were hard pressed for food, were found in 24 cases, sand or earth in 16 , and hair in 9. In the records of stomach contents from other parts of the island, examined and recorded by natives, sea eggs (Echinoderms) were frequently mentioned. These notes relating to a series of stomachs which were examined with some care, accord in a general way the results of stomach examinations made in former years on St. George.

In former times many sea lions were killed for their hides and for human food, and much of this meat was available for the foxes. At present the sea lion herd is much depleted and few are killed. Occasionally a dead sea lion, whale, or walrus is cast up and is utilized. A whale, if cast ashore at a point where a quantity of the blubber can be secured, furnishes a great store of excellent fox food. If obtained during the summer, or if desired for use during more than one season, it must be preserved by salting, and of course should be thoroughly freshened before being fed. Quantities of vegetable substances, including grasses and various herbaceous plants, are eaten by the foxes in times of scarcity, but these have little value as food.

Although lemmings are abundant on St. George, and it has always been assumed that they are devoured by the foxes whenever possible, there seems to be no positive evidence to this effect. Among the contents of large numbers of fox stomachs examined during past years no remains of lemmings seem to have been found. During the autumn of 1913 , at a time when lemmings were unusually abundant, no evidence was found that any were eaten. At the same time the stronger foxes were eating 
their own kind. It seems scarcely credible that lemmings should never be eaten, but it is plain that they can not form an important element in the food supply:

Needs of fores accorlino to season. -It is evident from the above discussion of

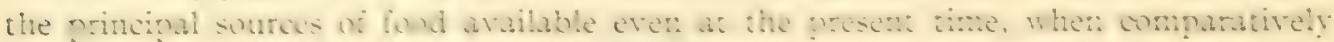

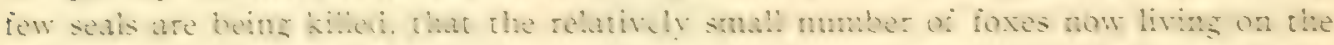

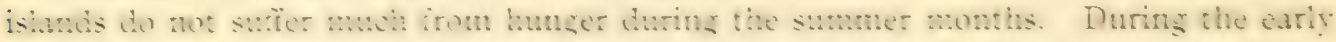

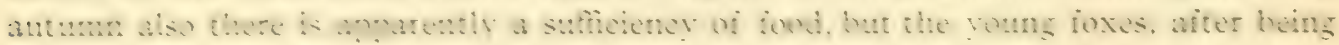

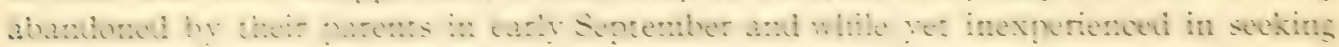
food, undoubtedly have a hard struggle for existence. But the fact that the fores taken in late Norember are almost invariably iat shows that thet have fared rell during the autumn. Conditions during midwinter and early spring, however, are

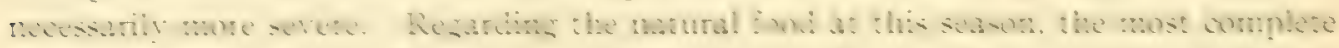
obsernations seem to be those of Dr. IF. I. Hahn. On January IS, I9II, he found indications showing that tunicates formed an important source of food supply. In late January he noted that the common stalked ascidian, together with a colonial form, and a large sessile, potato-like form, constituted a very-large part of the food of the foxes. Later he found that a few sea urchins were eaten. About the middle of April ascidians and other invertebrates were being eaten. During the winter, however, he noted that the shore ice prevented the foxes from securing a great deal of food which otherwise would have been avalable.

As regards food obtained from the sea, St. Paul Island on account of its more extensive benches offers better resources than St. George, where steep clifis form a lange part of the shore line.

Thus waging a constant struggle against starvation and the rigor of the elements

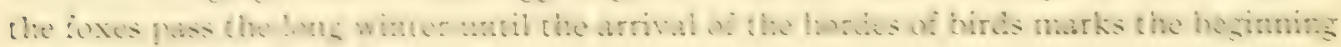
of a period of abundance.

History of sfecial fecting.-During the winter of IS94-95 when it began to be evident that the growing scarcity of foxes on St. George was due to lack of foad, an effort

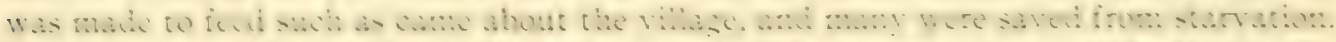

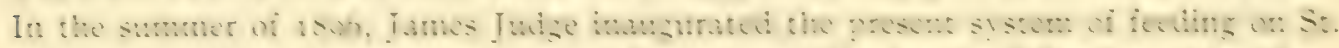

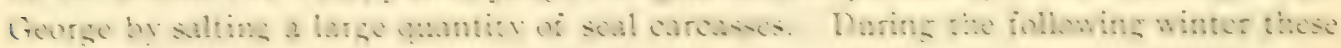
bodies which had been more or les periectly presened were ireshened a few at a time

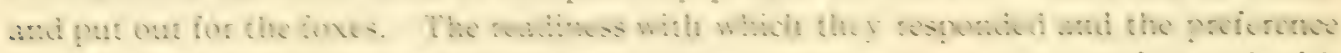
for this food which they exhibited faroned the continuance of the practice, and with various modifications this plan has been followed ever since. The lack of a sufficient


made it necessar to resort to other food. Salted or dried salmon and whale blubber

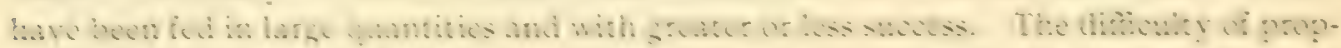
erly freshening the salted food, however, is aways very great. Sea mater does not

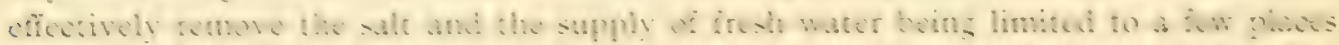

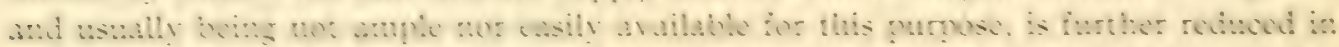



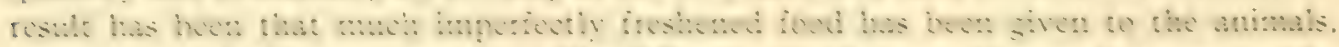

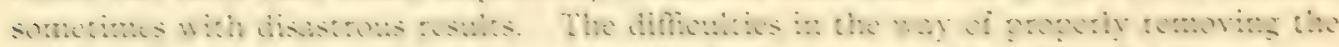

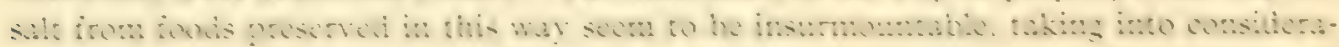
tion the neessity for supplying the food at a number of widely separated locations. 
On a muraber of ncossions the bodies of seals and the ofial irom those utilized for ind by the inhabiants have been buried in pits. Wher opened in the winter the meat is sometines entirely spolled, but usully a potion is eatable. Teat kept in this may is generally rot eaten at once, but erentually is consumed. A quantity of seal canerses buried in the autumn of Ioro ou St. Paul Island were examined about midwinter and found to be in a more or less putrid condition. They were not visited by the fores to any extent until towand the end of the winter, but were still being eaten as late as May Io. IorI. While it is unlikely that any harm to the foxes results from the eating of putrid or imperiectly cured meat, the grest waste involved and the hardship of handling the


freshened under the most iavorable conditions, is ummatural and can not iail to be more or less injurious.

The objections to salted or buried food make it recessary to look for some better method of presenation. It may be bome in mind that it is not neceswry for the ment to be presered periecty, but only suficiently to guard against loss and to put it in such shape that is can be handled. In the absente of cold storage the ramedy seems to be in the use of dried mest. With the improved methods of transportation absolutely necessary in order that the resources of the islands may be effectively and economically exploited. the badies of seals killed in the vicinity of the hauling grounds at points accessible to the ioxes may be hung in scneened shelters and dried. It has been proved by experiment that the meat can be preserved in this way at a very small expense, and that the foxes prejer it to salted ment.

The importance of increasing these valuable herds of fores justifies the expenditure of more care than has been devoted to the subject. The expense and labor of presening and distributing an ample supply of seal meat, when killing on a larser seale shall be resumed, will probably not be greater than that involved at present. This subject is discused at steater length elsewhere.

The fact that the methods now in rogue tare iailed to accomplish the result sought calls for no criticism of the persons who have been in charze. The iailure has been due to cirumstances which in most cases bave been beyond the control of the agents. The fact remains, however, that in spite of what has been done, the number of the amimals



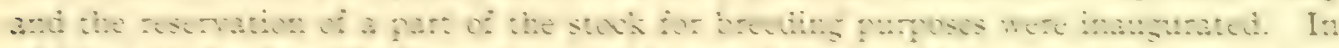

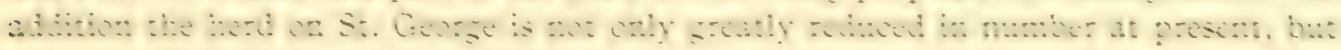
the animals are in very poor phrsical condition. It is hoped that the causes resulting

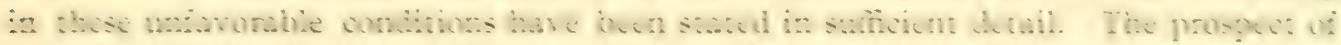
removing the main obstacles is good, and the outlook for the ultimate restoration of the herd is by no means dark.

\section{BREEDING HABTS.}

According to Judge, who has made more caniul observations on the fores than any other person, they mate in March or early April. Jew-bon young have been found irom May 17 to June 6 . The roung are usually born above ground, and are transierred to underground dens within a few days. The dens are usually in rocky sround, or, when situated in sandy areas, beneath a rock.

Among z : and the largest II pups. An nemly-bom pup weighed 2 ounces. He states that the

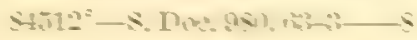


mortality among the young is large, and is due mainly to lack of nourishment and inclement weather. About the middle of June the young begin to be observed about the mouths of the burrows. While the young are small, the mother, assisted frequently by another fox, which is presumably the male parent, is very assiduous in providing them with food. Birds are the favorite prey at this time, and quantities of feathers and other remains which are scattered about the burrows testify to the skill of the animals as hunters. When the dens are in the vicinity of the seal rookeries, the bodies of many pups which have died are dragged away, and the bones picked clean of flesh may be found about the burrows.

\section{METHODS OF CAPTURING.}

Previous to 1890 the usual method of capturing foxes on the Pribilof Islands was by means of steel traps. When, however, the plan of feeding them was inaugurated on St. George, the readiness with which the animals came to the feeding places suggested capturing them in box traps, so that certain ones could be liberated for breeding. This proving successful, the plan was conceived of taking them in larger numbers by means of a larger trap. As finally perfected, this was a cage of woven wire 14 by 10 feet and 8 feet high, provided with a door which could be closed at will. This cage adjoins a house divided into three rooms, used for storing and freshening the food and handling the foxes. This trap, which is the regular feeding place, is usually left open so that the foxes can come and go at will. The animals having become accustomed to the cage, it is only necessary to remain in hiding until a number of them have entered the inclosure and then close the door by means of a rope. The animals are then examined and those to be reserved as breeders are marked by clipping a ring of fur from the tail, the males being marked near the end of the tail, and females near the base. Those left for breeders must be of good color, not too old, and in good physical condition. Males taken in early winter, in good condition, usually range in weight from about 8 to 14 pounds, and females from 7 to io pounds. In selecting those to be left for breeding, no males weighing less than io pounds are saved and no females less than $7 \frac{1}{2}$ pounds.

It was formerly the custom to reserve a preponderance of females, but the fact that the fox is a monogamous animal being recognized, the sexes are now left in approximately equal numbers. For a number of years previous to 1910 , approximately 200 pairs were usually released as breeders. Since then the number has usually been less. During the winter of 1913-14, 237 males and 192 females were released, but as before stated, the spring of 1914 found the animals in poor physical condition, so that this number can not be taken as an indication that the herd is in a prosperous condition.

In the annual trapping and handling of as many of the St. George foxes as can be be secured; all white ones and all those crippled or diseased are killed. On St. Paul Island the trapping has been almost cnirely by means of steel traps, thongh deadfalls are sometimes used. For many years it has been the custom to allow the natives to shoot all white foxes seen during the trapping season, and during some years for longer periods, but this method has not been very effectual. The reasons will be discussed later.

Of a lot of I,044 foxes handled on St. George Island during the winter of 1905-6, as recorded by Chichester (Senate Doc. 376, 6oth Cong., Ist sess., p. 51, I 908), 497 were 
males and 547 were females. Of these 2 I 8 males and 245 females were killed. Those released comprised 279 males and 302 females.

Of the entire number of males, Io weighed from $5 \frac{1}{2}$ to 6 pounds, inclusive, and 32 others between 6 and $71 / 4$ pounds; 239 fell between $7 \frac{1}{2}$ and 10 pounds, the minimum weight required of breeders. Of the remainder, 206 weighed between $101 / 4$ and 15 pounds, 7 between $15 \frac{1}{2}$ and $17 \frac{1}{4}$ pounds; and the other three weighed $171 / 2,20$, and $20^{I} / 4$ pounds, respectively.

Of the females handled on this occasion, 4 weighed from 4 to 5 pounds, and 7 others fell below 6 pounds; 280 weighed between 6 and 8 pounds, inclusive; r 97 fell between $81 / 4$ and Io pounds; 56 ranged from $10 \frac{1 / 4}{4}$ to $13 \frac{1}{2}$ pounds; and the remaining three weighed, respectively, $14,2,15$, and 2134 pounds, the last being the heariest blue fox on record from the Pribilof Islands.

The largest fox taken on St. Paul Island during the trapping season of $19 \mathbf{r}_{3}$, which comprised the last week of November, was a male weighing $19 \frac{1}{2}$ pounds.

\section{RECOMMENDATIONS.}

Feeding and method of capturing.-With the resumption of commercial killing of seals, an abundance of excellent food for the foxes will be assured. With increased facilities for transportation the killing would be done in the vicinity of the hauling grounds. The principal ones on St. Paul Island are as follows: Northeast Point, Polovina Point, Reef and adjoining points, Tolstoi, Lukanin, and the several hauling srounds at Zapadni. Practically all the foxes on the island live near or at points allowing easy access to these places. Roofed sheds screened from flies and provided with arrangements for hanging quantities of seal bodies should be built for the purpose of drying the meat. These sheds should be so constructed as to keep out the foxes, but a free circulation of air slould be allowed. The drying process can be facilitated by slow fires of driftwood; this can be gathered nearby in sufficient quantities for this purpose. The use of a fire will dry the air and also protect the meat against flies. The drying shed could serve also as a storehouse for the meat.

The feeding inclosures, at least preceding and during the annual trapping season, should be trap cages similar to those now used on St. George, but future experience will doubtless suggest some improvements. Such traps have never been used on St. Paul but there is, of course, no reason why they can not be introduced. It will be desirable to avoid the necessity of remaining at watch all night during the trapping season to spring the traps, especially if these trapping stations are established at a number of places. Inclined funnel-shaped entrances have been recommended by G. Dallas Hanna. These or inclined walkways from the end of which the animals can jump down to a tipping shelf can without doubt be devised. A larger feeding trap would prevent the animals from crowding and by allowing the food to be more scattered would insure a share to the weaker animals. If low houses were provided in the corners of the feeding corrals, the foxes on finding themselves trapped would doubtless hide in these and could easily be secured for examination.

In addition to the feeding which should be maintained at these places during the winter season, some judicious scattering of food suitable for the young foxes in certain well-stocked breeding areas would doubtless result in a larger proportion of young reach- 
ing the age when they are self-supporting. This secms to be especially desirable at Northeast Point, which is very suitable as a breeding ground for foxes, but which has no important bird rookeries. When the killing of seals on a commercial basis is resumed, the refuse from the killing fields may be sufficient for this purpose. Careful observations regarding the needs of the young foxes during the summer are needed.

On St. George Island the foxes are more numerous and more generally distributed than on St. Paul because of the extensive bird rookeries, which occupy about one-half of the shore line, and the many square miles of the interior where innumerable auklets raise their young; but since the same topographic features which determine the distribution of the birds, and in turn that of the foxes, limit the seals to a few scattered areas, probably not more than half the foxes have their homes near the hauling grounds. Still the comparatively small size of the island makes it possible for most of the animals to reach easily some place where seals might be killed. Owing to the limited number and small size of the hauling grounds and the diflicult nature of the ground, it will probably never be feasible to develop as complete a system of transportation on St. George as is necessary for St. Paul, but such improvements should be made as will render Staraya Artel, Zapadni, and East Rookeries more accessible. This will permit arrangements to be installed at these places for the feeding and trapping of foxes. The remaining place where feeding seems to be desirable is Garden Cove. This place is one of the few possible landing places and is often the only one feasible. At present it is connected with St. George village only by a foot trail. If a wagon road were built it would be possible at times to utilize Garden Cove to good advantage as a landing place for supplies, and the food necessary for maintaining a foxing station could be easily transported. Failing the construction of a wagon road, the food could be taken there by boat at some favorable time in the summer.

kescres for brecding.- With improved methods of feeding and capturing the foxes, enlarged opportunities for selecting and reserving a sufficient number of animals fit for breeders will be possible, since a larger proportion of the entire herd may be handled. The standards governing the selection of animals for reservation, as practiced in the past, seem to call for no criticism, and if the methods of feeding and capturing the foxes be improved and carried into effect on both islands a marked advance in the effective strength of the herds should soon be apparent.

Elimination of white foxes.-As before stated, the blue foxes, though representing an abnormal state, are so predominant on the Pribilof Islands as to be practically the normal condition. Owing to their greater value, it is desirable that they form as large a percentage as possible of the herd, and the elimination of the white element as far as practicable is therefore important. This fact has long been recognized, and ever since sclective trapping on St. George Island has been practiced all white ones caught have been killed. The result has been that the number of white ones now found there is almost negligible. During the last Io years St. George Island has produced 3,560 foxes, only 88 of which have been white; during the last four years out of 888 foxes only 5 have been recorded as white.

On St. Paul, where the attempt to eliminate the white element has been prosecuted only in a half-hearted way during the past five years, the proportion of white is much larger. In the last five years out of 83 o foxes taken for fur on St. Paul ' 48 have been white. The proportion from year to year has not varied greatly. 
It is evident that the attempt to eliminate the undesirable white element on St. George Island has been successful and that this success is due to the method of capture. It is also evident that merely allowing the natives to shoot the white ones during a part of the year has met with no success.

There is good reason to believe that continuance of the methods now practiced on St. George will keep the white foxes down to a negligible proportion and perhaps eliminate them entirely. The establishment of similar methods of trapping on St. Paul should eventually achieve the same result. But success will be attained much sooner if the undesirable animals are pursued in other ways. The natives should be encouraged by a reward to shoot the white foxes during the entire hunting season. They are now forbidden to use firearms during the summer, and such a prohibition is desirable for many reasons, but they are and should be allowed to shoot during the fall and winter. Most of the skins of foxes taken during the winter will be salable. The reduction of white foxes by any other method than shooting outside of the regular trapping season is obviously not feasible. The white foxes can be as easily distinguished from the blue when in the summer coat as in the white winter pelage, and they should be vigorously pursued and destroyed at all seasons. It might be best to leave white foxes which were found caring for pups until the latter are large enough to take care of themselves. During this time the animal could be kept under observation and might be destroyed at the close of the summer. But against this is the objection that presumably a part of the litter raised would be white animals also, the destruction of which, together with that of the parent, would be thus left to the chances of the future. This point is one which might well be left to the judgment of those in charge, but in common with many others needs the careful consideration of some one who shall be free to give his attention to such problems.

Animals which are suffering from disease should be killed whenever possible at all seasons. This is especially important at the present time, when the foxes on St. George are in poor condition. The process of raising the herd to a high state of perfection, even under the favoring influence of better food, will be greatly retarded if the pursuit of animals suffering from mange or other diseases can be prosecuted only during the few weeks of the trapping season. The natives should be encouraged to cooperate in this work.

Care of skins.-More care needs to be taken to cleanse the fox skins that they may reach the market in as good condition as possible. Those trapped in steel traps become more or less bedraggled during their efforts to escape, while those taken in cage traps become soiled from contact with the greasy meat and by scrambling over each other. Care should be taken to avoid such soiling as far as possible, and better facilities should be installed for cleaning and drying such as become soiled by blood, grease, or dirt. The skins can best be cleaned when freshly taken from the animal. Washing the soiled skins with soap and water will probably be found the most advantageous method and will probably be sufficient. To facilitate drying the skins, some arrangement for tumbling them could easily be devised, to be used with some absorbent. Stretching the skins in a uniform manner and taking care that they be well shaped and well dried are also important points.

Sale for brecding.- On a few occasions in past years blue foxes have been sold at a nominal price to persons engaged in breeding them, usually to those holding leases of 
islands in Alaska for such purposes. In recent years the growing scarcity of the animals and the relatively high price obtainable for the shins have made it inadvisable to dispose of the live animals at a price less than that brought by the skins. The advisability of offering some encouragement to those engaged in the business of propagating foxes being recognized, however, the following announcement was issued by the Secretary of Commerce on July I, I9I3, in connection with the information relative to the leasing of certain islands in Alaska for the purpose of raising foxes:

The Secretary of Commerce will undertake to supply from the Pribilof Islands fox herds a limited number of blue foxes for breeding stock to lessees of any of the islands that may be leased, or to other responsible parties operating fox ranches in Alaska. Such foxes will be sold under competitive bids and will be delivered to the purchasers at Unalaska on a date to be agreed upon.

Later this offer was extended to include persons engaged in raising foxes elsewhere than in Alaska. As a result of this offer a few small lots of foxes have been sold, at a price of about $\$ 100$ each. These have been young animals.

In considering the advisability of continuing this practice, it is necessary to bear in mind a variety of peculiar circumstances, particularly the present low state of the fox herds in point of numbers and vitality, and the impossibility of arranging for prompt and uninterrupted carriage of the animals from the islands to their destination. The latter difficulty is likely to lead to undue mortality during transit, resulting in the waste of valuable life and causing dissatisfaction to buyers.

The present unsatisfactory state of the fox herd is an even more serious objection to the disposition of animals for breeding. The herds need the retention of the best blood, and it is of course unwise to allow inferior stock to be used for starting new herds elsewhere.

It seems wise, therefore, to discontinue for the present the sale of animals for breeding purposes. When the herds shall be brought up to a higher state of efficiency as regards numbers and quality, the disposal of a limited number of animals of high quality might well be considered. This could then be done without injury to the herds, and would facilitate greatly the establishment of a legitimate and profitable industry.

Experiments in domesticating foxes.-The readiness shown by the foxes of St. George Island in responding to feeding has resulted in many of them becoming semidomesticated. This has led to the advocacy of experiments being made with a view to improving the fur and the physical condition of the animals by selective breeding. It is thought also that the raising of a larger proportion of the young to maturity might be effected, since it would assure their proper nourishment during the critical period when in a state of nature they are abandoned by their parents. It is thought by some that the eventual domestication of all the foxes of the islands would be profitable. While it is believed that this is impracticable, it is evident that some experiments in raising the animals in inclosures may well be made. The experience thus gained would be of great importance to prospective breeders of the animals and would also help to an understanding of the needs of the wild foxes on the islands. 
THE REINDEER.

\section{INTRODUCTION AND GROWTH OF HERD.}

For some years the Department of the Interior, in connection with its work on the education of the natives of Alaska, has maintained large herds of domesticated reindeer at various points on the mainland. These herds have prospered and from time to time have been drawn upon to stock other places, including several islands in the Aleutian chain and elsewhere.

In the course of a study of the economic resources of the Pribilof Islands it was seen that they afforded a quantity of food suitable for reindeer and it was believed that utilizing this product to maintain herds of these useful animals would be a wise procedure. Accordingly arrangements were effected with the Department of the Interior for the transfer of enough of the animals to start a herd on each island. By the cooperation of the Revenue-Cutter Service, 40 animals were brought to the islands at the end of August, I9Ir. Twenty-five of these, 2 I does and 4 bucks, were landed on St. Paul on August 31, and the remaining I5-I2 does and 3 bucks-were put on St. George on September I. Practically all the animals were of breeding age. There has been little mortality and both herds have shown a good percentage of increase.

In the spring of 1912 the St. Paul herd produced 17 fawns and had suffered the loss of only 2 of the original herd, a male and a female. In the spring of 191318 fawns were born, and in I9I 425 were produced. The mortality has continued to be small, and the herd on St. Paul in the summer of I9r4 numbered about 75 animals. All seemed to be healthy with the exception of 2 of the older males, which were lame and seemed to be suffering from some trouble of the feet. This is probably the same disease that has occasionally occurred among the herds on the mainland. The exact nature and cause of this disease does not appear to be well known. The animals are said to recover occasionally, but it would seem best to kill the animals now affected, since they are consuming food which will be needed for the healthy animals and they are not needed for the growth of the herd.

The animals on St. George also are in good condition. In spite of the fact that the oldest buck disappeared soon after the animals were landed, i of the 12 females produced fawns in the spring of 1912 . In the spring of 1913 , according to the report from the island, I 5 fawns were born. This would mean that some of the young only i year old produced fawns. Of those born, 13 survived the summer. In 1914 2I young were produced, and the herd numbered 58 animals. The total number now on both islands therefore is slightly more than 150 .

The reindeer on both islands keep rather closely to the higher, less frequented parts, where they are seldom disturbed and where their favorite food is most abundant. The animals of course require no feeding and no special care except at fawning time, but in order that they may not become too wild to be easily handled, they should be frequently visited and rounded up. In no other way can they be kept under observation and their actual condition be known. At fawning time some special care and attention is necessary to prevent undue loss of the newly born young. On St. Paul the females are driven into a corral for the fawning. This prevents the desertion of the young ones by their mothers, which often occurs during the prevalence of hard storms, and which results in heavy mortality. The newly born young are also in some danger from the old bucks. 


\section{LIMITED CAPACITY OF THE ISLANDS.}

Although the Pribilof Islands afford a favorable habitat for reindeer it is plain that their relatively small size will not permit an unlimited increase, though larger herds than now exist can undoubtedly be supported. As the summer food is practically unlimited in quantity, the main factor limiting the size of the herd seems to be the quantity of the various lichens which constitute the main source of food in winter. These lichens are not evenly distributed over the islands, but occupy certain fairly extensive areas. Unlike the grasses and herbaceous plants which die down and renew their growth annually, the lichens grown persistently but very slowly, and when once destroyed do not restock a given area for a long time, perhaps as long as 20 years. Detailed study of the habits of the animals in their special haunts, and of the areas drawn upon for their subsistence must precede any definite prediction as to the number that the islands can maintain permanently. It is certain, however, that the herds can be increased considerably over their present numbers. Observations made while this increase is going on should lead to a better understanding of the actual relation of the animals to their present habitat and make it possible to avoid letting them increase beyond the danger point.

Since with a few exceptions none of the animals have been killed, it follows that there is now a considerable number of males in excess of the actual breeding requirements of the herds. A reduction in their number should of course be made as an aid in conserving the food supply. Diseased animals should be killed and the meat utilized for the foxes. Other males should be killed from time to time and utilized to the best advantage.

\section{INDIFFERENCE OF NATIVES REGARDING REINDEER.}

Although the reindeer were introduced primarily for the benefit of the natives, they take practically no interest in the animals. For many generations these people have lived and died among the seals and foxes. The direct or indirect results of the exploitation of these animals have formed their sole means of livelihood and have satisfied their every need. It is very difficult therefore for them to realize that these new animals can ever prove of any real benefit to them, especially as no benefit has yet been realized. On each island two natives are paid $\$ 2.50$ each per month to care for the reindeer. With only this small reward, unsupported by any natural interest in the animals, it follows that the so-called herders never see the animals they have in charge unless told to look them up, and even when this occurs their observations are more or less inaccurate or misleading and are seldom of much value. This is only one manifestation of the native's inherent lack of interest in any project or occupation apart from sealing. This apathy will be difficult or impossible to overcome, although certain ones anong the natives will doubtless show more aptitude than others in this and other new lines of work. But unless natives are found who will take a real interest in the reindeer, their services except for work which is mainly mechanical will be of little use. The animals undoubtedly need closer attention. They should be herded and driven often enough to become accustomed to their attendants so that when it becomes necessary to corral them they may be more readily handled. At present they are scarcely seen from month to month with the natural result that they are more or less wild and intractable and difficult to impound or to observe. 
USE AND VALUE OF THE HERD.

It would seem that the reindeer on the Pribilof Islands are destined to be useful mainly as a source of fresh meat for the Government employees on the islands and as a possible source of supply for stocking other places. The training of some for driving has been suggested, but considering the small size of the islands and the rough nature of the ground it does not seem advisable to take this up on an extensive scale. The killing of a large proportion of the young males is desirable, and the meat of these would form a welcome substitute for some of the more costly canned foods which now necessarily form a large percentage of the provisions in the islands during the entire year. At times the meat could be issued to the natives, although it is doubtful if it would be as acceptable to them as that of the seal, which naturally forms their staple meat diet. The skins of the animals killed could be tanned and used for making gloves and other articles of clothing, but it would involve a radical departure from fixed habits on the part of the natives and it is doubtful if much can be hoped for in this regard, especially as the supply of skins will never be large. But by turning into desirable food certain natural resources which would otherwise be wasted it is believed that the reindeer herds will more than justify the expenditure of the comparatively small amount of time and money involved in their introduction and care.

The presence of growing herds of reindeer on the Pribilof Islands seems to afford an excellent opportunity to make detailed studies of great value. Here in a habitat which is favorable and yet is so limited in area as to allow of easy observation, a naturalist can study the diseases and the general relation of the animals to their habitat with comparative ease, and the knowledge thus gained should be of help in realizing to the best advantage the fullest value of the herds, not only on the Pribilofs but in other parts of Alaska.

\section{THE SEA LIONS.}

Steller's sea lion (Eumetopias stelleri) is a huge animal, the adult male being about three times the bulk of the fur seal and weighing probably as much as 1,500 pounds. The females are rather less than half as large as the males. Such imposing animals occurring in numbers and in such situations as to admit of easy observation excite an interest, especially to the lover of wild life, scarcely second to that created by their smaller and more numerous relatives the fur seals, which they resemble rather closely in habits and beside which they dwell in amicable indifference.

\section{EARLY ABUNDANCE AND USES.}

Until comparatively recent times sea lions were found in thousands on both St. Paul and St. George Islands. In the primitive economy of the natives these animals played an important part. In addition to the use made of their skins as covering material for the bidarras, or large boats, the animals furnished to the Aleut material for waterproof clothing and boots and for many lesser articles, while the flesh, especially that of the pups, was particularly relished. But in later years, with the growing tendency of the inhabitants to adopt inported food and clothing, the importance of the animal has dwindled until practically its only economic use is found in the manufacture of the huge bidarras. The adoption of modern methods of managing the business of the islands will undoubtedy demand the discarding of these boats as a means of landing cargo, and with them will ranish the importance of the sea lion as an economic factor. 
Considering the relatively small number of the animals remaining on the Pribilof Islands, it is well that they are no longer indispensable. Where formerly there were many thousands of the huge creatures there are at present only a few hundred on both islands.

\section{BREEDING HABITS.}

The breeding rookeries are only two in number, at Northeast Point on St. Paul, and near Garden Cove on St. George. In former years they resorted in numbers to both Otter and Walrus Islands, and doubtless do so yet to some extent as they do to Sea Lion Rock. A few are said to have bred on Walrus Island in the days of their abundance, but otherwise the present breeding stations seem to be the only ones ever occupied on the Pribilof Islands.

In general habits they resemble the fur seals. The males take up their stations from about the first to the middle of May and are joined by the females about two weeks later. Young are recorded as having been born as early as May 24, and as with the fur seal the period of pup-bearing extends over several weeks. They grow very rapidly, and when less than three months old are as large as 3-year-old fur seals. The animals when breeding are much more wary and timid than the fur seals. On the approach of man the females forsake their young and take to the water, where they gather in company with the bachelors and the less courageous of the breeding males, and keep up a deafening roaring chorus of rage and defiance.

A few of the largest males hold their ground and in the general excitement wage relentless battle with each other while the pups which are too young to accompany their mothers avoid the intruders as far as possible. The animals remain about the islands the entire year, but appear to be more scattered in winter.

\section{NUMBERS KILLED IN FORMER YEARS.}

In early days great numbers of sea lions were taken for the skins and meat. The following table shows approximately the number killed on St. Paul Island from i 870 to 1890 according to the island records, which are probably incomplete. Unless otherwise stated practically all were killed at Northeast Point.

Sea lions killed on St. Paul Island, 1870-1890.

\begin{tabular}{|c|c|c|}
\hline Year. & $\begin{array}{l}\text { Number } \\
\text { killed. }\end{array}$ & Remarks. \\
\hline 1870 & 123 & About 500 skins sent to Unalaska spring 1870. \\
\hline 1871 & & No record of number killed. \\
\hline 1873 & 200 & A quantity of skins shipped probably to Unalaska and Kodiak. \\
\hline 1873 & 390 & $\begin{array}{l}160 \text { driven from Northeast Point to Village Sept. } 26 \text {; } 130 \text { driven from Northeast } \\
\text { Point to Village Nov. } 16 \text {. }\end{array}$ \\
\hline 1874 & 506 & $\begin{array}{l}\text { Includes about } 300 \text { driven from Northeast Point to Village October and } \\
\text { November. }\end{array}$ \\
\hline 1875 & 402 & $\begin{array}{l}\text { Includes } 340 \text { driven from Northeast Point to Village during year: } 295 \text { skins } \\
\text { shipped to Unalaska. }\end{array}$ \\
\hline 1876 & 292 & Includes I 88 driven from Northeast Point to Village in Novernber. \\
\hline 1877 & 38 & Mostly killed at Northeast Point. \\
\hline $\begin{array}{l}1878 \\
1879\end{array}$ & $\begin{array}{l}300 \\
195\end{array}$ & $\begin{array}{l}\text { All driven from Northeast Point to Village in November. } \\
\text { Driven from Northeast Point to Village in October. }\end{array}$ \\
\hline 1880 & 66 & Killed at Northeast Point. \\
\hline I88I & 287 & $\begin{array}{l}20 \text { killed on Walrus Island, remainder driven from Northeast Point to Village } \\
\text { in October and November. }\end{array}$ \\
\hline 1883 & $2 \mathrm{I}_{4}$ & Includes Ioo driven from Northeast Point to Village in November. \\
\hline $188_{3}$ & I39 & Killed at Northeast Point. \\
\hline $\mathrm{I}_{884}$ & 253 & Do. \\
\hline $188_{5}$ & 30 & Do. \\
\hline 1886 & 356 & Includes rgo driven from Northeast Point to Village. \\
\hline 5887 & $x_{3} 8$ & Killed at Northeast Point. \\
\hline 1888 & 30 & Killed at Northeast Point in spring. \\
\hline 1389 & 30 & Killed at Northeast Point. \\
\hline I 890 & $4 \mathrm{I}$ & Do. \\
\hline
\end{tabular}




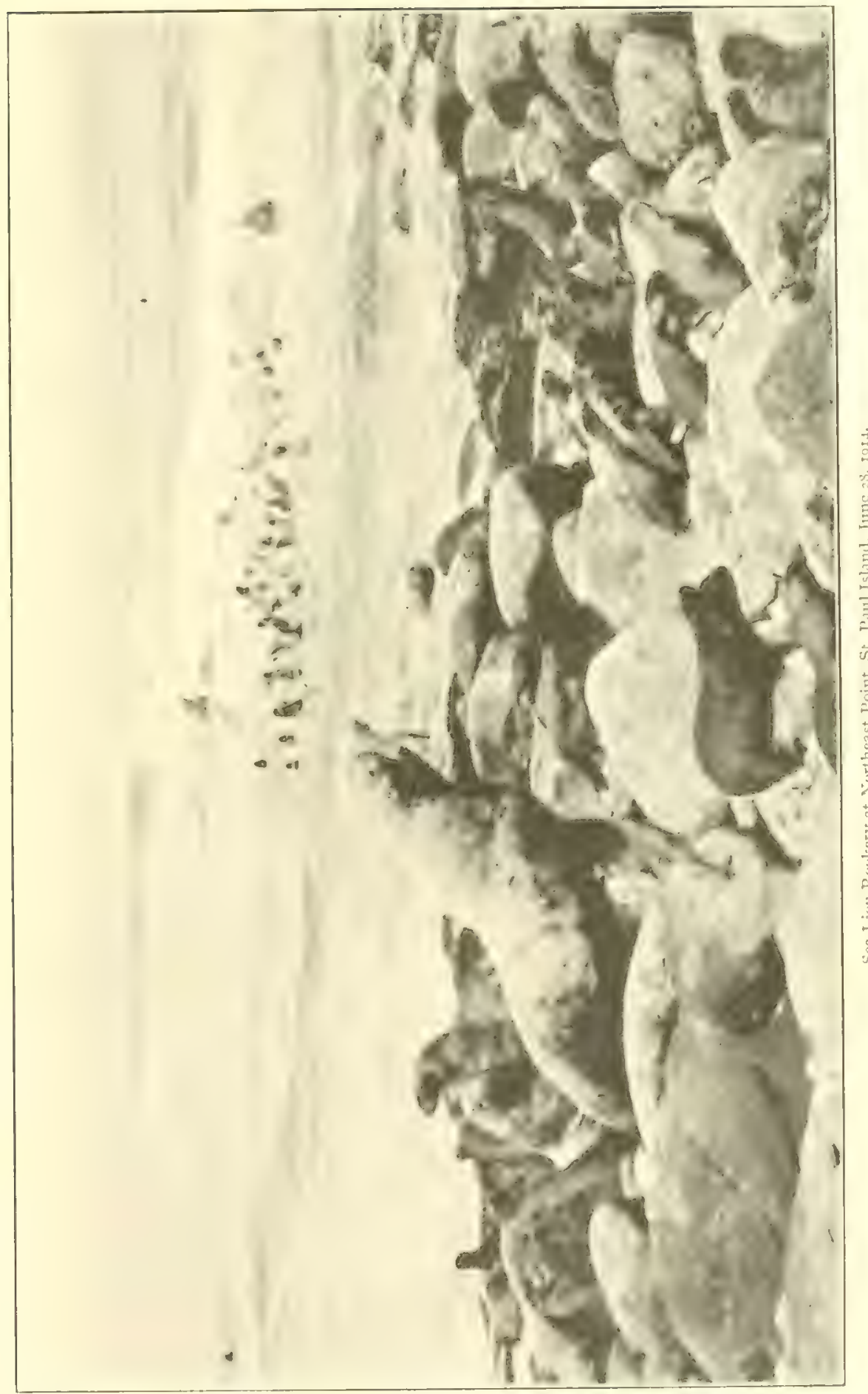



It will be seen that up to 1882 most of the sea lions killed were driven from Northeast Point to the village. This was done to avoid having to transport the meat and skins. It was necessary to let the huge animals travel very slowly, and from four to six days were required for the journey of 12 miles. After 1882 the animals became scarcer and more wary, and it became difficult to get enough together to make it profitable to conduct drives.

In 1891 a few only were killed, mainly pups taken for food. In 1892 about 50 , mainly pups, were taken. In 1893 about 35 were killed; in 1894,96 ; in 1895, i7 (bulls); in 1896,25 ; in 1897,22 ; in 1898,33 (bulls). From 1899 to 1909 only a few were killed annually to furnish skins for covering the bidarras, but the number had then become so reduced as to lead the agent to believe that it would be advisable not to kill any more for several years. Within the last ro years the number has slowly decreased. In the summer of 190.4 there were on the breeding rookery at Northeast Point about 30 bulls and 200 cows. In the summer of $191_{4} 4$ there were about 20 breeding bulls and somewhat over 100 cows.

On St. George Island the location of the breeding rookery does not readily allow driving, as the animals lie at the foot of bluffs and are difficult to approach. No figures as to the numbers killed are available, but it is known that in former years a great many were taken, probably being driven from the hauling grounds near East Rookery where about 50 were seen in July, I9I4. Comparatively few have been killed in recent years. No reliable data as to the number breeding on St. George Island are at hand, but it is thought that there are fewer than on St. Paul.

\section{MEASURES FOR PRESERVATION.}

Although the sea lions are no longer of great economic importance to the inhabitants of the Pribilof Islands, it seems desirable to preserve the remnants of the herds now existing there. The species is not of general distribution in the North Pacific, but is confined to certain restricted and widely separated localities. Of these the Pribilof Islands constitute one of the most northerly stations. In most other parts of its range the animals are subjected to persecution and are being rapidly extirpated. On the Pribilof Islandsa Govermment reservation-the sea-lion herds are protected from indiscriminate killing without special expense or trouble, and an excellent opportunity is afforded to preserve for all time small herds of these highly interesting animals. The herds may be drawn upon from time to time to furnish scientific specimens to museums and a few may be killed for other special purposes, but they should not be exterminated. The presence of these small herds is not detrimental to the more numerous and valuable seals, and their presenation as an example of an imposing and highly interesting form of wild life scems to be highly desirable.

\section{THE BIRDS.}

Even to the casual visitor, not especially interested in ormithology, the bird life of the Pribilof Islands affords an experience which never fails to call forth expressions of wonder and admiration, while to the naturalist the teeming hordes are a constant delight. Taken as a whole, the islands present an array of bird life scarcely equaled in the world. Nearly Ioo species have been detected on the Pribilofs, and of these about 20 species breed there. With a few exceptions the breeding species exist by tens of thousands and nest in large 
colonies, usually on the cliffs and rocky ledges fronting the sea. Besides the breeding birds, there are a larger number which nest on the Alaskan mainland or in other parts of the far North and merely visit the Pribilofs on their joumeys to and from their winter homes, which in some cases are as far distant as the Hawaiian Islands. A number of species of Asiatic distribution occur on the island and a few of these breed. In the case of a few species, the specimens taken on the Pribilof Islands constitute the only records for North America. It will be seen, therefore, that apart from their purely economic status, which is the subject of the present account, the birds of the Pribilof Islands are of unusual interest.

The species which are abundant and of economic importance to the human inhabitants fall into six natural groups. Mentioned in the order of their importance these groups are the murres, auklets, gulls, ducks and geese, shorebirds, and cormorants. Some of these groups are important also as furnishing food for the valuable herds of blue foxes. Their value in this regard is discussed in the account dealing with that animal.

\section{MURRES.}

With the exception of the least auklet, the murres, or arries as they are usually called, probably outnumber any other birds on the islands. They include two species, the Pallas Murre (Lria lomiza arra) and the California Murre (L'via troile californica). The first named is slightly larger than the other with the back glossy black, while the California Murre is of slighter build with the back more plumbeous. Both species breed on St. George, Walrus, and Otter Islands. The murtes of St. Paul are mainly, if not entirely, the Pallas Murre. The two species are of nearly equal abundance, and for present purposes may be considered together. The size of the birds, nearly equal to the mallard, the ease with which they can be captured, and especially the immense size of the nesting colonies, combine to make them an important economic feature. Many of the birds are shot, especially in the spring, and the eggs are an important article of food. The single egr is very large for the size of the bird, being at least twice the bulk of a hen's egg. Many are taken from the cliffs of the two main islands, but the main source of supply is Walrus Island, about ro miles from St. Paul. Here the birds nest to the number of many thousands. It is the custom for the natives to go to this island about the middle of June, when the birds liave fairly started nesting, and to gather all eggs from a certain area. About a week later the place is revisited and the area lately denuded will he found restocked with fresh eggs. The birds will lay again, even if the second set is removed, and in some cases even a fourth egg may be deposited, but as the breeding ground is seldom revisitcd more than once in a season, the taking of eggs causes practically no diminution in the species, but merely retards the breeding of a part of the birds a week or two. This is shown by the fact that in spite of the eggs having been gathered in this way for many years, practically all the available space on Walrus Island is still occupied by the breeding hordes, and the various colonies in other parts of the Pribilofs show no appreciable loss. The birds are never killed on the rookeries during the breeding season.

\section{GULLS.}

The gulls of economic importance are the Glaucous-winged Gull (Lams glaucescens), the Red-legged Kittiwake (Rissa brcirostris), and the Pacific or Black-legged Kittiwake (Rissa $t$. pollicaris). The two last named occupy certain areas on all the islands, usually 


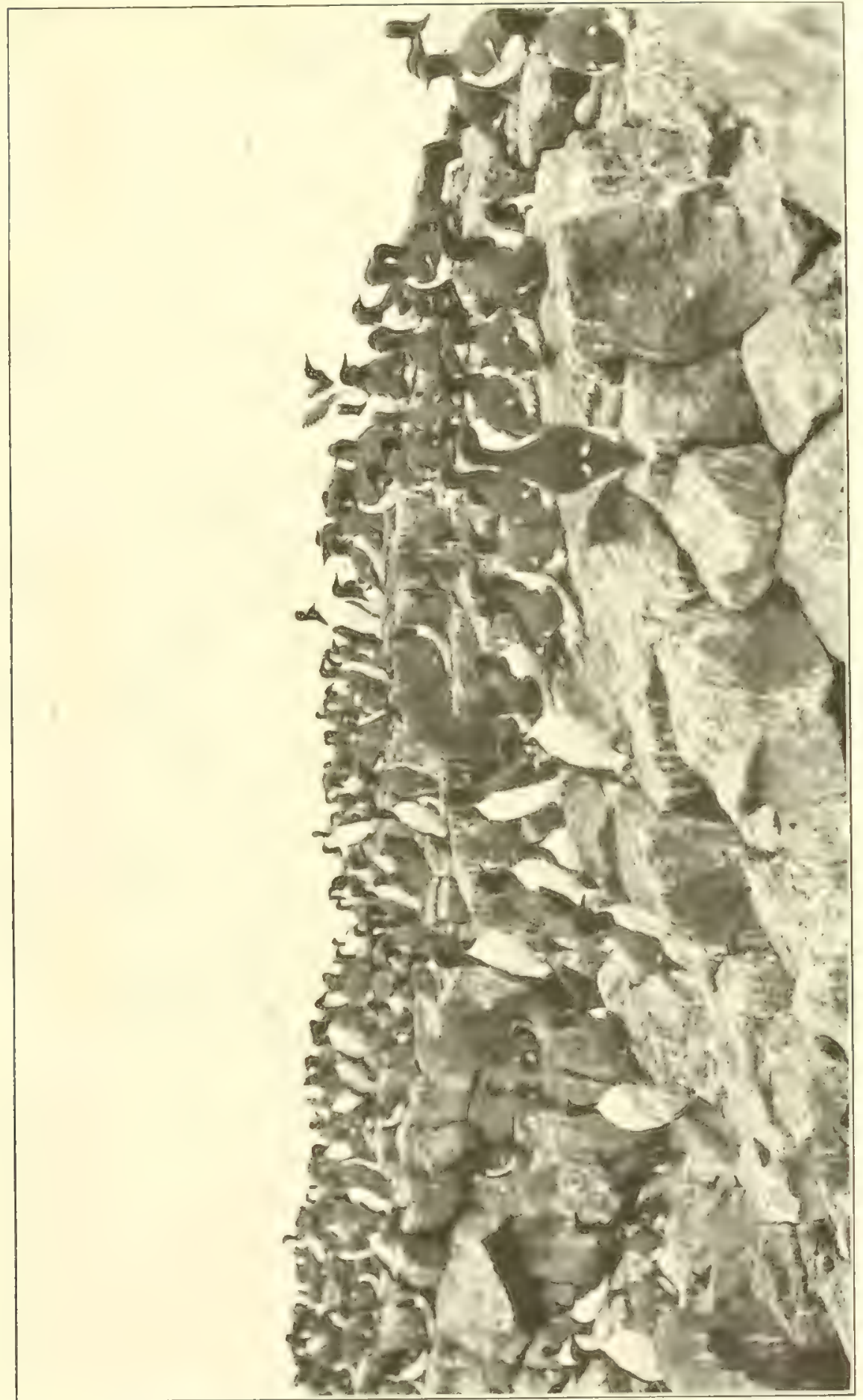



breeding in separate colonies, and are about equally abundant. The Glaucous-winged gull nests mainly or entirely on Walrus Island and Sea Lion Rock, but resorts to St. Paul Island in numbers throughout the summer. It is seldom seen on St. George Island at that season. The eggs are sometimes utilized, and during the colder part of the year the birds are shot for food.

The Kittiwakes are especially relished as food by the natives, and numbers are shot in early autumn as they $\mathrm{fly}$ along certain parts of the cliffs or cross from bay to bay over low portions of the islands. Their eggs are small and so difficult to secure that the birds suffer practically no loss in this respect. The continued abundance of the birds seems to be good evidence that the shooting of a few for food has had no serious effect.

\section{AUKLETS.}

Of the three species of auklets occurring in numbers on the Pribilof Islands, the only one of economic importance is the I,east Auklet (Aethia pusilla). This bird is scarcely larger than a robin, but exists in such myriads and is so easy to capture that it is of considerable value as food, and its arrival in April is eagerly awaited. The birds occur commonly on St. Paul, nesting mainly among the bowlders on the beaches, while on St. George the numbers are so great as to be almost incredible. On the latter island fewer nest in the bowlder-covered beaches, but large areas nearly throughout the island are occupicd by nesting colonies. Although the bird lays only one egg, the nesting period extends from late May to mid August, and probably at least two young are raised. Those taken for food by the natives are netted in spring as they fly along the cliffs, and the birds are practically unmolested during the breeding season. Many thousands are destroyed by the foxes throughout the summer, but in spite of the large numbers which meet death from these causes the birds continue to occur in such myriads that it is difficult to conceive of any larger numbers existing.

\section{DUCKS AND GEESE.}

Several species of ducks and geese occur in comparatively small numbers on the Pribilof Islands either as scarce breeders or as more or less regular visitors during migration. Several species are of some importance, and of these may be mentioned the eider ducks (the King Eider, Somateria spectabilis, being the commonest) and the Emperor Goose (Philacte canagica). The latter is taken mainly in autumn. The eiders are more or less numerous during the autumn, winter, and spring, particularly in seasons when the ice packs closely about the islands.

The eiders are birds of wide distribution, and the comparative few which are killed on the Pribilof Islands can not affect the species to any appreciable extent. The Emperor Goose is of rather restricted range, but so few visit the Pribilofs that the destruction there may be considered negligible.

\section{SHORE BIRDS.}

The list of shore birds, including sandpipers, turnstones, plovers, curlews, and godwits, is rather extensive, but the only species which need consideration in the present connection are the Pribilof Sandpiper and the Pacific Turnstone.

The Pribilof Sandpiper (Arquatella ptilocnemis), as far as known, breeds only on these islands and on St. Matthew Island. The breeding season is passed by the birds 
mainly on the higher, more barren parts of the islands, where they suffer no harm from man. At the close of nesting, in August, the old and young congregate on the beaches, where they are shot in some numbers by the natives, being highly relished as food. Considering that the bird has such a limited habitat and is of unusual interest from a scientific point of view, it would seem wise to restrict somewhat its killing, especially since no hardship to the natives would result. This subject is discussed at greater length beyond.

The Pacific Turnstone (Arenaria interpres) occurs during the spring migration, and in August and September when old and young are on their way to their wintering ground on the Hawaiian Islands. While on the Pribilofs the birds spend most of their time on the killing fields, where they feed on the larvæ of flesh flies in the remains of the slaughtered seals. They become very fat and are much prized as food by the natives, but soon become wary and are not killed in any great numbers.

\section{CORMORANTS.}

The Red-faced Cormorant is the only cormorant resident on the islands. It is not very abundant, but is easily obtained in winter when other birds are scarce, and is, therefore, welcomed. It raises a large brood and appears to have few natural enemies besides man, and seems to maintain its numbers.

\section{MEASURES FOR PROTECTION.}

The fact that the Pribilof Islands now constitute a national reservation insures the continued preservation of the hordes of birds which annually go there to rear their young. Ever since the first occupancy of the islands by man, the supply of birds has been drawn upon to furnish large quantities of food for the people who have lived there.

The fact alone that this drain has not resulted in the extirpation of a single species, and as far as known has not caused the appreciable diminution of any, seems to allay apprehension that any of the species are in danger from this cause. As a matter of fact the birds are probably subjected to less persecution now than at any time since the islands were first discovered. The habits of the natives have changed considerably in many respects. They have contracted a liking for innorted food, and with this the need and desire for pursuing the bircls lias waned to a considerable degree. They do not now seek the eggs of the birds to any such extent as formerly; and they are losing their skill in taking birds in nets, by means of which they formerly sccured great numbers. The introduction of firearms has, of course, offset this to some extent, but it is believed that fewer birds are killed now than formerly.

Although most of the species are still very abundant and none seem to be in actual danger of extermination, one or two species slould perhaps be accorded some measure of protection. The one of most importance is the Pribilof Sandpiper. This species breeds oniy on the Pribilofs and on St. Natthew Island. Apparently it goes no farther away to winter than the Aleutians, and it has, therefore, a very limited distribution. Its long-continued insular isolation under conditions which seem to be particularly favorable has apparently resulted in the development of a large and strikingly handsome species, and it is very desirable that it be perpetuated. Apparently it has not suffered appreciable diminution as yet, and the prospect of preserving it is therefore excellent. The general interest in the bird because of its restricted habitat and comparative scarcity 
causes it to be much desired by museums, and as it is practically impossible to obtain the species elsewhere, the collection of specimens for scientific purposes should be allowed, but it is believed that the killing of unlimited numbers for food should be prohibited.

In the case of this or any species which future investigations may show to be in need of special consideration it would be well for the agent or naturalist to be given authority to prohibit entirely the killing of such species, or to extend to it the benefit of such restrictive measures as would meet the requirements.

\section{FISHING.}

Since early times the natives of the Pribilof Islands have obtained a part of their subsistence by fishing. The stormy and inclement weather which obtains during the greater part of the year, and the fog which almost continually enshrouds the islands, have prevented this industry from being prosecuted to the extent that the abundance of fishes probably warrants. Notwithstanding the unfavorable conditions and the lack of systematic effort, however, large quantities of fish have been taken, the aggregate food value of which has been very great.

The species taken are mainly halibut (Hippoglossus hippoglossus) which here appears to attain as large a size as is usual in other parts of its range. Examples weighing roo pounds or over are frequently taken, and one of 350 pounds is recorded. The Alaska cod (Gadus macrocephalus) which does not attain a large size, usually not exceeding Io or I5 pounds, is also taken in large numbers. Sculpins, perhaps of several species, are also abundant, and are frequently caught about both islands. Because of the weather conditions it follows that most of the fishing is done in the summer, but it can be successfully conducted in some seasons as late as the last of October, and in some cases even into December.

So far as known, the best places for fishing have never been searched for systematically, though the places now selected by the natives are of course in accordance with the experience gained in former years. The place usually resorted to by the people of St. Paul is a mile or two off East Landing, where both cod and halibut are taken. Off St. George there are two principal fishing banks, one about 3 miles to the eastward of the village landing, and about half a mile from shore where only cod are taken; the other is 2 miles west of the village, and half a mile from shore, and here the principal catch is halibut. This species is said to be seldom caught here during the winter. It is probable that other fishing banks await discovery. In former years the natives fished largely or entirely from their small skin boats or bidarkas, but they have now entirely abandoned the use of this craft, in the management of which their ancestors were so proficient, and now fish only from large rowboats.

In order to give a clearer idea of the extent of the fishery than it is possible to gain from general statements, it may be well to set forth a ferv examples of the success which has attended fishing parties in past years. The following entries in the St. Paul Island $\log$ are selected from a very large number of records of fishing trips, very few of which were not to some extent successful: Parties were very successful in taking halibut on August 9, IO, II, and I2, I876; on August I4, 8 large ones were caught, and on August 23, seven bidarkas took 30 halibut, some of them very large. On August 25, r880, between I,000 and I,500 pounds of halibut were taken, and on August 3 I, one 6 
feet long is noted. A number of halibut taken in September, isy 1 , weighed from 50 to Ioo pounds each. In I892, many cod were taken during May, the first of the season being caught on May i9. In September, I9or, two natives took 29 halibut in two days. In more recent years, extraordinary catches of halibut are recorded on August 6, rgo8, and good catches of cod, halibut, and sculpins, on November Io, rgro. During the summer of I9I4 many very fine halibut and some cod were taken off East Landing on several occasions.

As regards St. George Island, fewer records are at hand. The fishing places are more accessible than the St. Paul stations, and being closer to shore the fishermen are less exposed to danger from foggy weather and sudden storms, and the chances for success seem to be rather better than on St. Paul. Mr. G. Dallas Hanna, on June 8, 1914, on a trip which took four hours, including the time consumed in the round trip to the fishing grounds, caught on one hook 90 pounds of cod and Ioo pounds of sculpin. On June 20 , r9ז4, on a similar trip of five hours, he took on one hook 120 pounds of cod, 80 pounds of sculpin, and 60 pounds of halibut.

The success which attends the fishing as conducted at present seems to warrant the prediction that with systematic exploitation the fishery will prove of considerable value. The establishment of a cold-storage plant, which is needed for many reasons, would insure the economical utilization of the product. During the year ended June 30 , 1914 , over 4,000 pounds of camned and salted salmon, in addition to a great quantity of preserved meats, all of which were of course imported, were consumed by the natives of the two islands. There seems reason to believe that this amount can be materially reduced by better utilizing the resources of the sea. Fish is relished by the foxes also, and as it has been proven by experiment that it can he easily dried on the islands, the use of the poorer part of the product for this purpose may prove feasible. All things considered, it seems certain that in the more systematic development of the resources of the islands which is demanded, the fisheries will prove of considerable value.

\section{INTRODUCTION OF NEW ANIMALS.}

The occupation of the Pribilof Islands by man early led to the introduction of various domestic animals, the presence of which has been of considerable advantage to the inhabitants. Another class of animals requiring consideration are those intended to furnish food for the foxes. Since the killing of seals has been limited to the number actually necessary for the support of the natives, the resulting hardship to the foxes has led to recommendations regarding the introduction of various small species which it was thought might supplement the reduced food supply of these valuable animals. Some experiments on a small scale have been attempted, but no success has as yet been achieved. It should be noted that in the consideration of the rarious species which might prove useful for this purpose, the important fact has been overlooked or disregarded that the Pribilof Islands are called upon to support a fox population far in excess of the normal. In a state of nature, a white or blue fox requires several square miles of territory for its support, while on the Pribilof Islands there are many foxes to each square mile. It is plain that any animals introduced here for fox food would need to become exceedingly abundant to be of any material benefit, and that while gaining a foothold they would have to contend against enormous odds. With the full signifi- 
cance of these self-evident facts before us, it seems plain that the chances of success attending the introduction of any animals intended to prove of benefit to the foxes are very small. The various species which have been introduced and those which have been recommended for introduction are discussed beyond.

DOMESTIC ANIMALS.

Horses and mules.-Draft animals, usually mules, have been used for many years on St. Paul to haul supplies from the landings to the warchouse's, and for transportation to and from the more distant seal rookeries. The animals find abundant past urage during five or six months of the year and are fed for the remainder of the year on imported food.

It is believed that if the work were undertaken in a systematic way that a sufficient quantity of hay and ensilage could be put up annually to support the small herds of domestic stock during the winter. A coarse beach grass (Elymus mollis) is very abundant and grows luxuriantly. Unsuccessful attempts to make ensilage of this grass are reported, but since it is successfully put up on Kodiak Island at a cost of less than $\$ \mathrm{r}$ per ton ${ }^{a}$ there seems to be no reason why the process should not be successful on the Pribilofs if properly managed. It is practically certain also that hay can be made from some of the grasses which grow abundantly in certain localities. It must be conceded that favorable weather can not be depended on. Even in the best hay regions, however, periods of rainy weather often occur, but with proper management most of the crop can usually be saved. Directions for the proper care of hay under unfavorable weather conditions are given in Bull. 3 of the Alaska Experiment Stations, I907. Although the conditions on the Pribilofs are perhaps less farorable than at Fort Kenai, to which place this bulletin refers, the drying properties of the air, when precipitation is not actually occurring, are very marked, and it is confidently believed that hay in moderate quantities can be made on the islands.

The animals appear to withstand well the peculiar climate of the islands. They are indispensable since they furnish the only means of transportation at present available.

Cattle.-A few cattle have been maintained on each island for many years, furnishing a supply of milk and occasionally beef for the tables of the employces. Like the horses and mules, the cattle have to be housed and fed during a large part of the year. All things considered, they do very well, but there is little doubt that the effectiveness of the herds would be increased if a breed were selected with reference to fitness for the peculiar climatic conditions. Instances of animals living for several years on the islands without care are on record, and while it is not desirable to adopt this method of treatment, it is plain that a greater measure of efficiency could be secured from a breed especially adapted to the rigorous climate.

Sheep.- Small flocks of sheep, usually composed mainly of ewes, have been brought to the islands from time to time, but no attempt has been made to keep up the supply by breeding, although it is likely that this would be successful if a hardy race were selected. On one or two occasions sheep which have strayed away in the fall have survived the winter. This argues remarkable ability to withstand the severe winter conditions, and suggests that if a breed were selected with this factor in mind the herds might be kept up with less care than is now necessary. The question of attempting

a Ann. Rept. Alaska Agric. Exp. Stations for r907, p. 6r, rgo8.

84512ㄴ.S. Doc. 980. $63-2-1$ 
to maintain small herds of sheep on both islands is one that may well merit careful study.

Swine.-For many years swine have been kept by the natives on both islands. The well-known omnivorous propensities of the animals enable them to pick up an easy living during the summer, as they usually have the run of the villages and the neighboring fields, where they secure a variety of vegetable food. The near-by killing fields are also drawn upon for a part of their subsistence. No prejudice against pork produced from a diet of seal offal seems to have arisen in the minds of the natives, and perhaps has no just grounds for existence.

There seems to be no valid objection to the raising of a limited number of pigs by the natives, but the careless habits of the people and the crowded nature of the villages tend to undesirable conditions with this industry unless there is very strict supervision.

Cats.-These animals were early introduced on both islands and have thrived. They seem to have been ineffective in reducing the numbers of house mice which here, as elsewhere, are a great pest. No apparent benefit has resulted from the presence of the felines, nor has any particular harm been apparent, excepting the annoyance which always accompanies the presence of large numbers of cats.

Poultry.-The Government, as well as many native families on both islands, have flocks of fowls which furnish their owners with a fair supply of eggs. Owing to the length and severity of the winter, against which no adequate protection is provided, it follows that the productivity of the fowls during the colder season is very limited. Many of the natives are obliged at this season to house their poultry in the attics of their own crowded homes, with results that may be imagined.

The establishment of a large poultry house to be used by the community has been suggested. The large amount of animal food which will be available when seal killing on a commercial scale is resumed, would greatly simplify the problem of the maintenance of a good sized flock, and with proper arrangements for the care of the fowls and the equitable distribution of the product it is evident that a large stock of poultry could be kept at slight expense. The project seems well worth consideration.

\section{WILD ANIMALS.}

Hares and rabbits.-The introduction of hares, jack rabbits, cottontail rabbits and Arctic hares have at various times been recommended as a source of food supply for the foxes. On one occasion several years ago a number of jack rabbits from Kansas were shipped, but they died on the voyage.

It is not believed that the introduction of either hares or rabbits would ever prove of any benefit to the foxes. The great number of foxes would nake it very difficult to establish a colony of rabbits of any species. Furthermore, it is not believed that the winter climate of the Pribilofs, coupled with the meager food supply at that season, would favor the existence of any species excepting the Arctic hare. This animal is able to withstand conditions even more severe than those found on the Pribilofs, but even under the most favorable conditions never becomes really abundant, although occasionally a number of individuals, driven by stress of circumstances, may congregate in a particularly favorable place. The Arctic hare requires for its winter food an abundance of willow. Several species of these shrubs occur in a dwarfed condition on the Pribilofs, but the supply is by no means abundant. The cost of procuring a 
stock of hares for introduction, owing to the scarcity and wariness of the animal, would be very great; it would be difficult if not impossible to protect these after their introduction, and even in the event of their becoming established, which is scarcely possible, the islands would support only a limited number. The abnormally crowded condition of fox life on the Pribilofs has already been alluded to, and this fact has a sinister bearing on the practicability of adding to their food resources by introducing small mammals among them. The introduction of any species of hares or rabbits, therefore, can not be recommended.

Ground squirrels.- The introduction of ground squirrels has been attempted on two occasions, but neither has proven a success. In I 899 some were brought from Unalaska and liberated on St. Paul, near the village. Their disappearance has been attributed to cats, but whether they were eaten by cats or foxes is immaterial.

In the summer of $19{ }^{1} 3$ the assignment of G. Dallas Hanna for work on St. George Island afforded an opportunity to make another attempt, and 22 ground squirrels, including both sexes and different ages, were captured at Nushagak. Of these, four died from natural causes before their journey was begun. Various circumstances made it impracticable to provide small cages for the animals, and they were shipped in a single large crate. Although plentifully supplied with green food, they preyed on each other, and while this tendency was overcome to some extent by supplying them with meat, the stock of 18 had been reduced to 5 before they reached their destination. These 5 , an adult female and 4 young, including both sexes, were liberated near the village on St. George Island in August. At least two survived the winter, and were seen on several occasions in early May, I9I4. They are not known to have been observed later; during our visit in early August none were seen, and a careful search disclosed no positive evidence of their presence. It is doubtful if any survived the summer, and in view of the fact that numbers of foxes continually ranged in the vicinity of the spot where they had been observed, the destruction of the squirrels would seem to be inevitable.

Although the two attempts which have been made to introduce ground squirrels have failed, there is little doubt that the animals could be established if brought in larger numbers and liberated in selected places where they could most easily find shelter in small natural rock cavities and where the foxes were least abundant. They are rapid breeders, and once established they might increase. But the fact that they retire in the autumn to deep underground burrows and would thus be unavailable as food during the entire winter and early spring-in other words, during the only part of the year when they would be needed by the foxes-seems to be an insuperable argument against their becoming useful as a source of fox food.

Muskrats. - The project of introducing muskrats on the islands has received considerable consideration and has once been attempted, but without success. In the summer of $19{ }_{13}$ G. Dallas Hanna captured seven muskrats near Nushagak for introduction on St. George Island. Unfortunately the animals preyed on each other during transit until only one remained to be liberated, and this is not known to have survived the winter.

Perhaps the most important factor bearing on the chances of survival of this animal is the suitability of the ponds where it must live. Those on St. George are believed to 
be so shallow that they freeze to the bottom, and if so, this makes them unsuitable for muskrats. Most of the ponds on St. Paul Island were surveyed by the late Dr. Hahn to ascertain their fitness for muskrats. The majority of those examined were found to be too shallow. The work was never completed, and two ponds which apparently are the best adapted to muskrats of any on the islands were not critically examined. One of these, Antone Lake, appears from a somewhat cursory examination to be suitable for the animals. Webster Lake is also a possibility, but is less likely to be favorable than the other.

There is little doubt that the introduction of muskrats on St. Paul Island can be successfully accomplished, but its advisability is questioned. Muskrats seek their food in winter entirely beneath the ice, and, however abundant, could not be caught at that season by the foxes, while their habits at other times of the year are such as to render them almost immune from the attacks of any land animal. The native boys, however, could increase their earnings by trapping the animals, but it is somewhat doubtful if the number which the limited amount of suitable ground would support would justify the undertaking on this basis. At any rate, a more careful cxamination of the deeper lakes by some one familiar with the habits of muskrats should precede any further attempt to establish the animals.

Sea otter.-This valuable animal played an important part in the discovery by white men of all the region bordering Bering Sea on the south and east. After its practical extermination from Kamchatka, the Russians in the middle of the eightesnth century gradually uncovered and devastated its haunts on the Aleutians and the neighboring groups until its growing scarcity in the more accessible regions led to its pursuit and virtual extinction in the uttermost parts of its range. At the time of the discovery of the Pribilof Islands, in 1786 , sea otters were very abundant there, and as many as 5,000 are said to have been taken from St. Paul during the first year of its occupancy. They were abundant also on St. George. They rapidly declined in numbers, and according to Veniaminoff had become scarce by is i and extinct within the next 30 years. Although the species apparently was practically exterminated on the Pribilofs about this time, small numbers remained and single individuals have been reported in a few instances even during recent years. According to the St. Paul log, a sea otter, the first observed for several years, was reported by fishermen on September 23, 1889. One was found dead at Rocky Point, St. Paul, in June, I896, and in December of the same year a live one was reported close to shore in Southwest Bay. Skulls or other remains, probably of animals long dead, are still occasionally found.

For some time after the commercial extermination of the sea otter on the Pribilofs many of the animals retained a foothold among the Aleutian Islands and in other parts of the North Pacific, but the incessant persecution to which the species was subjected gradually reduced it to the verge of total extinction. Now the pitiful remnant left is protected for a term of years in the hope that the species, which ranks among the most valuable of all fur bearers, may gradually repopulate its former haunts.

It has been suggested that sea otters be restored to the Pribilofs. If the difficulty of securing a stock for this purpose could be overcome, the animals might be induced by protection to remain on or about the islands, but the project is a doubtful one. Otter Island, so named from the former abundance of the sea otter on its shores, seems to be eminently adapted to the peculiar needs of this animal, is uninhabited, and yet is close 
enough to St. Paul to render its supervision practicable. It is not well adapted to foxes; the seals no longer resort to it, and even if they should do so, no conflict of interests need result. It is barely possible that an attempt to restore the sea otter to the Pribilofs, where formerly it was so abundant, might be successful.

Mink and otter. - While it is possible that mink might be introduced on the Pribilof Islands, it is not believed that the attempt is advisable. The animals would undoubtedly gain an easy living in summer from the bird rookeries, but the well-known blood-thirsty proclivities of the animals would insure the destruction of such vast numbers of birds that the harm inflicted would be out of all proportion to the benefit gained. The lack of streams with their accompanying food supply, and the dearth of small mammals, would form insuperable obstacles against the maintenance of any number of mink during the winter. In short, the conditions on the Pribilofs are unnatural and on the whole unfavorable for mink, and their introduction can not be recommended.

The objections to mink apply in a great measure to the land otter. The habits of this animal in winter are very similar to those of the mink. While otter live to a considerable extent on islands, their food is gained chiefly from fresh-water lakes and streams, and the absence of these from the Pribilofs is a strong argument against the advisability of attempting their introduction.

Lemmings and other small mammals.-The black-footed lemming (Lemmus nigripes) is found on St. George Island only, where it sometimes becomes very abundant. Its introduction on St. Paul, where the conditions are essentially similar, has been advocated. It is said that a number of years ago lemmings from St. George were released on St. Paul on two occasions, but no evidence that they survived was ever noted. There seems to be no good reason, however, why they would not become established if liberated in sufficient numbers. Since, however, there is no evidence that the lemmings have ever been of any particular benefit to the foxes on St. George, the experiment would be interesting chiefly from a zoological standpoint. The species is known only from St. George Island, and its introduction on St. Paul would decrease the danger of its extermination from any chance cause, a fate which frequently overtakes island species, and would afford an opportunity at some future time to study any effect on the species which its new habitat might induce.

For the same reasons the Pribilof shrew (Sorex pribilofensis), a tiny animal known only from St. Paul Island, might be transplanted to St. George. Much the same reasoning holds true in regard to meadow mice (Microtus), which are not found on the Pribilofs. Certain marshy areas on both islands seem admirably adapted to these animals, and there seems to be no reason why they should not succeed there, since they are abundant on several similar islands in Bering Sea and on some of the Aleutians. These species are in most cases peculiar to the island on which they are found.

House mice were early introduced on both islands and have long been abundant, and a pest. The presence of so many cats does not seem to have acted as a check on their numbers. Rats seem never to have gained a foothold, although it is altogether likely that occasionally they are landed with cargo.

Ptarmigan.-The introduction of ptarmigan on the Pribilofs has been suggested. While the general conditions as to climate and food are rather favorable than otherwise, it is believed that the great number of foxes would prevent the birds from establishing themselves or from increasing to any extent. It is likely also that the isolation of the 
islands from any other land masses would result unfarorably, since it is likely that the birds would attempt to migrate from the new habitat forced upon them, and in that event their loss would be inevitable. Therefore the project does not seem feasible.

\section{THE NATIVES.}

\section{ORIGIN AND EARLY HISTORY.}

When the eager search for the unknown land resorted to by the fur-seal millions was rewarded by the discovery of St. Creorge Island in 1786 , no signs of human occupancy were found. St. Paul was not visited until the following summer, and although the first party which landed there is said to have found the remains of a recent fire, proving that they had been preceded by some chance risitors, no evidence that human beings had previously made the islands their home has ever been discovered.

The exploitation of the mine of wealth thus fallen into the hands of the discoverers demanded the services of laborers-a people accustomed to the peculiar climate and inured to the life of hardship which must become their lot. The Russians turned naturally to the near-by islands, whose inhabitants, already in a state of virtual slavery, offered no opposition to the will of their masters. Unalaska and Atka islands furnished the bulk of the natives, said to be about $\mathrm{I}$ fo in number, who constituted the nucleus of the present population. Villages were founded at Staraya Artel (Old Sittlement), Zapadni Bay, and Garden Cove on St. George; and on the North Shore, near Big I,ake, and at Polovina and Zapadni on St. Paul.

In 1799 the government of the whole region passed into the hands of the RussianAmerican Co. The various rival traders whose dependents had inhabited the different villages were banished from the islands and all the inhabitants on each island were finally gathered into single settlements, the sites of which are now occupied by the villages of St. George and St. Paul. In the early days the natives were in a state of practical bondage, and were in many respects worse off than slaves. They lived crowded together in semisubterranean huts, subject to the whims of their brutal masters. Scanty fires of driftwood and blubber, which added greasy smoke to the filth which naturally pervaded their hovels, were their only means of cooking and keeping warm. In winter, crowded together in their squalor, neglected and unnoticed, they perished or survived as it happened, and when the sealing season came they slaughtered and skinned the seals for their masters until another winter rolled around. The number necessary for the work was kept up not by natural increase but by annual recruits from other parts of the region, including Sitka and Kodiak. On the heterogeneous mixture naturally resulting from the intermarriage of these diverse native peoples, their Russian masters, and to a less extent people of other nationalities who have since from time to time made the islands their home, have left their impress. The resulting combination is a people having many characteristics in common, yet probably including individuals as different in appearance and character as can be found in any isolated community of this size anywhere in the world.

\section{RELATION TO LESSEES.}

In I870, shortly after the purchase of Alaska by the United States, the Alaska Commercial Co. was formed by the banding of several enterprising traders who had taken advantage of the cessation of Russian monopoly to gain a foothold on the islands. 
To this company was given the exclusive right to take sealskins on the Pribilofs for a period of 20 years. The lease was framed with due regard to the moral rights of the native inhabitants. By its terms the Alaska Commercial Co. was required to furnish annually to the natives, free of charge, 25,000 dried salmon and salt and barrels for preserving a supply of meat; a school was to be maintained for eight months of the year on each island, and furnishing any spirituous liquor to the natives was forbidden. By further regulations the natives were to be employed in the work of sealing and were to receive 40 cents for each skin taken, the rate of wages for other work done to be agreed upon between the company and the natives; all provisions and merchandise were to be fumished at prices not higher than retail prices in San Francisco; the natives were to receive free the necessary fuel and oil; all widows and orphans were to be supported; free transportation to the Aleutian Islands was allowed; medicine and the services of a physician were to be supplied free of cost; dwelling houses were to be furnished rent free; no interference in their sacial or domestic relations or in their religious ceremonies would be allowed, and they were to be accorded kind treatment and aided by precept and example to appreciate the advantages to be gained by proper conduct.

An annual rental of $\$ 55,000$, an internal-revente tax of $\$ 2$ for each sealskin taken, and certain other minor taxes were required of the sealing company. To keep a proper check on the operations of the company and to safeguard in all ways the interests of the Government and the rights of the natives, agents of the United States Treasury were stationed on each island.

Thus raised from a life of degradation and misery to a condition of comparative comfort, the natives responded in a manner which is highly creditable to them. Already expert in sealing, the advantages of better food and shelter were soon apparent. The company ras able to take its annual quota of 100,000 seals in from 40 to 50 working days. At the same time the natives acquired a taste for many imported foods hitherto unknown to them and adopted the manner of dress of the white inhabitants and gradually began to lose many of the more useful of their primitive habits and handicrafts.

On the expiration of the lease of the Alaska Commercial Co. in 1890 a similar lease was given to the North American Commercial Co. for a further period of 20 years. Its provisions, as far as the privileges accorded the natives are concerned, were substantially the same as those of the previous arrangement, but the rate of compensation for the sealing and other work which the natives were fitted to perform was to be fixed by the Secretary of the Treasury. For several years following the advent of the new company comparatively few seals were killed and the natives were called upon to perform a correspondingly small amount of labor. During the incumbency of the leasing companies a system of compensating the natives was developed which is now impossible of operation, but which has become so ingrained into the minds and customs of the people that it is difficult for them to accept or understand any other. The total sum due the natives for performing the work of sealing was divided into a certain number of shares, a number considerably larger than the number of laborers. The workmen were divided by agreement among themselves, and supposedly according to their ability, into several classes, and from time to time received what was due them according to this arrangement. Some shares went to the church, others to the priest, and others to the widows and orphans. This arrangement did very well under the leasing 
system and while a large number of seals were being killed; some of the natives accumulated considerable sums which were deposited with the companies and bore interest. But the diminution in the herd necessitated a reduction in the quota, and during the modus rizendi an appropriation was made by the Government for the support of the natives. This continued to be done down to IgI I the annual amount, at least during the later years, was $\$ 19,500$.

\section{CONDITIONS UNDER GOVERNMENT MANAGEMENT.}

The lease of the North American Commercial Co. having been terminated in I9ro, the Government deemed it best to abandon the leasing system and accordingly took charge of all the activities on the Pribilof Islands. The special appropriation of \$I 9,500 was discontinued, but a part of the general appropriation for Alaskan seal and salmon fisheries was made available for the support of the natives. For this purpose the sum of $\$ 40,000$ was set aside, which the natives were supposed to earn by taking the seal and fox skins and by miscellaneous labor. For some of this work the natives received cash, but the greater part was paid in provisions and merchandise drawn in the form of weekly allowances. In $19 \mathrm{I} 2$ the killing of seals, excepting the number actually needed for food, was prohibited, and the sealing work involved was reduced to a negligible quantity. The consequent necessity of making the natives dependent in a great measure on the bounty of the Government marks a decided backward step in their progress along many important lines. Some of them consider that the Government is bound to support them in any case, and as they can get very little beyond a mere living they do not feel that they should be called upon to do any work not directly concerned with sealing. Others are willing workers, but are dissatisfied because they can not attain a condition superior to that allowed their associates who make no special effort.

\section{PRESENT SYSTEM OF SUPPORT.}

The following extract from the report of Walter I. Lembkey, former agent in charge of the islands, as published in Appendix II of the Report of the United States Commis. sioner of Fisheries for I9I3 (Bureau of Fisheries Document No. 797, pp. I4I-I48) states so clearly the present method of dealing with the natives that it may be quoted:

PROBLEMS IN COMMUNISTIC SYSTEM.

The instructions of the bureau provide that the natives shall be supplied, so far as funds will permit, with the necessaries of life to an amount sufficient to maintain them in comfort, due regard being paid to economy and thrift. To this end various supplies to be used by the natives, as fuel, food, clothing, etc., were purchased in San Francisco at the best wholesale rates obtainable and transported to the islands on the bureau's chartered steamer Honner. These supplies upon arrival at the islands were placed in the two general stores (one on each island), where they were marked for issue or sale at a price one-third above wholesale cost, including sil discounts except for cash. They mere then distributed after the methods hereafter detailed. The increase of one-third over the wholesale cost was made to cover cost of transportation and handling only.

The instructions of the bureau further provided that from the supplies thus taken to the islands merchandise to the amount of $\$ 40,000$ be furnished the native inhabitants for their support and maintenance during the fiscal year ending June 30 , I9I3. These supplies were not to be received by the natives as a gratuity but as a return for services rendered. Services such as might be performed in the taking of sealskins and in the management of the herd in general were considered the main labor for which the natives were to receive this support; but, as the killing of seals was to be greatly curtailed, the natives, in return for their support by the Government, were to be required to perform such other 
labor of a nature to benefit the community generally as might become necessary or desirable. Individual natives, however, who were willing to perform such labor of a skilled or unskilled nature as might be necessary to the upkeep of the Government property and the maintenance of the stations in general were to be compensated individually in cash from funds other than the $\$ 40,000$ set apart for the community support at the rate of, for skilled labor 25 cents an hour, and for unskilled I5 cents an hour. The skilled labor embraced that of carpenters, engineers, painters, and ironworkers, etc.; the unskilled mere laboring work requiring no special aptitude.

The system involved in the foregoing arrangement for natives" support is one of almost pure communism. The main problem confronting those charged with its conduct was to support the people in such comfort and happiness as the resources would allow and at the same time to minimize those admitted evils of communal existence which, in this case, could easily result in reducing the island inhabitants to a mental condition of stolid apathy, and a physical condition of virtual peonage, if not slavery.

If no labor were required of these people the problem would be simply to give gratuitously to each person supplies sufficient to insure his existence. It is necessary, however, at almost all times of the year to require some of them to perform services for which they receive no specific compensation, but merely a right to participate in the general fund. If all labor required of them were alike in character and amount and if all the natives could perform this labor with a like degree of proficiency, no special difficulty would be encountered. Some of the labor, however, requires aptitude and special training which some natives do not possess; also, some by reason of physical imperfections can perform less work even of a general nature than others, and some no work at all. To support the natives only to the extent that they perform service would be to allow some to suffer and others to starve because of inability to work and therefore to earn.

But if a helpless cripple and his family should not be allowed to starve, on the other hand a man of high efficiency should not be required to expend his best efforts for a compensation no greater than that which the cripple and his family receive for their bare maintenance in return for which they furnish no labor whatever, and which, too, the efficient would receive as a matter of course without rendering any service in return. Then, moreover, the fund for natives support is not large enough to allow special compensation to some and general support to all, but sufficient only to prevent suffering no matter what labor may be required of them.

These and other questions, which perhaps appear trivial to the casual observer, become of vital importance to those managing the natives' affairs. It may be of interest to detail the methods which are used in the distribution of the fund for the support of the natives, all of which methods have been the subject of careful study.

The $\$ 40,000$ fund was considered as belonging to the community and to be used for its support without regard to the question whether the person so supported was or was not able to perform service in return. It was therefore divided between the two islands on a strict per capita basis; that is to say, the whole amount was divided into as many parts as there were natives on both islands, and each island was allotted as many of these parts as there were natives on that island. From this fund before distribution, however, coal enough for both islands was paid for. This coal was turned over to the native community, and the community, through its chief men, was allowed to make distribution of it without official interference. No cash was paid from this fund except $\$ \mathrm{I}$ apiece to each native man on Christmas and Easter, for church purposes, and a payment to a midwife of $\$ 5$ for each baby born.

From the amount remaining after the deduction for coal, a suit of clothes was given to each man and boy, each individual was provided with two pairs of shoes, each family with material enough to make underclothing for the children and women, and each person with a supply of rubber footwear. From the remainder an "emergency fund" of perhaps \$r,500 was set apart. What was left was available for purchase of food and clothing on regular issues. This remainder was divided into 52 equal parts, representing weeks in the year, thus fixing the amount that might be spent weekly for support of the whole population.

The total number of persons to be supported was next ascertained from the census-two children being considered as one adult - and divided into the weekly allotment for the whole island, thus establishing a per capita tentative allowance for each person per week.

The number of individuals in each family was then ascertained, and the per capita amounts combined to give a basis for the expenditure for each family for the week. 
It having been demonstrated that a large family under the same roof can live more cheaply per capita than a small one, a readjustment of amounts was made, deducting a certain sum from the largefamily allotments and adding it to those of small families. In this way a final adjustment of allotments was reached, giving about $\$ 5$ weekly to a family of two, and about $\$ 7.50$ weekly to a family of six or sever.

Having thus established the amount which each family may spend weekly, issues of food and such clothing as could be purchased out of the allowance were then made on Saturday of each week to the heads of families, each head being given an order for such supplies as he wished not exceeding his allowance, which order when taken to the store was filled and the merchandise represented thereon given to the person presenting the order.

The emergency fund, already mentioned, was used to meet expenditures not contemplated in the regular allowance, such as occur in cases of death, sickness, marriage, childbirth, etc.

In this way the amount available for support of the matives is expended, not in cash, as stated, but in merchandise itself. The amount is just about enough to support the population without want. It reaches a little more than \$roo per capita. Everything to eat, to wear, and to keep the fires burning has to be transported over 2,000 miles, and the food is mostly in tins. Nothing edible except seal flesh can be obtained locally. It can be realized, therefore, that if the fund for natives' support is barely enough to provide the actual necessities of each person, little can be done toward encouraging and compensating extra effort or otherwise alleviating the objectionable features of communistic life in general.

Where a number of persons share equally in the distribution of a general fund, as these natives do, the natural tendency of each is to take and use the whole of that share without regard to whether it is needed or not. There is no inducement for a native to strive through self-denial to exist upon less than his share from the general fund when such abstention would result simply in increasing the share of his less provident neighbor. The whole tendency of a scheme of this character is to produce an attitude of carelessuess in the use of communal resources--in short, to create that attitude of mind which says: "As there is no reward for economy, let's get all we can. The other fellow will get it if we don't."

EXPERIMENTAI, PLAN TO INDUCE THRIFT AND SELFE-RELIANCE。

This tendency toward shiftlessness, which is an inevitable result of these peculiar circumstances, has long been recognized, and efforts have been made to palliate it at least. In ror a plan was put in operation designed to induce the natives to save at least a small portion of their earnings. It was based upon the general principle that by reducing weekly and other issues of supplies to a minimum an unexpended balance would be created, which balance at the year's end was to be distributed in cash among the earners according to their proficiency as workers. If even from a weekly allowance the native saved something, that saving was to be given him in cash at once. It was hoped he could be induced to open savings accounts with cash thus obtained, or at least to use it in purchasing some article not otherwise obtainable that would increase his happiness and comfort.

This scheme was placed in operation on St. George during the winter of IgII-I2. The results from a careful following of the plan are interesting. At the end of the first month in which the native men were informed that such savings as they made from their weekly allowances for family supplies would be paid to them in cash more than half the families in the village drew cash savings thus derived, the sums varying from $\$$ I to as much as $\$ 8$ or $\$ 9$. They continued to do thus during each remaining month in the year, almost every family saving something out of the amount allowed for its support.

Careful inquiries into the motives goveming the making of these savings developed some interesting points. It seemed, on the whole, that the main object of the native was not to hoard the cash thus obtained by saving but, on the other hand, to get possession of the cash itself, which in many instances he at once took to the store to expend for perhaps the very articles he had denied himself in order to make the saving. Some few, of course, used the cash to purchase in San Francisco articles which could not have been issued to them had they not the cash. No savings accounts were created. If any sums were saved, they were secreted in the natives' houses.

Some of the natives who made the largest savings had previously complained that their allowances were too small; those who have always been thrifty, however, redoubled their efforts to save, increasing their hoards regularly every month. But it was found that, to make these monthly savings, in some 
cases the children in the family were made to suffer through deprivation of proper clothing and sometimes food.

At the end of the year the sum of $\$ 6_{32.48}$ was unused from the natives' fund and remained for distribution. This amount was divided among the sealers, the furst-class men receiving about $\$ 32$ each and the lower grades in proportion. This money was nearly all spent in the store for articles of general use. No portion of it, asıstated, was used to create or to increase savings accounts in bank. It is reported, however, that the natives were greatly pleased with the plan as operated and under it many of them came into possession of more money than they ever owned before.

The net result of this one year's experiment is not large. It shows that the natives desire their earnings in cash rather than a mere credit. It shows also that if paid in cash for their labor in taking sealskins, etc., the greater portion, if not nearly all, of their money would be used for the same purpose for which the credit is used, namely, the purchase of the necessaries of life. It shows that under the present communal system the natives are not desirous of creating permanent savings funds because of their inability to profit greatly by the result of the self-denial necessary to create the fund.

It must be stated that conditions were not favorable for carrying the operation of this plan beyond the mere point of inducing the natives to curtail their use of the necessaries of life to a minimum. It was impossible to demonstrate to them that any particular benefit would follow this saving, because there was nothing they might obtain with their savings except the bare necessities of life, of which they had deprived themselves in order to create the savings fund. And, having saved, all they could buy was what they could have had without saving. Under the present system it is not permitted to purchase for island use anything but the barest necessaries of life. Articles from the use of which the average citizen finds enjoyment or benefit, and by means of which he is able to bring his life above the level of mere animal existence, are not allowed to be purchased for sale on the islands. Neither can the native improve his mind and broaden his education by travel, because no means of transportation are available. His clothing is of a certain fixed grade each year; if he desires a better suit or an unusual article of clothing he can not purchase it because it is not in the store; nor can he order it unless through some cumbersome private arrangement almost impossible to make. In short, he is held down to the use of a greatly circumscribed class of merchandise, on an isolated spot of the universe, in which use he must live and die, practically without power to alter the condition.

Why, therefore, should the native save money? Money has no value unless it can be used as a medium of exchange. The mere hoarding of it induces no satisfaction or comfort to any normal person. The reward of self-denial exists in the possibilities for greater enjoyment and greater comfort created as the result of the self-discipline. If the native has no use for his money after saving it, he will not save it; neither will anyone. To carry out successfully any scheme of this character, it is necessary to broaden the possibilities of the native's purchasing power. He must be able to buy desirable and attractive articles at least to the amount of his savings.

Everywhere, except to these people, a prize is offered for thrift. It should be held out to them, too. For example, it should be so arranged that the shiftless must wear poor clothing, but the provident may wear better. The provident, industrious man should be able to obtain better food than his careless and lazy neighbor. Under the present system this is impossible. This situation could be adjusted readily by a private concern, and it should present no more difficulties to the Government.

NEED FOR BROADENED OPPORTUNITY.

Since the killing of seals has been stopped on the islands, except a few for food, and because of the material reduction in the appropriation by Congress for the natives' support, the system of cash paymeats has, unfortunately, been discontinued after only one year of trial. The building up of the moral and intellectual fiber of a people is a matter of generations, not of years, even under ideal conditions. In the case of these natives, not only shouli precept and example be afforded, but an intelligent read justment of conditions on the islands should be made to give point and object to mere academic advice.

It may seem from the foregoing that because no greater results were obtained from this experiment it is useless to attempt to lead the natives to greater self-reliance and thrift. It is believed, however, that such object is not so near an impossibility as supposed. The cause should be sought in the system, not the native. The instinct of self-preservation is as highly developec in these natives as in the more effete races, and this instinct forms the basis of all desire to lay by something of what is in hand to insure 
against future want. Under the present system the native expects that his future will be provided for, and has, therefore, no incentive to deny himself and no self-reliance. While no one would be willing to make the existence of these people a matter of doubt, on the other hand, it is thought that it can be so managed that the native would have to depend more upon himself through the removal of certain of the paternalistic offices performed in his behalf by the Government.

As the situation is at present, the native merely has to work and to draw his weekly rations. He might complain in order to get more, but beyond that he has no voice in the disposition of his earnings. All the managing of his resources is done in his behalf by the agent in charge, under departmental instructions, and the only open line of endeavor is to hoodwink the agent into giving him more than his share. This unnatural situation should be remedied by allowing the natives more voice in the management of their domestic financial arrangements. It is believed, contrary to general opinion, that nearly all the native men are capable of handling their earnings in a thrifty and judicious manner, once they understand that it is necessary for them to do so or starve. Under this hypothesis it would be better for the native to receive his earnings, or at least a large portion of them, in cash at the close of each season, with the understanding that this sum must suffice to support him and family for a year; or monthly amounts could be given them with the same understanding.

* * * Should a native be grossly improvident, a stated sum from his earnings should be set apart for use of his children. The Government slould arrange to deposit any savings the native might make, or to expend them for such articles as the native may request to be ordered. At present this latter privilege is denied.

In short, the strongly paternalistic attitude of the Government, together with the communal system of living, has robbed these people of all chance of self-improvement by destroying the incentive. Any effort along the lines indicated or others to increase this self-reliance will be salutary. It is conceived that a certain small percentage of receipts from the sale of skins taken by these people, set apart for them, either for their support or as a fund for the improvement of local conditions, or as a sheer bonus to increase efficiency and faithful cooperation, would be a paying investment.

CASH PAYMENTS FOR SUNDRY LABOR.

What has been said in the foregoing concerning natives' earnings relates wholly to the fund earned by the community in general, mainly from the taking of skins. Such work as the natives perform as laborers or skilled workmen in maintaining the station buildings, exclusive of their own residences, is paid in cash monthly. These sums, although small, are welcome as representing the only cash the natives receive, and because this desultory labor is the only means through which the native may get individual results from independent action. Cash thus obtained almost invariably is used to augment the regular allowance of supplies, and the work through which it is obtained is eagerly sought. Not to pay them individually for such work, which is not at all for their benefit, would be to destroy the feature which removes their system of existence from mere peonage. * * *

In the above painstaking account of the manner of caring for the natives several points of vital importance are brought out, some of which may be briefly discussed. (1) The native wishes to be paid in cash for his work even though he may be impelled, either from inclination or necessity, to spend that cash almost at once. This tendency may be observed among native races anywhere as soon as money comes into use as a medium of exchange and is, of course, merely an indication that the native mind has grasped the fundamental idca underlying its use. He has labored and having obtained his reward, he would exchange it for something he needs or wishes. (2) Some of the people desire to accumulate their savings, showing that they possess a measure of thrift. (3) Some wish to exchange the results of their labor for articles other than mere necessitics such as food and ciothing, but that this is rendered impossible or difficult because the articles are not available on the island, and the delay and other difficulties of sending outside for the desired commodity are discouraging. (4) The opportunities for profiting from the possession of special talents or abilities are too limited, 
causing dissatisfaction to those possessed of stch abilities and remoring in a great degree the incentive which those less favored should have for striving to increase their earning capacity.

Since 1912 less money has been available for cash payments for miscellaneous labor than was contemplated. The necessities of life have been provided the natives, but with the cessation of sealing on a commercial scale they have been receiving their support in return for a minimum of labor. As before stated, the custom of receiving this support in return for the work of sealing has become so fixed in their minds that it is very difficult to make them understand that, in the absence of this work, other labor should be required of them. The fact that miscellaneous work has not always been rewarded, owing to lack of funds, has created much dissatisfaction, some of which is natural and justified.

\section{POPULATION.}

The native populations of the islands of St. Paul and of St. George on June 30, I9I4, were I92 and II6, respectively. During the preceding year on St. Paul there were 9 births, I arrival, and 8 deaths, 3 departures and I dropped by marriage, making a reduction of two in the population. During the same period on St. George there were 9 births and 3 deaths, an increase of 6 . Of the 192 natives on St. Paul, 94 were males and 98 females; and of the I I 6 on St. George, 58 were males and 58 females. Although the proportions of sexes are favorable for normal marriages, the regulations of the church forbich mariage within such distant degrees of relationship that in restricted communities such as these recruiting from outside bodies must often be resorted to. Thus the population of Unalaska has frequently been drawn upon.

In addition to the native population, there were on June 30 , I9I4, on St. Paul Island, Io white residents, I Chinese (cook) and 6 white visitors, and on St. George, 5 white residents and I Chinese (cook).

\section{PRACTICAL ABILITY OF NATIVES.}

It has become somewhat usual to regard the native inhabitants of the Pribilof Islands as of little intelligence and practical ability, but this is by no means the case. It is true that they have failed to develop along many lines as rapidly as has been hoped, but to those who understand the conditions this is not surprising. That they do not understand the reasons for the various changes in methods of administration is only natural since some of these changes have affected them adversely, and the complex conditions which have given rise to them are to these isolated beings an absolutely unknown quantity. It is true that they are somewhat childish in their methods of reasoning, but this is always true of a semicivilized people having but a limited outlook. One of the most effective means of helping them to broaden their viewpoint will be the more widespread use of the English language. This matter is discussed elsewhere.

Regarding their practical ability along mechanical lines there is much to be said in their favor. There is on the islands a good assortment of tools for working both wood and iron, and many of the natives are proficient in their use. Under intelligent supervision they can do practically any work necessary for the upkeep and enlargement of the station. The steam and gasoline launches are run by natives. The large amount of work done under the direction of James Judge in the autumn of I II is a good illus- 
tration of their varied ability. This work included the building of a bridge 168 feet long, including approaches; the remodeling, painting, and shingling of a large number of buildings, including dwelling houses, shops and offices; the laying of several concrete floors, pavements, and boat ways; and a great variety of minor jobs of carpentry, such as desks, book shelves, and filing cabinets. The women, under the inst ruction of the wives of the agents and others, have become expert dressmakers, and make a large part of their own and their childrens' clothing, and some of them do lacework and embroidery of a high order of merit.

It will be necessary in order to put the sealing plant on an efficient basis to do a great deal of work of a varied character during the next few years, and in most of this work the natives may well be employed. After the resumption of commercial sealing most of the available force will be needed during June and July on the actual work of taking the skins, but during the spring and autumn the other work necessary may gradually be accomplished.

During the incumbency of the Alaska Commercial Co. about 75,000 seals were taken annually on St. Paul Island. All the work of driving, killing and skinning this large number was done by about 70 men in from 40 to 50 working days. In late years, owing to the small number of seals killed, the ability of the natives has undeniably lessened, and care will be necessary to restore their old-time skill.

\section{KNOWLEDGE OF SEALS OVERESTIMATED.}

The native's knowledge of seals has been greatly exaggerated. It is, of course, undeniable that a native who has lived all his life among these animals acquires a great deal of information, but the average white man similarly situated would learn far more. Much of the lack of definite knowledge which has always prevailed, and which has been the source of a great deal of trouble, is due to the fact that agents and others in charge have been too ready to rely on the statements of the natives instead of ascertaining the real facts for themselves. The belief that he is supposed to know all about the seals gives the average native an exaggerated idea of his value in this regard and causes him to underestimate the true value of exact observation. An instance of this tendency came to our attention in August, I9I4. It was wished to make a drive from Reef Rookery, but the natives reported only a very few seals there, and said that it would be impossible to get a sufficient number. Our observations convinced us that this was an error and the drive was ordered, with the result that 1,600 bachelors were easily found. This may have been a case of deception rather than ignorance, or more probably a combination of the two, but it illustrates the fact that in matters requiring exact information it is unwise to rely wholly upon the natives. A white man soon learns to know as much of seals as the average native, and his judgment regarding seals, as of other matters, is greatly superior. For the work of killing, skinning, and curing, however, the services of the natives can not well be spared.

\section{PROPOSED REMOVAL OF NATIVES IMPRACTICAL.}

The removal of the inhabitants to a reserve elsewhere has been suggested, but the proposal is subject to numerous objections. These islands constitute the only home that the inhabitants know, and almost without exception each one thinks that the Pribilof group in general, and his own island in particular, is the best place on earth. 
The greatest punishment that can be suggested is banishment to some other place. To remove these people would be cruel in the extreme, nor under present conditions would it be justified from any standpoint of expediency or economy. They would have to be supported elsewhere, while here as long as the seal herd endures they will be selfsupporting and under proper management will be happy and contented. In the event of their removal it would be necessary to have their work done by temporary employees probably less suited to the peculiar conditions than are these people born and raised on the islands. As far as possible the reforms needed should be put in operation gradually. It should be borne in mind that the ideas and habits of these people have back of them many generations of training under peculiar and somewhat adverse conditions, and that it is impracticable to change these habits abruptly or to settle the problems in regard to their management by transfer to a different and less favorable field.

\section{PRESENT APPROPRIATION INADEQUATE.}

The appropriation available for the Pribilof Islands is wholly inadequate to manage the business in an efficient manner. It is not enough that a certain quantity of provisions and other merchandise, varying according to the amount which can be spared for this purpose from a given year's allowance, be landed on the islands and doled out to them in weekly portions in exchange for what work they may that year be called upon to do. Even under present conditions, when no fur seals are taken except for food and when the fox herds are in poor condition, the net receipts from the sale of skins in 1913 were over $\$ 67,000$. It would seem no more than reasonable with this amount of revenue actually being turned into the Treasury that the islands be allowed a substantial increase over the $\$ 40,000$ now available. The system now followed in paying the natives for their services is merely a legacy from former times, with many of the objectionable features retained and with no improvements added. It does not meet the requirements of the situation, and is unsatisfactory alike to the natives and to the officials of the Government on the islands and elsewhere who have its administration in hand. This subject in its relation to the natives may here be considered briefly.

From a generous appropriation the stores on the islands should be annually stocked with a supply of goods sufficient to last at least one year, and to provide against accidents and emergencies a surplus of the most essential articles should be kept on hand. This stock should include the staple articles of food, clothing, and other merchandise which experience has determined are most suitable for the purpose. Some arrangement should be made for the support of those unable to earn their living - the widows, orphans, and those crippled or otherwise incapacitated. 'This might be done by issuing rations, and probably it might be well, in view of the impracticability of furnishing them with steady work throughout the year, to issue a minimum ration to all the natives. They should then be paid in cash for all work performed at a fair rate of wage. They themselves have petitioned that they be paid in cash for their work and be allowed to buy their provisions. Most of this cash almost at once will be expended in the store-in other words, will be retumed to the Government-and after the first year it or its equivalent may be expended in paying for further labor or in the purchase of provisions.

If the business of the islands were in the hands of a private concern, this is exactly the method which would be followed, and it should be possible for the affairs there to be administered by the Government in a manner equally efficient and simple. The details 
of such an arrangement will, of course, need to be worked out. A careful study of the conditions on the islands convinces one that the work necessary to put the plant on an efficient working basis will keep the natives employed for several years during the seasons when outdoor work is possible.

\section{FOOD REQUIREMENTS.}

The diminution of the seal herd and the consequent restriction of the killing of seals to the number considered necessary for native food has sometimes led both on St. Paul and St. George to so limited a kill as to be hardly sufficient for the maintainance of the community. As a result the use of large quantities of imported foodstuffs has been necessary. Thus, during the fiscal year ending June 30 , I9I4, the natives on both islands consumed over 3,000 pounds of canned salmon, about 1,400 pounds salted salmon, 7,500 pounds canned meats, about 6,500 pounds salt beef, and over 1,000 pounds of salt pork. While it would be inadvisable to stop entirely the importation of these articles of food, since the natives have acquired a taste for them and would be dissatisfied if they were withheld, it is plain that the quantity of these costly foods consumed would be greatly reduced if an abundance of seal meat, fresh or properly preserved and which costs nothing, was furnished them.

To ascertain the amount of seal meat really necessary for the natives, a conference was held on St. Paul with the agent in charge, Mr. Hatton, and with the native chief, John Stepetin. It appeared that a family of eight persons would consume in one month I 4 fresh seal carcasses or 7 salted ones; hence fresh meat would be eaten at the rate of $I_{3}^{3}{ }_{4}^{\prime}$ careasses per capita per month and salt meat at half that rate or seven-eighths of a carcass per capita per month.

As fresh seal meat is available for eight months in the year and salt meat must be relied upon for the remaining four months, it follows that the total amount of seal meat needed for one native for a year is 17.5 carcasses. This amounts to not more than one pound of meat free of bone per day for each person. A seal carcass as roughly dressed by the natires and including bone weighs ahout 35 pounds. St. Paul, with a population of 192 natives, is therefore entitled to 3,360 seal carcasses per year for native food, and St. George, with about half that number of natives, to about half that amount of meat. Scaling these figures to conservative round numbers, it seens not unfair to set the allowance for native food on St. Paul at 3,000 seals and on St. George at I,500 seals, making a total of 4,500 seals for the native food on the two islands combined. The economical utilization of this meat would be greatly facilitated by the establishment of a cold-storage plant on each island. The natives also consume freely soda biscuits, sweet crackers, preserved fruit, jellies, and condensed milk. Sugar, candies, and sweetened foods of all descriptions have been used in considerable quantities in the home manufacture of an intoxicating drink called quass. Various means of stopping this custom have been attempted, hut without complete success, although there is undoubtedly much less intemperance than formerly.

\section{HOUSING.}

The natives live in small wooden houses. With few exceptions these houses were built in the first few years of the incumbency of the Alaska Commercial Co. and are, therefore, about 40 years old. At that time the natives were living in their primitive barrabkies, a combination of sod house and hurrow, compared with which these neat 


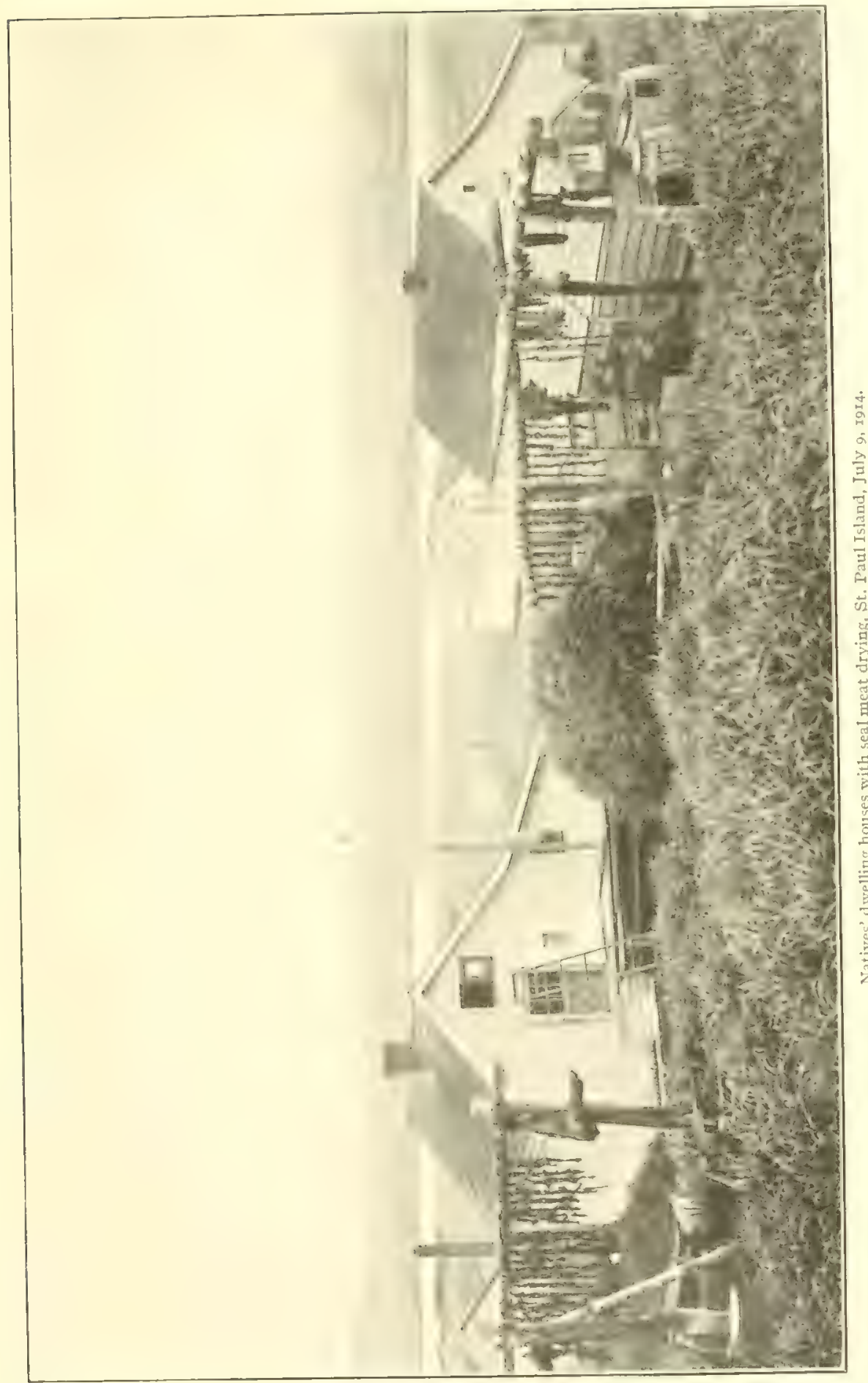



frame houses, small though they were, seemed like palaces. Even now they make very comfortable dwellings for small families. They are of one story, about $\mathrm{I} 2$ feet by 20 feet, usually with an inclosed side hall or "calidor" through which is the single entrance. Windows at the front and back, and sometimes on the side opposite the entrance, light them fairly well. Most of them have been kept in fair repair, but in many instances the floors, sills, or roofs are defective.

The native populations of the two islands are distributed in households of the following numbers:

Number and size of households on Pribilof Islands, IQI4.

\begin{tabular}{|c|c|c|c|c|c|c|c|c|c|c|c|c|c|c|c|}
\hline & \multicolumn{13}{|c|}{ Size of household. } & \multirow{2}{*}{$\begin{array}{c}\text { Number } \\
\text { of house- } \\
\text { holds. }\end{array}$} & \multirow{2}{*}{$\begin{array}{l}\text { Total } \\
\text { popula- } \\
\text { tion. }\end{array}$} \\
\hline & I & 2 & 3 & 4 & 5 & 6 & 7 & 8 & 9 & ro & $\mathrm{xI}$ & 12 & $: 3$ & & \\
\hline On St. Paul. ....... & 2 & 7 & $I_{4}$ & 14 & 6 & 2 & 4 & I & & & & & & 50 & 192 \\
\hline On St. George..... & I & 3 & 5 & 4 & 3 & 2 & 3 & I & I & & . & & 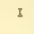 & 24 & 126 \\
\hline
\end{tabular}

It is evident that the houses, even though they are provided with a calidor and divided into two rooms, are too small for many of the families. A few of them have been enlarged and have a third room, but there is still entirely too much crowding for proper considerations of comfort, sanitation, or morals. The most striking instance of overcrowding was met with on St. George, where a house of four rooms, the largest room being I I by 12 feet, the smallest 7 by i I feet, contained a man, his wife, and I 2 children. The children were 8 girls, aged in years as follows: $18,16,9,7,6,4,2$, and 8 months; and 3 boys, aged I2, IO, and 5. This family had been assigned the largest native house in the village, but it was obviously much too small.

The principle of meeting the needs of the various families by assigning to the large ones the larger houses seems to have been carried out with reasonable fullness on both St. Paul and St. George. The Government will, however, be obliged from time to time to undertake rather extensive repairing and rebuilding and it is suggested that under such circumstances greater variety be introduced into the new construction so that families of different sizes can be better accommodated than in the more nearly uniform houses at present available.

\section{HYGIENE AND SANITATION.}

The native houses are as a rule overcrowded and filthy, and in all cases they are unprovided with water and are poorly ventilated. They reproduce all the conditions of congested tenements in our worst city slums except that outside their doors there is an unlimited supply of uncontaminated fresh air.

On St. George the water for village use is in part hauled from wells and in part taken in the midst of the village from a pipe which leads by gravity from a pond behind the settlement. On St. Paul the water has heretofore been hauled entirely from wells half a mile from the village. During the past year large storage tanks have been erected on the village hill and spring water is pumped into these by way of the radio station and is to be delivered by pipes at several points in the village. For cooperation in installing and maintaining this system the village is indebted to the Navy Department. At the time of inspection (July, I9I 4 ) this system was only partly installed and the water in the tanks was much discolored by the new wood. This state of affairs had brought the system into some disfavor with the natives, but there is no reason to S4512 - S. Doc. $950,63-3-10$ 
suppose that when it is in working order it will not prove a decided advantage over that of the past. With water carried in wagons, sledges, or on the back for half a mile it is no wonder that its use is limited and that filthiness is thereby encouraged. Too much emphasis can not be laid on the importance of establishing in each village a good supply of easily available water.

If the water supply of the villages is meager, the means for disposal of waste is absolutely inadequate. Most native houses are provided with a privy, consisting of a pit in the ground covered with a small wooden structure. Many of the privies are filled and receive no further attention. Much of the waste, including that from cooking, is thrown on the ground just outside the houses. The result is that the whole settlement is permeated with filth. If underground drainage can not be provided, it seems that some form of waste collection and disposal ought to be instituted. Privies might be arranged with collecting pans and these, together with receptacles for household waste, ought to be emptied and the contents disposed of once or twice a week as a part of the community work.

As matters are at present the natives find it easy to remain in a condition of much filthiness, but with a reasonably available water supply and a simple but adequate system for the disposal of waste in each village this condition might well be improved. The natives are resistant to all such changes and seem to harbor a deep-seated antipathy, if not a religious one, against having anything to do with community refuse. It is therefore doubtful if they could be induced easily to take these steps in reform. Such measures would have to be enforced, and it would seem impossible to accomplish this without semimilitary methods. If the Government provides village water and institutes a system of waste disposal, it might well declare the law of the land to be "Clean up and keep clean or you will be sent away."

The results of the filthiness of both villages are secn in the reports of their respective physicians. At St. Paul about half the native population showed evidence of tubercular trouble, and intestinal disorders were very prevalent. St. George, though not reported in so detailed a manner, seemed to be in much the same condition as St. Paul. In both places the work of the physician was greatly handicapped, if not made entirely ineffective, by the fact that the patient was obliged to stay in a filthy house where little or no attention was given to physicians' directions; a bath, for instance, ordered by the doctor was seldom if ever taken, for the reason that these people rarely bathe and see no relation between health and personal cleanliness. In cases of desperate sickness the priest is usually summoned, and if he declares that death is at hand the doctor's advice is entirely ignored. The invalid is kissed by most of the community and, if death follows, the same kissing is resorted to with the corpse. All these practices have religious significance to the natives, but they are unhygienic and render futile the best efforts of a physician bent on preventive measures. Improvement in these matters could be made by maintaining in each village a small hospital and inculcating through it some idea of clean living. A start in this direction has been made on St. Paul, where during the past season a small hospital building has been fitted up. The need for a hospital on St. Paul was so great that, although no appropriation was available, a fairly serviceable old building was moved and remodeled in 1914 and fumished as well as could be done by utilizing scattered material collected from various sources on the island. The physician in charge, to effect much, should have a semimilitary control over the community. 


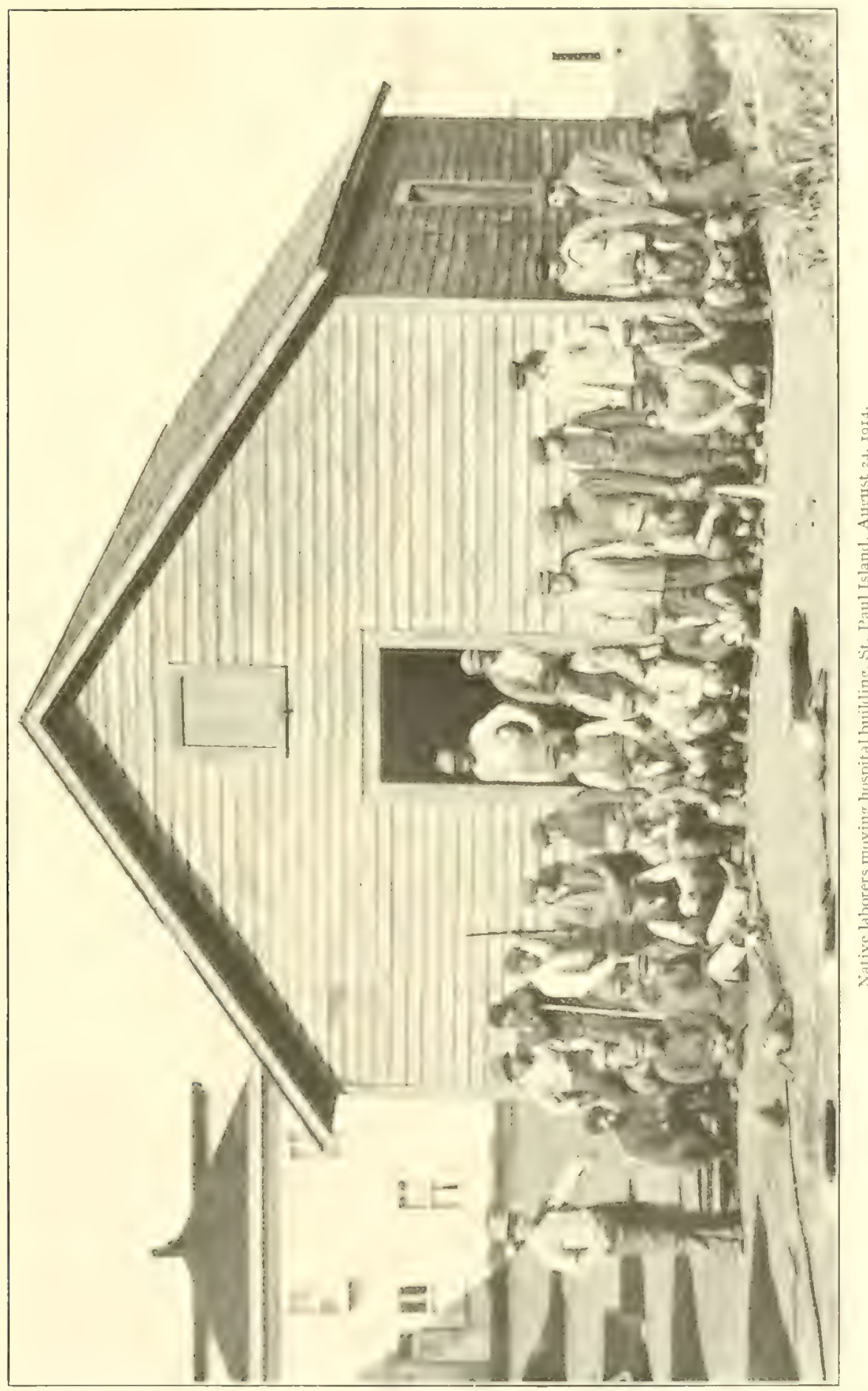



MORALS.

The natives give the impression of an honest, docile body of people, devoid of the small vices of the poorer parts of American towns, but addicted to a certain amount of drunkenness and to sexual looseness.

Though not supposed to have access to alcoholic drink, they brew for themselves, from the sugar and other sweets supplied them, an alcoholic beverage known as quass, which is the occasion of most of their drunkenness. From the reports of those whites who have wintered on the islands, it appears that quass debauches are of not infrequent occurrence. This practice could be suppressed only through the action of the natives themselves, and even its partial control presents many difficulties.

Sexual looseness is seen in the considerable number of illegitimate births and in the prevalence of venereal diseases. So far as the natives are concerned, these conditions are due not so much to viciousness as to purely animal habits. In some respects the natives resemble children with the appetites of adults. They are reasonably honest; they are not vicious, but they indulge their appetites almost without control. Changes in these conditions can result only from racial improvement brought about through sanitary surroundings and proper education.

\section{RELIGION.}

The natives are members of the Russian Church. On each island there is a church building and priest answerable to the head of the American division of the Greek Church in New York City. The services are usually conducted in Russian with some Aleut interpretation. Each priest maintains with more or less regularity a Russian school which is chiefly concerned with teaching the Russian Church service. The priests have been extremely diverse; some have been self-seeking, deceitful, and cunning; others have been simple, kindly, and benevolent. All seem to be strongly conservative and oppose those steps in the social and educational organization of the islands that from the American standpoint mean progress. It is difficult to see how many needed improvements can be carried out on the islands without the cooperation of the church. If intelligent priests could be obtained and thoroughly sympathetic relations established with them, a most effective avenue for advance would probably be opened up.

\section{EDUCATION.}

The education of the natives, as the reports of the several school-teachers on the islands have shown, is not a simple task. School is in session for eight months each year, and the pupils in attendance range from 6 to 16 years of age. In the past year on St. Paul there were 26 boys and 16 girls enrolled, and on St. George 12 boys and 13 girls. The schoolhouses are single-room frame buildings, poorly and inadequately furnished, and in wretched condition, particularly on St. George. While the school on St. George can be managed by one teacher, that on St. Paul requires two, one of whom should be a woman. Some improvement has been accomplished during the present year on St. Paul by the utilization of a smaller building for the younger scholars, thus relieving somewhat the congestion. New school buildings with better equipment, or extensive repairs and enlargement of the old buildings, are urgently needed on both islands. Although the time devoted to school is nominally eight months, this period is considerably reduced by the large number of holidays. The total number of school days in the school year is ahout 
I 70 , but during this period there are $25 \mathrm{I} / 2$ days of vacation, 4 American holidays and $211 / 2$ Russian Church holidays. These reduced the school days last year (1913-1+) by is $1 / 2$ days. Besides this many name days fall in the school period, and as these are religiously observed, they cause each child an additional absence once a year. One of the teachers in particular has complained much about these holidays, but they are not more numerous than in German schools, which do not seem to have been seriously affected by them. In one respect the school year might be changed to advantage. The holiday period centers around the Russian Christmas (Jan. 6-14), a time of year when the days are very short and the light poor. A vacation covering these holidays might be given at this period, and the time thus taken might be added to the school year, in part at the beginning and in part at the end, thus increasing the year at periods when the season is more favorable than in the dark winter.

The subject most taught in the schools is Linglish, and the exercises deal with speak. ing, reading, and writing this language. Besides this, arithmetic, some geography, history, personal hygiene, and a little natural history have been tried. Mr. G. Dallas Hanna, the teacher on St. George, noticed that though the native children could learn with great ease to write after a copy and even spell difficult words, their real understanding of their performances was very slight. They were remarkable imitators, but otherwise of very low intelligence. He therefore spent much time in teaching them words and their uses. But even so simple a matter as this is not easily accomplished. Most schoolbooks are written and illustrated for children who live in a land where tree, river, dog, train, etc., are already things of experience. Not one of these objects is on the Pribilofs, and it is not surprising that a new language about strange things, many absolutely unknown to them, should be troublesome to inculcate. But the matter is rendered still more difficult from the fact that the native child on leaving school for the day hears nothing but Aleut and speaks nothing but Aleut till he returns to school the next morning. The daily speech of the native is Aleut with a few Russian and English words, and to such a native the English school must seem a most impractical and academic affair.

This side of the educational situation was recognized by the teachers on both islands, and instruction in sewing and dressmaking for the girls and in making nets, working ropes, and working and tempering steel for the older boys and men were begun. It would seem that if the educational aim could be made more practical and the English language made incidental to this training, a more secure advance might be made. Certainly the common-school aims and methods in the States are not well adapted to the natives of the Pribilofs.

Some improvement could doubtless be attained by the use of special readers, dealing more generally with objects which are familiar to the native child.

The ability of the natives to use English is quite different on the two islands. On St. Paul about six, mostly old people, can speak no English, but about two-thirds of the total population speak the island's capacity of this tongue. About half the population can answer simple English questions, and five or six speak English well. It is easy to get an English answer on St. Paul; it is rather difficult on St. George. This difference is probably due to the greater frequency with which Government vessels call at St. Paul than at St. George. The native on St. Paul has considerable use for his English as compared with his brother on St. George. 


\section{CONCLUSIONS.}

It will be seen from the foregoing account that the people of the Pribilof Islands, though not natives, have for so long made the islands their home that they know and recognize no other. They are a people still in a state of semicivilization, and considering their limited environment they seem to be as well able to embrace its advantages and as successful in combating its disadvantages as is usual among such peoples. They constitute a heritage acquired by the United States with the islands and their valuable wild inhabitants, and considerations of economy and of humanity demand that they be accepted as such and managed with all possible wisdom and faimess. Many of the details of the present system of dealing with them are survivals of the past, and the conditions under which they developed are no longer existent. Many changes and improvements have been recommended by the agents and other officials, but in most cases they have not been accomplished, either on account of controversy, sudden and radical changes of régime, or small appropriations. Many changes in the methods of dealing with the natives seem to be necessary. Such changes should be instituted gradually, and in such a way that the natives will be able to perceive their faimess and expediency. In some respects they deserve more liberal treatment; in others they must be dealt with more firmly. In their management a great deal will depend on the personality of the officials in charge.

The changes in methods which seem desirable have been pointed out in the foregoing pages. It is believed that the work necessary to put the sealing plant on an efficient basis and the resumption in the near future of commercial sealing, accompanied by a better system of compensation, and the opportunity of exchanging the reward of their labor according to their desires will help to make the natives self-respecting and gradually lead to their betterment in many directions. By such a course the people of the islands may become an entirely self-supporting, efficient, and happy community.

\section{SUMMARY.}

The results of the investigation of 1914 may be summarized under two principal headings, (1) existing conditions and (2) conclusions.

\section{EXISTING CONDITIONS.}

The actual conditions on the Pribilof Islands as detailed in the foregoing pages may be stated briefly, as follows:

(I) The herd of fur seals contains approximately 294,000 individuals, of which not less than 93,250 are bearing females.

(2) The stock of adult males is small, and though there is no proof that breeding is thereby diminished, it is evident that adolescent males participate in it to a greater extent than is natural. There is every reason to believe that this condition will cease to exist in 1915.

(3) The supply of idle bulls is small and insufficient for the service of the virgin cows, which must therefore mate either with the old bulls or with the adolescent halfbulls. There are good grounds for believing that this condition also will cease to exist in 1915 . 
(4) The maintenance of a supply of harem bulls in the ratio of I bull to 40 bearing cows meets all possible demands of safety and conservation.

(5) The operation of the law of 1912 has already resulted in a great increase of male seals. The number of young males is very large and increasing rapidly. Of those now living, enough will come to maturity in I9I5 to supply the needs of the herd for both harem and idle bulls. The next generation, coming to maturity in 1916 , promises to exceed greatly the needs which will then exist and succeeding generations will furnish further excess.

(6) The herd is in excellent physical condition. Seals of all classes appear healthy and robust. Mortality of pups was small and natural and no epidemic of any kind was prevalent.

(7) Yearling seals were not found on the hauling grounds except in exceedingly small numbers and very late in the season. The evidence is practically conclusive that they rarely come to land at all until after the close of the killing season, July $3 \mathrm{I}$.

(8) The increase in the number of bearing cows in 1914 was small and is probably due to an abnormal death rate among old cows as a result of former pelagic sealing.

(9) Observation and handling in 1914 of seals branded with hot irons in 1912 shows that the marking of breeding reserves with a permanent brand is practicable.

(10) With more facts available than at any previous time, it is conservatively estimated that when once proper proportions are established in the herd they may be continued by reserving 3 -year-old males in numbers increasing at the rate of 8 per cent per annum, the reserve in any given season being 22 per cent of the number of bulls required for the cows of the previous season.

(II) The method of killing seals is not objectionable from the humane standpoint, but shorter drives are desirable.

(12) The system of weighing skins, introduced during the period of leasing, is antiquated, unreliable, and no longer necessary. A more economical and more trustworthy classification can be made by measuring the dead animals before they are skinned.

( 13 ) The condition of the buildings on the islands, the means of local transportation, and many of the methods of work are but little changed since the lessees left. They are the inheritance of obsolete conditions and in many cases unsuited to the demands of modern efficiency.

(I4) The fox herd is in poor condition and demands special care and study.

(15) The reindeer herd is increased and in good condition.

(I6) The sea lions and certain of the birds need continued protection.

(i7) The natives constitute a serious problem demanding careful consideration; their present condition, while far from hopeless, is not creditable to the Government.

(I8) The resident employees on the islands have a heavy responsibility divided between the management of the seals and the government of the natives, each presenting special problems requiring a high degree of ability for their solution.

\section{CONCLUSIONS.}

As a result of the investigations of 1914 , the findings of which are summarized in the preceding section, the following conclusions seem justified:

(I) There are good reasons both from the standpoint of economy and from that of the welfare of the seal herd to resume commercial sealing at once. Commercial sealing 
in which the growth and preservation of the herd would be practically guaranteed could be practiced under only two restrictions, namely that females should not be killed for their skins or for food, and that breeding bulls should be maintained in numbers suficient to supply one to each 40 bearing cows.

(2) The management of the seals and other animals of the Pribilof Islands needs to be placed in charge of a specially qualified officer and the management of the natives and the fiscal affairs might well be conducted by another. The officer in charge of sealing, in addition to physique and general good character, should have a deep intcrest in the problems he would have to deal with and a desire to make of them practically his life work. These qualifications are most readily found among naturalists, but general fitness for the position is more important than training as a zoologist. The position would have certain disagreeable features that are unavoidable, and in order to attract a man of the necessary ability, he should be well paid, should have certain perquisites, and should be detailed for service in Washington during the winter season so far as possible. The officer in charge of natives and fiscal affairs should be similarly qualified. Each should have at least one competent assistant. Complete division of authority being administratively impossible, the man in charge of sealing should be the senior officer on the islands, but the man in charge of fiscal affairs should have the same degree of freedom in his field that the physician and the school-teacher have in theirs.

(3) The Pribilof seal herd is a property of great value warranting immediate liberal expenditures in preparation for a most promising future. The very prevalent idea that the fur seal is on the verge of extinction is not in accordance with the facts. The present size and condition of the herd is such that its complete rehabilitation may be confidently expected. Provisions commensurate with the needs and importance of the property involved are to be regarded as wise investments and curtailment of operations at this time is not justified by conditions.

\section{BIBLIOGRAPHY.}

The following list, though known to be incomplete, is believed to include most of the important titles relating to the fur seals of the Pribilof Islands which have appeared in English since the purchase of Alaska. To attempt has been made to include references to all the minor laws and regulations or resolutions of Congress, and the list is known to be especially lacking in this respect. Articles in magazines and other periodicals of a popular nature have not, as a rule, been included. No bibliography relating to the. Pribilof fur seals has ever appeared, and therefore the publication of the present list, despite its limitations, seems justified.

The work of compiling the list has been done almost entirely by Miss Rose M. MacDonald, librarian of the United States Bureau of Fisheries.

I868 Bulkley, Charles S.

St. Paul's Island, Alaska [Report by Charles S. Bulkley and Charles M. Scammon] r867-I868. Washington, 1868, I6 p. (40th Cong., 2d sess., House Misc. Doc.)

St. Paul and St. George, Alaska. Letter from Frank N. Wicker to Hon. Robert C. Schenck, with copy of report made to the Solicitor of the Treasury relative to the Islands of St. Paul and St. George, Alaska. Washington, I869. 3 p. (4Ist Cong., $2 \mathrm{~d}$ sess., House Misc. Doc. II.) 
I870 Alaska Commercial Co.

Letter from the Alaska Commercial Company, by N. L. Jeffies, their attorney, to Hon. Nathan F. Dixon, Chairman Committee on Commerce, H. R. 1870. 25 p.

Dall, William Healey.

Alaska and its Resources. Boston. I870, XII, 627 p. illus. pls.

U. S. Congress. House. Committee of Ways and Means.

Alaska. Ietter from the Secretary of the Treasury, in answer to resolution of the House of December 5 [1869] transmitting a copy of the report of the late special agent [H. H. McIntyre] of his department for Alaska. [Supplementary report concerning the islands of St. Paul and St. George, and the fur seal: p. II-I7.] Washington, I870. I8 p. (4Ist Cong., 2 d sess., House Ex. Doc. 36.)

U. S. Congress. House. Committee on Commerce.

Fur-seal fisheries of Alaska. Letter from the Secretary of the Interior in answer to a resolution of the House, of February 9, 1870, transmitting a copy of a portion of Vincent Colyer's report relating to the fur-seal fisheries of Alaska. Washington, 1870. I2 p. (4Ist Cong., 2d sess., House Ex. Doc. I44.)

U. S. War Department.

Report of Major General George $\mathrm{H}$. Thomas [relative to seal life, natives and military posts on the islands of St. George and St. Paul] September 27, 1869. (In Report of the Secretary of War for 1869. Washington 1870 . p. II $3-12 \mathrm{I}_{\text {. }}$ )

I87I U. S. Congress. House. Committee on Commerce.

Alaska seal fishery lease. Letter from the Secretary of the Treasury, in relation to the leasing of the Alaska seal fishery. Washington, 187 I. 24 p. (4Ist Cong., $3 \mathrm{~d}$ sess., House Ex. Doc. 108.)

U. S. Congress. House. Committee on Commerce.

St. Paul Island, Alaska. Letter from the Secretary of the Treasury, transmitting a report of the special agent [Charles Bryant] of the Treasury Department, stationed at St. Paul Island, Alaska Territory, in charge of the seal fishery. Washington, I87I. 7 p. (4Ist Cong., 3 d sess., House Ex. Doc. 322.)

U. S. Congress. House. Committee on Commerce.

Fur-seal fisheries, Alaska. Letter from the Secretary of the Treasury, transmitting copy of report of the special agent [Charles Bryant] in charge of the fur-seal fisheries at the islands of St. Paul and St. George, Alaska. Washington, 1871. 9 p. (42d Cong., $2 \mathrm{~d}$ sess., House Ex. Doc. I22.)

1873 U.S. Treasury Department.

Report on the Prybilov group, or Seal Islands, of Alaska. By Henry W. Elliott. Wash. ington, I873. [I25] pages. plates. (Date on cover 1875.)

1874 Scammon, Charles Mellville.

The marine mammals of the north-western coast of North America, described and illustrated: together with an account of the American whale-fishery. By Charles M. Scammon ... New York, I874. 319, v. p. illus., XxvI pl. (6 double) incl. front.

1875 Anti-Monopoly Association of the Pacific Coast.

A history of the wrongs of Alaska. An appeal to the people and press of America. Printed by order of the Anti-monoply association of the Pacific coast. San Francisco, 1875. (The operations of Hutchinson, Kohl \& Co., and their successors, the Alaska commercial company, in connection with the fur-seal islands.) $43 \mathrm{p}$.

U. S. Congress. House.

Alaska seal fisheries. Letter from the Secretary of the Navy, transmitting a copy of the report by Lieut. Washburn Maynard, U. S. N., on the subject of the Alaska seal fisheries. Washington, 1875. 23 p. (44th Cong., Ist sess., House EX. Doc. 43.)

U. S. Congress. Senate. Committee on Territories.

Letter from the Secretary of War, transmitting a report of the commanding general [O. O. Howard], Department of the Columbia, of his tour in Alaska Territory in June, 1875. Washington, 1875. 33 p. (44th Cong., rst sess., House Ex. Doc. 12.) 
I875 U. S. Treasury Department. Special Agents Division.

A report upon the condition of affairs in the Territory of Alaska. By Henry W. Elliott, special agent Treasury Department. Washington, 1875. 277 p. (Published also as part of $44^{\text {th }}$ Cong., Ist sess., House Misc. Doc. 83 .)

I876 U. S. Congress. House. Committee on Ways and Means.

The Alaska commercial company ... Report ... [Relating to the lease made between the United States and the Alaska commercial company, of the right to kill fur seals on the islands of St. George and St. Paul, in Alaska]. Washington, 1876. I43 p. (44th Cong., Ist sess., House Rept. 623.)

U. S. Congress. House.

... Seal-fisheries in Alaska. Letter from the Secretary of the Treasury, transmitting, in response to resolution of the House of Representatives, information relative to the sealfisheries of Alaska. [Washington, 1876. 478 p.] (44th Cong., Ist sess., House Ex. Doc. 83.) Contains: "A complete list of papers on file in the office of the Secretary of the Treasury, in the Alaska business since the date of the lease of the Alaska Commercial Company, August 3,1870 , to the present date."

1880 Allen, Joel Asaph.

History of North American Pinnipeds. A monograph of the walruses, sea-lions, sea-bears, and seals of North America. Washington, 1880. xvx, 785 p. (Department the Interior. U. S. Geological and Geographical survey of the territories. Misc. pub. no. 12.)

U. S. Congress. Senate.

Letter from the Secretary of the Treasury, transmitting, in answer to a resolution of the Senate of March 9, 1880, the report of Capt. Bailey upon the number, occupation, and condition of the people of Alaska; the report of the Supervising Surgeon General Marine Hospital Service on the same subject; also report of Special Agent Otis upon the illicit traffic in rum and firearms. Washington, I880. 7 p. (46th Cong., $2 \mathrm{~d}$ sess., Senate Ex. Doc. 132.)

I88I U. S. Revenue-Cutter Service.

Report of the cruise of the U. S. revenue steamer Corwin in the Arctic Ocean, by Capt. C: L. Hooper . . . Washington, I88I. 7 I p. plates, fold. chart, fold. tables.

Elliott, Henry W.

. . The history and present condition of the fishery industries . . The seal-islands of Alaska. Washington, I88I. I76 p.illus., xxix pl. 2 fold. maps. (Tenth Census of the United States.)

Taylor, W. B.

Letter published in the Wenona (Illinois) Index, October 20, 27, and November 3, 188I; Descriptive of a trip to the seal islands of Alaska. Towards the North Pole. The ocean, the sea, the natives (Alutes). The seal, skins, etc. Wenona Index Extra.

1882 Elliott, Henry Wood.

.. A monograph of the seal islands of Alaska. Reprinted, with additions, from the report on the fishery industries of the tenth census. Washington, 1882.4 p.1., 3-176 p. illus., $\operatorname{xxIx}$ pl. 2 fold. maps. (U. S. Commission of Fish and Fisheries. Special bulletin I76.)

1883 U.S. Revenue-Cutter Service.

Cruise of the revenue steamer Corwin in Alaska and the N. W. Arctic Ocean in $188 \mathrm{r}$... Notes and memoranda...Washington, 1883, I20 p. front. illus., plates (partly col.) [Treasury Dept. Doc. 429.]

Swan, James G.

Report of investigations at Neah Bay, Wash., respecting the habits of fur seals of that vicinity, and to arrange for procuring specimens of skeletons of Cetacea. (In Bulletin of the United States Fish Commission for 1883. Washington, 1883. Vol. III, p. 201-207.)

1884 Elliott, Henry Wood.

Report on the seal islands of Alaska, by Heary W. Elliott. (In U. S. Census Office. Ioth census, 1880. [Census reports] Washington, I884. [v 8] 2 p. 1., 3-188 p. illus., plates, fold. maps.) 
I886 U. S. Congress. Senate.

Letter from the Secretary of the Treasury, transmitting, in response to Senate resolution of December I3, I886, report by Agent Tingle on condition of the seal islands of Alaska in I886. Washington, I886. 4 p. (49th Cong., 2d sess. Senate Ex. Doc. 7.)

I887 U. S. Congress. Senate.

Letter from the Secretary of the Treasury, transmitting, in response to Senate resolution of December 13, 1887, Special Agent G. R. Tingle's report on the condition of the seal islands of Alaska in 1887 . Washington, 1887. 12 p. (5oth Cong., Ist sess., Senate Ex. Doc. 3r.)

U. S. Revenue-Cutter Service.

... Report of the cruise of the revenue marine steamer Corwin in the Arctic Ocean in the year 1885. By Capt. M. A. Healy, U. S. R. M., commander. Washington, 1887. (General report of operations of vessel for the protection of the seal fisheries and sea-otter hunting grounds, by M. A. Healy.) I02 p. plates (partly col.) 2 fold. maps. (49th Cong., Canada. Ist sess., House Ex. Doc. 153.)

Correspondence relative to the seizure of British American vessels in Behring Sea by the United States authorities in I886. Ottawa, I887. cover-title, 47 p., fold. map.

1888 U. S. Congress. Senate. Committee on Indian Affairs.

Letter from the Secretary of the Treasury, transmitting, in response to Senate resolution of December 13, I888, information about Indians in Alaska. [Report of Geo. R. Tingle, special agent of the Treasury Department, of the operations of the fur-seal islands of Alaska, for the year ending July 3r, 1888, p. 2-5.] Washington, I888. 6 p. (5oth Cong., 2d sess., Senate Ex. Doc. 30.)

I889 U. S. Congress. House. Committee on Merchant Marine and Fisheries.

. . Investigation of the fur-seal and other fisheries of Alaska. Report from the Committee on Merchant Marine and Fisheries of the House of Representatives. Washington, I889. L, 4 I 5 p. pls. charts. (5oth Cong., 2d sess., House Rept. 3883.)

U. S. Revenue-Cutter Service.

. . Report of the cruise of the revenue marine steamer Corwin in the Arctic Ocean in the year 188.4. By Capt. M. A. Healy. Washington, 1889. I28 p., front. plates. (Partly col.) (5oth Cong., Ist sess., House Misc. Doc. 602.)

U. S. Congress. Senate.

Letter from the Secretary of the Treasury transmitting, in response to Senate resolution of January I7, I889, report of Special Agent George R. Tingle on condition of the seal islands of Alaska in I88g. Washington, I88g. 5 p. (5oth Cong., ad sess., Senate Ex. Doc. go.)

U. S. President.

Message from the President of the United States, transmitting, in response to Senate resolution of January 2, I889, a report upon the seal fisheries in Bering Sea. [Washington, I889] 281 p. (5oth Cong., 2 d sess., Senate Ex. Doc. 106.)

r89o U. S. Department of State.

Seal fisheries of Behring Sea. Message from the President of the United States transmitting a letter from the Secretary of State, with accompanying papers, touching the subjects in dispute between the Government of Great Britain in the Behring Sea, including all communications since March 4, I889. Washington, I89o. 96 p., fold. map. (5Ist Cong., Ist sess., House Ex. Doc. 450.)

U. S. Department of State.

Seal fisheries of the Behring Sea. Message from the President of the United States transmitting a letter from the Secretary of State submitting the official correspondence between the Govemment of the United. States and the Govemment of Great Britain touching the seal fisheries of the Behring Sea since the nineteenth of July last. Washington, I89o. 53 p., 2 fold. maps. (5Ist Cong., 2 d sess., House Ex. Doc. I44.)

I89I U.S. Congress. Senate.

Letter from the Acting Secretary of the Treasury, transmitting, in response to a resolution of the Senate, reports concerning the condition of seal islands of Alaska. Washington, 1891. 35 p. (5Ist Cong., 2d sess., Senate Ex. Doc. 49.) 
U. S. Department of State.

Great Britain, fur-seal fisheries; modus vivendi respecting fur-seal fisheries in Behring

Sea. Signed and proclaimed at Washington, Jume $15, \mathrm{I} 89 \mathrm{I}$. [Reprint, 1896.] 2 p.

Act to amend act to give effect to award rendered by Tribunal of Arbitration at Paris, under treaty becween United States and Great Britain, concluded at Washington February 29, I892, for purpose of submitting to arbitration certain questions concerning preservation of fur seals. (In Stat. L., vol. 28, p. 64.)

Hart, Albert Bushnell.

- Extracts from official papers relating to the Bering Sea controversy. I790-I892. New York r892. 26 p. (American history leaflets . . Ed. by A. B. Hart and E. Channing . . no. 6.) Caption title.

U. S. President.

Message of the President of the United States, transmitting the convention of February 29 , I 892 , between the United States and Her Britannic Majesty, submitting to arbitration the questions which have arisen between those Governments concerning the jurisdictional rights of the United States in the waters of Bering Sea, etc.; and also transmitting recent correspondence upon that subject with the British Govermment. Washington, I892. 102 p. map. [52 Cong., Ist sess., Senate Ex. Doc. 55.]

I893 [Blowitz, H. G. S. A. O. de.]

The Behring Sea arbitration. Letters to the Times by its special correspondent; together with the award. Reprinted by permission of the proprietors. London and Toronto. 1893. $87,[\mathrm{r}] \mathrm{p}$.

Carter, James Coolidge.

Fur-seal arbitration. Oral argument of James C. Carter ... on behalf of the United States before the Tribunal of Arbitration convened at Paris under the provisions of the treaty between the United States of America and Great Britain, concluded February 29, I89z. Paris, I893. 379 p.

Elliott, Henry W.

Report on the condition of the fur-seal fisheries of the Pribylov Islands in 1890 . Produced on April 4, 1893, by the agent of the United States to the Tribunal of Arbitration convened at Paris. Paris, $1893 . \quad \mathrm{xv}, 33^{8} \mathrm{p}$.

Great Britain.

Behring Sea Arbitration ... Iondon, 1893. Foreign Office. United States. Nos. I-8, IO-II.)

No. I.-Case presented on the part of the Government of Her Britannic Majesty to the Tribunal of Arbitration... between Her Britannic Majesty and the United States of America, [C. 6918]

No. 2.-Report of the Behring Sea Commissioners of June 2I, I892. (With maps and appendices.) [C. 6grg]

No. 3.-Counter case presented on the part of the Government of Her Britannic Majesty to the Tribunal of Arbitration... between Her Britannic Majesty and the United States of America. [C. 6920 ]

No. 4.-Argument presented on the part of the Government of Her Britannic Majesty to the Tribunal of Arbitration ... between Her Britannic Majesty and the United States of America. [C.692 I]

No. 5.-Map of the northern portion of the north Pacific Ocean, annexed as part of the appendix to the case of Her Majesty's Government. [C. 6922]

No. 6.- The case of the United States, including the reports of the Behring Sea Commission... [C. 6949]

No. 7. Counter case of the United States ... [C. 6950]

No. 8.-Argument of the United States... [C- 695I]

No. Io.-Award of the Tribunal of Arbitration. [C. 7I07]

No. II.-Papers relating to the proceedings of the Tribunal of Arbitration. [C. 7I6I] Myers, L. W.

Seal catch, 1893. (In Consular Reports, I893, vol. 43, p. 32, 320-321.) 
1893 Myers, L. IV.

Sealskin industry. (In Consular Reports, I893, vol. 43, p. I64-I65.)

United States.

Behring Sea Arbitration. Argument of the United States before the Tribunal of Arbitration, convened at Paris under the provisions of the treaty between the United States of America and Great Britain, concluded Fiebruary 29, 1892. Presented to both Houses of Parliament by command of Her Majesty. London, I893. iv p., 327 p. (United States. No. 8, I893.) Gt. Brit. Parliament. Papers by command. C. 6951.

Bering Sea Tribunal of Arbitration.

... Opinions of Mr. Justice Harlan at the conference in Paris of the Bering Sea Tribunal of Arbitration, constituted by the treaty of February 29, 1892 , between Her Britannic Majesiy and the United States of America . . Washington, I893. $228 \mathrm{p}$.

U. S. Congress. Senate.

- . Letter from the Secretary of the Treasury, in response to Senate resolution of February $8,189.3$, transmitting several reports of special agents to the seal islands. [Washington] 1893. I 40 p., 3 pl. (part. fold.) (52d Cong., 2 d sess., Senate Ex. Doc. 107.)

Welling, James Clarke.

The Bering Sea Arbitration; or, "Pelagic Sealing," juridically considered according to a particular analogy of municipal law, by James C. Welling . . . Washington, 1893. Covertitle, I8 p. (Columbian University studies.)

Wishart, Andrew.

The Behring Sea question, the arbitration treaty, and the award . . . Edinburgh, 1893. 54 p., front. (fold. map).

1894 U. S. President.

Proclamation (of act to give effect to award of Tribunal of Arbitration at Paris concerning fur seals) April 9, I894.

Same; with license for sailing vessels on reverse.

Same; In Stat. I., vol. 28, p. I245-1247.

Myers, L. W.

Seal catch for I893 and prospects for 1894. (In Consular reports, 1894, vol. 44, p. 276-279.)

U. S. Congress. House. Committee on Foreign Affairs.

Bering Sea controversy. Letter from the Secretary of State, transmitting, pursuant to House resolution dated December I $_{5}$, the correspondence touching the Bering Sea controversy. [Washington, I894.] II p. (53d Cong., 3d sess., House Ex. Doc. 132.)

U. S. Department of State.

Agreement between the United States and Russia for modus vivendi in relation to fur-seal fisheries in Bering Sea and north Pacific Ocean. Signed, Washington, May 4, April 27, 1894. Proclaimed May 12, I894. $4 \mathrm{p}$.

1895 U. S. Bering Sea Tribunal of Arbitration.

.. Fur-seal arbitration. Proceedings of the Tribunal of Arbitration, convened at Paris, under the treaty between the United States . . . and Great Britain, concluded at Washington, February 29, 1892 , for the determination of questions between the two Governments conceming the jurisdictional rights of the United States in the waters of Bering Sea. .. Washington, 1895 . I6 vols. plates, fold. maps, facsims., tables, diagrs. (U. S. 53d Cong., 2d sess., Senate Ex. Doc. I77, pt. I-16.)

(Each volume is preceded by the t.-p. and index of "The Executive Documents ... Senate... 1893-94." Vol. I6 has half-title: Facsimiles of documents in the Alaskan archives, Department of State of the United States. To accompany the case and countercase of the United States as presented to the Tribunal.)

Roberts, W. P.

Seal catch of r894. (In Consular Report, 1895, v. 47, p. 84-87.)

U. S. Bureau of Navigation.

[Laws relating to] seal fisheries. (In Navigation Bureau. Laws relating to Navigation and Merchant Marine, 1895. p. 219-226.) 
I895 U. S. Congress. House. Committee on Ways and Means.

Bering Sea Tribunal. Letter from the Secretary of Treasury, transmitting, pursuant to House resolution dated December II, 1894 , information relating to the Bering Sea Tribunal, convened at Paris in 1893. Washiugton, I895. 4 p. (53d Cong., $3 \mathrm{~d}$ sess., House Ex. Doc. 243.)

U. S. Congress. House. Committee on Appropriations.

. . Letter from the Secretary of the Treasury, transmitting a communication from the Secretary of State in regard to an appropriation for the payment by the United States of all claims that may be made by Great Britain arising out of the Bering Sea controversy. Washington, I895. 2 p. (53d Cong., 3d sess., House Ex. Doc. 3ro.)

U. S. Congress. House. Committee on Ways and Means.

Information relating to fur seal in Bering Sea. Letter from the Secretary of the Treasury, transmitting, pursuant to House resolution of the $23 \mathrm{~d}$ ultimo, additional information relating to fur seal in Bering Sea. Washington, i895. 5 p. (53d Cong., $3 \mathrm{~d}$ sess., House Ex. Doc. 306.)

U. S. Congress. House. Committee on Ways and Means.

Fur-bearing animals in Alaska. .. Report [to accompany H. R. 8909] (to amend act to prevent the extermination of fur-bearing animals in Alaska, as substitute for H. R. 8633). Washington, I895. 3 p. (53d Cong., 3d sess., House Rept. 1849.)

U. S. President.

... Message from the President of the United States, in response to Senate resolution of January 8, 1895, transmitting information relating to the enforcement of the regulations respecting fur seals, adopted by the Governments of the United States and Great Britain in accordance with the decision of the Tribunal of Arbitration convened at Paris, with other information called for by said resolution.... Washington, IS95. 438 p. 4 fold. pl. (53d Cong., 3d sess., Senate Ex. Doc. 67.)

U. S. Revenue-Cutter Service.

Regulations governing vessels employed in fur-seal fishing during the season of 1895 . Washington, I895. Io p. (On verso of t.-p.: Treasury Depart. Doc. 1742. Office of the Secretary. Division Revenue-Cutter Service.)

U. S. State Department.

Modus vivendi between the United States and Great Britain respecting fur-seal fisheries in Bering Sea June 15 , I89 (printed 1895). 2 p.

U. S. Treasury Department. Division of Special Agents.

Information respecting pelagic catch of fur seals, April I2, I895. 2 p. (Dept. circular 75.)

U. S. Treasury Department. Division of Special Agents.

Amendment to circular giving information respecting pelagic catch of fur seals. September I9, 1895. I p. (Dept. circular 154. I895.)

I896 Brice, John J.

Remarks on the movements and breeding grounds of the fur seal, based on observations made while on the United States naval patrol of Bering Sea in I894. By J. J. Brice. . . . Washington, 1896. p. 573-577. (Appendix 7. Extracted from the Report of the U. S. Commissioner of Fish and Fisheries for 1894 :)

Elliott, Henry Wood.

Letter from the Secretary of the Treasury, transmitting, in response to the House resolution of the $22 \mathrm{~d}$ instant, a copy of the report of Henry W. Elliott on the condition of the fur-seal fisheries of Alaska, together with all maps and illustrations accompanying said report, January 27,1896 . . . Ordered to be printed. Washington, 1896. 240 p. $48 \mathrm{pl}$. I4 maps (partly fold.) (54th Cong., ist sess. House Doc. 175.)

Found also in U. S. Treasury Dept. Special Agents Division. Seal and salmon fisheries and general resources of Alaska. ... Washington, 1898 .

Stejneger, Leonhard Hess.

The Russian fur-scal islands. By Leonhard Stejneger . . Washington, I896. I48 p., $66 \mathrm{pl}$. (partly fold). (Extracted from U. S. Fish Commission Bulletin for 18,6.) 
I896 U. S. Congress. House. Committee on Ways and Means.

Lease of Alaska seal islands, etc. Letter from the Secretary of the Treasury, replying to the House resolution of the 7 th ultimo in regard to the lease of the seal islands and the policing of Bering Sea. Washington, 1896. 3 p. (54th Cong., Ist sess., House Doc. 197.)

U. S. Congress. House. Committee on Ways and Means.

Fur-bearing animals in Alaska . . Report < to accompany H. R. 3206>(from Committee favoring bill, to amend act to prevent extermination of fur-bearing animals in Alaska [by providing for commission to arrange modus vivendi, and for destruction of herd in default of same]) February 20, I8g6. Washington, I8g6. 2 p. (54th Cong., Ist sess., House Rept. 45I.)

U. S. Congress. Committee on Ways and Means.

Fur seals. A bill to amend an act entitled "An act to prevent the extermination of furbearing animals in Alaska," and for other purposes. Hearing before Committee on Ways and Means... Bill under discussion: H. R. 3206. Washington, 18g6. 2I p. (54th Cong., Ist sess., House Rept. 3206.)

U. S. Congress. Senate.

Act [Senate bill 2997 making appropriations for commission] to provide for fulfillment of treaty between United States and Great Britain signed February 8, 18g6 [as to Bering Sea controversy], approved May 7, I896. (In Stat. L., v. 29, p. II5.)

U. S. Congress. Senate.

. Letter from Henry W. Elliott, of Cleveland, Ohio, relative to condition and driving of fur seals on the Pribilof Islands, Bering Sea, Alaska. April I4, 1896. Washington, 1896. 6 p. (54th Cong., Ist sess., Senate Doc. 215.)

U. S. Congress. Senate.

Joint resolution to authorize scientific investigation of fur-seal fisheries. Approved June 8, 1896. (54th Cong., Ist sess., Senate Doc. 155.) Also in Stat. L., v. 29, p. 475.

U. S. Congress. Senate.

. . The Vice President presented the following letter from Acting Secretary of the Treasury, inclosing a communication from N. L. Jeffries, attorney for the North American Commercial Company, lessee of the islands of St. Paul and St. George, Alaska, protesting against the proposition to destroy fur seals by order of the United States, as contemplated by bill 3206 , which recently passed the House. [Washington, I896.] I p. (54th Cong., ist sess., Senate Doc. 162.)

U. S. Congress. Senate. Committee on Foreign Relations.

Report < to accompany H. R. 3206>(from committee favoring bill to amend "act to prevent extermination of fur-bearing animals in Alaska" [by providing for commission to arrange modus vivendi, and for destruction of herd in default of same]). Washington, I896. I p. (54th Cong., Ist sess., Senate Rept. 402 [pt. 1]).

U. S. Congress. Senate. Committee on Foreign Relations.

Views of the minority, < to accompany H. R. 3206> (adverse to House bill 3206, to amend "act to prevent extermination of fur-bearing animals in Alaska " [by providing for commission to arrange modus vivendi, and for destruction of herd in default of same]), April I6, 1896. Washington, 1896. 7 p. (54th Cong., ist sess., Senate Rept. 402, pt. 2.)

U. S. Congress. House. Committee on Ways and Means.

Fur-seal fisheries . . Report <to accompany H. Res. IgI $>$ [favoring joint resolution to authorize scientific investigation of seal herd]. Washington, I8g6. I p. (54th Cong., Ist sess., House Rept. 2095.)

U. S. President.

Proclamation [declaring sec. I956, Revised Statutes, to be applicable to waters designated in award of Tribunal of Arbitration under treaty between United States and Great Britain concluded Feb. 29, 1892; concerning] fur-seal fisheries, April 14, 1896. Washington, I8g6. $2 \mathrm{p}$. 
1896 U. S. Treasury Department. Revenue-Cutter Service.

Fur-seal, sea otter, and salmon fisheries. Acts of Congress, President's proclamations, regulations governing U. S. vessels, acts of Parliament, orders in council, pertaining to the fur-seal fisheries in Bering Sea and north Pacific Ocean, sea otter regulations, laws as to salmon fisheries in Alaska. Washington, I896. $7^{8} \mathrm{p}$. [Treasury Dept. Doc. 1850. Office of Division of Revenue-Cutter Service.]

U. S. Treasury Department. Revenue-Cutter Service.

Regulations governing vessels employed in fur-seal fishing during season of $18 \mathrm{~g} 6$. Washington, I8g6. II p. (Treasury Dept. Doc. 1836.)

U. S. Treasury Department.

Statistics relating to Bering Sea seal fisheries, being tables W-GG accompanying annual report of Secretary, 1895. [Washington, 1896.] $43 \mathrm{p}$.

U. S. Treasury Department.

Reports of agents, officers and persons, acting under the authority of the Secretary of the Treasury in relation to the condition of seal life on the rookeries of the Pribilof Islands, and to pelagic sealing in Bering Sea and the north Pacific Ocean, in the years $1893-1895$. Washington, 1896. 2 pts., vur, 379, 154 p. 23 pls. II maps and atlas. (54th Cong., rst sess., Senate Doc. I37.)

U. S. Treasury Department. Commission on fur-seal investigation.

Observations on the fur seals of the Pribilof Islands. Preliminary report by David Star. Jordan . . commissioner in charge of fur-seal investigations for 1896 ; aided by . . . Leonhard Stejneger and Frederic A. Lucas ... Jefferson F. Moser... Charles H. Townsend ... George A. Clark .. Joseph Murray ... Washington, r8g6. 69 p. fold. map. (On verso of t.-p.: Treasury Depart. Doc. rgı. Office of the Secretary.)

I897 Macoun, James M.

[Report, by James M. Macoun, to the minister of marine and fisheries, Canada, of an examination of the fur-seal rookeries on the Pribilof Islands in I896.] Report presented January 12, 1897. (In Compilation of Documents. Alaskan seal fisheries. U. S. Bureau of Fisheries.)

Macoun, James M.

[Report by Mr. James M. Macoun to the Minister of Marine and Fisheries, Canada, of an examination of the fur-seal rookeries on the Pribilof Islands in IS97.] Report presented September 25, 1897. (In Compilation of Documents. Alaskan seal fisheries, U. S. Bureau of Fisheries.)

Thompson, D'Arcy Wentworth.

Report by Professor D'Arcy Thompson on his mission to the Behring Sea in 1896, dated March 4, IS97. [London, I897.] 39 p. chart.

United States.

Fur-seal arbitration. In the matter of the claims of Great Britain against the United States of America before the Bering Sea claims commission. Argument for the United States in reply. Washington, I897. IV, 496, IV p. (Counsel for the United States: Don M. Dickinson, Robert Lansing, C. B. Warren.)

U. S. Congress. Senate.

Revenue from rental of the seal islands of Alaska. Letter from the Secretary of the Treasury transmitting, in answer to a Senate resolution of January 5, I897, information relative to the revenue derived from the North American Commercial Company, by the rental of the seal islands of Alaska. Washington, I897. I2 p. (54th Cong., 2d sess., Senate Doc. 8I.)

U. S. Congress. Senate.

Act [26I2] prohibiting killing of fur seals in north Pacific Ocean. Approved December 29, I897. (In Stat. L., vol. 30, p. 227, 229.)

U. S. President.

. Protection of fur seals in Bering Sea. Message from the President of the United States transmitting, in response to resolution of the Senate of May 25, I897, a report to the Secretary of State, accompanied by copies of correspondence of record in the Department of State, touching the protection of fur seals in Bering Sea and the north Pacific Ocean. Washington, 1897. 67 p. (55th Cong., 2d sess., Senate Doc. 40.) 
1897 U. S. President

Protection of fur-seal herd in Alaska. Message from the President of the United States, transmitting, in response to Senate resolution of the I7th instant, a report from the Secretary of State touching the reply of the British Government in regard to failure of the negotiations of the Paris tribunal to protect the fur-seal herd of Alaska. February 20, I897. [Washington, I897] 2 p. (54th Cong., 2d sess., Senate Doc. I42.)

U. S. Department of State.

Agreement between United States and Russia for modus vivendi in relation to fur-seal fisheries in Bering Sea and north Pacific Ocean. Signed Washington $\frac{\text { May 4, }}{\text { April 22, }}$ 1894, proclaimed May 12, I894 [reprint, Washington, I897]. 4 p. [English and French.]

U. S. Treasury Department.

Regulations governing vessels employed in fur-seal fishing and sea-otter hunting during season of 1897. Washington, 1897. I2 p. (Treasury Depart. Doc. 1920.)

U. S. Treasury Department.

Statistical tables. Fur-seal catch, season of I8g6. List of vessels engaged, with other sta. tistical information showing total pelagic catches from American and Asiatic herds since 1868 and land catch, Pribilof Islands, since 1870 , etc. Washington, 1897.38 p. (Treasury Depart. Doc. I932.)

U. S. Treasury Department.

Prohibition of killing of fur seals in north Pacific Ocean and of importation of fur-seal skins taken in such waters. Dec. 30, I897. (Treasury Department, Division of Special Agents. Dept. circular 2I4.)

Same (In Treas. Dept. Fur seals, fur-seal islands of north Pacific Ocean, 1898 [1899]. Pt. I, p. $246-248$.)

U. S. Treasury Department, Revenue-Cutter Service.

Regulations governing vessels employed in fur-seal fishing and sea-otter hunting during the season of 1897. Washington, 1897. I2 p. (Treasury Dept. Doc. 1920.)

U.S. Treasury Department.

Answer to resolution relative to revenue derived from the North American Commercial Company by rental of seal islands of Alaska. Jan. 23, 1897. I2 p. (54th Cong., 2nd sess. Senate Doc. 8r.)

U.S. Treasury Department, Special Agents Division.

Report on the rookeries of the Commander Islands, season of 1897 , by Leonhard Stejneger. Washington, I897. I7 p. (On verso of t.-p.: Treasury Depart. Doc. I997. Office of the Secretary, Special Agents Division.)

I8g8 Barrett-Hamilton, Gerald Edwin Hamilton.

Report by Mr. G. E. H. Barrett-Hamilton on his mission to the Russian seal islands in 1897 . [London, I8g8.] 67 p., map. (Appendices: r. Extract from report of N. C. Waxmuth, acting commander of the Kommandorski Islands, dated August, 1897 (section III). ח. Drives at the Commander Islands in I897. Mr. Memorandum of seals taken on the "Rookeries" by vessels sailing from or putting in to Japanese ports (comp. by H. J. Snow, of Yokohama). IV. Statement of prices obtained at the fur seal-skin sales on the gth December, 1897 (C. M. Lampson and Co.). V. List of photographs. VI. Map of North Rookery, Bering Island, by Leonhard Stejneger.)

Great Britain.

Joint Statement of conclusions signed by the British, Canadian, and United States delegates respecting the fur-seal herd frequenting the Pribilof Islands in Bering Sea. London, 1898. $5 \mathrm{p}$.

International Bureau of the American Republics.

Alaska. (Handbook No. 84, 1897.) [Washington, I898] I33 p. front (fold. map).

([U. S.] $55_{\text {th }}$ Cong., 2 d sess., Senate Doc. 178, pt. 13.) 
I8g8 Thompson, D'Arcy Wentworth.

Despatch from Prof. D'Arcy Thompson forwarding a report on his mission to Bering Sea in 1897. [London, I898] I5 P. (U. S. No. I, I898.)

U. S. Congress. Senate.

Award of commissioners appointed pursuant to convention of February 8, 1896 , between United States and Great Britain for settlement of claims in virtue of convention of February 29, 1892 [on Bering Sea controversy], Washington, 1898.15 p. (55th Cong., $2 \mathrm{~d}$ sess., Senate Doc. 59.) [Summary of claims by the Secretary of State and text of convention of February 8, 1896 , are included.]

U. S. President.

Seizure of British ships in Bering Sea. Message from the President of the United States, transmitting, in response to the resolution of the Senate of February I, 1898, a report from the Secretary of State, with accompanying papers, relating to the work of the commission appointed pursuant to the convention of February 6,1896 , between the United States and Great Britain for the settlement of claims presented by Great Britain against the United States by virtue of the convention of February 29, I892. Washington, 1898. 94 p. (55th Cong., 2d sess., Senate Doc. I6.)

U. S. President.

Bering Sea awards. Message from the President of the United States, transmitting a report from the Secretary of State in regard to the award of the commissioners appointed pursuant to the stipulations of the convention of February 8,1806 , between the United States and Great Britain, providing for the settlement of the claims presented by the latter against the former in virtue of the convention of February 29, 1892 . Washington, 1898. I5 p. (55th Cong., 2d sess., Senate Doc. 59.)

U. S. Department of State.

Fur seals in Bering Sea. Letter from the Secretary of State, transmitting a corrected copy of Senate document no. 40, Fifty-fifth Congress, second session, in relation to the protection of fur seals in the Bering Sea, and requesting that the same be reprinted. [Washington, I893.] 3 p. (55th Cong., 2d sess., Senate Doc. 40, pt. 2.)

U. S. Treasury Department. Commission on fur-seal investigations.

Second preliminary report of the Bering Sea fur-seal investigations by David Starr Jordan, assisted by Leonhard Stejneger, Frederic Augustus Lucas, and George Archibald Clark, I897. Washington, I898. 48 p. (Treasury Dept. Doc. I994.)

U. S. Treasury Department. Special Agents Division.

Seal and salmon fisheries and general resources of Alaska . . Washington, 1898. 4 vols. illus. plates (partly col., partly fold.) ports, maps, charts. (55th Cong., Ist sess., House Doc. 92, pt. I-4.)

Contents. - v. I. Reports on condition of seal life on the Pribilof Islands by special Treasury agents . . I I868 to 1895 ... by D. S. Jordan. v. 2. Reports on seal and salmon fisheries ... and correspondence between the State and Treasury Departments on the Bering Sea question... I895 to ... 1896, with comments on that portion thereof which relates to pelagic sealing by D. S. Jordan. v. 3. Reports by H. W. Elliott and Lieut. W. Maynard, U. S. N., on the fur-seal fisheries, etc., of the Pribilof Islands, and by Rev. S. Jackson on "Reindeer in Alaska" and "Education in Alaska," with comments on Elliott's and Maynard's report by D. S. Jordan. v. 4. Reports by W. G. Morris, I. Petroff, C. H. Toknsend, F. W. True, J. J. Brice, and L. Stejneger on intemational resources of Alaska and the fur-seal fisheries of the North Pacific Ocean, with comments on the reports of Townsend, True, and Brice by D. S. Jordan.

U. S. Treasury Department. Special Agents Division.

Statistical tables. Fur seal catch. Season of 1897 . Washington, I898. 30 p. (On verso of t.-p.: Treasury Department, Office of the Secretary, Doc. 2009. Division of Special Agents.)

$84512^{\circ}-$ S. Doc. $980,63-3-11$ 
I8g8- U. S. Treasury Department. Commission on fur-seal investigations.

1899 The fur seal and fur-seal islands of the North Pacific Ocean. By David Starr Jordan . . commissioner in charge of fur-seal investigations of $1896-97$. With the following official associates: Leonhard Stejneger and Frederic Lucas, of the U. S. National Museum. Jefferson F. Moser . . in command of the U. S. Fish Commission steamer Albatross. Charles H. Townsend, of the U. S. Fish Commission. George A. Clark, secretary and stenographer; Joseph Murray, special agent. With special papers by other contributors. Washington, r898-99. 4 v. fronts. (V. I, 3) illus. plates, maps, diags,, and atlas of 14 fold., charts (No. 3214-3227).

Pt. I-4: Treasury Dept. Doc. 2017.

Atlas of charts has t.-p.: Report of the fur-seal investigations, $1896-1897$. Charts of the islands and fur-seal rookeries of St. Paul and St. George, Pribilof group, Alaska. Prepared by the U. S. Coast and Geodetic Survey from surveys by Will Ward Duffield and party in the summer of 1897 . Washington, I899.

Contents.-pt. r. The history, condition, and needs of the herd of fur seals resorting to the Pribilof Islands, by David Starr Jordan and George Archibald Clark . . . pt. II. Observations on the fur seals of the Pribilof Islands, I872-1897, as extracted from the log of St. Paul Island, and as recorded in the daily journal of the commission of 1896 and 1897 . pt. III. Special papers relating to the fur seal and to the natural history of the Pribilof Islands. pt. Iv. The Asiatic fur-seal islands and fur-seal industry, by Leonhard Stejneger.

I899 Townsend, Charles $\mathrm{H}$.

The American seal herd and pelagic sealing. (In Report of the Commissioner of Fish and Fisheries for 1898 . Washington, 1899 . p. CLXIV-CLXV.)

U. S. Treasury Department. Special Agents Division.

Amnual Report of the Supervising Special Agent for the fiscal year ended June 30, $x 899$. Washington, 1899. (Seal Islands of Alaska, p. 7-8.) I9 p. (On verso of t.-p.: Treasury Depart. Doc. 2158. Special agents.)

1900 U. S. Treasury Department. Special Agents Division.

Annual Report of Supervising Special Agent for fiscal year ended June 30, I900. Washington, 1900. (Seal fisheries of Alaska, p. 7-9.) 30 p. (Treasury Depart. Doc, 2204.)

U.S. Treasury Department.

Regulations governing vessels employed in fur-seal fishing during the season of 1900. Washington, 1900. 6 p.

IgoI U.S. Treasury Department.

Regulations governing vessels employed in fur-seal fishing during the season of Igor. Washington, I90I. $6 \mathrm{p}$.

U. S. Treasury Department. Special Agents Division.

Annual Report of the Supervising Special Agent for the fiscal year ending June 30, 190r. Washington, Igor. 30 p. (Treasury Dept. Doc. 2255.)

U. S. Congress. Committee on Ways and Means.

Fur seals of Alaska. Hearing before the Committee on Ways and Means, Fifty-seventh Congress, first session. Statement of Mr. Henry W. Elliott and appendix . . Washington, Ig02. I9 p. (57th Cong., Ist sess., House.)

U. S. Congress. House. Committee on Ways and Means.

Fur-bearing animals in Alaska. June 2, 1902. Committed to the Committee of the Whole House on the state of the Union and ordered to be printed . . Report < to accompany H. R. 13387>. Washington, 1902. 8 p. (57th Cong., Ist sess., House Rept. 2303 [pt. I]).

U. S. Congress. House. Committee on Ways and Means.

Fur-bearing animals in Alaska. June II, Igo2. Referred to the Committee of the Whole House on the state of the Union and ordered to be printed ... Views of the Minority <to accompany H. R. 13387>. Washington, 1902. 5 p. (57th Cong., Ist sess., House Rept. 2303, pt. 2.)

U. S. Treasury Department.

Regulations governing vessels employed in fur-seal fishing during the season of 'rgo2. Washington, 1902. $6 \mathrm{p}$. 
U. S. Treasury Department. Special Agents Division.

Annual Report of the Supervising Special Agent for the fiscal year ended June 30, r902. Washington, Igo2. (Seal fisheries of Alaska. p. 7-9.) 29 p. (On verso of t.-p.: Treasury Depart. Doc, 2308. Special agents.)

Ig03 U. S. Department of Commerce and Labor. Navigation Bureau.

Seal and salmon fisheries. (In Navigation Bureau. Laws relating to navigation and merchant marine. Washington, 1903. p. 252-263.)

Jordan, David Starr.

Fur seal as an international issue. By D. S. Jordan and George Archibald Clark. (In International Quarterly. New York, 1903. vol. 7, p. 220-230.)

1904 U. S. Congress. Senate. Committee on Foreign Relations.

To permit action to be commenced by American citizens for vessels seized in Bering Sea. Report from the Committee on Foreign Relations amending S. 3410. Wastington, 1904.

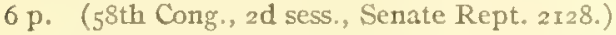

U. S. Congress. Senate. Committee on Territories.

... Conditions in Alaska. Report of subcommittee of Committee on Territories appointed to investigate conditions in Alaska ... [and hearings before subcommittee . . .] January I2, I904.- Ordered to be printed. Washington, Ig04. 2 V. in I. fold. map. (58th Cong., 2d sess., Senate Rept. 282.)

U. S. Congress. House. Committee on Foreign Affairs.

Fur seals. Report [from the Committee on Foreign Affairs amending S. J. R. 6r, requesting the President to conclude negotiations with Great Britain for review and revision of rules and regulations which now govern taking of fur seals in north Pacific Ocean and Bering Sea]. Washington, 1904. I p. (58th Cong, 2 d sess., House Rept. 2076.)

U. S. Congress. House. Committee on Ways and Means.

Fur seals of Alaska. Hearings before the Committee on Ways and Means . . March 9 and I0, Ig04 [on H. J. R. I24, directing the Secretary of Commerce and Labor to suspend killing of fur seals on Pribilof Islands, of Alaska, by the North American Commercial Company]. Washington, Ig04. III, 76 p. (58th Cong., 2d sess., House.)

U. S. Department of Commerce and Labor.

Regulations and instructions regarding the seal islands of Alaska. Letter from the Secretary of Commerce and Labor, transmitting, in response to a Senate resolution of January 22, 1905, copies of all regulations and instructions regarding the seal islands of Alaska. Washington, I905. I2 p. (5Sth Cong., 3d sess., Senate Doc. II4.)

U. S. Congress. Senate. Committee on Foreign Relations.

Alaskan fur-seal herd . . Letter from Henry W. Elliott, of Lakewood, Ohio, relative to the rules and regulations governing the agents of the Government in charge of the seal islands of Alaska and the condition of the fur-seal herd thereon. Washington, I905. 78 p. (58th Cong., 3d sess., Senate Doc. $x_{49}$.)

Townsend, Charles Haskins.

... Notes on certain Pinnipeds, with data respecting their present commercial importance. By C. H. Townsend ... New York, rgo5. p. $2 x-32$, illus. (Reprinted from the ninth annual report of the New York Zoological Society.)

U. S. Department of Commerce and Labor.

. Alaskan seal fisheries. Letter from the Secretary of Commerce and Labor, transmitting ... certain reports ... [Washington, I905]. (Preliminary and annual reports for Ig03-4 and I904-5, by W. I. Lembkey, agent. Dated June 7, Aug. I2, Sept. 7, I904, and June I 7 , Oct. 26, I905, respectively.) Ir5 p. (59th Cong., Ist sess., Senate Doc. 98.)

U.S. Department of Commerce and Labor.

.. Report on the Alaskan fur-seal fisheries, by Edwin W. Sims, Solicitor of the Department of Commerce and Labor, August 3I, I906. Washington, Igo6. (Appendices: A. Statistics of the Pribilof fur-seal herd from the discovery of the Pribilof Islands, I 786 to Igo6, inclusive. B. Probable increase of the Pribilof fur-seal herd in case there be a total cessation of pelagic sealing and a national land killing; computation by Walter I. Lembkey.) $59 \mathrm{p}$. (59th Cong., 2d sess., House Doc. 251.) 
1906 U. S. Congress. Senate.

Compilation of the acts of Congress and treaties relating to Alaska from March 30,1867 , to March 3, I905, with indices and references to decisions of the Supreme Court and opinions of the Attomey General. Prepared under the direction of Paul Charlton by . . Fred F. Barker. Washington, Igo6. 496 p. (59th Cong., Ist sess., Senate Doc. I42.)

U. S. Congress, House, Committee on the Territories.

Fisheries in Alaska. Hearings before the Committee on the Territories of the House of Representatives, February i6, Igo6. Washington, rgo6. (Statements of F. W. Cushman, B. W. Evermann, G. M. Bowers, E. W. Sims, and H. M. Kutchin, discussing bill H. R. I3543.) $19 \mathrm{p}$.

1907 U.S. Department of Commerce and Labor. Navigation Bureau.

Seal hunting and Alaska fisheries [Laws]. (In Navigation Bureau report for I907. pt. 2. p. 255-268.)

1908 U. S. Congress. Senate.

Fur-seal herd, I868-1908. (6oth Cong., Ist sess., Senate Doc, 407 [recalled, as it was confidential].)

U. S. Congress. Senate. Committee on Foreign Relations.

To permit action to be commenced by American citizens for vessels seized in Bering Sea. $\langle$ Report to accompany S. 390>. [Washington, I908]. 6 p. (6oth Cong., Ist sess., Senate Rept. I40.)

U.S. Department of Commerce and Labor.

Reports relating to Alaskan seal fisheries. Letter from the Secretary of Commerce and Labor, transmitting, pursuant to Senate resolution of March 2, I908, certain reports ... Washington, I908. (Preliminary and annual reports of W. I. Lembkey, agent in charge, 1906-7.) I20 p. (6oth Cong., ist sess., Senate Doc. 376. )

Evermann, Barton Warren.

Fur seals domesticated. (In Science, New York, Igog. n. s., vol. xxxi. p. 34.)

Igro Evermann, Barton Warren.

The Alaska fisheries service. By Barton W. Evermann. [Washington], Igro. cover-title, p. 219-224. (Reprinted from the Transactions of the American Fisheries Society, IgIo.)

Townsend, Charles Haskins.

Fur seals and the seal fisheries, by Charles H. Townsend . . . Address before the Fourth International Fishery Congress, held at Washington... September 22 to 26 , rgo8. Bulletin of the Bureau of Fisheries, vol. xxvII ... [Washington, 19I0.] p. 315-322. ([U.S.] Bureau of Fisheries Doc.66I.)

U. S. Laws, statutes, etc.

... Laws and regulations relative to fur-seal fishing . . Washington, Igro. 7 p. (Bureau of Fisheries Doc. 732.)

U. S. Congress. Senate. Committee on Foreign Relations.

Report. To permit action to be commenced by American citizens for vessels seized in Bering Sea [from the Committee on Foreign Relations favoring S. 3916, to confer jurisdiction upon Circuit Court of the United States for gth Circuit to determine in equity rights of American citizens under award of Bering Sea arbitration of Paris]. Washington, Igro. 6 p. (6rst Cong., 2 d sess., Senate Rept. 45.)

U. S. Congress. House. Committee on Judiciary.

Report. Claims for alleged unlawful seizures in Bering Sea [from Committee on Judiciary amending by substitute S. 3916, to confer jurisdiction upon the Court of Claims to hear and determine claims of American citizens for damages or loss resulting from alleged unlawful seizures in Bering Sea.] Washington, Igro. 2 p. (6rst Cong., ad sess., House Rept. 1270.)

U. S. Congress.

An act to protect the seal fisheries of Alaska, and for other purposes. [Washington, rgio.] 3 p. (6rst Cong., 2d sess., S. 7242.) [Public No. 146.] 
I9ı U. S. Congress. Senate. Committee on Conservation of National Resources.

Fur-seal fisheries. Hearings before the Committee on Conservation of National Resources on bill (S. 7242) entitled "An act to protect the seal fisheries of Alaska, and for other purposes" ...Washington, Igro. 32 p., 2 fold., maps., diag. (6rst Cong., 2d sess., Senate Doc. 605.)

U. S. Congress. House, Committee on Ways and Means.

Seal fisheries of Alaska. Hearings before the Committee on Ways and Means of the House of Representatives, 6ist Congress, 2d session, on S. 7242, April 2, I9IO. (Statements of W. I. Lembkey and Charles Nagel) Washington, 1910. III, 267-278 p.

U. S. Congress. Senate. Committee on Conservation of National Resources.

Seal fisheries of Alaska... Report <To accompany S. 7242> .. [Washington, I9Io.] $6 \mathrm{p}$. (6rst Cong., 2d sess., Senate Rept. 44I.) [For law, see Statutes at Large, vol. 36, pt. I, p. 326.$]$

U. S. Congress. House. Committee on Ways and Means.

Seal fisheries in Alaska... Report $\langle$ To accompany S. 7242 $\rangle$. . Washington, I9Io. 3 p. (6rst Cong., 2d sess., House Rept. 967.) (For law, see Statutes at Large, v. 36, pt. I, p. 326.]

U.S. Department of Commerce and Labor. Bureau of Fisheries.

The fur-seal fisherics of Alaska in I909. [By Walter I. Lembkey.] Washington, I910. 53 p. (Bureau of Fisheries Doc. 735.)

U. S. President.

Lease of North American Commercial Company. Message from the President of the United States, recommending the repeal of the provisions, authorized in section I 63 of the Revised Statutes, for the renewal of the lease of the North American Commercial Company in the matter of the taking of fur seals on island [islands] of St. Paul and St. George. Washington, Igro. 2 p. (6ist Cong., 2 d sess., Senate Doc. 43o.)

Same (In Congressional Record, I9Io. v. 45, p. 3190, 3222).

Same (In House Joumal. 6rst Cong., 2d sess., p. 432).

Same (In Senate Journal. 6ist Cong., zd sess., p. 219).

IgI Great Britain. Treaties.

Despatch from His Majesty's ambassador at Washington containing the text of the treaty for the preservation and protection of the fur seals which frequent the waters of the North Pacific Ocean. Signed at Washington, July 7, 1911 . Presented to both houses of Parliament by command of His Majesty, December, IgII. London, Pub. by H. M. Stationery off., [IgII], 5 p. (Foreign office. Miscellaneous, No.12 (I9II). Parliament. Papers by command. Cd. 6008.)

Heath, Harold.

Special investigation of the Alaska fur-seal rookeries, Igro. [By Harold Heath] . . . Washington, I9II. 22 p. ([U.S.] Bureau of Fisheries Doc. 748.)

Smith, Hugh McCormick.

Making the fur seal abundant. (In The National Geographic magazine. Washington, I9II. vol. XXIr, no. I2., p. II39.)

Townsend, Charles Haskins.

The Pribilof fur seal herd and the prospects for its increase. [By C. H. Townseud.] New York, I9II. 3 p. (Read at the forty-first annual meeting of the American Fisheries Society, IgII.) "Reprinted from Science, n. s., vol. xxxiv, p. 568-570."

Evermann, Barton Warren.

An experiment in fur-seal conservation. By Barton W. Evermann [Washington, I9II], cover-title, p. [227]-234. [Reprinted from Transactions of the American Fisheries Society, I9I0.]

U. S. Congress. Senate. Committee on Conservation of National Resources.

Alaskan seal fisheries. Hearings [Feb. 4, IgI ] before the Committce on Conservation of National Resources, United States Senate, on the bill S. 9959, to amend an act entitled "An act to protect the seal fisheries of Alaska, and for other purposes," approved April 2 I, I9I0, No. I. Washington, Igr. 86 p. 
IgI U. S. Department of Commerce and Labor. Bureau of Fisheries.

The fur-seal fisheries of Alaska in rgro. [By Walter I. Lembkey.] Washington, Igri. 40p. (Bureau of Fisheries Doc. 749.)

U. S. Department of Commerce and Labor.

Seal islands of Alaska. Letter from the Secretary of Commerce and Labor, transmitting, in response to House resolution No. 73, information relating to the seal islands of Alaska... Washington, IgII. $1232 \mathrm{p}$. [Appendix A to hearing before Committee on Expenditures in the Department of Commerce and Labor, House of Representatives.] (62d Cong., rst sess., House Doc. 93.) "Copies of all letters, reports, and documents received from agents of the department in charge of the seal islands of Alaska, together with copies of all instructions given to such agents... since January I, I904, to date."

U. S. President.

Fur seals. Message from the President of the United States, transmitting a treaty between the United States and Great Britain looking to the preservation and protection of the fur seals, signed at Washington on February 7, I9Ir. 4 p. (6rst Cong., 3d sess., Executive r.)

U. S. Treaties.

Convention between the United States and other powers providing for the preservation and protection of fur seals. Signed at Washington July 7 , I9II. Washington, IgII. [Ratification advised by the Senate July 24, I9II. Ratified by the President November 24, I9II. Ratified by Great Britain August 25, I9II. Ratified by Japan November 6, I9II. Ratified by Russia $\left\{\begin{array}{l}\text { October } 22 \\ \text { Nov. } 4\end{array}\right\}$, I9Ir. Ratifications exchanged at Washington December 12, I9II. Proclaimed December I4, I9II.] 9 p. (Treaty series No. 564.)

U. S. Treaties.

Fur seal protection. Message from the President of the United States transmitting a convention looking to the protection and preservation of fur seals and sea otters in a certain defined zone of the North Pacific Ocean, signed by the plenipotentiaries of the United States, Great Britain, Japan, and Russia at Washington on July 7, 19Ix. Washington, I9II. 9 p. (6ad Cong., ist sess. Confidential. Ex. G.) also ir p. (62d Cong., ist sess., Senate Doc. 75.)

U. S. Treaties.

Treaty between the United States and Great Britain providing for the preservation and protection of fur seals. Signed at Washington February 7 , IgII... Washington, I9II. [Ratification advised by the Senate February r5, Igrx. Ratified by the President March 6, I9II. Ratified by Great Britain April 20, IgII. Ratifications exchanged at Washington July 7, I9II. Proclaimed December I4, I9II.] 6 p. (Treaty series No. 563.) [Superseded by the Treaty of July 7 , IgII.]

I912 Clark, George Archibald.

Report of the Seal Commission. (In Science. New York. IgI2. n. s. vol, Xxxv. p. 54054I.)

Clark, George Archibald.

The fur seal census. (In Science. New York. Igr2. 11. s. vol. xxxvi, p. 894-897.)

Jordan, David Starr.

Fur seals and their enemies. By D. S. Jordan and Geo. A. Clark. (In Review of Reviews. New York. 1912. vol. 45. p. 315-317.)

Marsh, Millard Caleb.

The fur seal mortality of the Pribilof rookeries in the absence of pelagic sealing. (In Science. New York. 1912. n.s. vol. xxxvi. p. $897-898$.

McLean, Marshall.

Pribilof fur seal herd. (In Science. New York. Igr2. n. s. vol, xxxvi, p. 183-184.)

Townsend, Charles Haskins.

Pribilof fur seal herd. By C. H. Townsend and George A. Clark. (In Science. New York. 1912. I. s. vol, XXXv. p. 334-338.) 
U. S. Congress. House. Committee on Foreign Affairs.

Protection of fur seals and sea otter. Hearing before the Committee on Foreign Affairs of the House of Representatives, January 3 and 4, IgI2, on H. R. I6 57 I, a bill to give effect to the convention between the Governments of the United States, Great Britain, Japan, and Russia, for the preservation and protection of the fur seals and sea otter which frequent the waters of the north Pacific Ocean, concluded at Washington, July 7, Igr I [Text of Treaty] .. Washington, I912. [Statements of Chandler P. Anderson, Charles Earl, W. I. Lembkey, Barton W. Evermann, Henry Elliott, etc.] I5o p.

U. S. Congress. House. Committee on Expenditures in Department of Commerce and Labor. Hearings before the Committee on Expenditures in the Department of Commerce and Labor, House of Representatives, on House Resolution No. 73, to investigate the fur-seal industry of Alaska. May 3I, IgII-[July 3I, I9I2], to. I [-I4], Washington, IgrI-IgI2。 IoI3, [28] p

U. S. Congress. House.

An act to give effect to the convention between the Governments of the United States, Great Britain, Japan, and Russia for the preservation and protection of the fur seals and sea otter which frequent the waters of the north Pacific Ocean, concluded at Washington, July 7 , I9II. (Approved August 24, I9I2.) [Washington, 1912.] 4 p. (62d Cong., 2d sess., H. R. I657 I [Public 320]). (In Stat. L., vol. 37, pt. I, p. 499.)

U. S. Department of Commerce. Bureau of Fisheries.

Alaska fisheries and fur industries in IgIr [by Barton Warren Evermann], Washington, I9I2. 99 p. (Bureau of Fisheries Doc. 766.) (Contents include General administrative report, by B. W. Evermann and The Fur Seal Service by W. I. Lembkey.)

U. S. President.

Fur seal convention. Message from the President of the United States, urging the importance of enacting at the earliest possible moment, and at this session of Congress, legislation necessary to enable this Govemment to make the payments to Great Britain and Japan as required by a convention entered into by the United States with Great Britain, Japan, and Russia on July 7, IgII, and also to fulfill its obligations thereunder in so far as legislation is necessary for that purpose... [Washington, IgI2.] 3 p. (62d Cong., $2 \mathrm{~d}$ sess., Senate Doc. 921.)

U. S. Department of Commerce. Bureau of Fisheries.

Truth about the fur seals of the Pribilof Islands. [Washington, 1912.] 7 p. (Bureau of Fisheries, Economic circular No.4.) "Statement of Dr. David Starr Jordan and Mr. George A. Clark."

U. S. Treaties.

Fur seal convention... Washington [rgI2] (Signed at Washington July 7 , IgII, by representatives of the United States, Great Britain, Japan, and Russia) ${ }_{3}$ p. (62d Cong., $2 d$ sess., House Doc. 916.)

U. S. Congress. House. Committee on Foreign Affairs.

Protection and regulation of the seal fisheries of Alaska. . . Report < To accompany H. R. $20047>$ Washington, I9I2. 7 p. (62d Cong., 2 d sess., House Rept. .32I.)

U. S. Congress. House. Committee on Foreign Affairs.

The fur seal convention... Report. <To accompany H. R. 1657I> Washington, I9I2. ("Treaty series No. 564. Convention between the United States and other powers providing for the preservation and protection of fur seals. Signed at Washington, July 7, I9II..." p. 2I-29.) 29 p. (62d Cong., 2d sess., House Rept. 295.)

I913 [Anonymous] Seals of the Pribilof Islands. (In Popular Science Monthly. New York. Igr3. vol. 82.)

Clark, George Archibald.

Conservation of the fur seal. (In North American Review. New York. 1913. vol. I97. p. 640-644.)

Clark, George Archibald.

Administration of the fur seal service. (In Science. New York. IgI3. n. s. vol. xxxvI, p. 325-327.) 
I913 Clark, George Archibald.

The fur-seal census for Igr3. (In Science. New York. I913. д. s. vol. xxxvm, p. 9I8-9I9.)

Elliott, Henry Wood.

A statement submitted in re the fur-seal herd of Alaska to the House Committee on Expenditures in the Department of Commerce, by Henry W. Elliott, December 15, 1913, to supplement and complete the report and exhibits of the special agents of the House Committee on Expenditures in the Department of Commerce upon the condition of the fur-seal herd of Alaska and the conduct of the public business on the Pribilof Islands, as ordered by the committee June 20, 1913. Washington, 1913. 26I p. (Included, also, in "Hearings before the Committee on Expenditures in the Department of Commerce . . . October I3, I9I3, and January I7, 1914," p. I63-427.)

Jordan, David Starr.

Fur-seal legislation. By David Starr Jordan and George Archibald Clark. (In Science. New York. I9I3. n. s. vol. XxxvI, p. 553.)

U. S. Congress. House. Committee on Expenditures in Department of Commerce.

The report of the special agents of the House Committee on Expenditures in the Department of Commerce upon the condition of the fur-seal herd of Alaska and the conduct of the public business on the Pribilof Islands, as ordered by the committee, June 20, I9I3, and made by the said agents, August 3I, I9I3, to the chairman, Hon. J. H. Rothermel; by Henry W. Elliott and Andrew F. Gallagher ... Washington, I9r3. I39 p. illus. charts (part fold.).

U. S. Congress. House. Committee on Expenditures in Department of Commerce and Labor.

The fur-seal industry of Alaska . . Report [Washington, I913] 19 p. (62d Cong., 3d sess. House Rept. 1425.) At head of title: "House calendar no. 377." Submitted by Mr. Rotherme1. Ordered printed January 21, 19I3. "Views of the minority" (p. 7-10) submitted by Mr. McGuire. "Statement of the minority as to matters presented to the committee" (p. I I-I9) signed: Bird McGuire, Martin B. Madden, Chas. E, Patton.

U. S. Department of Commerce. Bureau of Fisheries.

Fishery and fur industries of Alaska in I912. By Barton Warren Evermann. Washington, I913. 123 p. (Bureau of Fisheries Doc. 780.) (Contents include: General administrative report, B. W. Evermann, and Fur-seal service, by Walter I. Lembkey.)

U. S. President

Message of the President of the United States on fur scals. Communicated to the two houses of Congress, Wednesday, January 8, I9r3 ... Washington, Igr3. 7 p. (62d Cong., 3d sess., Senate Doc. 997.)

1914 Clark, George Archibald.

The new fur-seal investigation. (In Science. New York. Igr4. n. s. vol. xxxux. p. $87 \mathrm{I}-S_{72}$.)

Clark, George Archibald.

Russian versus American sealing. (In Science. New York. IgI4. 1. s. vol. XL. p. 736-739.)

Osburn, Raymond C.

The fur-seal inquiry, the Congressional committee and the Scientist. (In Science. New [Editor] York. I9I4. I. s. vol. XL. p. 557-558.)

The fur-scal commission. (In Science. New York. I9I4. n. s. vol. Xxxix. p. 529.)

U. S. Congress. House. Committee on Expenditures in Department of Commerce.

Hearings before the Committee on Expenditures in the Department of Commerce, House of Representatives. Investigation of the fur-seal industry of Alaska. October I $_{3}$, I913 $_{3} \ldots \ldots$ [to April 2, I9I4] . . Washington, I9I4. 849 p. (63d Cong., 2d sess., House.)

U. S. Congress. House. Committee on Expenditures in Department of Commerce.

Fur-seal industry of Alaska . . Report [recommending action by Attorney General to collect bond from North American Commercial Company and to institute civil proceedings against Isaac Liebes and others] Washington, 1914. 8 p. (63d Cong., 2d sess., House Report 500.) 
1914 U. S. Congress. House. Committee on Expenditures in Department of Commerce.

Fur-seal industry of Alaska . . Minority report. 22 p. (63d Cong., 2d sess., House Rept. 500, pt. 2.)

U. S. Department of Commerce. Bureau of Fisheries.

... Alaska fisheries and fur industries. [By] Barton Warren Evermann. Appendix II to the Report of the U. S. Commissioner of Fisheries for I9I3 . . Washington, I9r4. $7^{8} \mathrm{p}$. (Bureau of Fisheries Doc. 797.)

U. S. Treasury Department, Revenue Cutter Service.

[Rules governing vessels designated to protect seal herds and sea otters] 7 p. Approved October 29, I913.

U. S. Congress. House.

Appendix. In re fur-seal investigation. Facts of record which show the decline of the fur-seal herd of Alaska and the cause of that destruction of this fine public property. [Washington, 1914] p. 53-260. (63 Cong., $2 \mathrm{~d}$ sess., House Rept.) 


\section{DESCRIPTION OF MAPS.}

Rooke, Res, Showing Number and location of Hareis a Height of Season, igr4.

ST. PAUL, ISLAND
I. Kitovi.
2. Lukanin.
3. Gorbatch.
4. Ardiguen.
5. Reef.
6. Sivutch.
7. Lagoon.
8. Tolstoi.
9. Zapadni.
Io. Little Zapadni.
I1. Zapadni Reef.
12. Polovina.
13. Polovina Cliffs.
I4. Little Polovina.
I5. Morjovi.
16. Vostochni.

ST. GEORGE ISLAND.

17. North.

18. Staraya Artel.

I9. Zapadni.
20. Little East.

21. East Reef.

22. East Cliffs.

General Maps.

23. St. Paul Island, with Otter Island and Sea Lion Rock.

24. St. George Island.

\section{KITOVI ROOKERY, ST. PAUL ISLAND.}

Nearly a mile northeast of the village and beyond the high cliff known as the Black Bluff, lies Kitovi Rookery. The harems occupy a stretch of broken ledge with numerous irregular features.

On June 25 this rookery contained 46 harem bulls and 24 cows in 17 harems. On June 30 this was increased to 47 bulls and I62 cows in 34 harems. On July I7, 58 harems and 5 idle bulls were counted. The count of pups showed 2,1 9 born on Kitovi.

The northern end of this rookery, known as the Amphitheater, is frequented by a small and variable number of bachelors. A small number haul also in the vicinity of Rock No. Io. Early in the season the number found in both these places was small, from 50 to 150 , but gradually increased and on July 28,446 were counted.

\section{LUKANIN ROOKERY, ST. PAUL, ISLAND.}

North of Kitovi Rookery and separated from it only by a short interval of sea-washed cliff, lies Lukanin. A few harems are situated on a limited space at the base of a steep bluff and beyond this a steeply sloping area studded with large bowlders is occupied.

On June 25 , when Kitovi still had very few cows, a single harem on Lukanin had as many as 18. There were 34 bulls, Ig harems, and 196 cows on June 30 and nearly half the cows were included in a single harem. On July $\mathrm{i} 7$, at the height of the season, there were 39 liarems and one idle bull. Bachelors hauled at the northern end of Lukanin with great irregularity. In June none were seen except at the water front, but on July 7 about a dozen were found hauled well up the slope and sleeping in the grass, and on July 28 as many as IS6 were counted about the rookery. The official count of pups showed 1,834 for Lukanin. 


\section{GORBATCH ROOKERY, ST, PAUL, ISLAND.}

This rookery occupies nearly half a mile of shore on the northwestern side of Reef Peninsula. Its extreme eastern harems are at the foot of abrupt cliffs, its central ones are situated on broadly shelving ledges, while those farther west occupy a bowlder beach. Being scarcely half a mile from the village, it is easily accessible and high banks in several places afford excellent observation stations.

. On the occasion of the first critical examination of this rookery on June 23 it held about goold bulls, 26 of which had small harems aggregating about 60 cows. Many harems contained but one cow, and the largest numbered only ro. About one-fourth of the cows had new-born pups. The next day the cows had increased to about roo and at least 20 pups were seen.

On June 25 roo old bulls were counted, 43 of which had harems containing in all I 43 cows. The pups had then increased to $4 I$. On June 26 the cows had increased to 198 and 79 pups were counted.

Gorbatch was next visited on June 30 , when Ior harem bulls were counted, 72 of which had harems aggregating about 550 cows and at least 170 pups. On July 3 no detailed count was made, but the number of cows had increased and the number of pups nearly equaled the cows. At this time many of the cows had begun to go to sea to feed. No more counts were made until July $I 7$, when the official harem count showed IIz bulls with harems. The females in these harems were later found to have given birth to $6,15^{2}$ pups.

A small hauling ground on a grassy hillside at the rear of the middle of the rookery was occupied by a moderate number of bachelors which slowly increased throughout the season. On June 30 , this number was slightly less than I00; on June 24 , it was not less than I 50 ; on June 26 , it was somewhat more than 200 ; on July 3 , by careful count, it was approximately 400 ; and on July 28 , it was 500.

\section{ARDIGUEN ROOKERY, ST. PAUL ISLAND.}

Beyond Gorbatch Rookery and separated from it by a short stretch of precipitous cliffs is the small rookery known as Ardiguen. It occupies a narrow beach at the foot of a high cliff, from the crest of which one may look almost directly down on the harems. This rookery, when first examined on June 24 , was occupied by only 9 bulls, 5 of which had small harems. The number of harems later increased to 14. From rgog to I9I3 this rookery had uniformly held II harems. The count of pups showed that 656 pups were born on Ardiguen.

\section{REEF ROOKERY, ST. PAUL, ISLAND.}

Extending for somewhat over half a mile along the southeastern side of Reef Peninsula is the populous rookery bearing this name. The ground occupied comprises mainly ledges of rock or bowldercovered beaches. The regular nature of the ground and the lack of eminences make observation difficult, as the harems extend some distance back from the shore and access to the front of the rookery mass from the rear is not possible.

On June 27 there were about $16_{5}$ harem bulls on this rookery. At the time of the official count of harems there were 193 bulls. In these harems were born I3,559 pups.

Near the center of the breeding ground on Reef Rookery is an extensive hauling ground, from which numerous drives were made in 19r4. A drive from this place on July I contained, by actual count, 780 seals, and these were estimated to constitute about one-fifth of the total number then on the ground.

On August 8, notwithstanding that practically all food killings in recent years have been taken from this place, 1,600 seals were driven from this hauling ground, forming the largest drive that has been made on the islands for a number of years. On July 3 between 2,000 and 2,500 seals were estimated to be hauled out here. On July 28 , when a one-day count of all bachelors on St. Paul Island was made, only I,500 were found on Reef.

\section{SIVUTCH ROOKERY, ST. PAUL, ISLAND.}

Sea Lion Rock or Sivutch, a small islet lying a few hundred yards off Reef Point, is the site of a populous rookery. When first visited, on June 29,63 breeding bulls were stationed there; 35 of these had harems, with a total of 364 cows. At the height of the season, there were 9 I harem bulls, and ro idle bulls. The count later showed that 4,052 pups were born there.

Bachelor seals haul out on Sivutch in some numbers. On July 28 at least 500 were present there. This hauling ground is resorted to later in the autumn than any other, and successful drives for food are sometimes made as late as December. A few sea lions are usually found on this island, and many birds breed on its summit. 


\section{I,AGOON ROOKERY, ST, PAUI, ISLAND.}

This rookery occupies the front of a wall-like reef composed of rounded bowlders which have been forced by the ice from the shallow bay called Village Cove, partially shutting off a lagoon from the sea. Lagoon was once an extensive rookery, but is now almost abandoned.

On June 23, when Lagoon rookery was first inspected, it contained two young and five old bulls, one of which had two cows. Seven bulls were present on July 2 and on July I 8 there were eight harem bulls and two young bulls. The count of pups on July 29 showed that 375 pups were born there.

There is at present no hauling ground near Lagoon Rookery.

\section{TOLSTOI ROOKERY, ST. PAUL ISLAND.}

This rookery occupies a continuous stretch nearly a mile long on the eastern shore of English Bay. The ground occupied is mainly a rocky beach, but in some places the harems extend part way up the steep slope which flanks the grassy bluffs of Tolstoi Head. At the northern end of the rookery a number of harems occupy a considerable portion of a broad sand flat upon which scattered rocks were placed some years ago. The southern part of the rookery is sometimes distinguished from the northern under the name Tolstoi Cliffs.

At the time of the earliest visit, on June 23, I06 harem bulls were found located on Tolstoi. These were guarding a total of about Ioo cows, of which 37 had pups. On June 25, I22 harem bulls were counted and the number of cows had greatly increased.

On July I8, I6r harems and I5 idle bulls were counted. In these harems were born 9,934 pups.

The principal hauling ground is at the northem end of the rookery. On June 23 it was estimated that 800 bachelors were hauled. On July 28,572 were counted, and after August $r$, although no exact counts were made, it was evident that nearly or quite $\mathbf{I}, 000$ were usually present.

\section{ZAPADNI ROOKERY, ST, PAUL ISLAND.}

This rookery lies northeast of the extremity of Zapadni Point, the western boundary of English Bay. The harems occupy a stretch of rocky ledges and bowlder beaches nearly half a mile in length. When first visited, on June 26 , this rookery held 103 bulls, 34 of which had harems with an aggregate of about Ioo cows. By July I8, when the official count of harems was made, there were II 4 harem bulls and 24 idle bulls. The count of pups on this rookery showed a total of 7,625 . On the several hauling grounds of this rookery about I, 300 bachelors were counted on July 28.

\section{LITTLE ZAPADNI, ST PAUL ISLAND.}

On the northwest shore of English Bay and separated from Zapadni Rookery by a small sandy beach lies Little Zapadni. It occupies about a half mile of rocky ledge backed by a gently rising slope. The harems extend up this slope in tiers so that in places five or six are in line between the water and the upper limits.

On June 26 , when this rookery was first visited, 68 harem bulls, 36 of which already had harems, were located. On July I8, 90 harem bulls and Io idle bulls were counted. The count of pups later showed that $4,9 \mathrm{I} 9$ had been born. On the hauling ground at the northern end of the rookery $28 \mathrm{I}$ bachelors were counted on July 28.

\section{ZAPADNI REEF, ST. PAUL, ISLAND.}

The remnant of a rookery at one time nearly continuous with Little Zapadnl is found on the northem shore of English Bay. The present season it contained 3 harem bulls and I idle bull. The count of pups showed that 206 were born. There are no hauling grounds in the vicinity.

POLOVINA ROOKERY, ST. PAUL, ISLAND.

This rookery occupies a rocky point about half way between the village and the northeastern extremity of the island. On Jume 27 , when first visited, 36 harem bulls had located, and 7 of these had harems, with a total of about 60 cows. At the height of the season, there were $5^{8}$ harem bulls and 3 idle bulls. The count later showed that 3,555 pups were born on the rookery.

At the southern end of the rookery is a hauling ground, which on July 28 contained about $55^{\circ}$ bachelors. 


\section{POLOVINA CLIFFS ROOKERY, ST. PAUL, ISLAND.}

This rookery consists of several interrupted groups of harems occupying a narrow strip of rough boulder beach at the foot of a line of low cliffs, behind which extends a level mossy plain. On June 27 there were 18 harem bulls in this rookery, II of which had a total of $3^{8}$ cows.

At the height of the season 22 harems and 6 idle bulls were stationed here. The count taken July 29 showed that $I, 449$ pups were born in these harems.

A very few bachelors haul out in the vicinity of this rookery; on July 28 the number found was 47.

\section{LITTLE, POLOVINA ROOKERY, ST. PAUL, ISLAND.}

Little Polovina lies a short distance north of Polovina Cliffs and is similar in character to Polovina Cliffs. On June 27 it held II harem bulls, 6 of which had 28 cows among them. On July Ig the number of harems was 18 . The count later showed that 927 pups were born here. On the small hauliag ground about 50 bachelors were usually found.

\section{MORJOVI ROOKERY, ST. PAUL, ISLAND.}

Morjovi is on the eastern side of Northeast Point, and separated from the larger rookery of Vostochni by the breeding herd of sea lions. It consists of two rather compact detached harem masses, with a few scattered outlying ones, and is the remnant of a rookery which formerly extended far down the shore. On June 27 it had 35 breeding bulls, and on July ig there were 43 harems and 4 idle bulls. On this rookery 2,3I2 pups were born.

Adjoining Morjovi Rookery are two small hauling grounds, on which about 400 bachelors were ustally found.

\section{VOSTOCHNI ROOKERY, ST. PAUL, ISLAND.}

This rookery, which is nearly continuous over a stretch of rocky shore line more than a mile in length, is the largest rookery of fur seals in the world. When first visited, on June 27,248 harem bulls were stationed there. At the height of the season, 29 I harems and 20 idle bulls were found. The count of pups later showed that I9,709 had been born in these harems.

From the summit of Hutchinson Hill one looks down on a closely packed mass of harems which at the height of the season in I9I4 held 106 harem bulls. The count of pups on August 2 showed a total of 9,504 in this mass, which, with their mothers and the harem masters, makes a total of over I 9,000 breeding seals in one compact mass. Surrounding this particular breeding area on three sides is a hauling ground usually containing several thousand bachelors. On the various hauling grounds of Vostochni, 3,652 bachelors were counted on July 28 . In former years the hauling grounds of Northeast Point were mach more populous than at present and furnished nearly one-third of the total quota of skins for St. Paul Island.

On the point near the eastern extremity of this rookery is a breeding rookery of sea lions, the only one on St. Paul Island.

\section{NORTH ROOKERY, ST. GEORGE ISLAND.}

North Rookery lies about a mile west of the village and consists of a narrow fringe of harems occu. pying a strip of rough beach at the foot of low abrupt cliffs. There were 85 harems on July I3, and 94 harems and 4 idle bulls at the time of the official count on July 20 . In these harems were born $5,30 \mathrm{r}$ pups. About ro bachelors usually resorted to the small hauling ground.

\section{STARAYA ARTEL, ST. GEORGE ISLAND.}

This rookery comprises a compact mass of harems on a hill, one side of which breaks suddenly to the water and another sweeps gradually to the same level.

There were 46 harems here on July $1_{3}$ and 63 harem bulls and 4 idle bulls on July 20 . The count later showed that 4,278 pups were born here. On the hauling ground there were usualiy from 500 to 600 bachelors. 


\section{ZAPADNI ROOKERY, ST. GEORGE ISLAND.}

Zapadni Rookery occupies a small patch of rough bowlder beach at the foot of an abrupt cliff, while a few harems extend around the end of the cliff and occupy a small area on its summit.

On July I3 there were I 5 harems on Zapadni and on July Ig this number was found to be reduced to I4. The count of pups showed that $x, 023$ were born here. About 50 bachelors haul on the ground immediately adjacent to the breeding area.

On the shore about a mile east of Zapadni there was in Igr 4 a small hauling ground. On August 4 a number of bachelors and two old bulls were found there. Among the seals which took to the water no females were distinguished but a single young pup was found, evidence of at least one harem. According to the natives there were three harems at this place in I9I3. In former years many seals hauled out here, and it was a regular killing place. Another hauling ground about half a mile west of the rookery was occupied in I9I4. On August I a total of 276 bachelors was counted on the several hauling grounds near Zapadni Rookery.

\section{LITTLE EAST ROOKERY, ST. GEORGE ISLAND.}

This rookery has dwindled in late years, and in I9I4 had only one harem, in which 26 pups were born. In $19{ }^{1} 3$ there were two harems with 25 pups, and in 1912 one harem with 26 pups. The rookery is on a beach at the end of the cliffs which extend for about a mile eastward from the village.

\section{EAST REEF ROOKERY, ST. GEORGE ISLAND.}

A short distance eastward from Little East Rookery is East Reef, occupying a slightly elevated stretch of ledge covered with large bowlders.

On July I4 there were $I_{4}$ harems on this rookery, and the same number were counted on July 20. About 175 bachelors were on the hauling ground on July 30 . On this rookery $5^{81}$ pups were born.

\section{EAST CLIFFS ROOKERY, ST. GEORGE ISLAND.}

This is the easternmost of the St. George rookeries, and occupies a gradually narrowing rocky beach and rough ascending slope. Back of it is a steep, grassy ascent, which at the eastern end of the rookery becomes an abrupt cliff. The harem bulls on July 14 numbered 54 . The count on July 20 showed 57 harems and 2 idle bulls. The pups born on this rookery numbered 2,658.

On the hauling ground at the western end of this rookery about 800 bachelors were counted on July 28. 


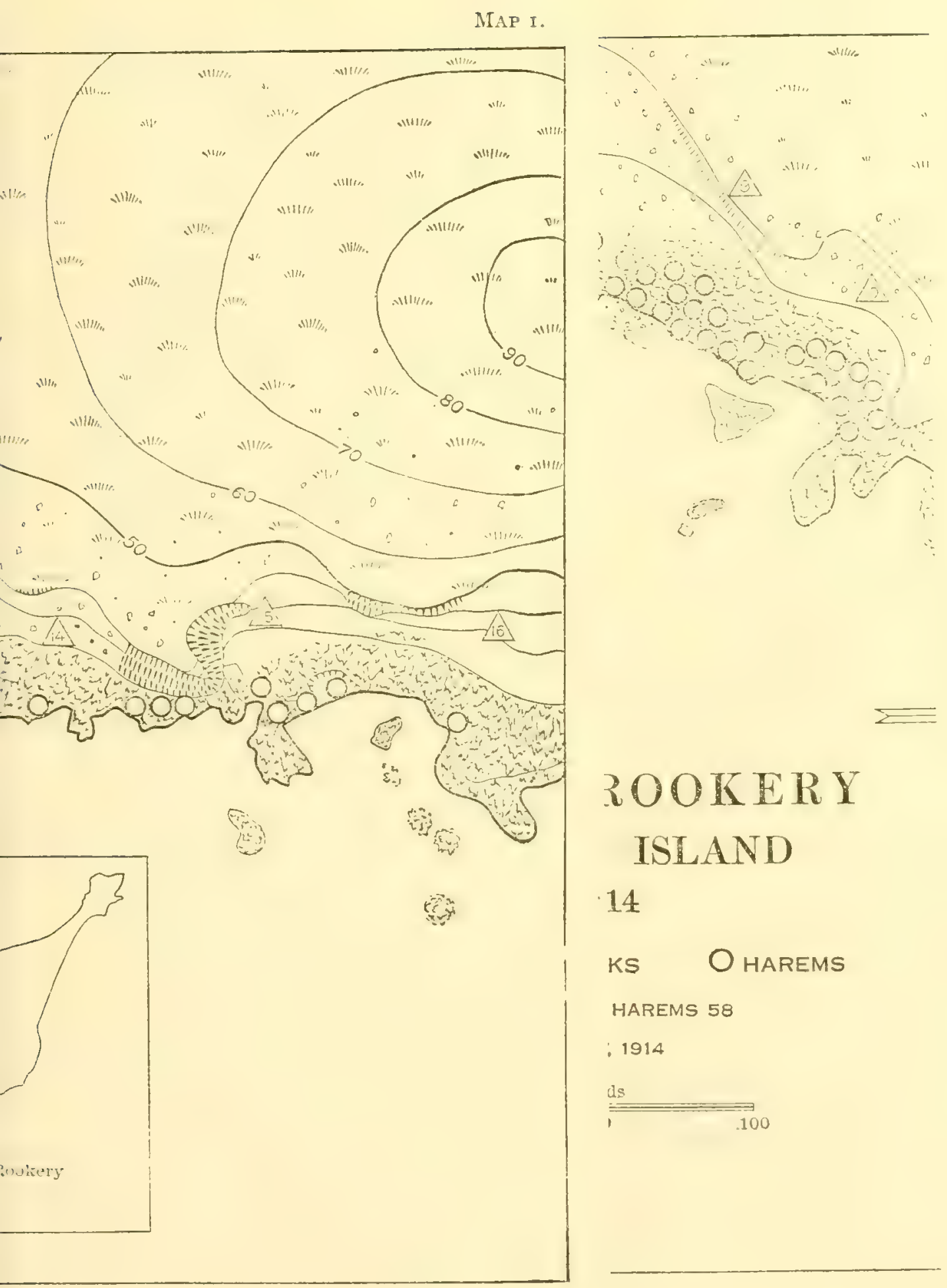





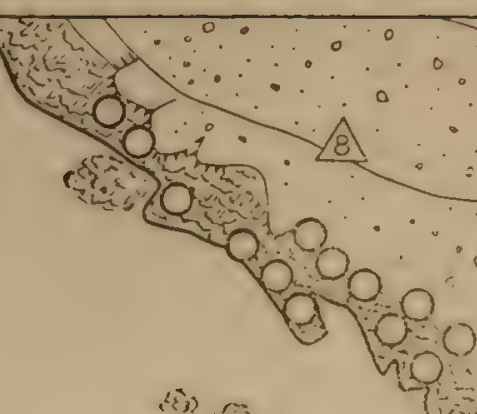

(6)

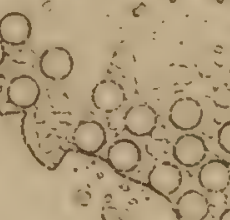

\section{KITOVI ROOKERY} ST. PAUL ISLAND 1914

(1) NUMBERED ROCKS

\section{O harems}

NUMBER OF HAREMS 58 JULY 17, 1914
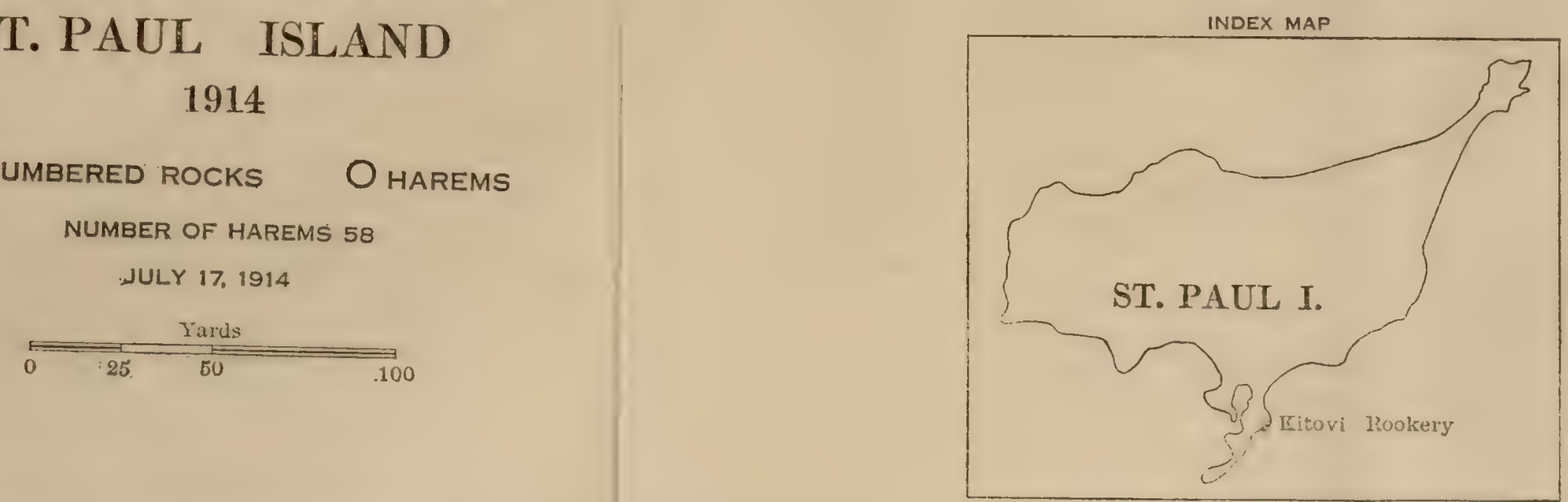

(i)

s.s







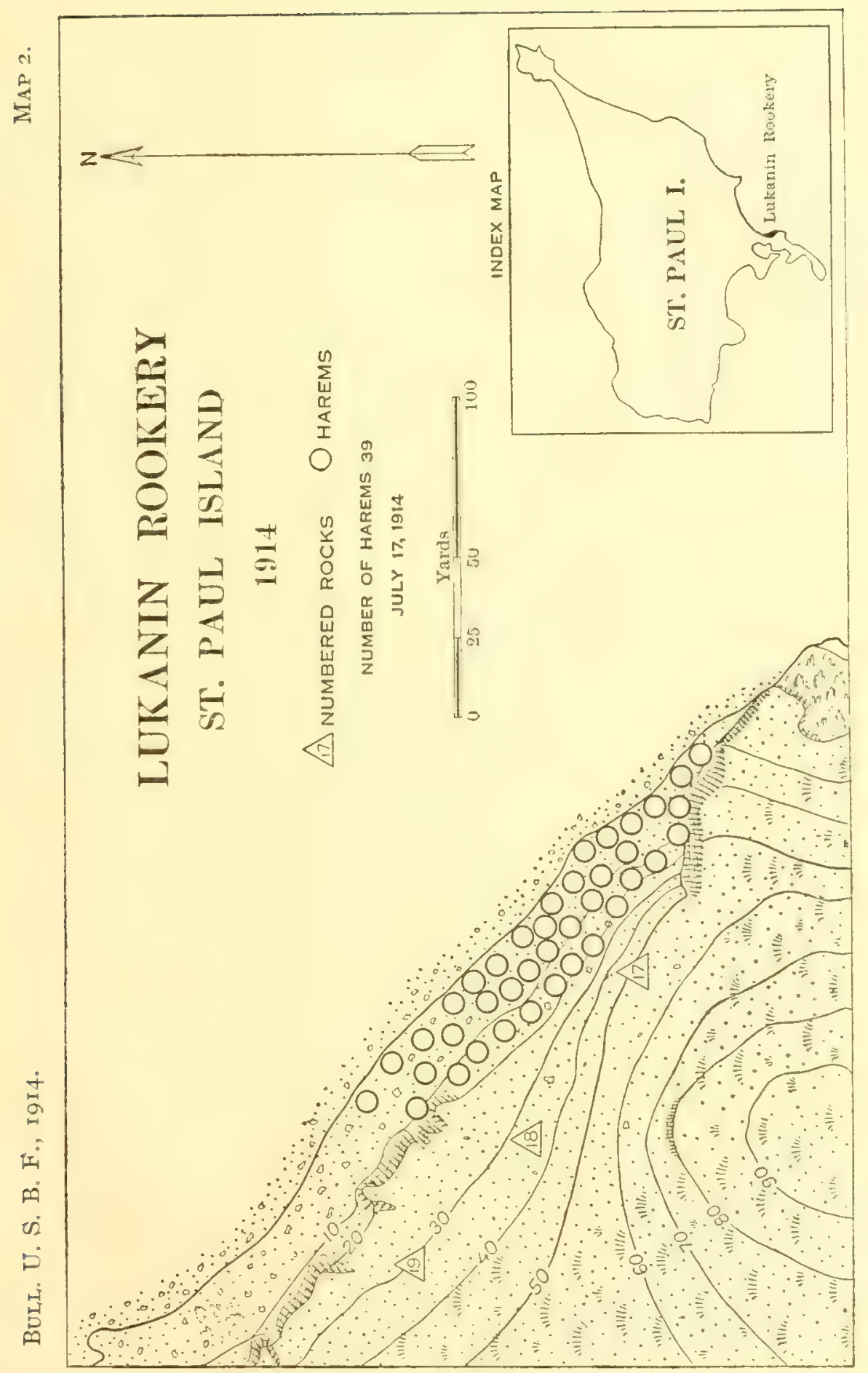



BULI. U. S. B. F., I9I4. Mar 3.

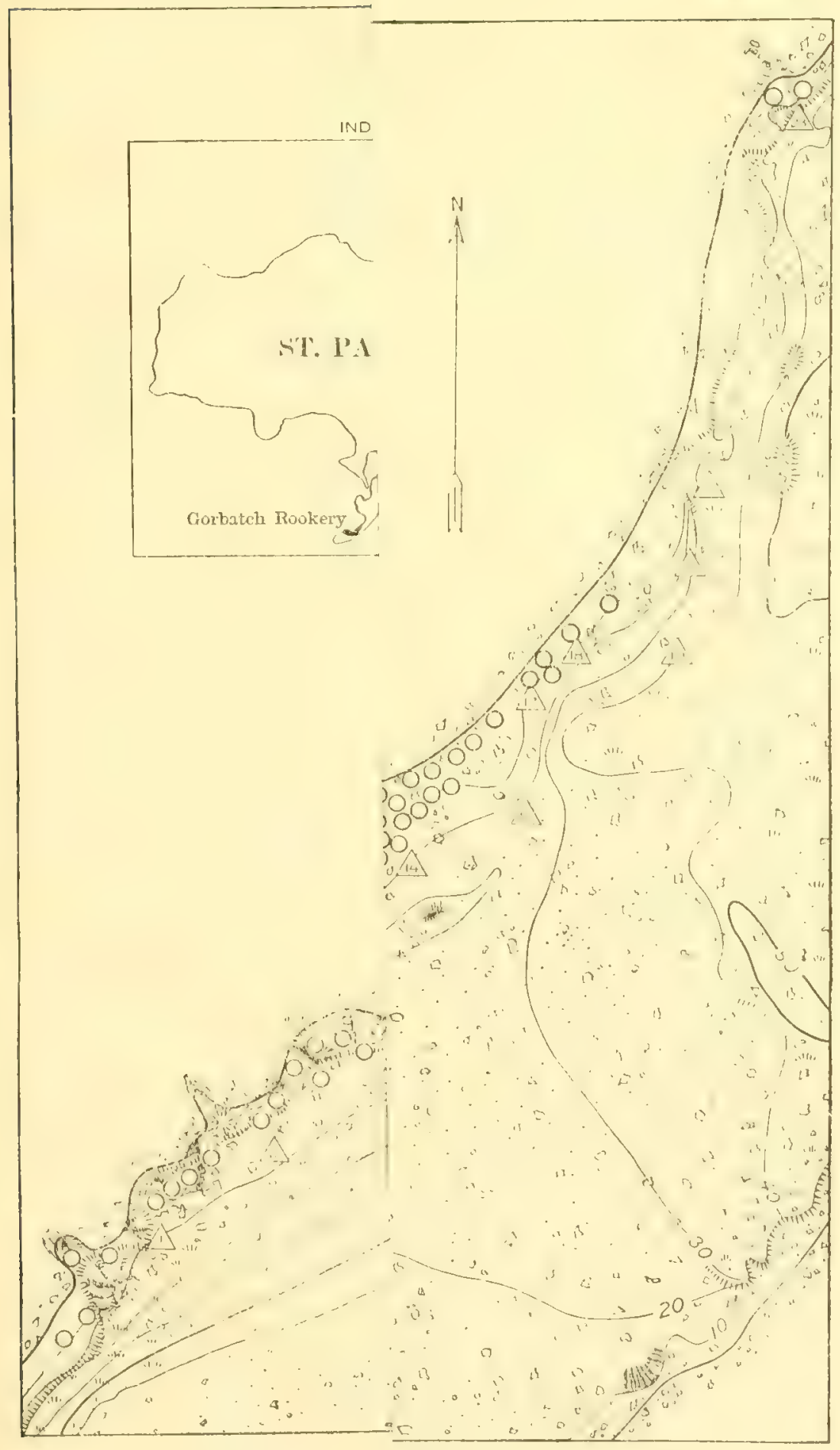





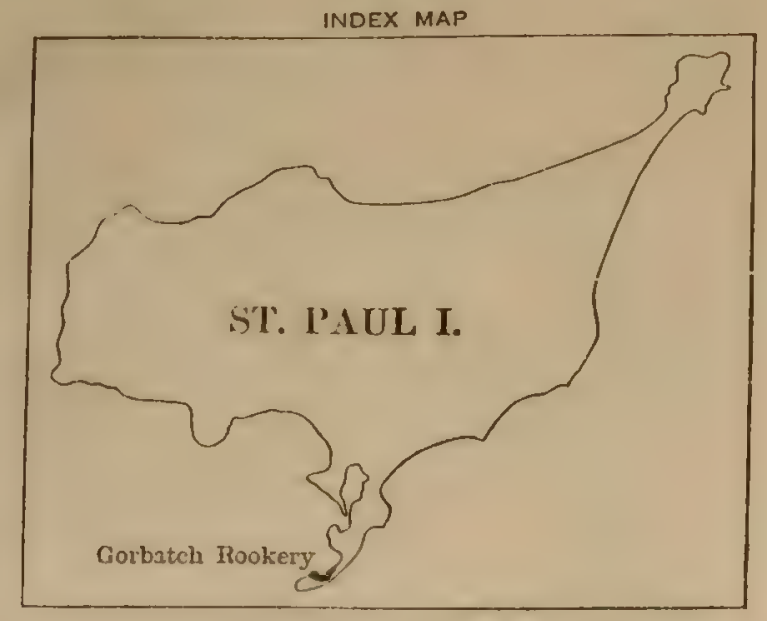

\section{GORBATCH ROOKERY} ST. PAUL ISLAND

1914

4 NUMBERED ROCKS OHAREMS

NUMBER OF HAREMS 112 JULY 17,1914

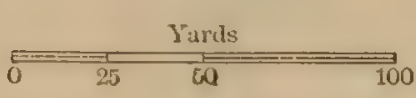





\section{ARDIGUEN ROOKERY}

ST. PAUL ISLAND

$$
1914
$$

2 Numbered rocks Oharems

NUMEER OF HAREMS 15 JULY 17. 1914
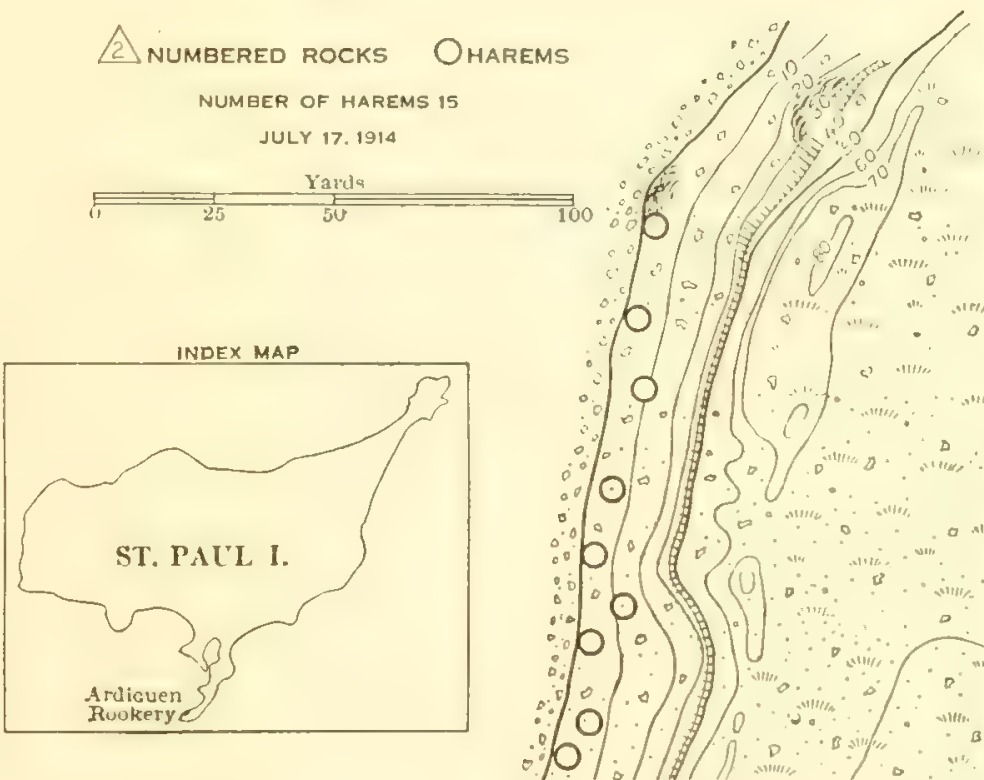

$\therefore$
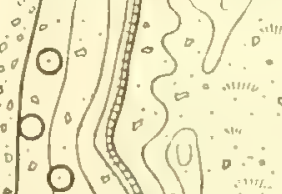

盟
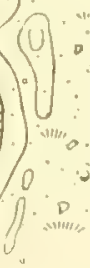




\section{REEF ROOKERY}

ST. PAUL ISLAND

1914

$\triangle$ NUMBERED ROCKS OHAREMS

NUMBER OF. HAREMS 193

JULY 17. 1914

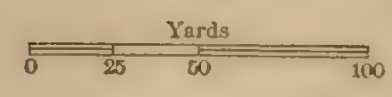

$\int_{0}^{4}$

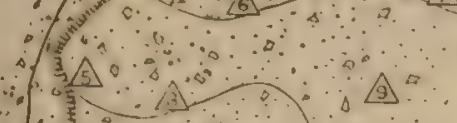

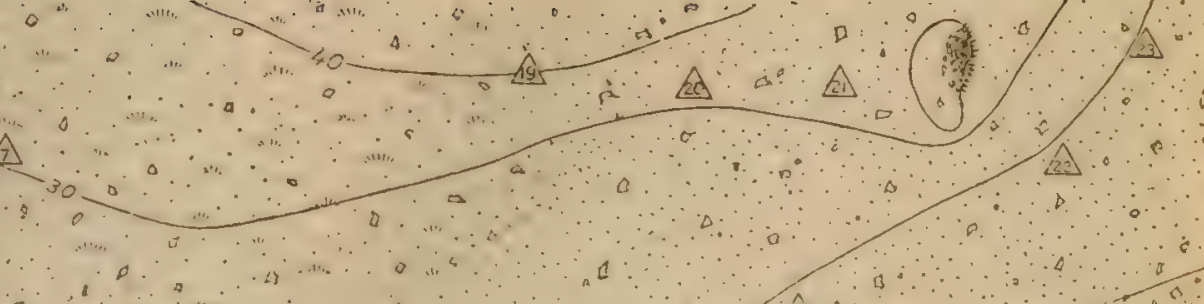

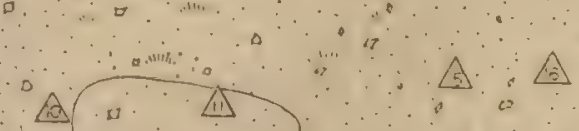

$\therefore / B$

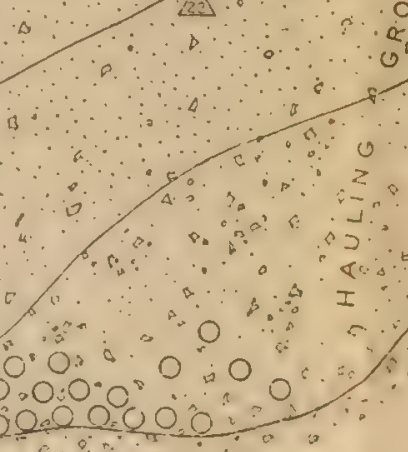

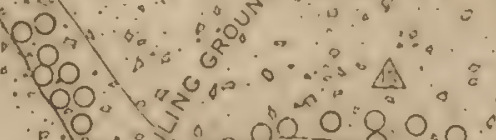

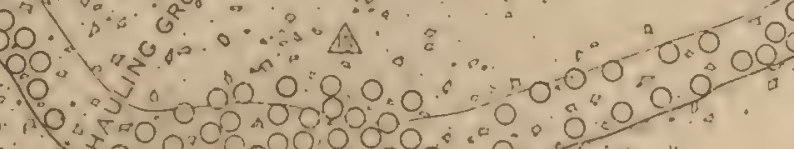

$00,000000000.00 \%$

$\therefore 00000$

INDEX MAP

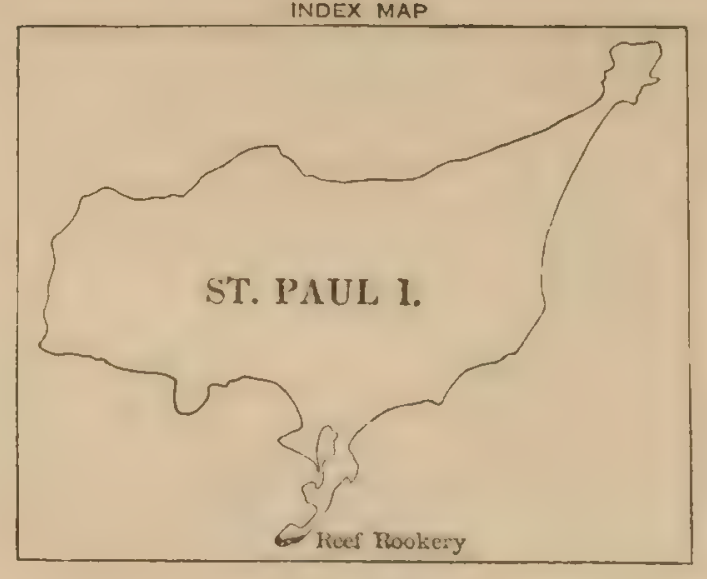





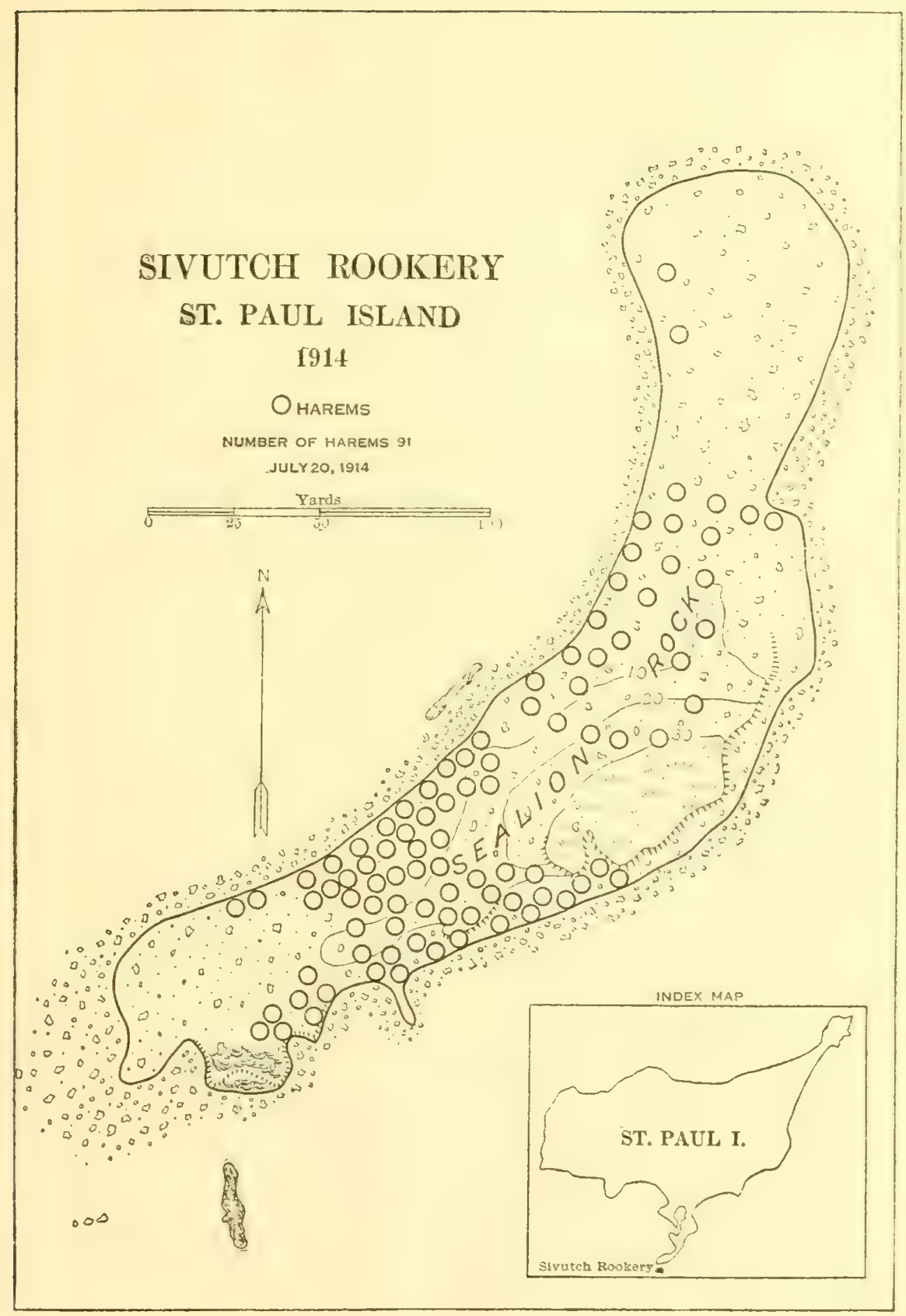



BuIL. U. S. B. F., I9I4.

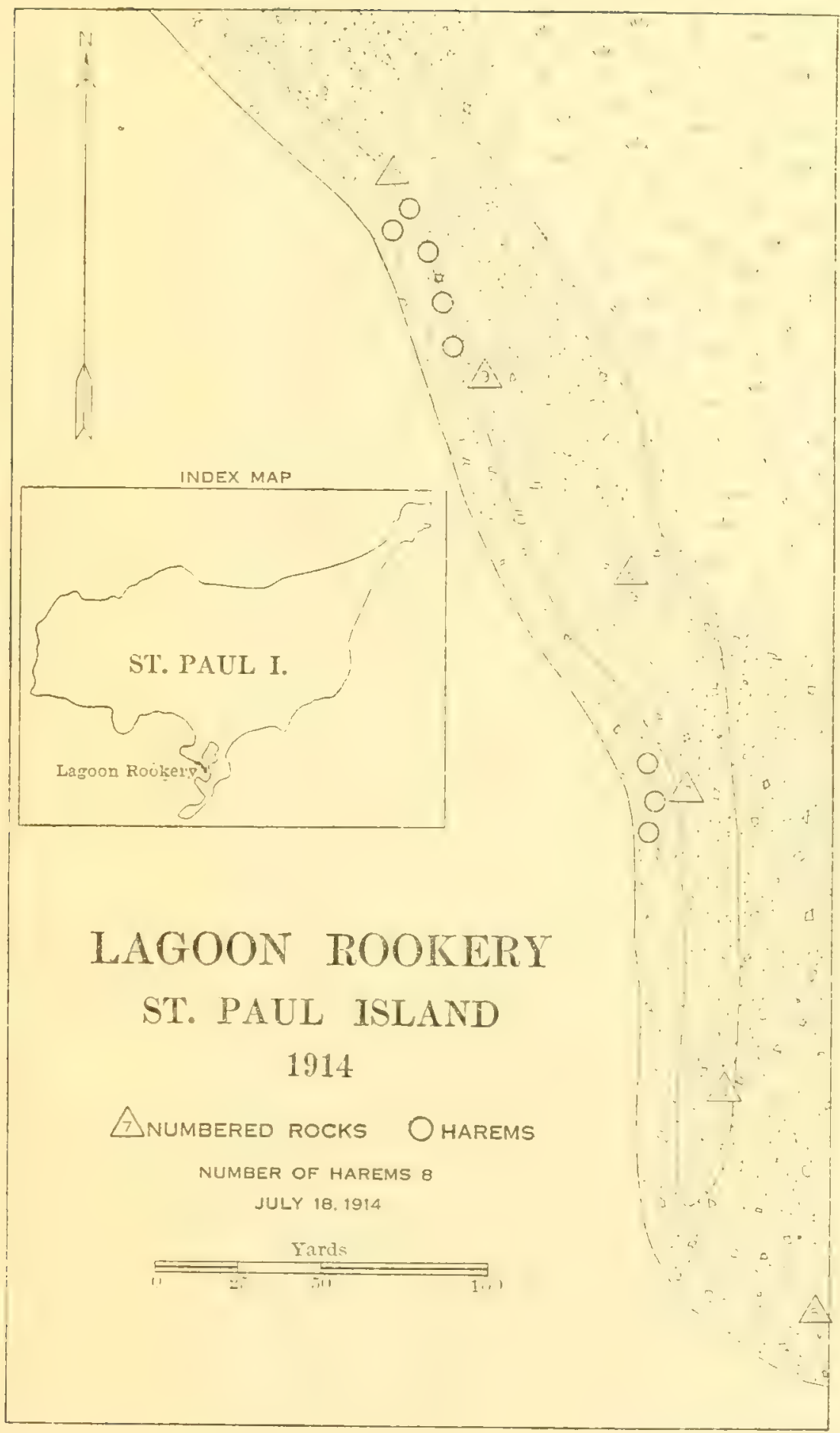



BULL. U.

MAP 8.

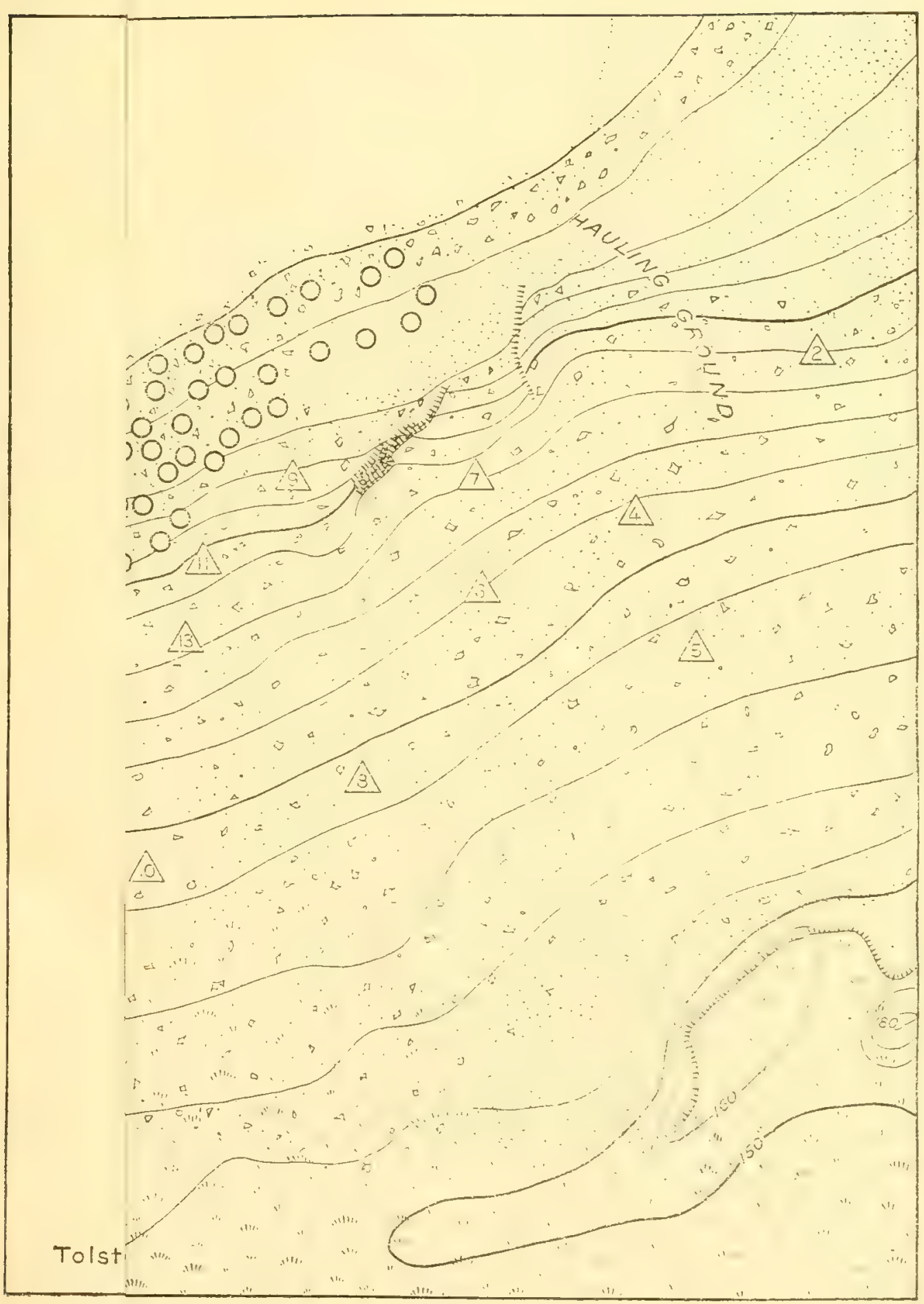





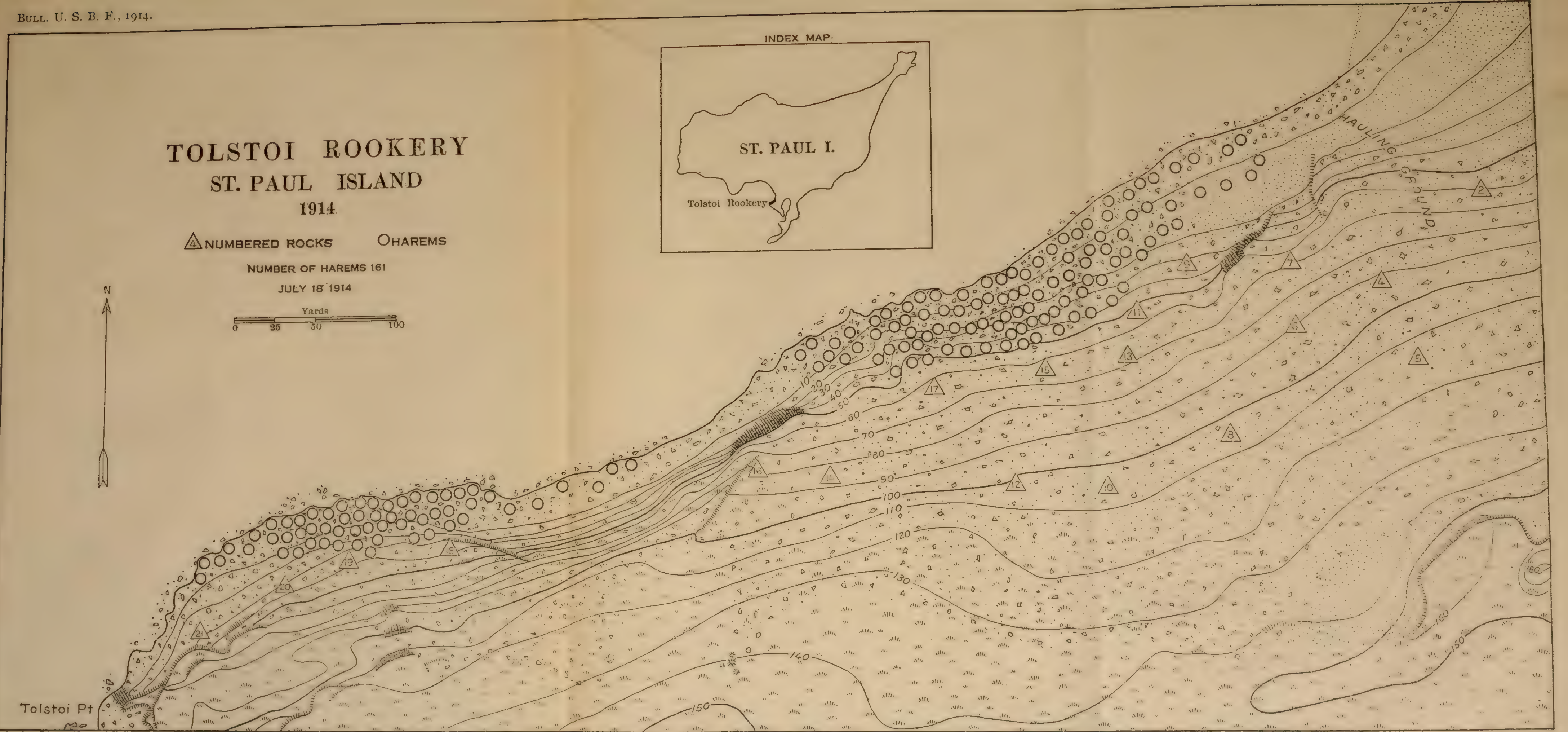





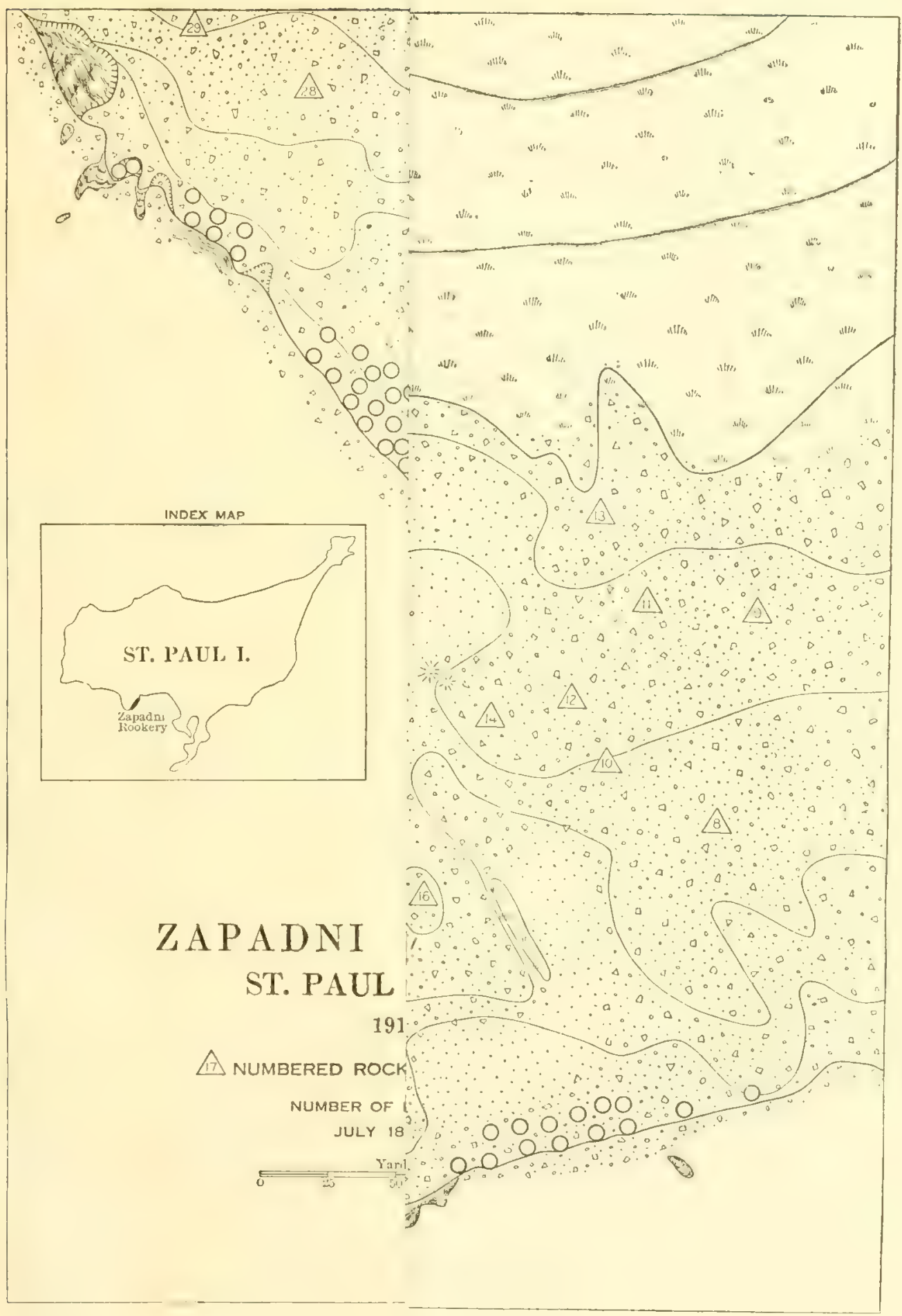





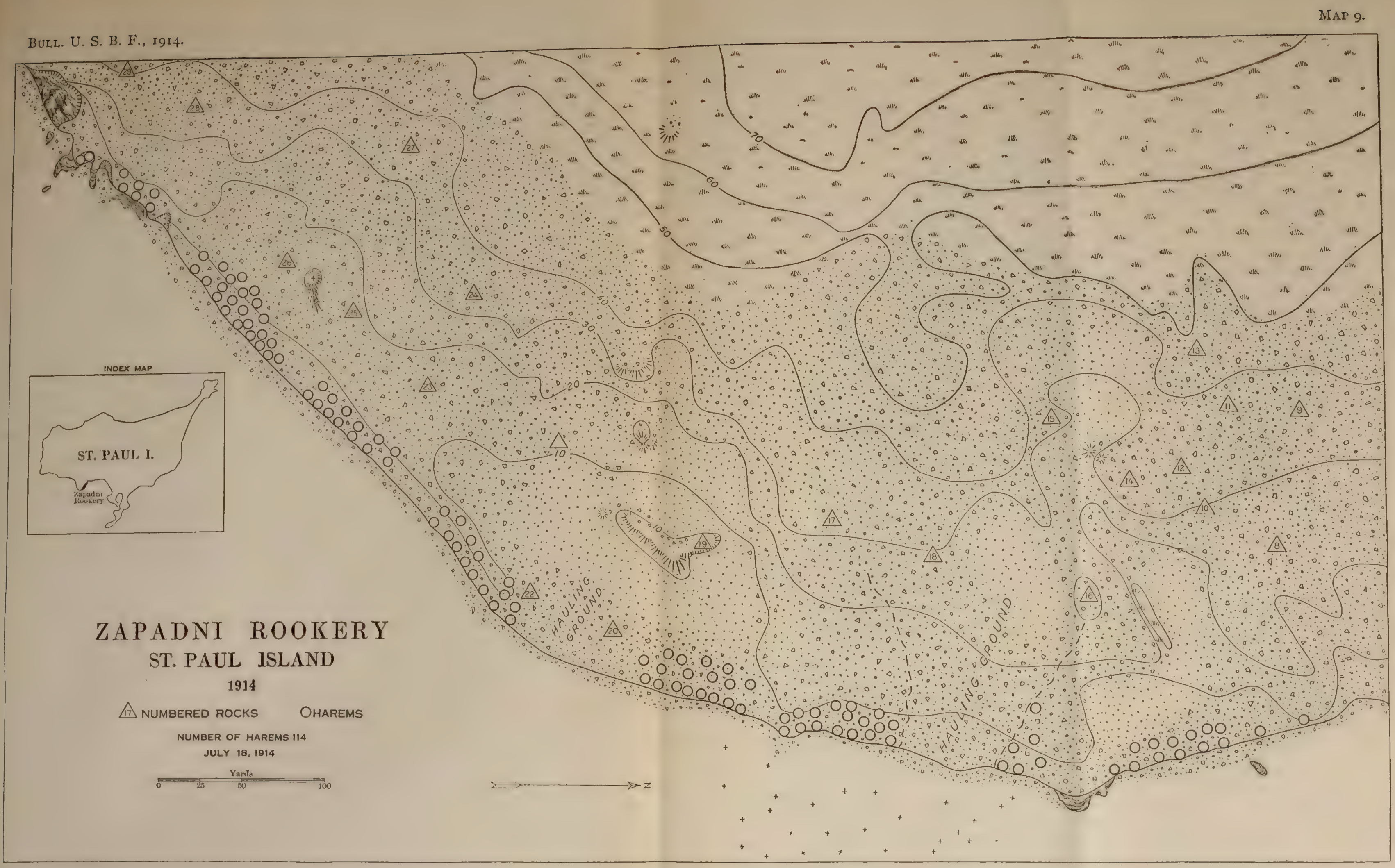




MAP IO.

BUL,I. U. S. B. F., I9I4

\section{LITTLE ZAPADNI ROOKERY} ST. PAUL ISLAND

1914

1

An NUMBERED ROCKS OHAREMS

NUMBER OF HAREMS 90

JULY 18,1914
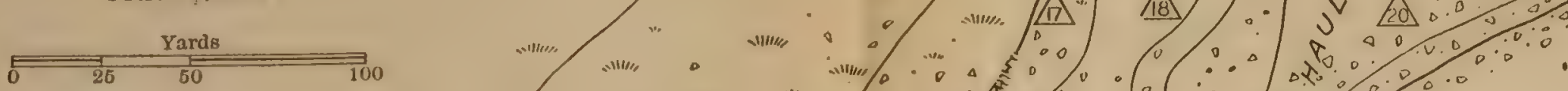

INDEX MAP

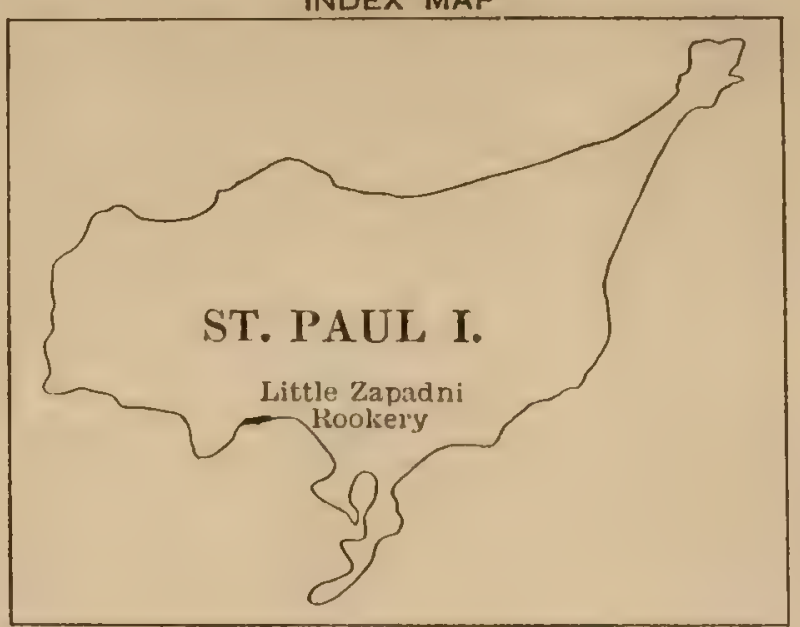





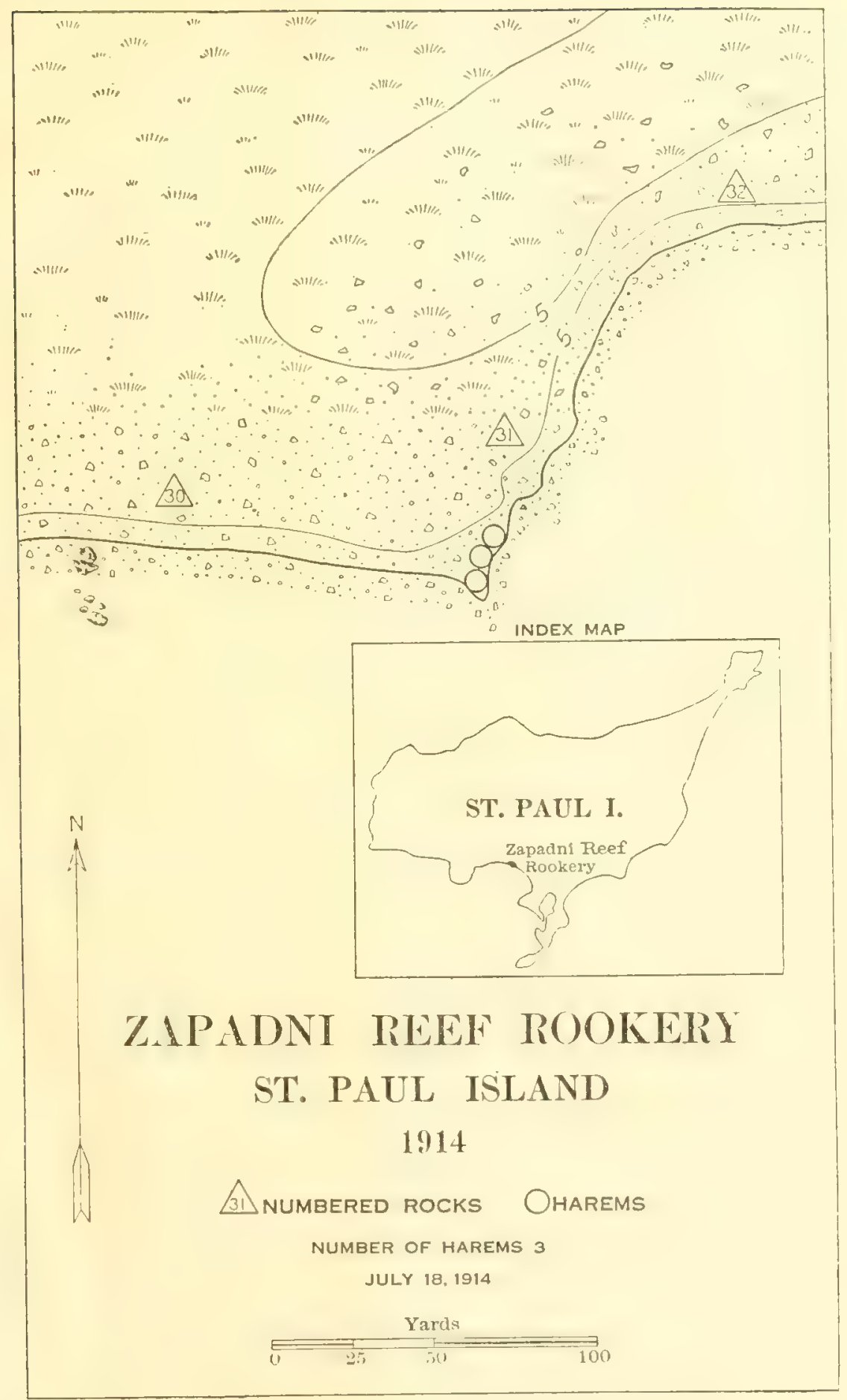



BULI. U. S. B. F., IgI4.

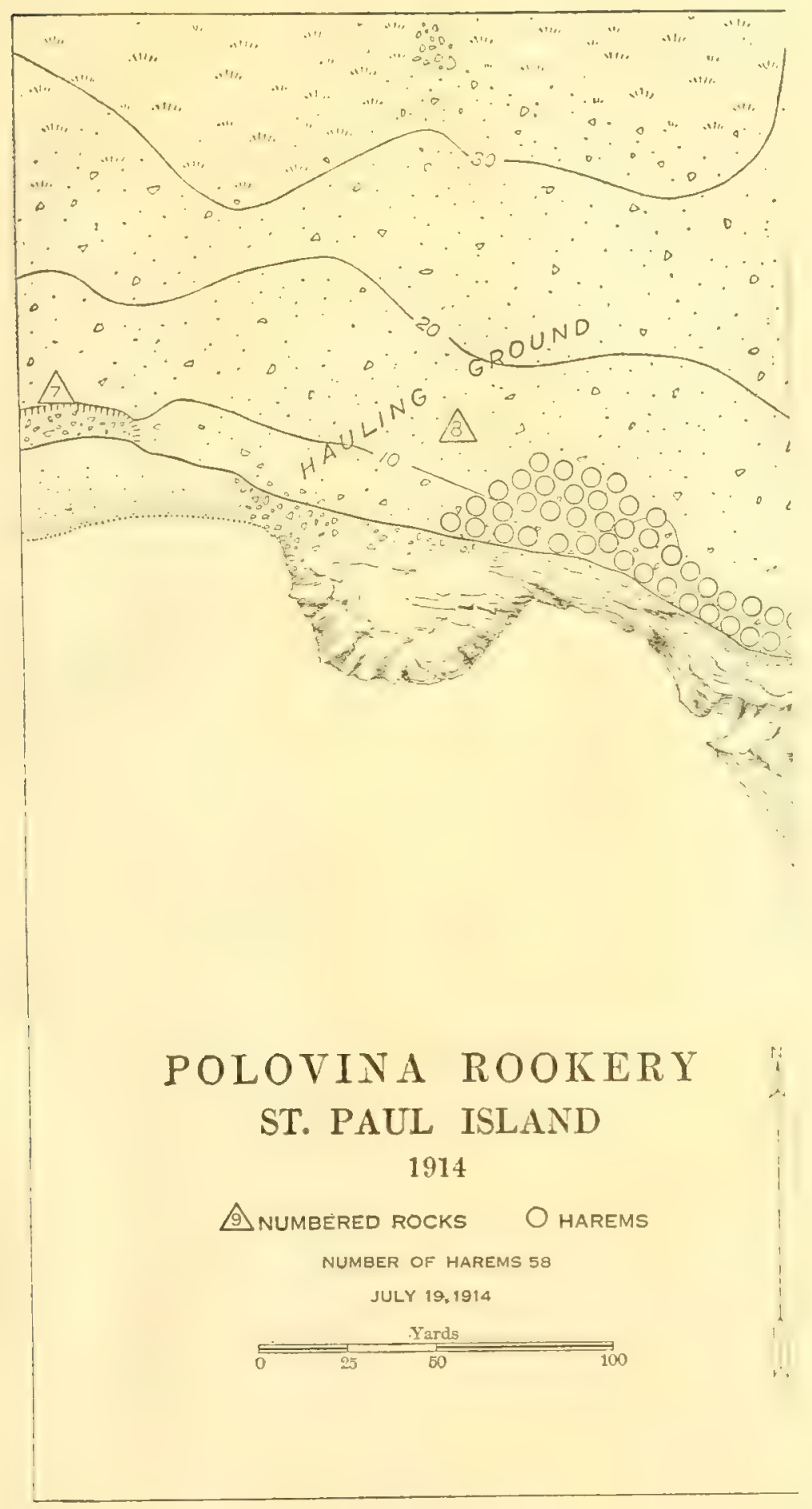



MAP 12.

BUL,L. U. S. B. F., I9I4.







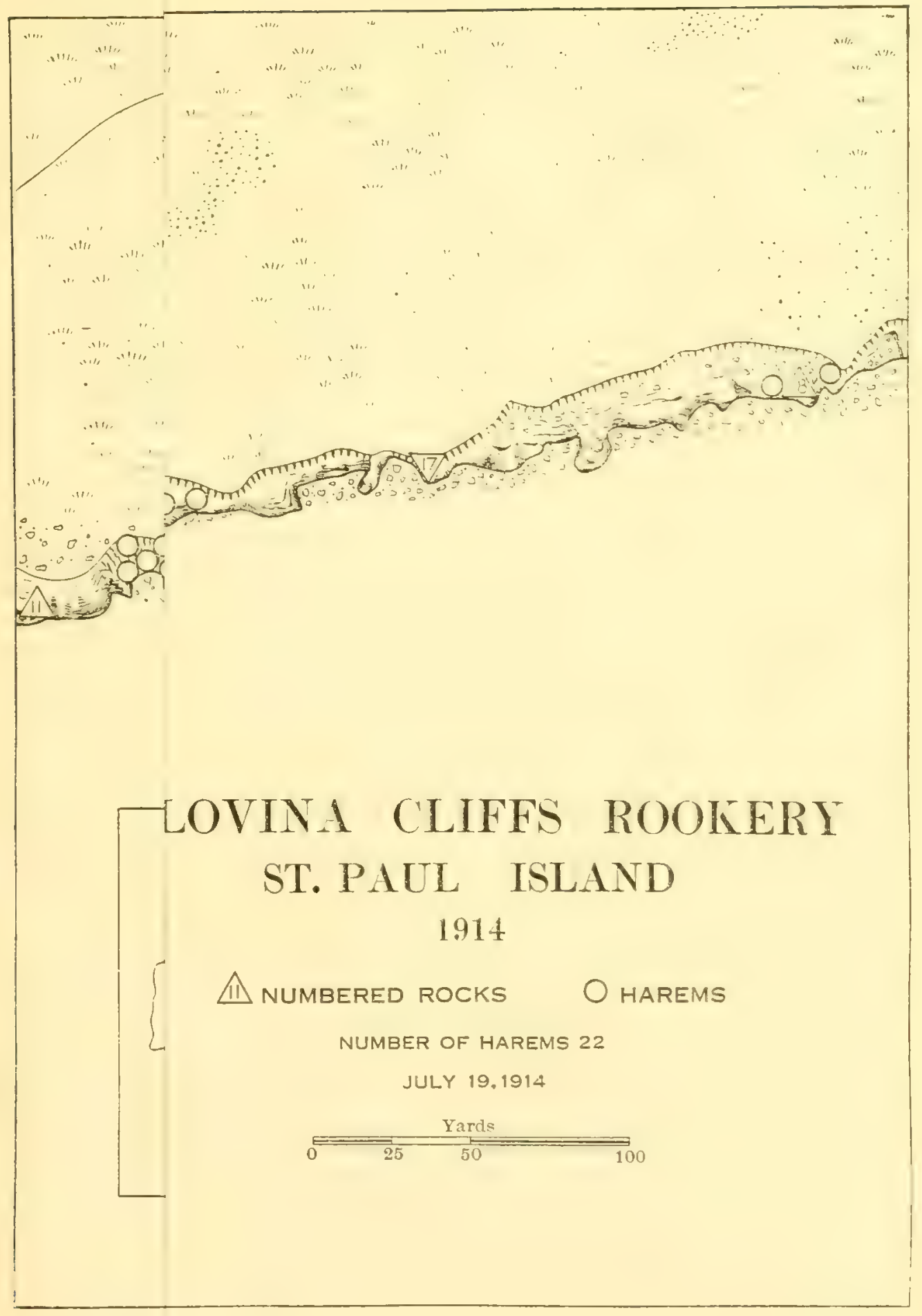





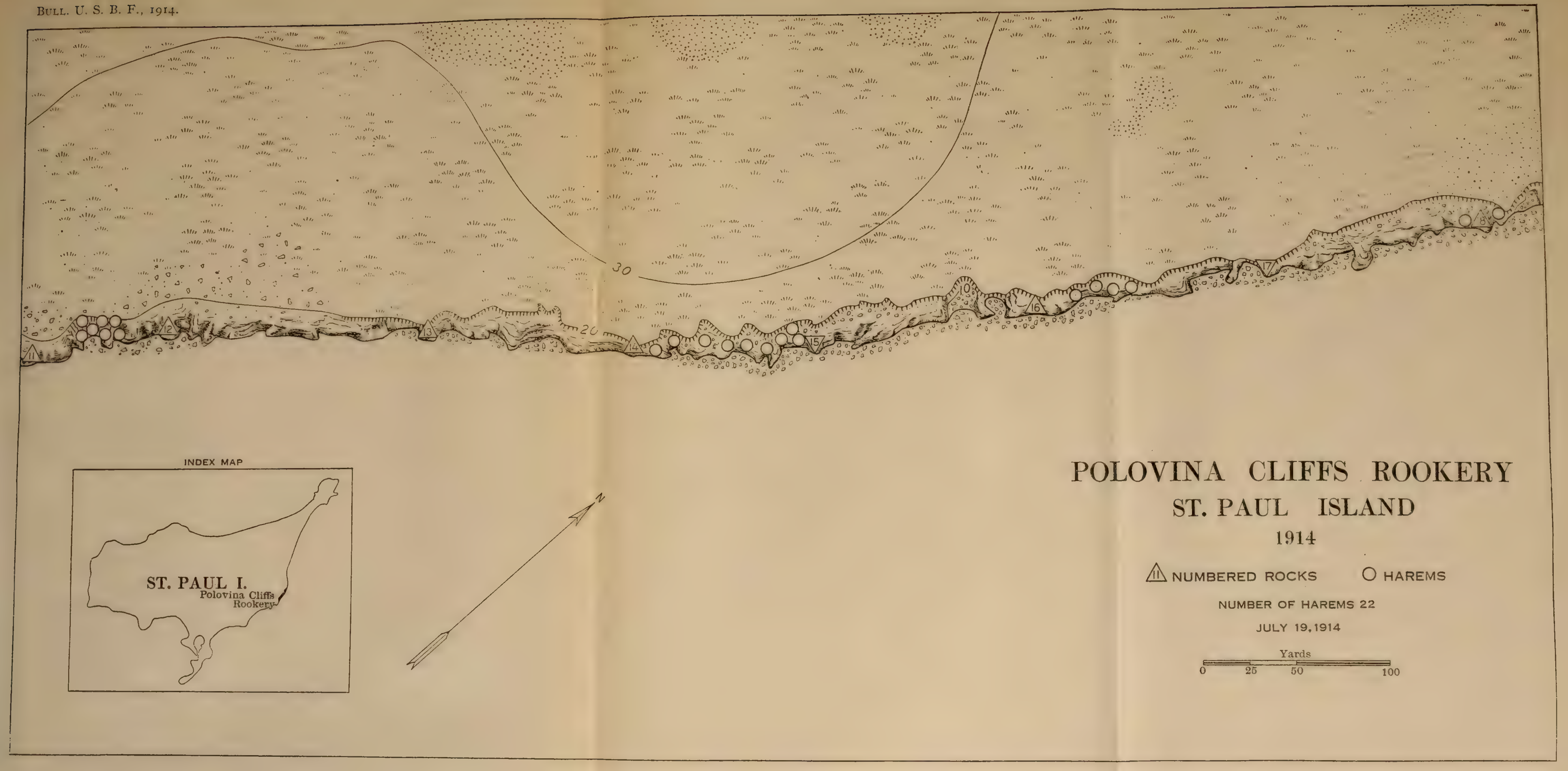



BuLI. U. S. B. F., IgI4.

MAP I. .

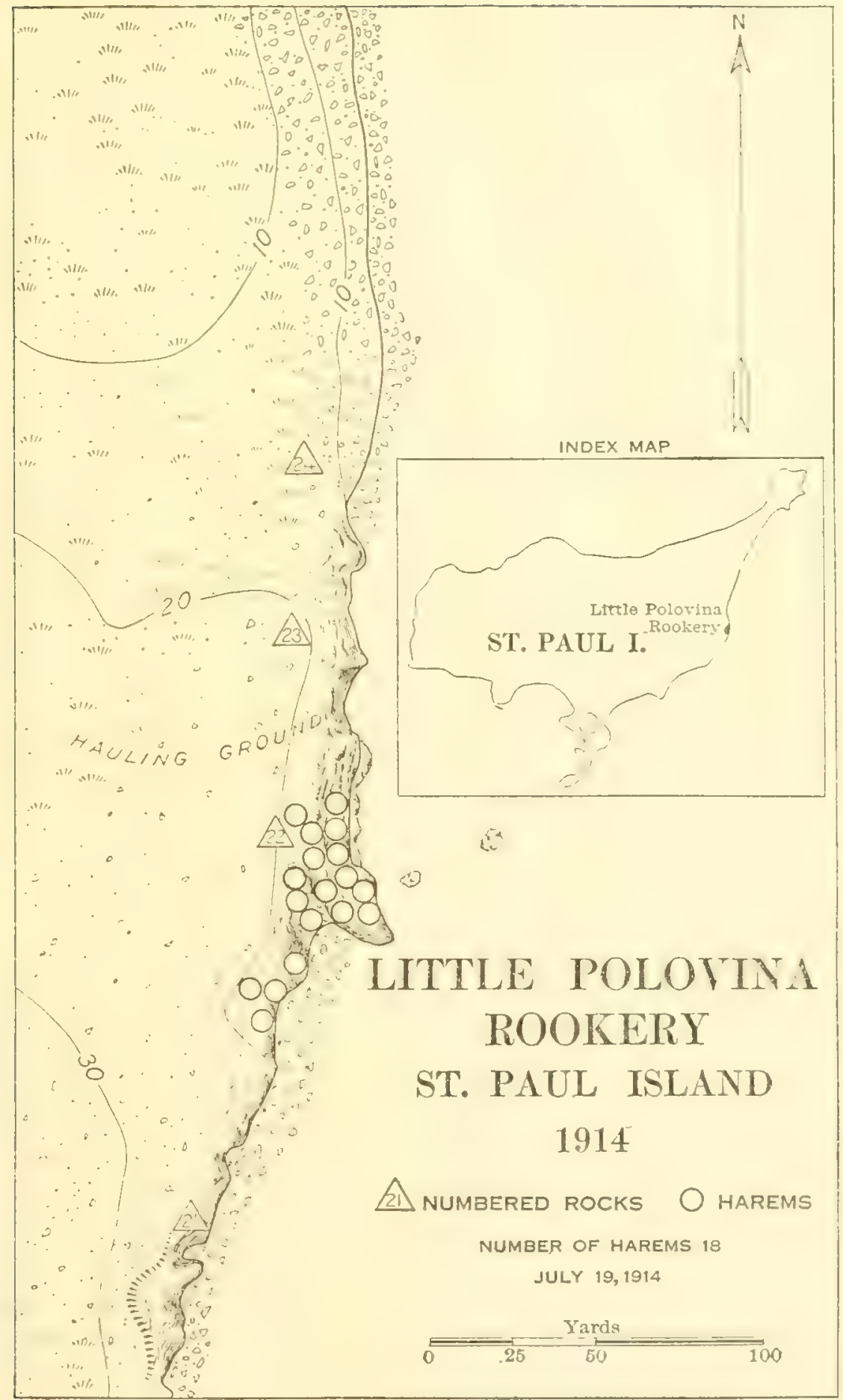



MAP I5.

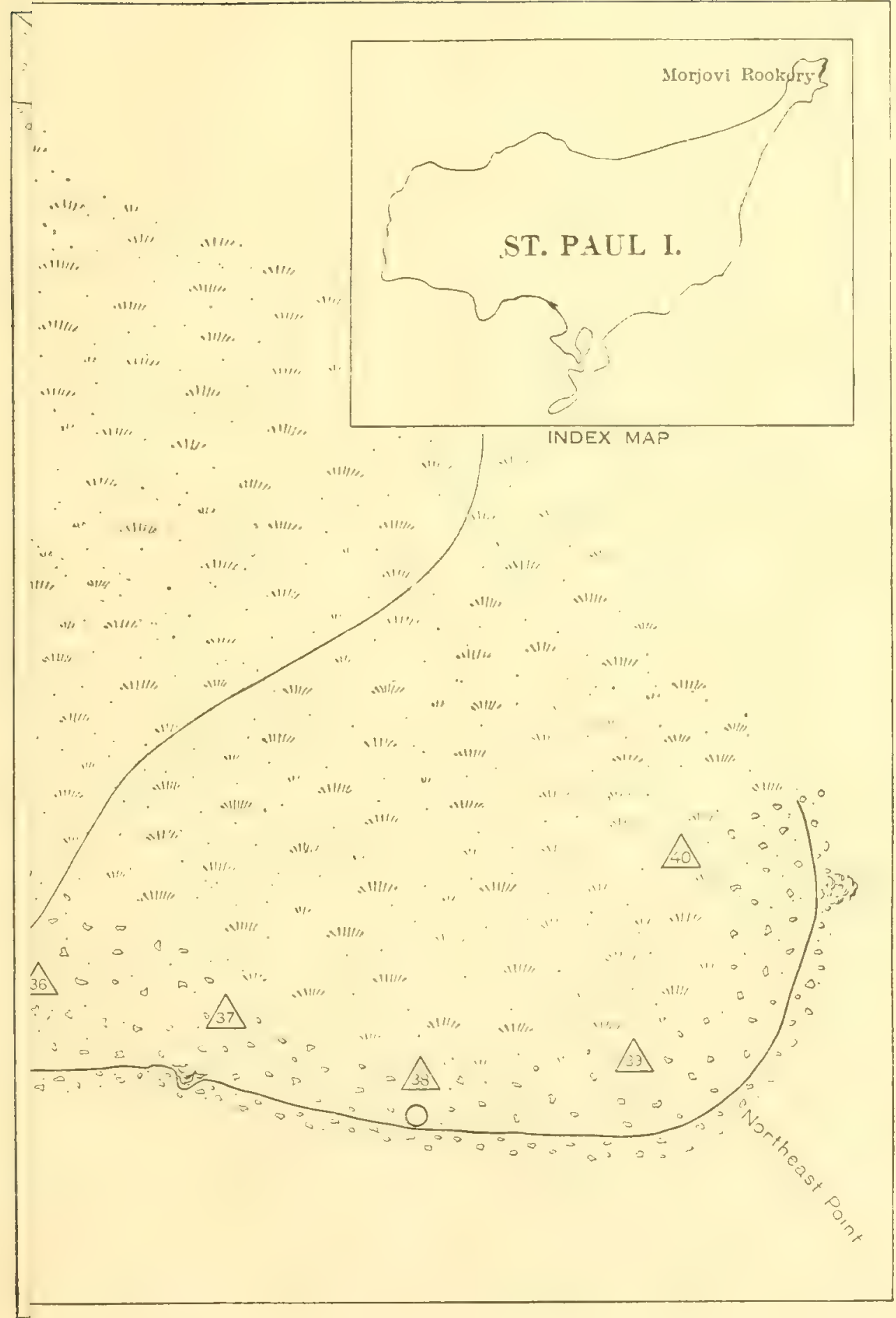





\section{MORJOVI ROOKERY}

ST. PAUL ISLAND

1914

(32) NUMBERED ROCKS OHAREMS

NUMBER OF HAREMS 43

JULY 19. 1914

$\stackrel{\text { Yards }}{\stackrel{25}{50}}$



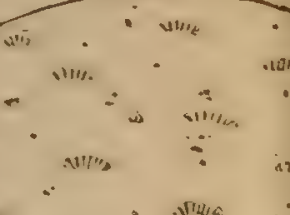

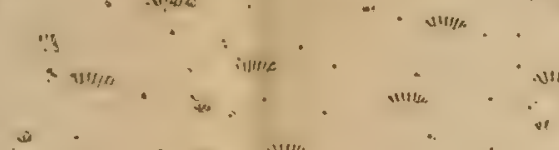

s.

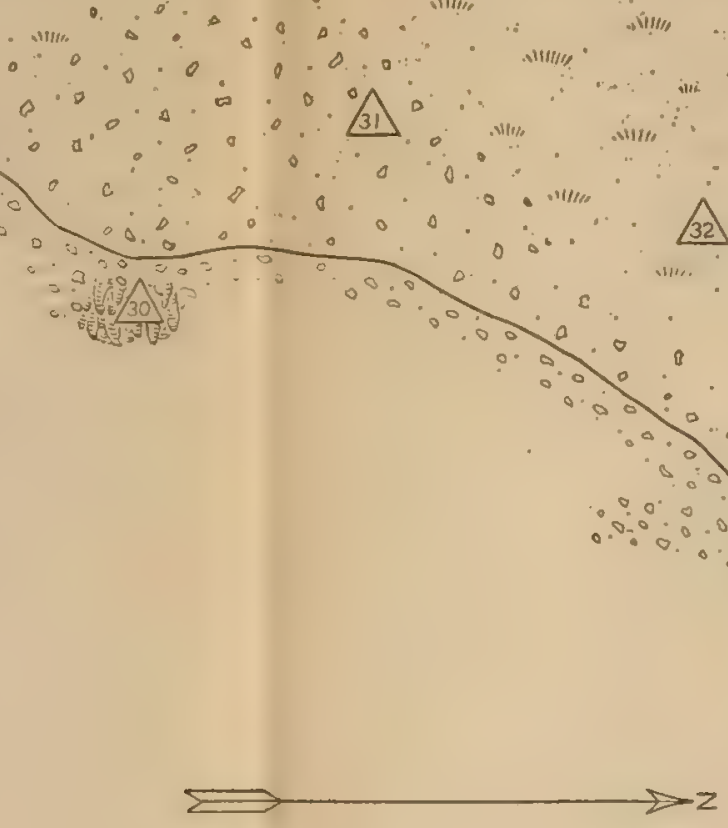

.

.
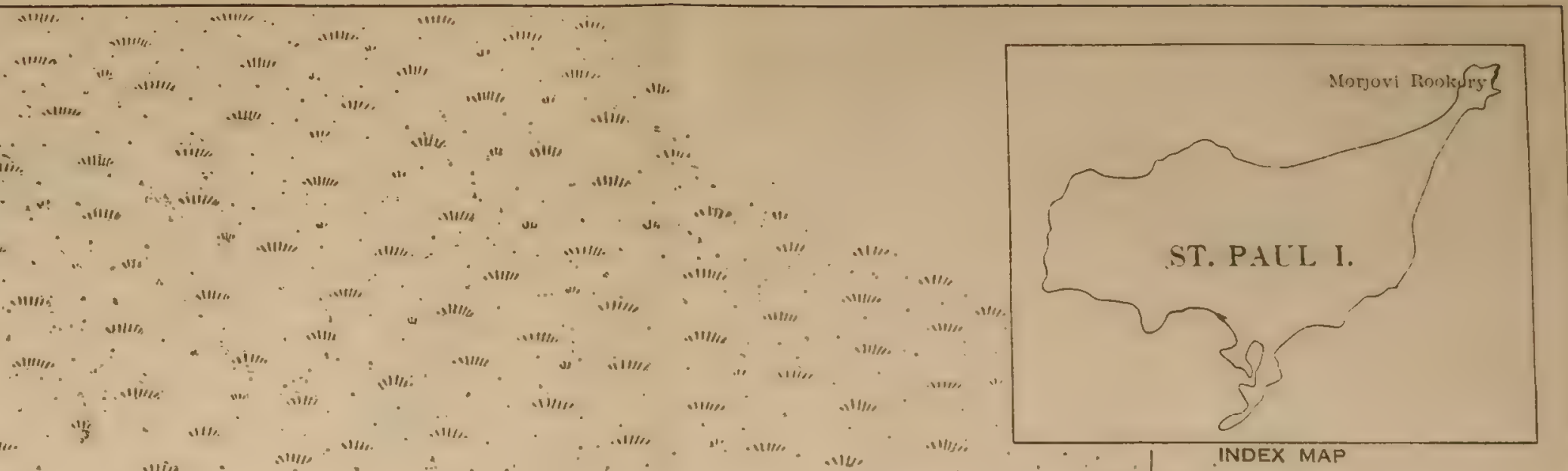

30
0 0
000
000

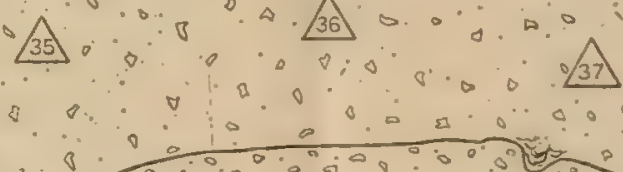
筃 





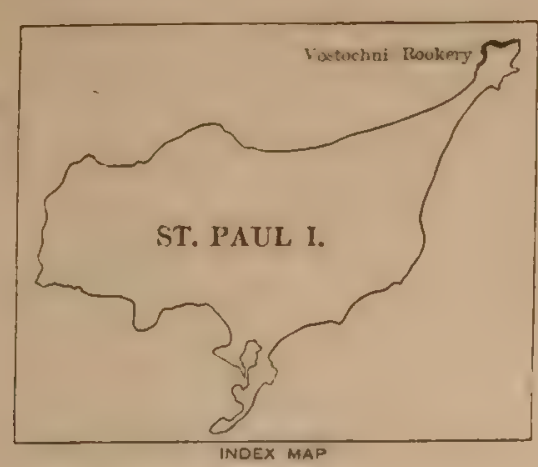

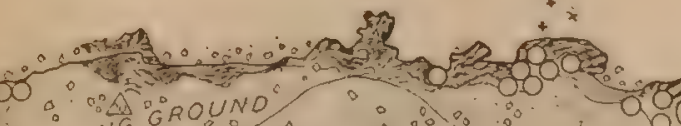

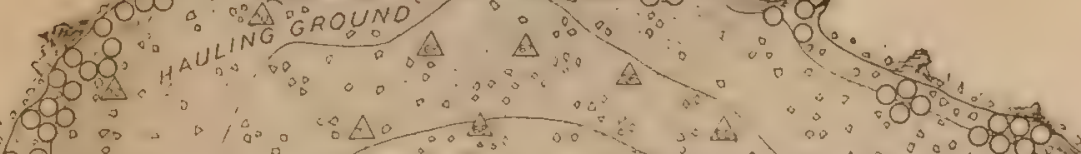

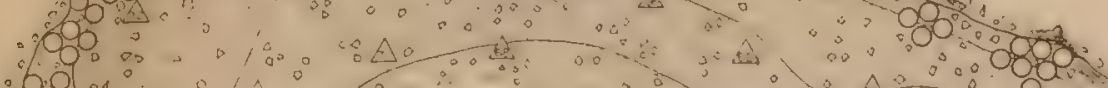

$80 \%=0$

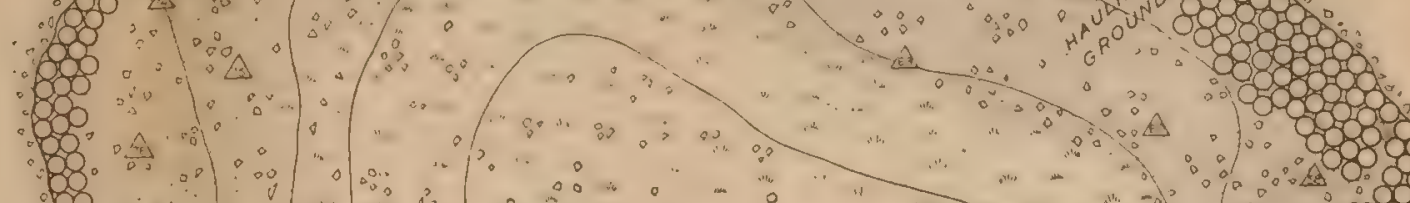

\%.

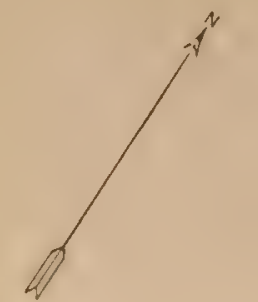

VOSTOCHNI ROOKERY

ST. PAUL ISLAND

1914
ANUMBERED ROCKS

NUMBERED ROCKS OHAREMS NUMBER OF HAREMS 291

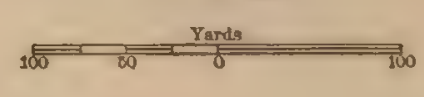



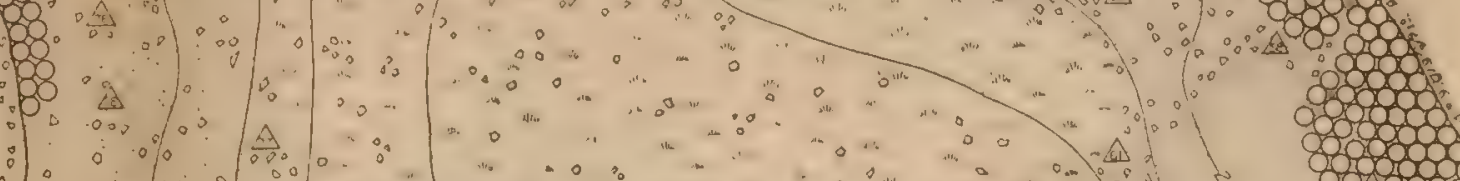

808.

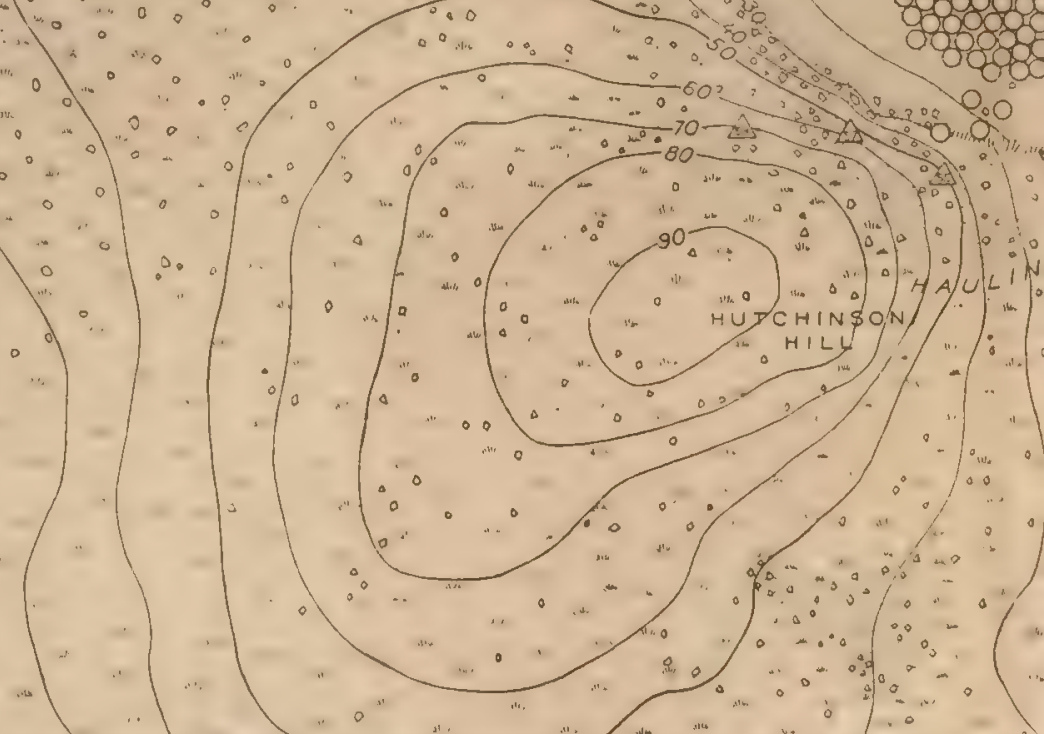

sos

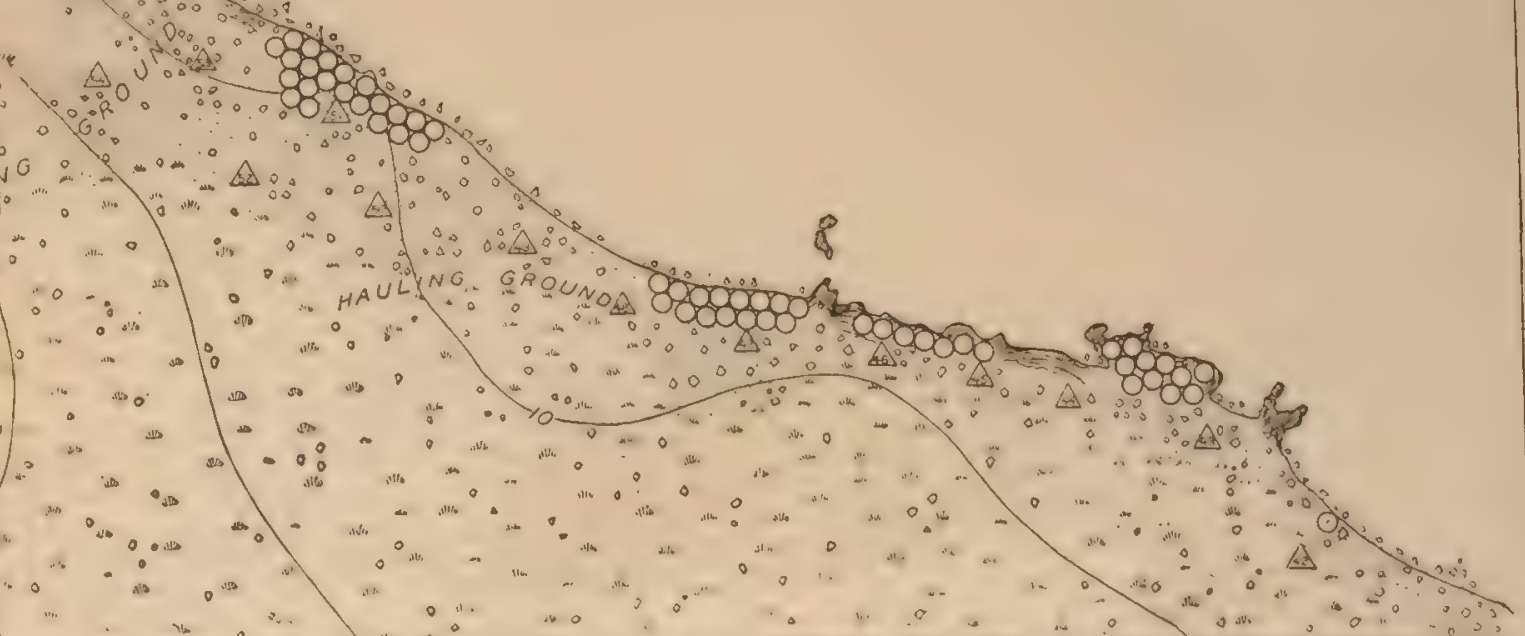






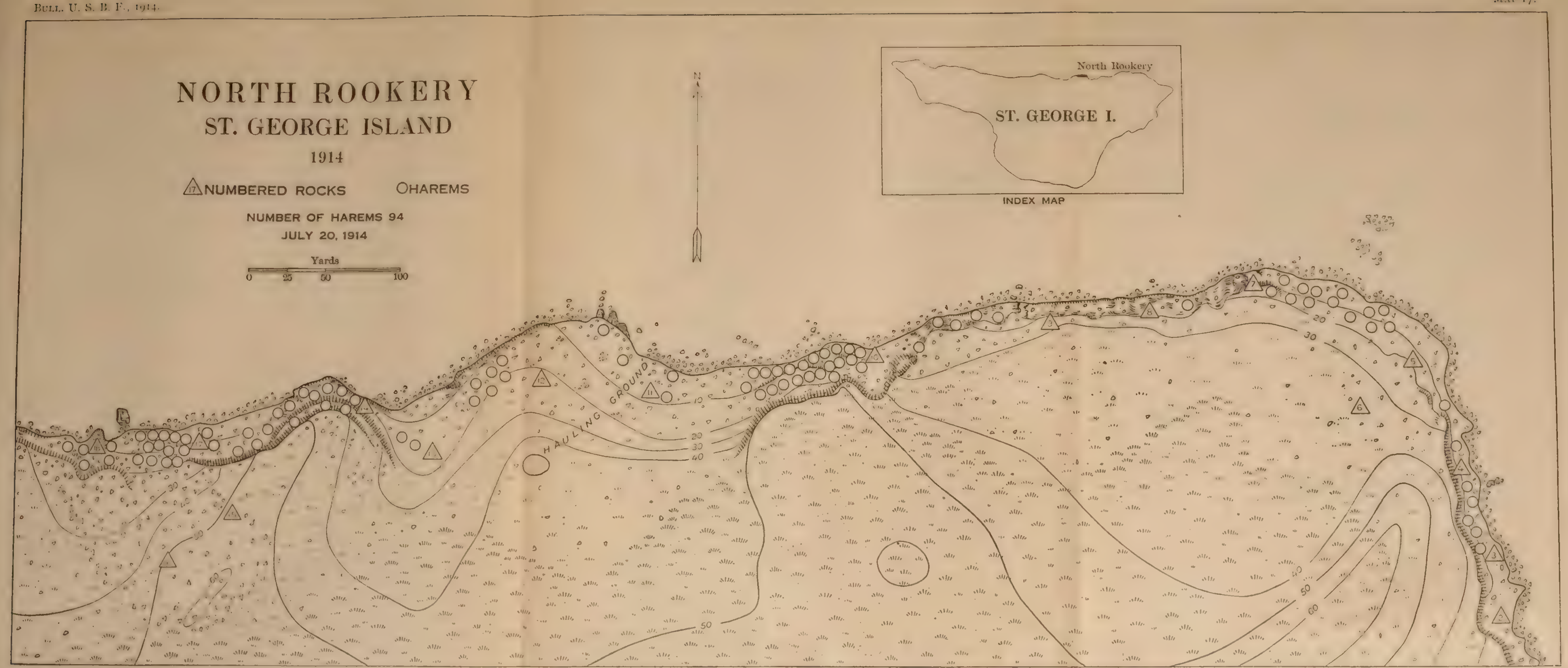






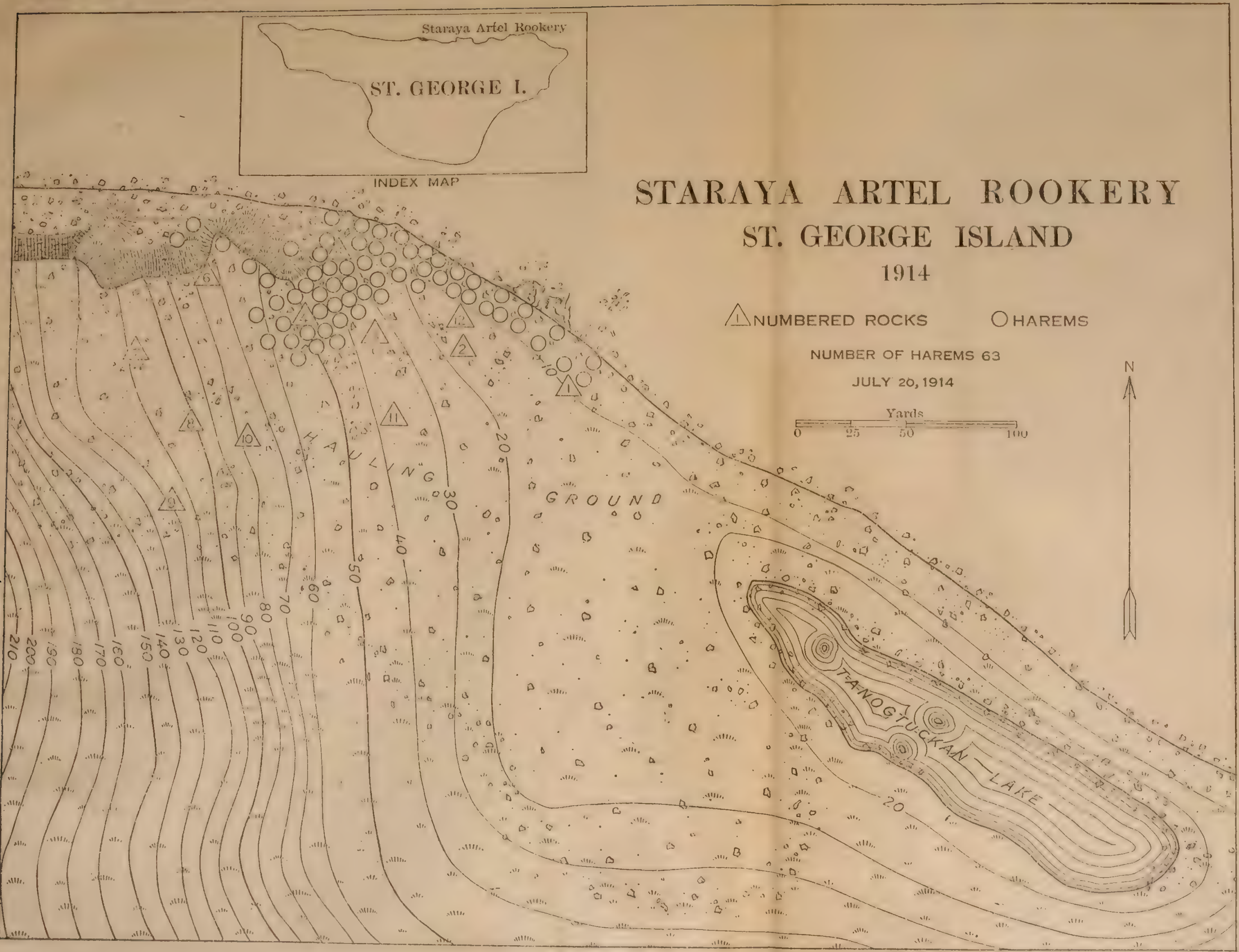





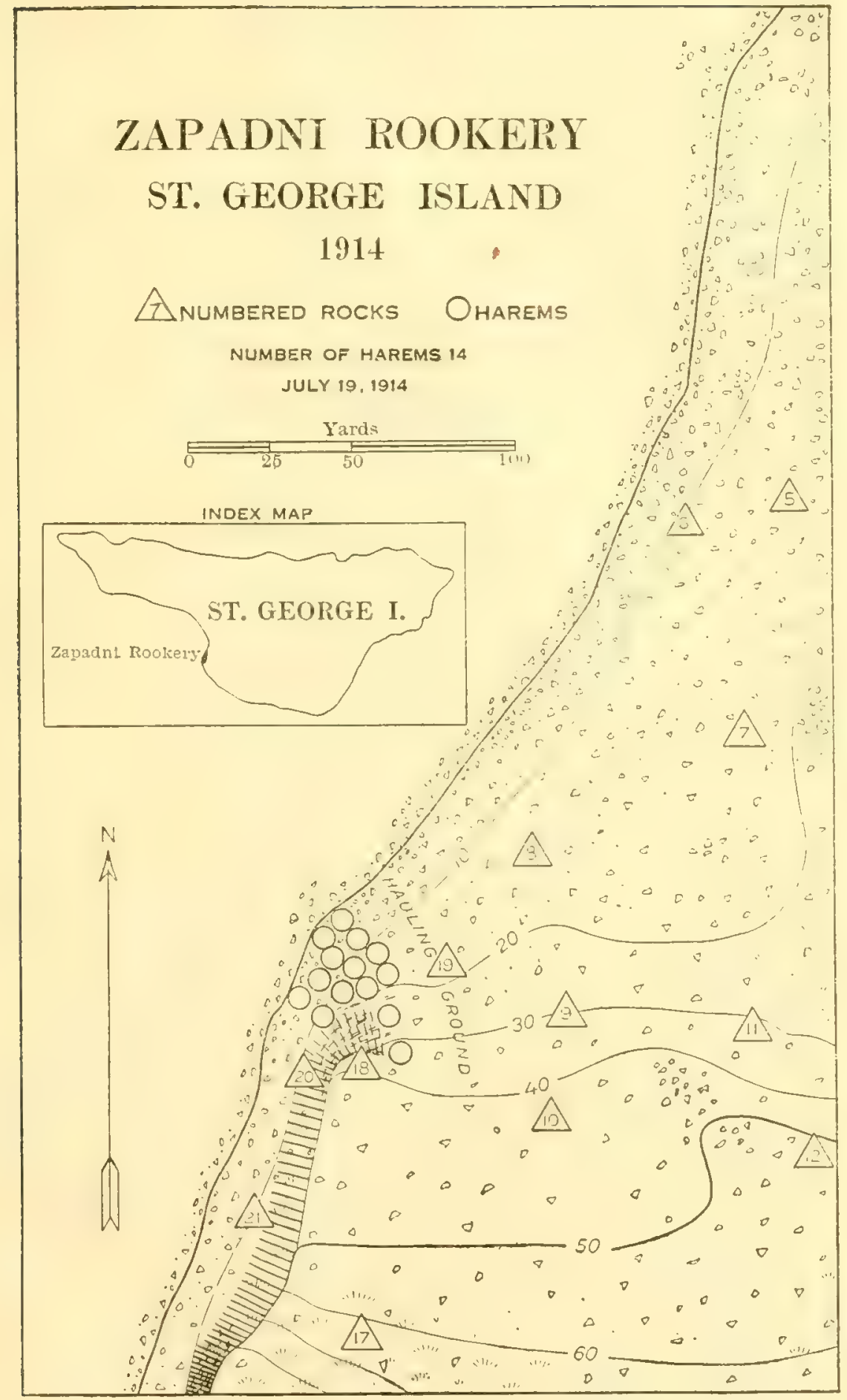



BULL. U. S. B. F., I9I4.

MAP 20.

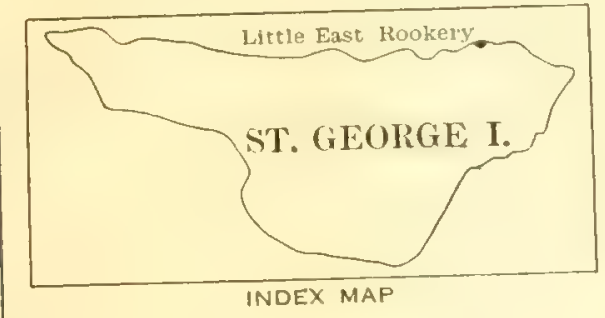

LITTLE EAST ROOKERY ST. GEORGE ISLAND 1914

2. NuMBERED ROCKS O HAREMS NUMBER OF HAREMS JULY 20, 1914

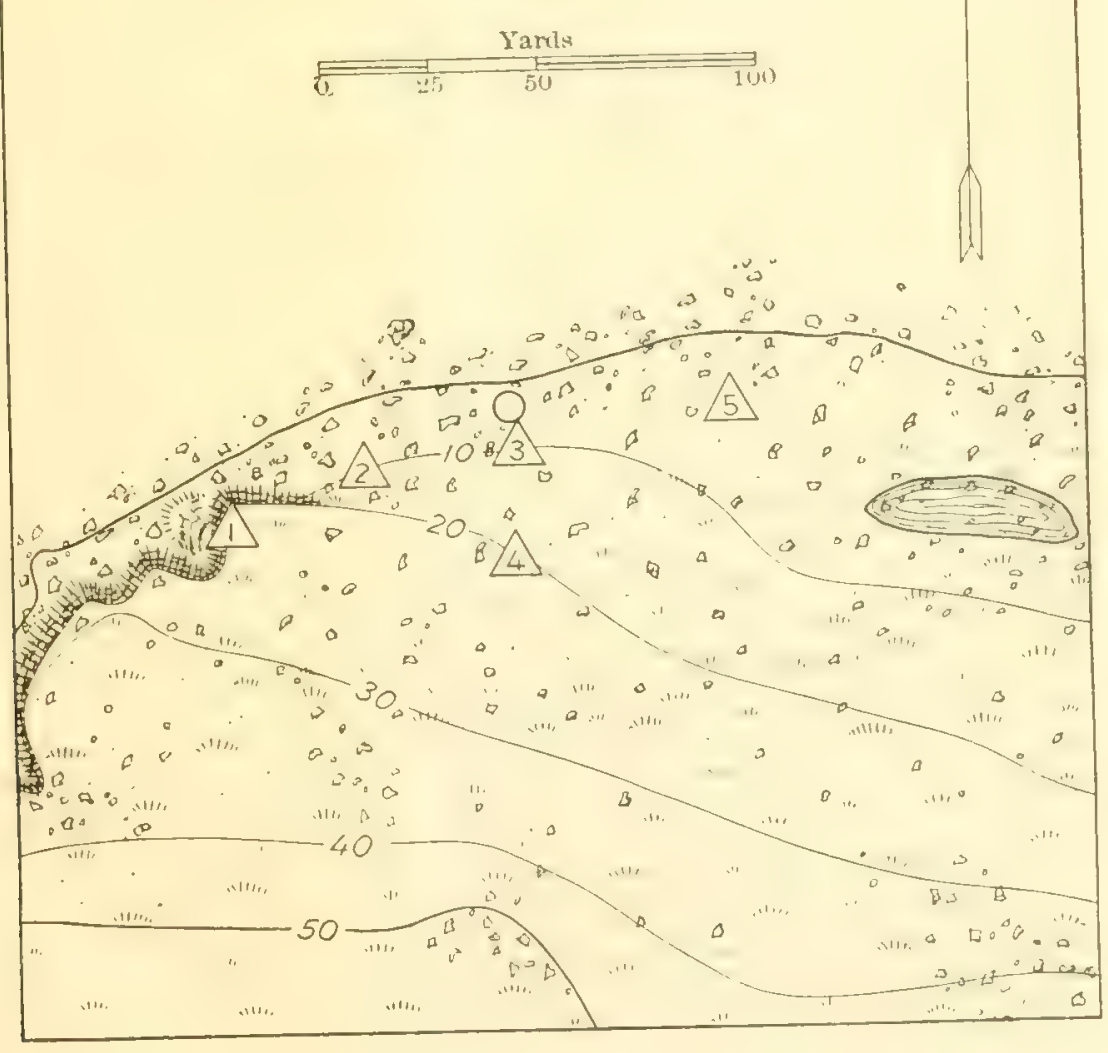



BULL. U. S. B. F.,

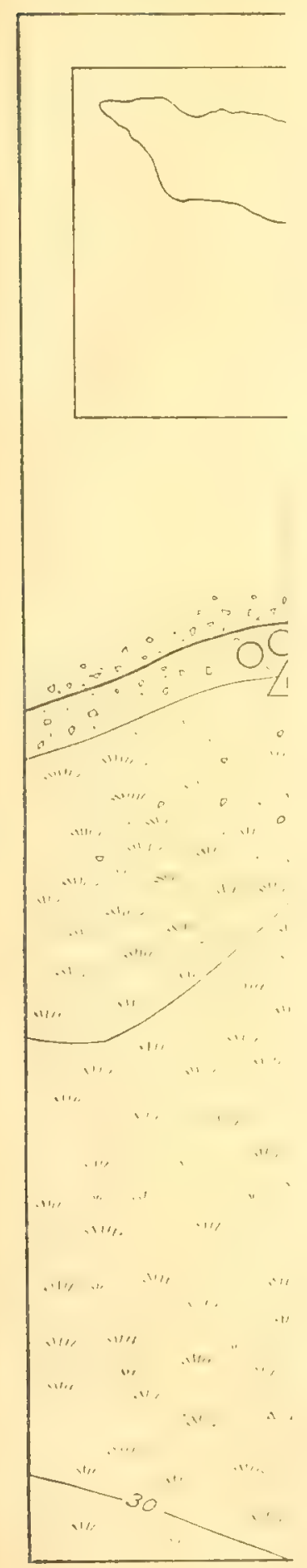





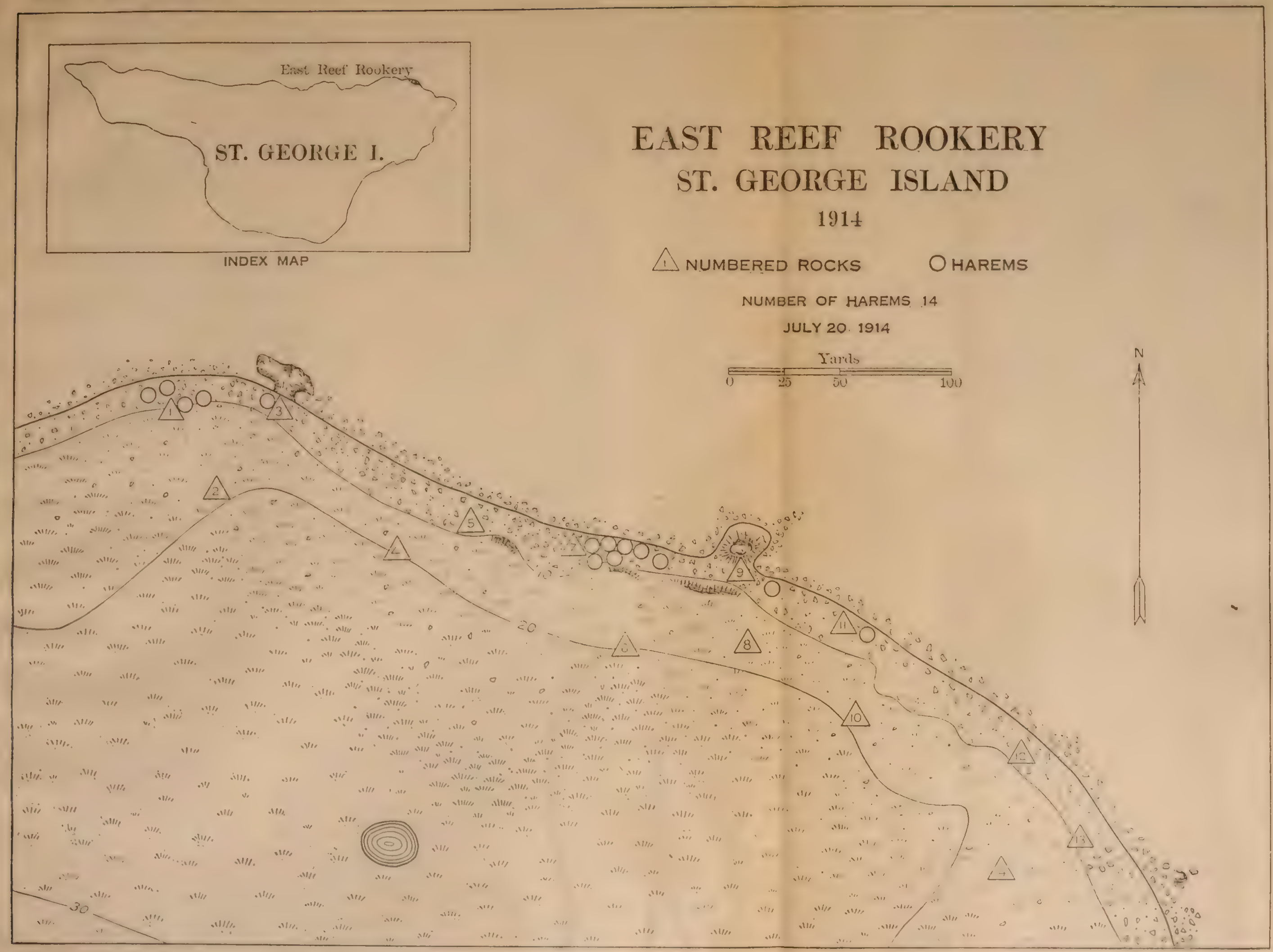



BULI. U. S. B. F., I9I4.

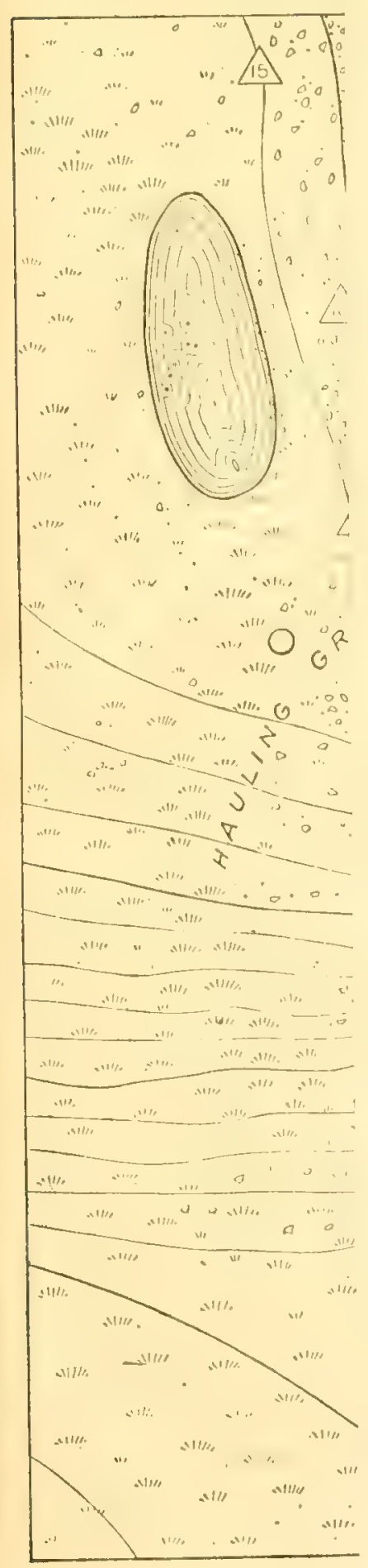





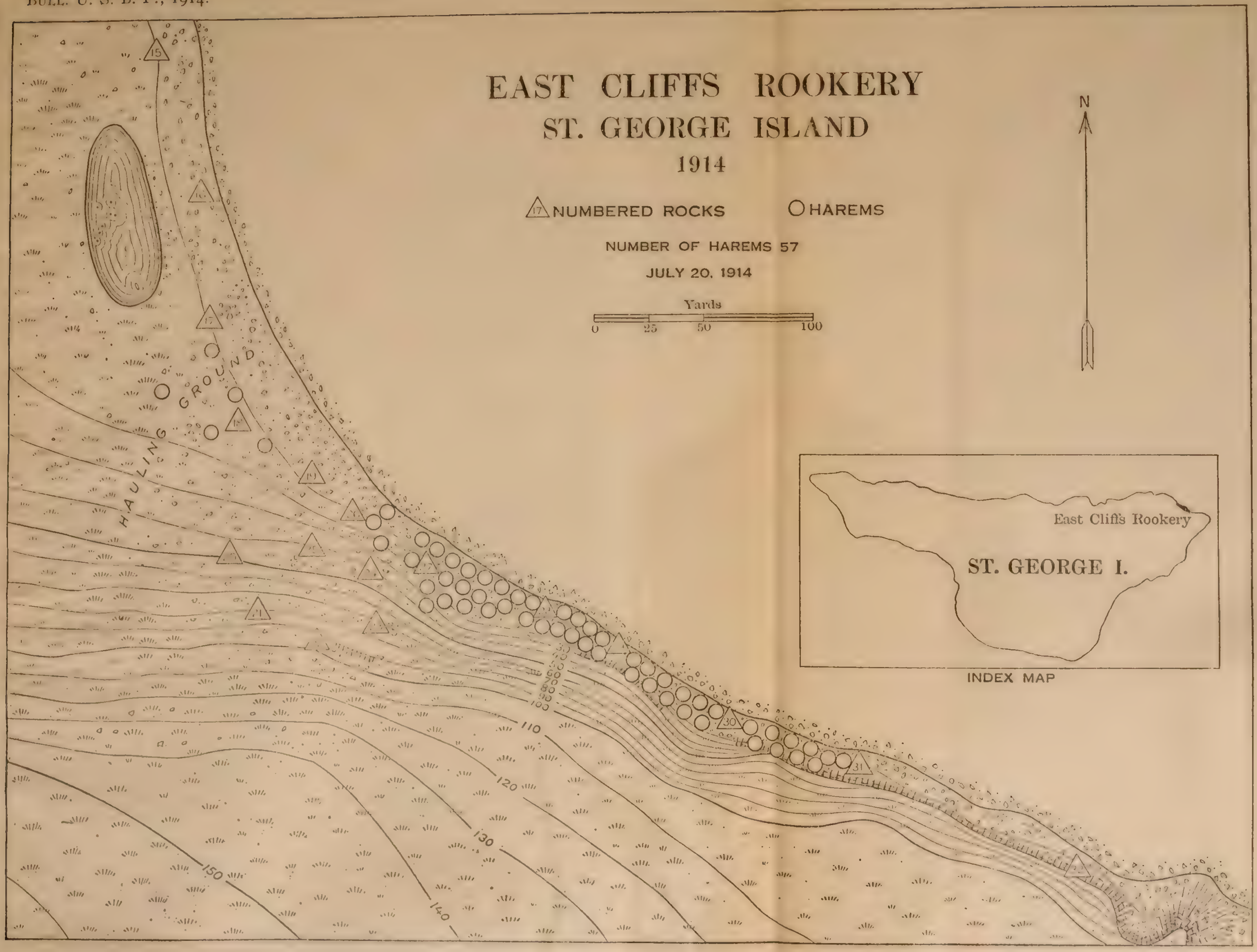





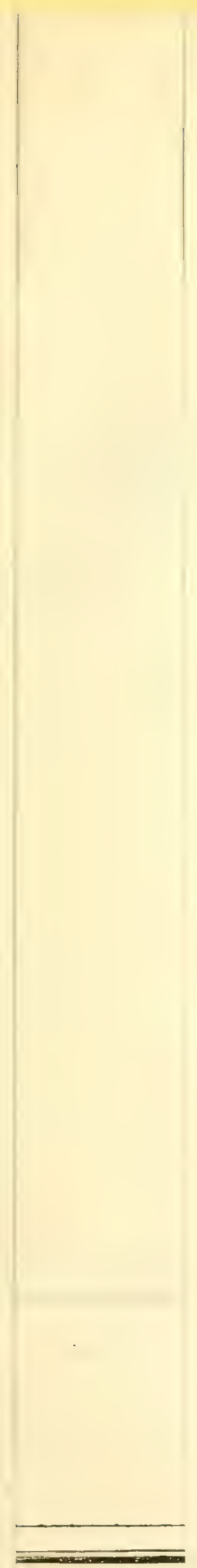














-

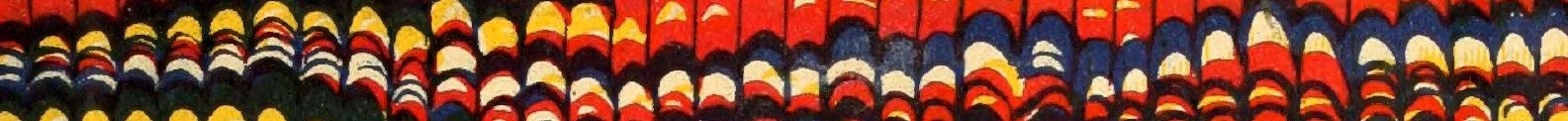

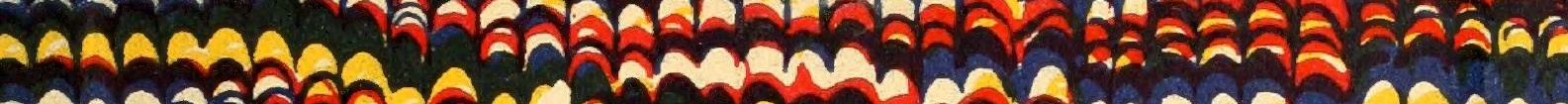

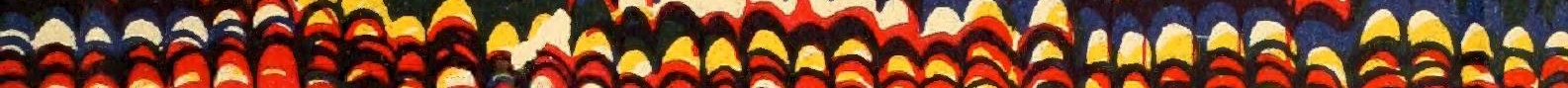
ตั* Man

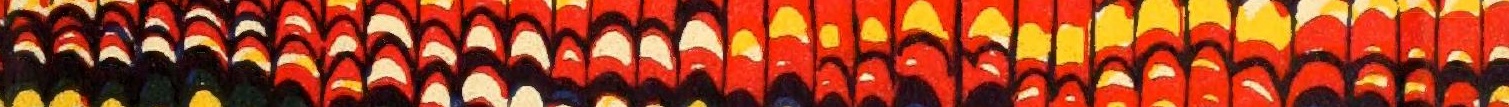

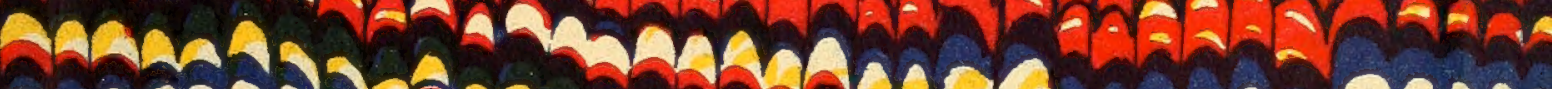


ââต

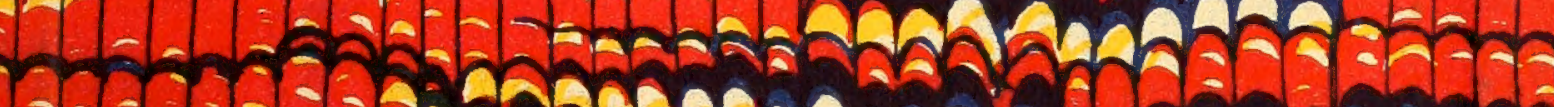

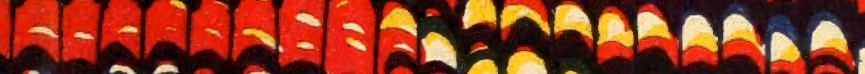

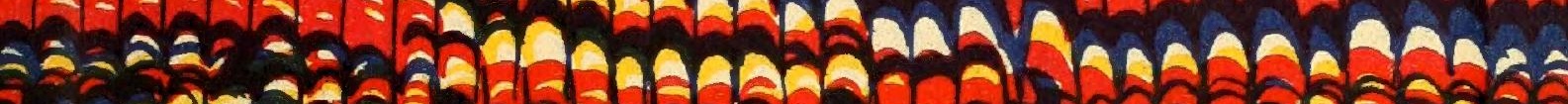

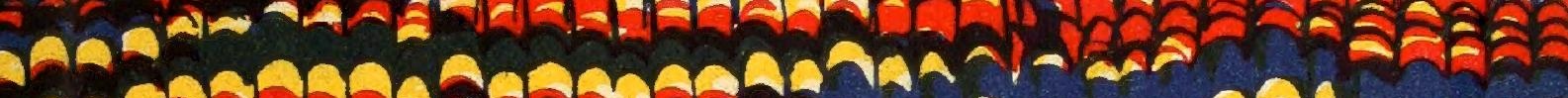
-

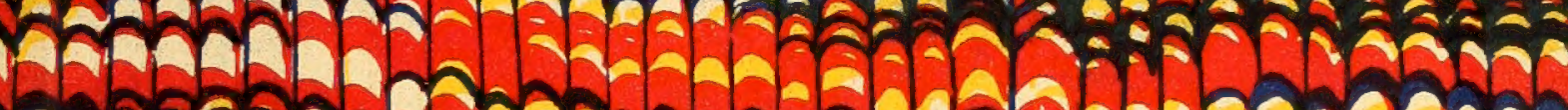

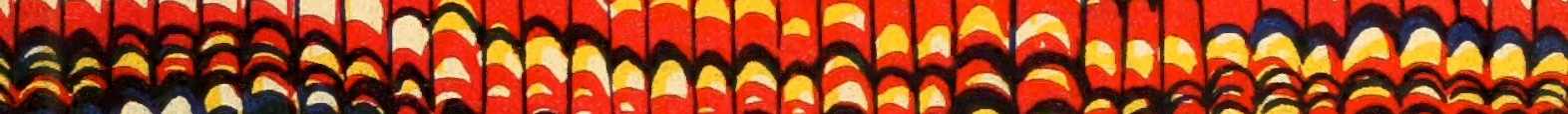
Wwa a a

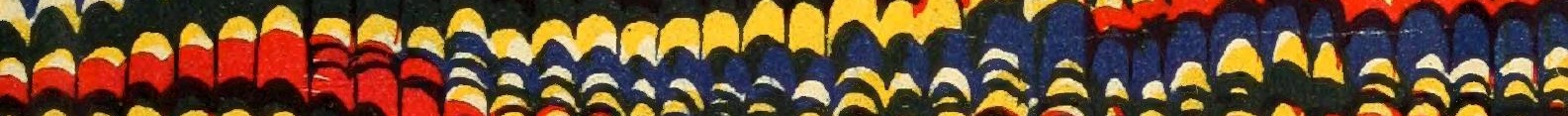

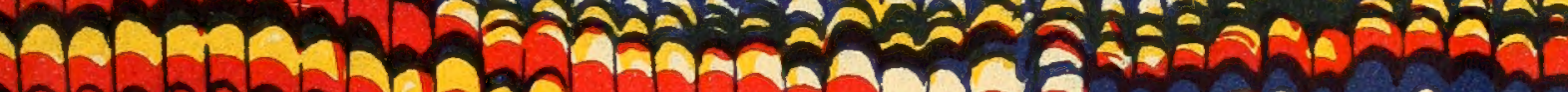

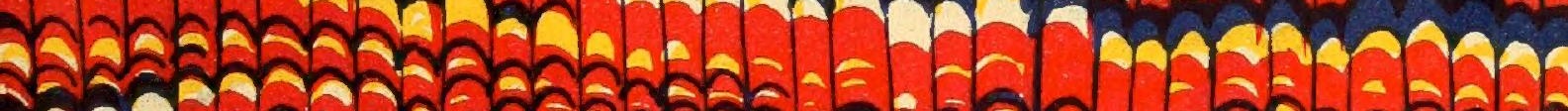

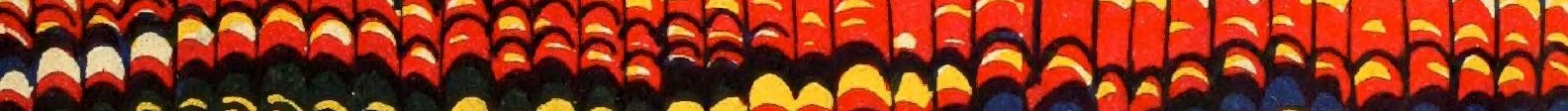

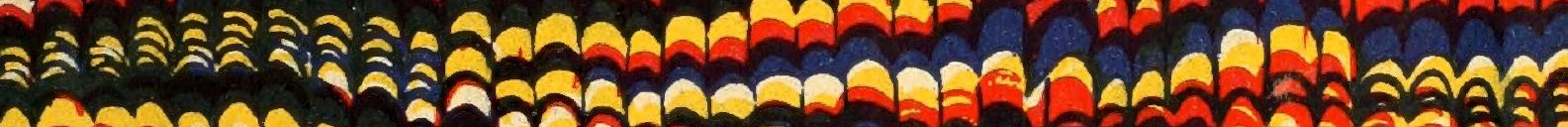
mmam mâmanch

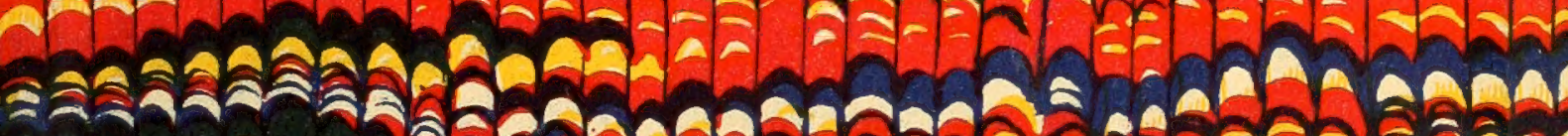

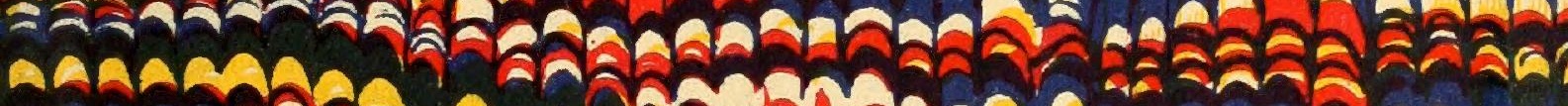

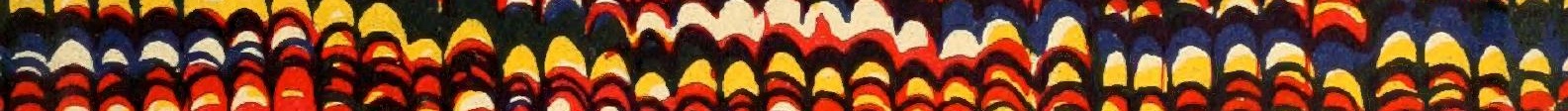

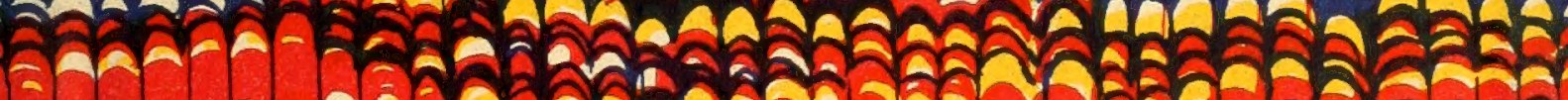

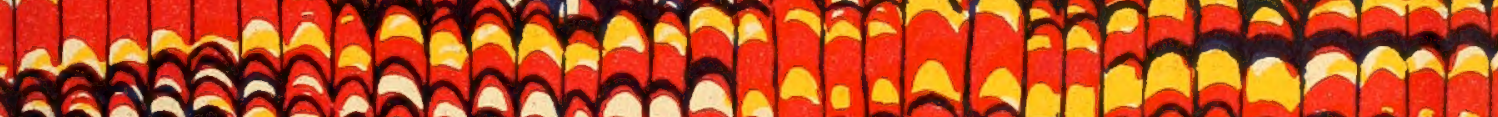

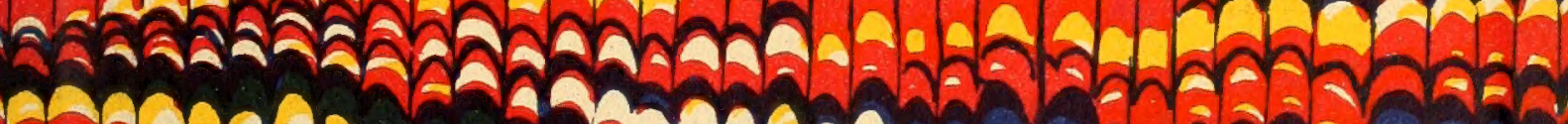

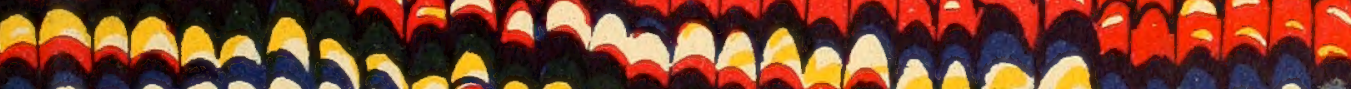
WAATMbâ. Aaลa-

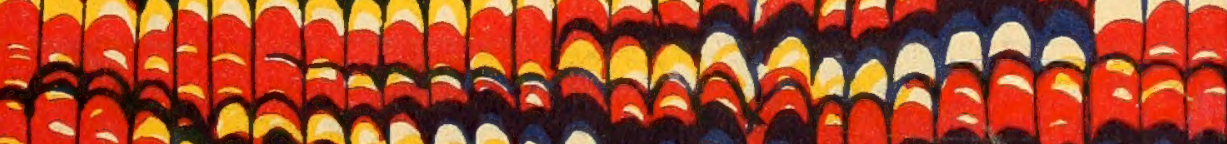


